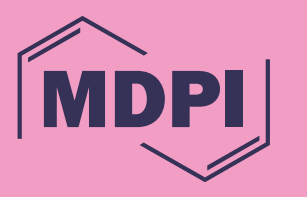

\title{
Transitioning to RESPONSIBLE CONSUMPTION AND PRODUCTION
} Lisa McNeill (Ed.) 


\section{Transitioning to Responsible Consumption and Production}




\title{
Transitioning to Sustainability Series: Volume 12
}

\author{
Series Editor: Manfred Max Bergman
}

Volumes in the series:

Volume 1: Transitioning to No Poverty

ISBN 978-3-03897-860-2 (Hbk);

ISBN 978-3-03897-861-9 (PDF)

Volume 2: Transitioning to Zero Hunger ISBN 978-3-03897-862-6 (Hbk);

ISBN 978-3-03897-863-3 (PDF)

Volume 3: Transitioning to Good Health and Well-Being

ISBN 978-3-03897-864-0 (Hbk);

ISBN 978-3-03897-865-7 (PDF)

Volume 4: Transitioning to Quality

Education

ISBN 978-3-03897-892-3 (Hbk);

ISBN 978-3-03897-893-0 (PDF)

Volume 5: Transitioning to Gender Equality ISBN 978-3-03897-866-4 (Hbk);

ISBN 978-3-03897-867-1 (PDF)

Volume 6: Transitioning to Clean Water and Sanitation

ISBN 978-3-03897-774-2 (Hbk);

ISBN 978-3-03897-775-9 (PDF)

Volume 7: Transitioning to Affordable and Clean Energy

ISBN 978-3-03897-776-6 (Hbk);

ISBN 978-3-03897-777-3 (PDF)

Volume 8: Transitioning to Decent Work and Economic Growth

ISBN 978-3-03897-778-0 (Hbk);

ISBN 978-3-03897-779-7 (PDF)

Volume 9: Transitioning to Sustainable Industry, Innovation and Infrastructure ISBN 978-3-03897-868-8 (Hbk);

ISBN 978-3-03897-869-5 (PDF)
Volume 10: Transitioning to Reduced Inequalities

ISBN 978-3-03921-160-9 (Hbk);

ISBN 978-3-03921-161-6 (PDF)

Volume 11: Transitioning to Sustainable Cities and Communities

ISBN 978-3-03897-870-1 (Hbk);

ISBN 978-3-03897-871-8 (PDF)

Volume 12: Transitioning to Responsible Consumption and Production ISBN 978-3-03897-872-5 (Hbk); ISBN 978-3-03897-873-2 (PDF)

Volume 13: Transitioning to Climate Action ISBN 978-3-03897-874-9 (Hbk); ISBN 978-3-03897-875-6 (PDF)

Volume 14: Transitioning to Sustainable Life below Water

ISBN 978-3-03897-876-3 (Hbk);

ISBN 978-3-03897-877-0 (PDF)

Volume 15: Transitioning to Sustainable Life on Land

ISBN 978-3-03897-878-7 (Hbk);

ISBN 978-3-03897-879-4 (PDF)

Volume 16: Transitioning to Peace, Justice and Strong Institutions

ISBN 978-3-03897-880-0 (Hbk);

ISBN 978-3-03897-881-7 (PDF)

Volume 17: Transitioning to Strong Partnerships for the Sustainable

Development Goals

ISBN 978-3-03897-882-4 (Hbk);

ISBN 978-3-03897-883-1 (PDF) 
Lisa McNeill (Ed.)

\section{Transitioning to \\ Responsible Consumption and Production}

Transitioning to Sustainability Series 
EDITOR

Lisa McNeill

Department of Marketing

University of Otago

Dunedin, New Zealand
EDITORIAL OFFICE

MDPI

St. Alban-Anlage 66

4052 Basel, Switzerland

For citation purposes, cite each article independently as indicated below:

Author 1, and Author 2. 2020. Chapter Title. In Transitioning to Responsible Consumption and Production. Edited by Lisa McNeill. Transitioning to Sustainability Series 12. Basel: MDPI, Page Range.

(C) 2020 by the authors. Chapters in this volume are Open Access and distributed under the Creative Commons Attribution (CC BY 4.0) license, which allows users to download, copy and build upon published articles, as long as the author and publisher are properly credited, which ensures maximum dissemination and a wider impact of our publications. 


\section{Contents}

About the Editor vii

Contributors $\quad$ ix

Abstracts $\quad$ xi

1 Preface to Transitioning to Responsible Consumption and Production 1

LISA MCNEILL

2 SDG 12, Sustainable Consumption and the UK's Leading Retailers PETER JONES, MARTIN WYNN AND DAPHNE COMFORT

3 Towards More Sustainability in Clothing Production and Consumption:

Options, Opportunities, and Constraints

SILKE KLEINHÜCKELKOTTEN AND HORST-PETER NEITZKE

4 Socially Responsible Fashion Practice: Looking Good and Feeling Good

ELAINE L. RITCH

5 Consumer Choice and Food Waste: A Demand-Side Perspective to Address the Challenge of Sustainable Consumption Models LUCA SECONDI AND LUDOVICA PRINCIPATO

6 From Open to Closed-Cycle Fast Moving Consumer Goods (FMCG)

Packaging Systems: An Overview of Potential Avenues for Progress ROBERT HAMLIN

7 Smell and Sustainability: Can Odour Shorten the Life Span of Clothing? RACHEL MCQUEEN, JENNIFER KOWTON AND LAUREN DEGENSTEIN

8 Repairing Fashion Cultures: From Disposable to Repairable KIRSI NIINIMÄKI AND MARIUM DURRANI

9 The Role of Young Consumers in Moving to a Sustainable

Consumption Future

LEAH WATKINS AND ROB AITKEN

10 Justice Concerns in SDG 12: The Problem of Missing Consumption Limits KATIA VLADIMIROVA 



\section{About the Editor}

Dr. Lisa McNeill is an Associate Professor of Marketing at Otago University, New Zealand. Her research interests focus on cultures of consumption, and their interrelationship to consumer identity and consumption choices. Most recently, Dr. McNeill's work has focussed on overconsumption and sustainability action in production, retail and consumption, with research that examines fashion and textile waste, disposal and slow fashion business models. Other work examines consumer attitude and behaviour in regard to food choices, including the efficacy of food labelling strategies and consumer views of clean meat products. Dr. McNeill teaches research methods at a postgraduate level, as well as innovation and new product development at an undergraduate level. 



\section{Contributors}

\section{DAPHNE COMFORT}

Research Assistant, School of Business, University of Gloucestershire, Cheltenham, Gloucestershire UK.

\section{ELAINE L. RITCH}

Senior Lecturer of Marketing, Glasgow School for Business and Society; Glasgow Caledonian University, Glasgow, UK.

\section{HORST-PETER NEITZKE}

Dr., ECOLOG-Institute for Social-Ecological Research and Education, Hannover, Germany.

\section{JENNIFER KOWTON}

Design and Creative Strategy Lead, Department of Human Ecology, University of Alberta, Edmonton, Alberta, Canada.

\section{KATIA VLADIMIROVA}

Postdoctoral Researcher, Institute of Sociological Research, University of Geneva, Geneva, Switzerland.

\section{KIRSI NIINIMÄKI}

Associate Professor, Design Department, Aalto University, AALTO, Finland.

\section{LAUREN DEGENSTEIN}

Graduate Research Assistant, Department of Human Ecology, University of Alberta, Edmonton, Alberta, Canada.

\section{LEAH WATKINS}

Associate Professor, Department of Marketing, University of Otago, Dunedin, New Zealand.

\section{LISA MCNEILL}

Associate Professor, Department of Marketing, University of Otago, Dunedin, New Zealand.

\section{LUCA SECONDI}

Associate Professor, Department for Innovation in Biological, Agro-Food and Forest Systems (DIBAF), University of Tuscia, Viterbo, Italy.

\section{LUDOVICA PRINCIPATO}

Dr., Department of Business

Administration, Roma Tre University,

Roma, Italy.

\section{MARIUM DURRANI}

Postdoctoral Researcher, Design

Department, Aalto University, AALTO,

Finland.

\section{MARTIN WYNN}

Reader in Business Information Systems, School of Computing and Engineering, University of Gloucestershire, Cheltenham, Gloucestershire UK.

\section{PETER JONES}

Emeritus Professor, School of Business, University of Gloucestershire, Cheltenham, Gloucestershire UK.

\section{RACHEL MCQUEEN}

Associate Professor, Department of Human Ecology, University of Alberta, Edmonton, Alberta, Canada.

\section{ROB AITKEN}

Associate Professor, Department of Marketing, University of Otago, Dunedin, New Zealand.

\section{ROBERT HAMLIN}

Senior Lecturer, Department of Marketing, University of Otago, Dunedin, New Zealand.

\section{SILKE KLEINHÜCKELKOTTEN}

Dr., ECOLOG-Institute for Social-Ecological Research and Education, Hannover, Germany. 



\section{Abstracts}

\section{Preface to Transitioning to Responsible Consumption and Production

\author{
by Lisa McNeill
}

Developed in 2015, the Sustainable Development Goals (SDGs) were a call to change the world that we live in. The UN proposed a method of change that centred on global sustainability targets, reached through national actions, yet some would argue that the gap between sustainability goals and environmental reality is still growing within high consuming countries. Responsible Consumption and Production, the twelfth UN Sustainable Development Goal (SDG 12), calls for significant change in how we view both production and consumption normsparticularly among resource hungry nations. This special volume is focused on SDG 12, and highlights significant areas of change required in the transition toward responsible consumption and production worldwide. The volume offers seven perspectives on SDG 12, from around the world, and proposes methods for encouraging sustainability in both our consumption choices, and also in the production methods employed to service our consumption needs.

\section{SDG 12, Sustainable Consumption and the UK's Leading Retailers by Peter Jones, Martin Wynn and Daphne Comfort}

The 17 United Nations Sustainable Development Goals (SDGs) offer a blueprint to achieve a more sustainable future for all, but in many ways, the concept of sustainable consumption (part of SDG 12) is fundamental to the transition to such a future. At the same time, there is a growing awareness that retailers have a vital role to play in promoting more sustainable patterns of consumption. This chapter provides an exploratory review of how the leading retailers in the UK are publicly addressing the issue of sustainable consumption, and the authors adopted a twin track method of enquiry. Firstly, two Internet searches were undertaken of the leading retailers' corporate websites to identify how the retailers were publicly addressing sustainable consumption. Secondly, the authors undertook a basic observational survey of if, and how, the selected retailers looked to engage customers with sustainable consumption within their stores. The results 
revealed that while the majority of the selected retailers publicly emphasised their commitment to sustainable consumption on their corporate websites, there was little or no reference to the SDGs or, more specifically, to sustainable consumption within stores.

\section{Towards More Sustainability in Clothing Production and Consumption: Options, Opportunities, and Constraints by Silke Kleinhückelkotten and Horst-Peter Neitzke}

Clothing represents an especially challenging field of action for achieving Sustainable Development Goal 12 due to the large volume of mass throughput, the globalized and highly branched production and trade chains, the strong dependence of national economies especially in least developed and threshold countries on the clothing production sector, and the serious social and environmental problems going along with the provision of raw materials for and the manufacturing of clothes. After some introductory remarks as to the importance of clothing in the context of SDG 12 this chapter starts with an outline of the economic importance of the textile industry and its social and environmental impacts. Then, some results of a representative population survey are presented that allow the identification of drivers of clothing consumption and conclusions as regards the social acceptability of more sustainable alternatives. Subsequently, options for action to reach more sustainability in clothing production and consumption and the probabilities for their implementation are discussed on the basis of the results of an expert survey. The chapter ends with conclusions as regards opportunities and constraints for a shift towards more sustainability in clothing production and consumption.

\section{Socially Responsible Fashion Practice: Looking Good and Feeling Good by Elaine L. Ritch}

Concerns for sustainability were prominent in 2019 amid fears that the impact from climate change on the planet would soon be irreversible. Despite the United Nations devising 17 Sustainable Development Goals (SDGs) as a blueprint to address global challenges, the fashion industry has made little progress in addressing current production processes. Given that the fashion industry is the second 
biggest global polluter, there exists the potential to make a significant difference to the future of the planet. In particular, this chapter addresses SDG 12: Ensure sustainable consumption and production patterns. However, previous research has found that consumers face a number of barriers which restrict the advancement of sustainable fashion, mainly due to sustainable fashion not following fashion trends. Previous research has also found that this induces guilt for consumers, who fear that their consumption derives from exploitative sources. This research explores how consumers can purchase fashion that makes them look good because they are portraying clothes that reflect their constructed self-identity, as well as feel good because they know that their garments were produced sympathetically to the environment and production workers. Utilising social identity theory, the literature and data examine how fashion contributes to self-esteem and confidence, noting that similar feelings are experienced from sustainable production. This chapter concludes on how fashion producers and retailers could capitalise on creating new tenants of value through socially responsive production and supporting socially responsive consumption though education and better use of labelling.

\section{Consumer Choice and Food Waste: A Demand-Side Perspective to Address the Challenge of Sustainable Consumption Models by Luca Secondi and Ludovica Principato}

In recent years a growing number of studies and contributions have been developed on the analysis of food losses and waste along the entire Food Supply Chain. Due to the importance and seriousness, this phenomenon has reached international levels. In industrialized countries, the largest share of waste occurs in the final phases of the food chain and especially in the consumption phase in which wastage of food is mainly related to behavioral issues, such as wasteful behavior and/or bad habits and practices at home and out-of-home. The purpose of this paper is to investigate-from the demand side-consumers' choice in terms of wasted (edible and not consumed) food at domestic level. Through the data collected on a sample of consumers in Italy, the paper aims to: i) examine types of food most wasted at household level, according to socio-economic characteristics of families; ii) evaluate, using the Working-Leser demand approach, if and to what extent propensity and responsiveness of wasting food vary according to both expenditure and price levels. The estimates of demand elasticities for commodity groups and household characteristics can help to plan interventions aimed at 
addressing initiatives to selected categories of consumers, thus contributing to minimizing food waste, to implementing sustainable consumption models and, therefore, to ultimately reducing food waste related impacts.

\section{From Open to Closed-Cycle Fast Moving Consumer Goods (FMCG) Packaging Systems: An Overview of Potential Avenues for Progress by Robert Hamlin}

This chapter examines the current situation with regard to closed-cycle packaging systems that are organised at a national rather than local or single product/business scale. A clear distinction is drawn between reuse and recycling where packaging is returned to its original function/value, and repurposing, where packaging is usually transformed into a lower value form. It is noted that repurposing cannot support a closed-cycle system, and that true recycling and reuse are only bases for such a system. The current situation with regard to FMCG packaging reuse and recycling are examined, and it is noted that the programmes that do exist are highly fragmented, and that true progress towards package waste reduction is not being achieved. Systems for reuse and recycling on a national scale are then examined, and the basic structures of such systems are identified. It is noted that when they are scaled up to a national level the distinction between systems that are based on FMCG package reuse or recycling become highly nuanced as the platforms converge. The only difference is whether a package completes a single or multiple reuse cycles before it is recycled (remanufactured). Finally the obstacles to such a system are examined. It is noted that such a system can only be established via aggressive government regulation and that some recent international trade treaties may be a major barrier to such regulation, and thus to the establishment of these systems.

\section{Smell and Sustainability: Can Odour Shorten the Life Span of Clothing? \\ by Rachel McQueen, Jennifer Kowton and Lauren Degenstein}

Scholars investigating the longevity of clothing have examined clothing attributes that enhance garment attachment. Deepening consumer satisfaction 
with clothing items is paramount in order to extend the life span of clothes. Kirsi Niinimäki and colleagues argue that a positive or pleasurable use experience deepens attachment to clothing items making it less likely that desirable clothing items will be discarded, thereby decreasing the likelihood of such clothing items ending up in landfills or incinerated. As part of the multi-sensorial experience of wearing clothing, odour can play a significant role, although it is more likely to mar the experience resulting in a negative-use experience and consumer dissatisfaction. The impact odour has on sustainable behaviour, particularly as it relates to when and how a consumer chooses to dispose of their clothing has not been previously examined. As such, this article draws upon focus-group and survey data from Canadian consumers exploring the impact that the development of unpleasant odours within clothing has on their satisfaction with clothing. The results indicate how odour perception impacts consumer behaviour relating to future clothing purchases as well as post-purchase practices as it pertains to the end of a garment's life cycle. More specifically, a negative use experience typically culminated in premature disposal of the clothing item, ultimately with the odorous clothing item being designated to the trash, impeding sustainability efforts.

\section{Repairing Fashion Cultures: From Disposable to Repairable by Kirsi Niinimäki and Marium Durrani}

It is time to change the unsustainable fashion culture and build a new paradigm. In the last 20 years we have experienced the emergence of a fast fashion culture, which has succeeded exponentially from a business point of view but has caused ever increasing environmental impacts. The increase in fashion consumption and increase in textile waste streams are part of this phenomenon. This text presents the current unsustainable practices in the fashion field, but it also shows that there is evidence of change happening through the aspect of repair. The change in repair culture can be approached from two angles: the consumer and the business point of view. Through this approach, a new paradigm can be constructed in consumptionproduction, and the current unsustainable fashion cultures could be challenged. 


\section{The Role of Young Consumers in Moving to a Sustainable Consumption Future by Leah Watkins and Rob Aitken}

This chapter presents the results of three different research studies that address the changes necessary to move towards a more sustainable consumption future. Each study focusses on young consumers as those most receptive to the need for change and the ones mostly likely to enact them. The first study presents results from a pilot project designed to increase young consumers' sustainable consumption literacy. Results suggest that providing young learners with the frameworks and language for understanding sustainable consumption issues can be successful in guiding future behaviour. The second study looks at young people's exposure to advertising and the relationship between the pervasive promotion of pro-consumption messages, the formation of materialistic attitudes and unsustainable consumption patterns. The study concludes by suggesting that the normalisation of consumption communicated through advertising should be subject to greater scrutiny and closer regulatory control. The final study asked young people to describe their visions of a sustainable consumption future to provide a blueprint from which to work backwards for its achievement. The project identified a number of practical elements such as shared provisioning systems and alternative forms of production and an emphasis on more holistic, integrated and communal approaches to living. Overall, each study provides support and encouragement for further work in these areas and the belief that young people will play an increasingly active role in leading and advocating for sustainable consumption change.

\section{Justice Concerns in SDG 12: The Problem of Missing Consumption Limits \\ by Katia Vladimirova}

As part of Agenda 2030, SDG 12 aims to offer a long-term vision for transforming existing unsustainable consumption and production patterns. These changes are bound to affect the lifestyles and livelihoods of billions of people and give rise to a multitude of morally relevant questions and trade-offs concerning matters 
of intra- and intergenerational (re)distribution. Among these moral dilemmas is the problem of setting consumption limits, especially at the upper tail of wealth distribution. This position piece argues that failure to translate scientific consensus on the biophysical limits of Earth into upper consumption limits, and the absence of references to consumption limits in Agenda 2030 and the SDGs, which can be explained in terms of moral corruption, leads to difficult moral choices being passed onto future generations. 



\section{2

\section{Preface to Transitioning to Responsible Consumption and Production}

\section{Lisa McNeill}

\section{Introduction}

Prior examination of national material footprints around the world note that developed countries have a significantly greater per capita impact on the environment than developing economies (Wiedmann et al. 2015). Indeed, the gap between reality and sustainability aims continues to grow around the world, particularly in developed economies where consumption demands oftern outstrip ethical concerns (Amos and Lydgate 2019). It is predicted that, at the current rate of population growth and consumption, the natural resources needed to sustain current lifestyles would require the equivalent of almost three planets by 2050 . It is clear that change is required, involving action from everyone from the producer to final consumer. Since sustainable consumption aims for world citizens to 'do better with less', all aspects of this change must be carefully considered with regard to critical ecological and social models that transform production and consumption practices recognised as negative (Franco et al., 2020). However, achieving change through halting and reconceptualising current consumption norms requires a focus on the interand intra-generational equity issues apparent around the world (Holden et al. 2014). One of the central problems faced by those seeking to enact the principles of SDG 12 , as put forward by the UN, is the lack of focus on direct areas of concern (e.g., planned obsolescence of products by producers) (Akenji and Bengtsson 2014). In this sense, SDG 12 is an extremely broad goal, with multiple avenues of potential for operationalization (Gasper et al. 2019).

The basic principle of environment justice - the equal sharing of environment benefit and harm - has not yet been reached in countries that have both high levels of production of consumer goods, but also high levels of consumption (Schlosberg 2007). This Special Issue, Transitioning to Responsible Consumption and Production, focuses on some selected examples of consumption forms that are increasingly recognised as problematic, offering models or alternatives that aid consumer and producer transitions. The volume presents a multi-disciplinary, multi-stakeholder conversation on this issue, with a focus on the intersection between encouraging and enhancing sustainable production processes, and enacting behaviour change and 
socially oriented decision-making by consumers. Further, the volume gives insight into hope for future generations of consumer, and the pathway to achieving the goals of SDG 12.

\section{Papers in the Volume}

This Open Access book series centers on the SDGs, in a contribution toward global academic efforts for a sustainable world. As such, this volume presents a series of papers that highlight the results of significant empirical, conceptual and applied research, in the area of responsibility in consumption and production. This Special Issue is unique in that not only offers perspectives on both the consumer and the producer, but it also offers insight into the current key topics of concern to academics who are focused on enacting change in how individuals view and manage their consumption lifestyles.

The first paper (see Jones, Wynn and Comfort) begins by reviewing how leading retailers in the UK are publically responding to calls for greater accountability in promoting sustainable consumption practices amongst their consumers. Overarchingly, there is a disconnect apparent between these retailers' emphasis on commitments to sustainable consumption, as per their corporate websites, and what happens in store. As the central point of communication to consumers of company values is likely to be in store, the evidence put forward by Jones et al. for this disconnect serves to highlight one of the core problems in promoting or supporting sustainable consumption practice to consumers-that of a lack of information and opportunity at point of sale, by retailers who do not show commitment to these principles on the shop floor.

The second and third papers in this volume deal with one of the critical areas of consumption concern around the world, that of overconsumption of textiles in the form of fashion clothing and accessories. Both papers focus on the drivers of the excess clothing consumption that is seen worldwide, with Kleinhucklkotten and Neitzke highlighting the challenging nature of clothing in regard to moderating both production and consumption toward a more sustainable model. This paper details the economic importance of the clothing industry, while contrasting the negative environmental impact of textile production. Drivers of clothing consumption by consumers are presented as a frame to understand the acceptability of sustainable clothing consumption alternatives. Extending on this theme, Ritch presents a paper that teases out the connections between self-esteem and identity confidence of consumers, and fashion textile consumption. This paper highlights the importance of socially responsive methods of production and communication by manufacturers, 
in enabling consumers to make sustainable consumption choices that make them feel good as well as look good.

Continuing to develop this examination of the intersect between sustainable production and consumer choice are the fourth and fifth papers in this Special Issue, which focus on consumer choice and production principles as related to sustainability in the food and FMCG industries. The first of this pair of papers (see Secondi and Principato) considers the problem of food waste from the demand perspective, examining the characteristics of household level food choice in relation to waste. The paper offers opportunities for the development of targeted consumer interventions to reduce food waste impacts by estimating demand elasticities in consumer categories. Following on from this discussion, Hamlin's paper also addresses the FMCG industry and waste, but from the perspective of intervening in the current cycle of associated packaging waste that increases the overall environmental impact of FMCG consumption world-wide. This paper proposes a closed-cycle packaging system as an alternative to current recycling and reuse programmes, with the aim of highlighting government and trade regulations that are required to implement such a solution in the modern world.

Understanding lifecycles of consumer goods, and embedded consumer perceptions of the useful life of goods, is crucial to developing models of practice that extend the life expectancy of products that have increasingly rapid waste cycles. Fashion and textiles are said to be one of the most waste producing consumer product categories worldwide, and the concept of product lifespan an increasingly challenging one in relation to this category of goods. The sixth and seventh papers presented in this volume deal specifically with the challenge of changing consumers perceptions of need for disposal. McQueen, Kowton and Degenstein examine the impact of negative use experience and consumer dissatisfaction in promoting premature disposal, exploring how one aspect of the multi-sensorial experience of textile consumption, that of odour, may stimulate not only early lifecycle disposal, but also unsustainable disposal methods. Niinimaki and Durrani approach the lifecycle issue by addressing one aspect of fashion garment life extension, textile repair. The paper considers the act of repair from both consumer and business perspectives, with the ultimate goal of challenging established consumption-production cultures in this industry.

To close this Special Issue, two papers focused on the future of sustainable consumption and production practice are presented. The first of these, by Watkins and Aitken, takes one promising segment of consumers, the youth, and offers suggestions for a pathway toward sustainable consumption literacy amongst this group. This paper presents the results of three studies of young consumers: one study 
focusing on sustainable consumption frameworks and language, the second on the impact of advertising and pro-consumption messaging for young consumers, and the third detailing young consumers visions of a sustainable consumption future.

The last paper in this volume (see Vladimirova) addresses the critical issue of social justice in the future of sustainable societies. Any move toward sustainable production and consumption practice introduces a set of moral dilemmas that must be considered as part of the wider solution to unsustainability. One of these moral issues concerns consumption limits, and the redistribution of resources in any sustainable consumption system. This paper raises a useful set of wider questions that should inform the ongoing theoretical discourse around SDG 12, as it reframes the notion of resource efficiency in an unequal world.

\section{Conclusions}

The aim of this volume was to highlight current academic research that supports the UN's 2015 call for more responsible consumption and production, as contained in SDG 12. To this end, the volume presents a series of perspectives on topics including consumer goods retail, food waste and production, fashion consumption and obsolescence, and youth and justice oriented perspectives on consumption. This volume presents a snapshot of some of the critical areas of concern related to consumption behaviour, and provides an overarching commentary on what must change in these areas for the goals of the UN to be realized.

Conflicts of Interest: The author declares no conflict of interest.

\section{References}

Akenji, Lewis, and Magnus Bengtsson. 2014. Making Sustainable Consumption and Production the Core of the Sustainable Development Goals. Sustainability 6: 513-29. [CrossRef]

Franco, Isabel B., Tathagata Chatterji, Ellen Derbyshire, and James Tracey, eds. 2020. SDG 12

Responsible Consumption and Production. In Actioning the Global Goals for Local Impact. Science for Sustainable Societies. Singapore: Springer.

Gasper, Des, Amod Shah, and Sunil Tankha. 2019. The Framing of Sustainable Consumption and Production in SDG 12. Glob Policy 10: 83-95. [CrossRef]

Holden, Erling, Kristin Linnerud, and David Banister. 2014. Sustainable Development: Our Common Future Revisited. Global Environmental Change 26: 130-9. [CrossRef]

Schlosberg, David. 2007. Defining Environmental Justice: Theories, Movements, and Nature. Oxford: Oxford University Press. 
Wiedmann, Thomas O., Heinz Schandl, Manfred Lenzen, Daniel Moran, Sangwon Suh, James West, and Keiichiro Kanemoto. 2015. The Material Footprint of Nations. Proceedings of the National Academy of Sciences 112: 6271-76. [CrossRef] [PubMed]

(C) 2020 by the authors. Licensee MDPI, Basel, Switzerland. This article is an open access article distributed under the terms and conditions of the Creative Commons Attribution (CC BY) license (http://creativecommons.org/licenses/by/4.0/). 



\title{
12

SDG 12, Sustainable Consumption and the UK's Leading Retailers

\author{
Peter Jones, Martin Wynn and Daphne Comfort
}

\section{Introduction}

Taken together the 17 United Nations Sustainable Development Goals (SDGs) offer 'the blueprint to achieve a better and more sustainable future for all' (United Nations 2019a, webpage), but in many ways the concept of sustainable consumption, part of SDG 12, namely Sustainable Consumption and Production, is fundamental to the transition to a sustainable future. Pantzar et al. (2018, p. 1), for example, argued that 'consumption of goods and services is at the very heart of the challenge of achieving a more environmentally, socially and economically sustainable Europe'. In a similar vein, the Nordic Council of Ministers (2018, p. 11), claimed that 'SDG 12 is the goal most interlinked to other goals, being coupled to no less than 14 out of the 16 remaining goals'. However, the 'Report of the Secretary-General on SDG Progress 2019' (United Nations 2019b, p. 22) on SDG 12 painted a pessimistic picture in that 'worldwide material consumption has expanded rapidly, as has material footprint per capita, seriously jeopardizing the achievement of Sustainable Development Goal 12 and the Goals more broadly'. Further the Secretary General reported that 'in 2017 worldwide material development reached 92.1 billion tons, up from 87 billion in 2015 and a $254 \%$ increase from 27 billion in 1970, with the rate of extraction accelerating every year since 2000' (United Nations 2019b, p. 22).

While business organisations in a range of commercial sectors are addressing the SDGs (Wynn and Jones 2020), retailing can be seen to be fundamental for any move to sustainable consumption. There is certainly a growing awareness that retailers have a vital role to play in promoting more sustainable patterns of consumption, not least in that they effectively act as gatekeepers between producers and consumers. As such, large retailers may be seen to be in a singularly powerful position to drive sustainable consumption in three ways, namely through their own activities, through their relationships and partnerships with suppliers and through their daily interactions with consumers. Durieu (2003, p. 7), for example, argued that large retailers 'can greatly influence changes in production processes and consumption patterns'. 
A number of the world's major retail trade associations have emphasised their commitment to sustainable consumption. In Europe, the Retail Forum was launched in 2009 to 'exchange best practices on sustainability within the European retail sector and to identify opportunities and barriers that may further or hinder the achievement of sustainable consumption and production' (European Commission 2018, webpage). Indeed, the European Commission (2018, webpage) claimed that 'retailers in Europe are in an exceptional position to promote more sustainable consumption'. Jones and Comfort (2018) reported that in its 2017 Retail Sustainability Management Report, the Retail Industry Leaders Association identified sustainable consumption as the most critical issue for retailers to address.

More specifically, within the UK, in 2018 the British Retail Consortium (BRC) launched 'Better Retail Better World' (British Retail Consortium 2018, webpage). This initiative looks to mobilise the UK retail industry to make a leading contribution to the SDGs, and here the BRC targeted SDG 12, which they formally redefined as 'responsible consumption', along with SDGs 8 (Decent Work and Economic Growth), 10 (Reduced Inequalities), 11 (Sustainable Cities and Communities) and 13 (Climate Action). With this in mind, this chapter provides an exploratory review of how the leading retailers in the UK are publicly addressing the issue of sustainable consumption. The chapter outlines the concept of sustainable consumption, examines if, and how, the UK's leading primarily store based retailers report publicly on their commitment to sustainable consumption, examines how these retailers are communicating sustainable consumption agendas to their customers in stores and offers some reflections on current approaches to sustainable consumption within the retail sector.

\section{Sustainable Consumption}

The earliest and most widely used definition of sustainable development is 'development that meets the needs of the present without compromising the ability of future generations to meet their own needs' (World Commission on Environment and Development 1987, p. 43). In a similar vein, sustainable consumption might simply be defined as the use of products and services in a way that minimizes the impact on the environment, so that human needs can be met not only in the present but also for future generations.

However, there is little consensus in defining sustainable consumption, and it is widely recognized to be a contested concept that embraces 'competing discourses' (Hobson 2002, p. 95), but it is also an elusive concept. As such, organisations wishing 
to pursue sustainable consumption policies face major challenges not only in defining, but also in operationalising, the concept.

In looking to put some flesh on the concept, Environmental Justice Organisations Liabilities and Trade (2019, webpage) suggested that sustainable consumption can be seen as 'an umbrella term that brings together a number of key issues, such as improving efficiency, minimising waste, taking a lifecycle perspective, but also taking into account the equity perspective, meeting needs, and enhancing quality of life, improving resource efficiency, increasing the use of renewable energy sources, minimising waste, taking a life cycle perspective and taking into account the equity dimension'. More specifically, the United Nations Environment Programme (2015, p. 11) has identified nine elements, namely 'waste management, sustainable resource management: design for sustainability; cleaner production and resource efficiency; sustainable transport; eco-labelling and certification; sustainable procurement; sustainable marketing' and 'sustainable lifestyles', which characterize sustainable consumption.

Such definitions aside, Hinton and Redclift (2009, p. 7) argued that sustainable consumption 'could be considered an ambivalent term: the discourse comprises many different parts, mobilised at different times and in different ways'. Jackson (2006) summarised a variety of definitions but noted that these adopt different positions on both the extent to which sustainable consumption involves changes in consumer behaviour and lifestyles as well as on whether sustainable consumption implies consuming more efficiently, consuming more responsibly or, more radically, consuming less. Gasper et al. (2019, p. 84) suggested that by the 1990s, sustainable consumption and production essentially 'meant re-engineered consumption, not reduced or constrained consumption'. Jackson (2006) further argued that the dominant institutional consensus sees sustainable consumption being achieved primarily through improvements in the efficiency with which resources are converted into economic goods.

At the same time, a distinction has been made between 'weak' and 'strong' sustainable consumption. Lorek and Fuchs (2013, p. 37) suggested that the former 'can be achieved via improvements in efficiency resulting from technological solutions and, frequently, that these technical solutions will spread through markets due to consumer demand'. The latter definition 'is based on the assumption that changes in consumption levels and patterns are necessary to achieve sustainable consumption' and 'emphasizes the need for a reduction in overall resource consumption instead of product-based individual consumption' (Lorek and Fuchs 2013, p. 38). Arguably more pointedly, Geels et al. (2015, p. 1) argued that current thinking on sustainable consumption (and production) is framed by two generic positions. The first, described 
as 'the reformist position' focuses on 'firms pursuing green eco-innovations and consumers buying eco-efficient products, represents the political and academic orthodoxy'. This echoes the beliefs that 'underlying SDG12 is a faith in human ability to manage the adverse environmental impacts of unending economic growth' (Gasper et al. 2019, p. 86) and more generally that 'organizations can harness the 17 SDGs to drive growth' (EY 2017, webpage). The second is described as 'the revolutionary position', namely 'a radical critique', which 'advocates the abolition of capitalism, materialism and consumerism and promotes values such as frugality, sufficiency and localism' (Geels et al. 2015, p. 1).

\section{Frame of Reference and Method of Enquiry}

This exploratory paper looks to address two simple research questions, namely if, and how, the UK's leading retailers are addressing sustainable consumption (i) at the corporate level and (ii) within their stores. To explore these two questions, the authors selected the UK's top ten store-based retailers for study, measured by retail revenue, as listed by Retail Economics (2018) and Deloitte (2019), namely Tesco, J. Sainsbury, Asda, Morrisons, Kingfisher (B\&Q), Marks and Spencer, Dixons Carphone (Curry's PC World and Carphone Warehouse), John Lewis Partnership (John Lewis and Partners and Waitrose and Partners), Co-operative Group and Next. The four largest retail companies in the UK, namely Tesco, J. Sainsbury, Asda and Morrisons, are often referred to as food retailers, although in part this is a misnomer in that while they were all initially established as grocery retailers, they now all sell a wider range of consumer goods. Tesco is the UK's largest retailer, with some 3400 stores and over 310,000 employees, and it trades from hypermarket, superstore, and convenience store formats. J. Sainsbury, initially founded in 1869, trades from over 600 supermarkets, some 800 convenience stores and 800 stores operating under the banner of Argos, throughout the UK. Asda was founded in Yorkshire in 1965, and though originally based in the north of England, the company now trades from over 600 locations within the UK. Morrisons, founded in 1899 in Bradford, Yorkshire, trades from some 500 stores. The company's operations were originally concentrated in the Midlands and North of England, but it is now well represented in the South of England.

The John Lewis Partnership operates a chain of over 30 John Lewis department stores and some 600 Waitrose food supermarkets. Kingfisher is a UK based home improvement retailer, with over 1200 stores in 10 countries across Europe, Russia and Turkey, and it trades as B\&Q, Brico Depot, Screw Fix, Castorama and Praktiker. Marks and Spencer, arguably the UK's most iconic retailer, specialises in the sale of 
clothing, household goods and food and trades from almost 1000 stores within the UK, including over 600 that sell only food products. Dixons Carphone is a multinational electrical and telecommunications retailer, which operates in eight European countries under a number of brands, including Curry's, PC World, Carphone Warehouse and Elkjop. The Co-operative is a consumer co-operative with a diverse range of retail operations, principally food retailing, but which also includes electrical retailing, travel agencies and funeral services. Next is a multinational clothing, footwear and home products retailer and trades from some 500 stores in the UK and a further 200 in Europe, Asia and the Middle East.

To address the two research questions, the authors adopted a twin track method of enquiry, although in pursuing both approaches, the focus was on how leading players within UK retailing approached and addressed sustainable consumption rather than on a comparative analysis of their approaches. Firstly, two Internet searches, the one using the key phrase 'sustainable consumption' and the name of each of the selected retailers, and the other using the key phrase 'sustainability report', once again with the name of each of the selected retailers, were conducted in November 2019 using Google as the search engine. The authors recognised that this approach has its limitations in that there are issues in the extent to which the information and reports posted on the Internet genuinely reflect current corporate thinking on sustainable consumption. However, in looking to undertake an exploratory review of the role retailers publicly claim to be playing in addressing sustainable consumption, the authors believe the Internet-based approach is appropriate.

Secondly, the authors undertook a basic observational survey of if, and how, the selected retailers looked to engage customers with sustainable consumption within their stores, and this survey was undertaken in the largest store operated by each of the selected retailers within Cheltenham, a town with a population of some 115,000 in the South West of England, during November 2019. More specifically, 'a walk through' survey combining structured visual observation and recording was undertaken and the authors recorded the extent to which sustainable consumption messages were being used in marketing communications on banners and posters on the shelves and shelf edges, on the products themselves and on information leaflets and promotional leaflets and flyers. The authors recognised that this approach provides a snap shot in both time and space of how the selected retailers are looking to address sustainable consumption within store but would argue that it had three advantages. Firstly, it was simple to conceptualise, easily executed and readily replicable. Secondly, the authors believe that it captured an accurate picture of the ways in which messages about sustainable consumption were, or were not, 
being presented to customers within stores and as such went some way to capture the reality of the customers' retail experience and their engagement with sustainable consumption at the point of sale. Thirdly, it located sustainable consumption in a dynamic retail setting and provided a view through the lens of the customer.

\section{Results: Corporate Level}

The Internet survey revealed that eight of the selected retailers outlined their commitment to sustainable consumption in their most recent sustainability reports and/or on their corporate websites. This commitment was largely couched within each retailer's description of how its business plans and strategies were aligned to the SDGs. The retailer's overall approach to sustainable consumption might be best described as aspirational. In addressing how its business plan was aligned to SDG 12, Marks and Spencer (2018, p. 42), for example, reported 'we'll develop and implement new product circular economy standards and services, ensure all packaging is easy to recycle and halve net food waste'. In addressing 'Product Sustainability' Marks and Spencer (2019a, webpage) claimed 'we want to lead our sector in terms of sustainable consumption and production-offering our customers good value, high-quality products and services', while in addressing 'Responsible Sourcing', the company (Marks and Spencer 2019b, webpage) claimed 'we want to be a leader on sustainable consumption and production in our sector'.

Under the banner 'UN Sustainable Development Goals', J. Sainsbury plc (2018, p. 21) outlined its commitment to 'ensure sustainable consumption and production patterns'. In recognising that 'the increasing demand on constrained natural resources could cause irreversible damage to our environment', the company (J. Sainsbury plc 2018, p. 21) reported 'we are committed to help halve global food waste per capita by 2030'. More specifically, the company (J. Sainsbury plc 2018, p. 21) reported 'we've been reducing food waste in our operations through a number of initiatives, including smarter and more tailored forecasting and supply chain efficiency, while growing our network of charity partners to redistribute unsold edible food'.

Kingfisher (2019, p. 92) reported how a number of 'our' sustainability 'targets' were linked to the SDGs. Under the banner 'Save money by saving energy and water' Kingfisher (2019, p. 92) claimed that its targets to 'enable a 50\% reduction in customer energy use through our products, services and advice' and to 'enable a 50\% improvement in customer water efficiency through our products, services and advice' were aligned with sustainable consumption and production and more generally with SDGs 8,11 and 12. In a similar vein, under the banner 'Live smarter by getting more from less, reusing or using longer', Kingfisher (2019, p. 93) claimed its targets to 
offer ' 20 products or services that help customers get more from less, reuse or use longer 'and to 'ensure sustainable management and efficient use of key resources' were aligned with sustainable consumption and production and more generally to SDGs 8,9 and 15 .

'In line with UN Global Compact guidance', Tesco (2018, webpage) identified which SDGs 'are particularly relevant to us: where expectations, risks and opportunities for Tesco are greatest, and where we can make the most significant contribution'. Here, SDG 12 was one of the eight SDGs identified by the company, and it was described as being 'particularly significant for Tesco' (Tesco 2018, webpage) because of its commitment to reduce food waste. Further Tesco (2018, webpage) claimed 'we were the first UK retailer to publish data on food waste in our own operations so that we can track our progress against this target. We are now encouraging other organisations, both within and outside our supply chain, to do the same'. Tesco (2018, webpage) also emphasised its role in contributing to SDG 12 through its target to make all packaging fully recyclable by 2025 . Here, the company claimed 'we want to create a closed loop system for packaging so everything can be re-used, recycled or re-purposed. We have committed to remove all hard to recycle materials from our Own Brand packaging by the end of 2019 and are working with our suppliers to find alternatives' (Tesco 2018, webpage).

The John Lewis Partnership (2019, webpage) identified nine 'priority SDGs', and here sustainable consumption was listed as contributing to each of the company's three 'business strategies', namely 'source and sell with integrity', 'better jobs, better performing partners, better pay' and 'deliver more for less'. The Co-op (2019, p. 27) reported that it had aligned its 'Future of Food Commitments and Property Environment and Resource Strategy' and its 'material activities' with the SDGs. More specifically, in outlining its alignment with SDG 12, the Co-op (2019, p. 27) reported that 'by 2023 we want $100 \%$ of our food product packaging to be easy to recycle by product line, and our latest data shows we're at $72 \%$ ' and that 'we've also set a target to reduce food waste generated in our stores and depots by $50 \%$ by 2030 compared to 2015'. Morrisons linked their policies on 'changing our use of plastics' (Morrisons 2019, p. 9) and 'tackling food waste' (Morrisons 2019, p. 12) to SDG 12.

Next $(2019$, p. 5), outlined how it was aligning its sustainability reporting 'against the 9 SDGs that are most material to our business operations and the products we sell' in that 'these are the goals where we have the greatest opportunity to contribute'. SDG 12 was one of the nine SDGs, but Next $(2019$, p. 5) described it as 'Responsible Consumption and Production' rather than sustainable consumption and production. Asda made no explicit reference to the SDGs on its corporate 
website, although it is a signatory of the BRC's 'Better Retail Better World' initiative. Dixons Carphone (2019, webpage) 'pledged to support the United Nation's sustainability goals of reducing modern slavery, inequality and climate change whilst supporting sustainable economic growth and responsible consumption and production' but provided no specific details on how the company would pursue its commitment to sustainable consumption.

While the majority of the selected retailers outlined their commitment to sustainable consumption, they were generally less forthcoming as to how this was to be achieved, but two specific examples provide some illustration of their thinking. In outlining their approach to product sustainability, Marks and Spencer (2019a, webpage), for example, suggested that it took product sustainability to mean that each product 'has a demonstrable positive or significantly lower environmental and/or social impact during its sourcing, production, supply, use and disposal', and it looks to ensure that 'social and environmental principles are always taken into consideration and inherent in individual products'. In outlining its approach to responsible sourcing, Marks and Spencer (2019b, webpage) claimed, for example, 'we have a responsibility to ensure workers' rights are at the forefront of our decision making'.

In addressing the reduction of food waste, Morrisons (2019, p. 13) reported 'we have well developed systems for preventing food waste and increasing the distribution of any surplus so that we keep edible food within the human food chain. We buy direct from meat and produce farmers and suppliers in the UK and utilise more of what we buy through our own abattoirs or produce pack houses. We buy whole animals and where practical, we have the capability to process whole crops. This enables us to manage and reduce associated waste and related costs'. At the same time, Morrisons (2019, p. 14) highlighted its activities in 'helping customers to reduce their food waste'. Here, the company noted that 'over $50 \%$ of food wasted in the UK comes from UK households. As a food retailer we have a responsibility to drive down avoidable food waste where we can, by providing our customers with clear and consistent information in stores, online and on packaging to help them to effectively store and cook food with little waste'. More tellingly, a survey by Morrisons (2019, p. 14) conducted amongst their customers suggested 'it is evident that people aren't aware of the food that they're wasting and there is disconnect between personal behaviour and habits and how this is contributing to the global food waste problem. In looking to tackle this problem Morrisons (2019, p. 14) suggested 'it's important that we incentivise customers to reduce their food waste in a way where they can see or feel the positive impact of their day-to-day actions, whether this is through money saving or through environmental benefit'. 


\section{Results: Store Level}

The observational survey revealed two contrasting sets of themes. Firstly, the authors found no explicit reference to sustainable consumption, nor to SDG 12 or to any of the SDGs, in any of the stores surveyed. There were, however, a limited number of notices and messages about what could be described as being consistent with sustainable consumption. In the Marks and Spencer store, for example, there were two prominent notices on the walls at the side of the escalator between the ground and first floors. The first was entitled, 'Sustainable Raw Materials', and it read 'Our goal is to make sure our key raw materials are from the most sustainable sources available to us'. The second read, 'There's nothing uniform about our staff uniforms. They're made from recyclable bottles. We never lose our bottle when it comes to making a better environment'.

In the Co-op store, a notice on the wall by the front window, entitled 'Local Food is Miles Better For You' announced that '50 local products are sourced from within 40 miles of the store and a further 20 that are from our region'. At the back of the fish counter in the J. Sainsbury store under the banner, 'Responsibly Sourced', a notice read, 'We are committed to bringing you great quality responsibly sourced fish all year round.' A notice at the back of the fish counter in the Morrison's store announced 'Our Tuna is Responsibly Sourced'. In the B\&Q (Kingfisher) store the own label Good Home product range included a notice that carried the title, 'Small Change Big Impact' and which read 'We've made it easier for you to make sustainable choices by making sure all laminate and wood flooring is FSC certified and by using minimal Volatile Organic Compounds in our paint'.

Within most of the stores surveyed, there were a limited number of messages about what might be termed responsible sourcing on the packaging of a small number of own label and branded products. In the John Lewis and Partners store, for example, the boxes containing the retailers' own brand Duck and Feather and Down Duvets carried the following message: 'This product supports cotton farmers who are water efficient, care for the environment and promote fair and decent work. The feather and down used is certified to ensure high animal welfare and is fully traceable from farm to product'. In the B\&Q store, the sacks of own brand Verve Small Landscape Bark carried the following message: 'Verve puts the well-being of our environment at the heart of everything we do. We aim to conserve precious resources by making it our policy not to buy or sell peat taken from sites of ecological, archaeological or conservation value anywhere in the world'.

Bags of Morrisons French Style Coffee carried the message 'Rainforest Accredited Certification means that farmers follow more sustainable agricultural practices that 
protect forests, rivers, soils and wildlife, while being good community neighbours'. The packaging for Asda's own brand Loose Leaf Tea, for example, carried the message, 'We're working with farmers in the Rainforest Alliance to grow our tea to in an ecologically and sustainable way ... that means careful use of pesticides, control of waste water and less soil erosion'. In J. Sainsbury, a message on the packets of Taylor's of Harrogate Coffee read 'Rainforest Alliance Certification helps the environment and helps ensure sustainable livelihoods. We don't just buy coffee, we work to improve livelihoods, protect landscapes and support thriving communities-facing the future together with our coffee farmers'. In the same store, there was a similar, if shorter, message on Taylor's Yorkshire Tea, namely, 'Rainforest Certification Alliance helps protect the environment and ensure sustainable livelihoods'.

The second theme confronting customers within the surveyed stores was the messages, which emphasised price enticements to encourage increased consumption, rather than to encourage more sustainable patterns of consumption. There was marked variation in the number of these messages between the surveyed stores, and they were most prominent in stores selling food, but they covered a wide range of products. Many of the selected retailers advertised offers on multiple purchases at reduced unit prices. In the Tesco store, for example, such offers included blocks of Excreme Salted Caramel Ice Cream at ' 2 for $£ 4$ ' (where the individual price was $£ 3$ ), Schweppes Tonic and Ginger Ale 'Any 3 for $£ 3^{\prime}(£ 1.25)$, two boxes of Mr. Kipling Mince Pies '2 for $£ 2.50$ ' ( $€ 1.85$ ), cans of Heinz Soups ' 6 for $£ 4$ ' and ‘3 for $£ 2.50$ ' ( $£ 0.95)$, Head and Shoulders Conditioner and Shampoo 'Any 3 for $£ 10$ ' (£5), ' $25 \%$ off six or more bottles' on a range of wines and 'Buy One Get One Free' on packs of Energizer Batteries. Morrisons advertised offers on a range of beers and lagers including packs of bottled Stella Artois at ' 2 for $£ 20$ ' ( $£ 14.50$ ), packs of cans of Carling at ' 2 for $£ 20$ ' (£13. 50), packs of bottled Old Speckled Hen at '2 for $£ 20$ ' (£12) and packs of canned Coors Light at ' 2 for $£ 20$ ' (£12).

In a similar vein, in Asda, offers on the edge of shelves included ' 2 for $£ 1.50$ ' ( $£ 1$ ) on selected cookies and doughnuts, ' 2 for $£ 3^{\prime}$ ( $£ 2$ ) on selected Mini Bites, ' 2 for $£ 2$ ' ( $£ 1.75$ ) on selected Dolmio Sauces, ' 6 for $£ 4$ ' ( $£ 0.95$ and $£ 0.85$ ) on Heinz Soups, ' 3 for $£ 3$ ' (£1. 60) on bags of dried nuts and fruit and 'Save $25 \%$ when you buy 6 or more bottles of wine'. Multi Buy messages on Asda's chilled meat cabinets included Steaks '2 for $£ 6$ ' ( $£ 4), 18$ Rashers of Smoked Back Bacon ' 3 for $£ 10$ ' (£3.90), and Pork Loin Steaks ' 3 for $£ 10$ ' ( $€ 4)$. Marks and Spencer offered bags of Oranges ' 2 for $£ 4.00$ ' ( $€ 2.50)$, packs of Premier Bacon and Sausages at ' 2 for $£ 5$ ' (£3.00) and 'Any 3 for $£ 10$ ' $(£ 4)$ in the fish deli cabinets. Marks and Spencer also had advertised offers on their clothing merchandise including ' 2 for $£ 30$ ' (£19.50) on Long Sleeve Oxford Shirts and '2 for 
$£ 30$ ' (£19.50) on Super Soft Jumpers. B\&Q offered '3 for 2' ( $£ 0.85)$ on Heat Logs, '3 for $£ 18$ ' (£7.95) on Coffee Logs and ' 3 for $£ 6$ ' ( $£ 2.34$ ) on Natural Firelighters. Curry's PC World offered ' 3 for 2' on a range of Smart Phone and iPhone Accessories.

\section{Discussion}

This paper has a number of limitations. It draws on corporate information posted on the Internet, rather than on discussions with company executives responsible for drawing up corporate policy; and the observational survey presents a snap shot of details of sustainable consumption in just one of each of the selected retailers' stores. Nevertheless, it offers an exploratory review of how the UK's leading retailers are addressing sustainable consumption, and the two sets of findings reported above reveal mixed messages about the leading UK retailers' approaches to sustainable consumption. On the one hand, it is important to recognise the majority of the selected retailers publicly emphasised their commitment to sustainable consumption, usually as an integral part of their wider commitment to the SDGs, and particularly to SDG 12, on their corporate websites. However, much less attention was given to how the retailers planned to promote more sustainable patterns of consumption. Here, the absence of customized or government measurable and verifiable targets, and/or key performance indicators, are conspicuous by their absence in the retailers' commitments to sustainable consumption. Indeed, the old English proverbial saying 'fine words butter no parsnips' resonates when describing the retailers' public approach to sustainable consumption outlined on their corporate websites. On the other hand, at store level, the authors found that the retailers made no reference to the SDGs or more specifically to sustainable consumption, and while there was some very limited information on what might at best be described as responsible consumption, it was often in small print on product packaging. While such information might be located and read by committed customers who look for products with sustainable consumption credentials, many of the marketing messages within stores appeared to be designed to promote consumption rather than to encourage more sustainable consumption.

More generally, six sets of issues merit reflection and discussion. Firstly, there are issues about the definition of sustainable consumption. Indeed, while some of the selected retailers follow the British Retail Consortium in redefining sustainable consumption as responsible retailing, none of them offers a definition of their own. Their approach to sustainable consumption suggests that they generally couch their corporate commitments to it in the loose and wide-ranging idiom suggested by Environmental Justice Organisations Liabilities and Trade (2019) and the United 
Nations Environment Programme (2015) earlier in this paper. At best, the retailers' approaches to sustainable consumption would seem to reflect the definition of weak, rather than strong, sustainable consumption, as also outlined earlier in the paper, and they would certainly seem to reflect Jackson (2006) argument that the dominant institutional consensus is that the road to sustainable consumption lies in improvements in the efficiency in which natural resources are converted into economic goods. This also reflects the retailers' more general position on sustainable development, where Jones and Comfort (2018) have argued that the focus is on driving business efficiencies and cost savings and on continuing growth.

Secondly, there are issues surrounding measurement and reporting. The United Nations (2017) specified eight specific targets, three targets related to means of implementation and thirteen indicators, for SDG 12, all of which are, in principle, universally applicable. However, Gasper et al. (2019, p. 90) argued that 'the SDG indicators show major deficiencies, in particular inadequate coverage of corresponding targets and a checklist orientation which privileges counting of reports over examination of their content and quality'. Almost all leading retailers produce an annual sustainability report, which addresses their commitments and achievements across a wide range of environmental, social and economic arenas. However, attempts to directly map the retailers' achievements in addressing sustainable consumption are conspicuous by their absence from these reports.

Nevertheless, while much of the content of these reports is based around narrative accounts, retailers increasingly use a range of quantitative measures and statistical data to report on their achievements. Here, measures cover many of the issues included in the loose definitions of sustainable consumption cited by the International Institute for International Institute for Sustainable Development (2017) and the United Nations Environment Programme (2015). Kingfisher's 2018/2019 Sustainability Report, for example, includes performance data on energy efficiency, carbon emissions, waste disposal and recycling and the company's carbon footprint. However, there are two concerns about using such performance data to assess a retailer's success in moving towards sustainable consumption.

On the one hand, there are concerns about the independent external assurance of the performance data included in retailers' sustainability reports. Jones et al. (2014) have suggested that, at best, some large retailers' commission limited assurance of their performance data and that such assurance includes some, but not all, of that data. This can be seen to reduce the credibility, integrity and reliability of the sustainability reporting process and more specifically of the reporting of achievements in moving towards more sustainable consumption. The UK's leading retailers are large, complex 
and dynamic organisations, and capturing and storing comprehensive information and data in a variety of geographical locations and then providing access to allow external assurance is a challenging and a potentially costly venture. On the other hand, the existing performance data collected and reported by the retailers would seem to have little relevance to definitions of sustainable consumption, which are focused on fundamental changes in consumption patterns and reductions in consumption and which stress frugality, sufficiency and localism.

Thirdly, there are tensions between the selected retailers' corporate commitments to sustainable consumption and price offers within their stores designed to encourage consumption. Price is always likely to be an important factor in influencing the behaviour of the majority of consumers, but Shell (2009) argued that discounted prices may prove to be unsustainable in that, inter alia, they generate waste from over purchasing and lead to irreversible environmental damage. Although the UK's leading retailers have been very successful in developing marketing strategies built around competitive pricing, much less is known about how consumer concerns about the environmental damage associated with consumption influence their buying behaviour. Rather pessimistically, while Goss (2006, p. 244) claimed that 'various movements have emerged to promote alternative consumption lifestyles', he reported 'there is widely observed to be an attitude gap' in that 'customers are not willing to pay higher prices for cause related products, lack adequate information to make effective choices ... and are easily distracted by marketing rhetoric' (Goss 2006, p. 245).

Fourthly, the consumer is often seen as having a central role to play in adopting a move towards more sustainable consumption, but Brand (2010) argued that approaches to sustainable consumption that focus on individual behaviours do not take account of the complexity of the consumption process, its symbolic meanings within society or the conventions of everyday life. In looking to address these complex issues, Shove and Spurling (2013) suggested that examining the ways social practices evolve and influence the consumption of resources will pay dividends. Such thinking draws on the wider genre of practice theory (Cetina et al. 2001), which essentially seeks to understand the role that practices play in our lives. More specifically, Ropke (Ropke 2009, p. 2492) noted that 'the practice perspective emphasizes the immense challenge involved in promoting sustainable consumption' and concluded that 'moralizing or trying to persuade individuals that curbing consumption would contribute to environmental improvements and increased wellbeing, has little chance of success'.

Fifthly, information and communication technologies can play a significant role in improving information flows across the supply chain and thereby facilitate more 
sustainable consumption. Two of the eight specific targets for SDG 12 mentioned earlier, for example, point to the significance of improved information. Target 12.6 is to 'Encourage companies, especially large and transnational companies, to adopt sustainable practices and to integrate sustainability information into their reporting cycle', whilst target 12.8 has the objective to 'By 2030, ensure that people everywhere have the relevant information and awareness for sustainable development and lifestyles in harmony with nature' (United Nations 2019a). Currently, despite the development of integrated business systems used by many of the large retailers, the absence of consistent cross-referenced information from the different parties involved in the extended supply chain (consumer, customer, retailer, producer and various intermediaries) is commonplace. However, as Zhang et al. $(2015$, p. 1) note, 'Recent technological developments have the potential to streamline the information flow from producer to consumer within supply chains, helping consumers to make more sustainable buying choices'. Currently, supply chain operations still generate, and are reliant upon, silos of information particular to the different parties within the extended supply chain, and sometimes within these entities themselves.

In the 1990s, the objectives of the company-wide integrated business systems projects pursued by the large retailers were to lower costs, increase efficiencies and improve customer service, and were in the main focused on the companies themselves. With the advent of the Internet, E-business or EDI (electronic data interchange), connections were established with customers and suppliers (Business-to-Business) and consumers (Business-to-Consumer) to facilitate data transfer across the extended supply chain (Wynn 2000). Now, however, the new web-based technologies—often termed 'disruptive' technologies-can facilitate a further level of integration and availability of information that can underpin a move to more sustainable consumer choices and retailer operations. Zhang et al. (2015, p. 1) note 'Ontologies, Linked Data, and Semantic Web technologies can handle the problems that arise when integrating massive amounts of multi-thematic and multi-perspective information from heterogeneous sources to answer complex questions that cut through supply chain domain boundaries. The innovative use of information technologies could reduce the "information asymmetry" that pervades modern supply chains. Reducing barriers to information would benefit not only consumers but also other actors in the supply chain'.

Finally, there are issues about power, described as 'the missing element in sustainable consumption' (Fuchs et al. 2016, p. 298). Geels et al. (2015) have suggested that the role of politics and power could be strengthened in future research into sustainable consumption and production, and Bradshaw et al. (2013) emphasised 
the need for a politically-oriented analysis of consumption, not only for the sake of informing academic debates, but also for the sake of informing contemporary consumption practices. In concluding their review of the importance of focusing on the importance of power in sustainable consumption, Fuchs et al. (2016, p. 306) argued that 'power is essential in understanding what drives overconsumption and creates barriers against attempts to make it sustainable, and in identifying where potentially effective intervention points may exist'.

Large retailers are seen to be in a singularly powerful position to define and drive sustainable consumption. However, they currently seem to choose to define the term in a loose and wide-ranging way, which effectively embraces their more general approach to sustainable development. This tends to favour business efficiency and continuing growth over a genuine concern for the conservation of environmental and social capital. At the corporate level, a number of the selected retailers implicitly claim to be using their power to work with their suppliers and customers to encourage more sustainable patterns of consumption. However, at the store level there is little evidence that the selected retailers are looking to encourage customers to adopt more sustainable patterns of consumption; rather, the focus of many of the marketing messages in store is to encourage increased consumption. At the same time, the retailers' focus on continued growth, with its attendant dependence on the world's shrinking stock of natural resources, can be seen to be the antithesis of sustainable consumption.

\section{Conclusions}

Sustainable consumption is both a contested and an elusive concept but, in many ways, it lies at the heart of the United Nations wide ranging SDG agenda. Large retailers have a pivotal position between producers and consumers, and, as such, they can potentially play a key role in promoting more sustainable patterns of consumption. Many of the UK's leading retailers report on their corporate commitment to SDG 12 and sustainable consumption, but there is, at best, limited evidence of this commitment at store level. Here, the retailers might be seen to be transferring the responsibility for adopting more sustainable approaches to consumption to customers without providing them with any information to guide their choice at the point of sale. However, the pessimistic picture of overall progress on SDG 12 cited at the start of this paper and the UK's 'shockingly low' public awareness of the SDGs cited by the House of Commons Environmental Audit Committee (2019, p. 33) suggest that large retailers could, and arguably should, play an important role in increasing awareness amongst the large numbers of customers who visit their stores 
on a regular basis. However, in many ways sustainable consumption is the antithesis of the large retailer's business models, which are underpinned by continuing growth and driven by aggressive marketing strategies designed to promote consumption. More generally, a major move towards sustainable consumption might be seen by the majority of consumers as 'a reverse of progress towards a better life' that involved 'a sacrifice of our current, tangible needs and desires, in the name of a better but uncertain future' (European Commission 2012, p.9).

While this paper offers an exploratory review of how the UK's leading retailers were addressing sustainable consumption, it also offers a platform for future research into this subject. Such research might look to provide a more critical analysis of the retailers' approach to sustainable consumption and will need to adopt a more rigorous research methodology, include the collection of extensive primary information and specify its objectives clearly. A first step might be for researchers, or more likely for research teams or institutes, to establish a formal collaborative research project with one (or possibly more) large UK retailer, designed to investigate how the retailer is contributing to sustainable consumption. The negotiation of agreements between researchers and retailers for such a collaborative research venture would be complicated, even more so if it also involved research access to suppliers. Researchers might well want access to sensitive commercial data, and both retailers and suppliers might demand the right to control or veto the researchers' findings.

More generally, academic research might be undertaken at both the strategic and the operational levels. At the strategic level, research amongst senior retail executives might profitably explore a number of issues. Such issues might include corporate thinking and policy development on sustainable consumption and on the circular economy; the challenges of, and opportunities for, integrating sustainable consumption within corporate retail strategies; retailers' relationships with suppliers in promoting sustainable consumption, and perceptions of the locus of power within such relationships; on if, and how, different groups of stakeholders are looking to influence retailers to pursue more sustainable consumption; and on how retailers can encourage sustainable consumption at the point of sale within stores. At the operational level, specific research investigations might focus on how corporate policy on sustainable consumption is communicated both to employees, at store level, and in distribution centres; on consumer attitudes to sustainable consumption, and of how such attitudes influence everyday buying behaviour; on how data on environmental, social and economic impacts is collected within supply chains and on how such data is independently verified; and on the success of practical schemes 
designed to reduce waste and encourage and facilitate recycling. Such research endeavours could include comparative investigations across a number of retailers and detailed case studies of individual retailers. Ultimately, if independent academic research is to contribute to the transition to a more sustainable future, then work which looks to challenge current corporate approaches to sustainable consumption must be linked to conceptual approaches to consumption and be firmly rooted in a formal research approach, which allows the creation of a defendable evidence base.

Author Contributions: Conceptualization, P.J., M.W. and D.C.; methodology, P.J. and D.C.; software, M.W.; validation, M.W. and P.J.; formal analysis, P.J. and M.W.; investigation, P.J., D.C. and M.W.; resources, P.J., M.W. and D.C.; data curation, P.J.; writing-review and editing, P.J. and M.W.; project administration, P.J. and M.W. All authors have read and agreed to the published version of the manuscript.

Funding: This research received no external funding.

Conflicts of Interest: The authors declare no conflict of interest.

\section{References}

Bradshaw, Alan, Norah Campbell, and Steven Dunne. 2013. The Politics of Consumption. Ephemera; Theory and Politics in Organisations 13: 203-16.

Brand, Karl-Werner. 2010. Social Practices and Sustainable Consumption: Benefits and Limitations of a New Theoretical Approach. In Environmental Sociology. Edited by Matthias Gross and Harald Heinrichs. Dordrecht: Springer, pp. 217-35.

British Retail Consortium. 2018. Better Retail Better World. Available online: https://brc.org. uk/making-a-difference/priorities/better-retail-better-world (accessed on 3 June 2020).

Cetina, Karin Knorr, Theodore Schatzki, and Eike von Savigny. 2001. The Practice Turn in Contemporary Theory. London: Routledge.

Co-op. 2019. Co-op Way Report 2018: Our Ethics and Sustainability Performance. Available online: https://assets.ctfassets.net/5ywmq66472jr/2cJboNfqhy8Wh0aief9Hlo/ fe1933952ef2d6234552568526c6c2c4/Co-op_Way_Report_2018.pdf (accessed on 11 May 2020).

Deloitte. 2019. Global Powers of Retailing. Available online: https://www2.deloitte.com/ content/dam/Deloitte/global/Documents/Consumer-Business/cons-global-powersretailing-2019.pdf (accessed on 14 May 2020).

Dixons Carphone. 2019. Sustainable Business. Available online: https://www.dixonscarphone. com/en/sustainable-business (accessed on 23 March 2020).

Durieu, Xavier. 2003. How Europe's retail sector helps to promote sustainable production. Industry and Environment 26: 7-9.

Environmental Justice Organisations Liabilities and Trade. 2019. Sustainable Consumption. Available online: http://www.ejolt.org/2015/02/sustainable-consumption/ (accessed on 12 February 2020). 
European Commission. 2012. Policies to Encourage Sustainable Consumption. Available online: http://ec.europa.eu/environment/eussd/pdf/report_22082012.pdf (accessed on 30 May 2020).

European Commission. 2018. Retail Forum. Available online: https://ec.europa.eu/ environment/industry/retail/index_en.htm (accessed on 19 May 2020).

EY. 2017. Why Sustainable Development Goals Should Be in Your Business Plan. Available online: https://www.ey.com/en_gl/assurance/why-sustainable-developmentgoals-should-be-in-your-business-plan (accessed on 14 October 2019).

Fuchs, Doris, Antonietta Di Giulio, Katharina Glaab, Sylvia Lorek, Michael Maniates, Thomas Princen, and Inge Ropke. 2016. Power: The missing element in sustainable consumption and absolute reductions research and action. Journal of Cleaner Production 132: 298-307. [CrossRef]

Gasper, Des, Amod Shah, and Sunil Tankha. 2019. The Framing of Sustainable Consumption and Production in SDG 12. Global Policy 10: 83-95. [CrossRef]

Geels, Frank, Andy McMeekin, Josephine Mylan, and Dale Southerton. 2015. A Critical Appraisal of Sustainable Production and Consumption Research: The Reformist, Revolutionary and Reconfiguration Positions. Global Environmental Change 34: 1-12. [CrossRef]

Goss, Jon. 2006. Geographies of consumption: The work of consumption. Progress in Human Geography 30: 237-49. [CrossRef]

Hinton, Emma, and Michael Redclift. 2009. Austerity and Sufficiency: The Changing Politics of Sustainable Consumption. Available online: https://www.kcl.ac.uk/sspp/departments/ geography/research/Research-Domains/Contested-Development/HIntonRedcliftWP17. pdf (accessed on 24 November 2018).

Hobson, Kersty. 2002. Competing Discourses of Sustainable Consumption: Does the Rationalisation of Lifestyles Make Sense. Environmental Politics 11: 95-120. [CrossRef]

House of Commons Environmental Audit Committee. 2019. Sustainable Development Goals in the UK Follow up: Hunger, Malnutrition and Food Security in the UK. Available online: https://publications.parliament.uk/pa/cm201719/cmselect/cmenvaud/1491/1491. pdf (accessed on 28 May 2020).

International Institute for Sustainable Development. 2017. Oslo Roundtable on Sustainable Production and Consumption. Available online: https://enb.iisd.org/consume/oslo004. html (accessed on 2 June 2020).

J. Sainsbury plc. 2018. Our Values Make Us Different. Available online: https://www.about.sainsburys.co.uk/ \{\}/media/Files/S/Sainsburys/documents/makinga-difference/Sustainability_Update_2018.pdf (accessed on 11 December 2019).

Jackson, Tim. 2006. Readings in Sustainable Consumption. In The Earthscan Reader in Sustainable Consumption. Edited by Tim Jackson. London: Earthscan, pp. 1-26. 
John Lewis Partnership. 2019. Sustainable Development Goals. Available online: https://www.johnlewispartnership.co.uk/content/cws/csr/our-approach/sustainabledevelopment-goals.html (accessed on 15 April 2020).

Jones, Peter, and Daphne Comfort. 2018. Sustainable Consumption and the Leading US Retailers. Indonesian Journal of Corporate Social Responsibility and Environmental Management 1: 1-15.

Jones, Peter, David Hillier, and Daphne Comfort. 2014. Assurance of the leading UK food retailers' corporate social responsibility/sustainability reports. Corporate Governance International Journal of Business in Society 14: 130-38. [CrossRef]

Kingfisher. 2019. Sustainability Report 2018/2019. Available online: https://www.kingfisher. com/sustainability-highlights/Kingfisher_Sustainability_Report_2018_19.pdf (accessed on 13 January 2020).

Lorek, Sylvia, and Doris Fuchs. 2013. Strong sustainable consumption governance-precondition for a degrowth path? Journal of Cleaner Production 38: 36-43. [CrossRef]

Marks and Spencer. 2018. Plan A and the Sustainable Development Goals. Available online: https://corporate.marksandspencer.com/annual-report-2018/mands_ plana-2018_frameworksandassurances.pdf (accessed on 14 August 2019).

Marks and Spencer. 2019a. Product Sustainability. Available online: https://corporate. marksandspencer.com/sustainability/business-wide/product-sustainability (accessed on 8 March 2020).

Marks and Spencer. 2019b. Responsible Sourcing. Available online: https://corporate. marksandspencer.com/sustainability/business-wide/responsible-sourcing (accessed on 21 March 2020).

Morrisons. 2019. Listening and Responding: Corporate Social Responsibility Report 2017/2018. Available online: https:/www.morrisons-corporate.com/globalassets/corporatesite/ corporate-responsibility/documents/2018/morrisons_cr_report_2018.pdf (accessed on 14 May 2020).

Next. 2019. Corporate Responsibility Report. Available online: https://www.nextplc. co.uk/ \{\}/media/Files/N/Next-PLC-V2/documents/cr-reports/cr-2019.pdf (accessed on 13 March 2020).

Nordic Council of Ministers. 2018. Sustainable Consumption and Production. Available online: https://norden.diva-portal.org/smash/get/diva2:1231011/FULLTEXT01.pdf (accessed on 3 August 2019).

Pantzar, Mia, Rosa Strube, Susanna Gionfra, and Kristina Modee. 2018. Sustainable Consumption-Policy Approaches for Systems Change. Available online: https://ieep.eu/uploads/articles/attachments/6ba62504-96f4-463a-b077-b37cb739043a/ Think\%202030\%20Sustainable\%20consumption.pdf?v=63710011359 (accessed on 11 May 2020). 
Retail Economics. 2018. Top 10 UK Retailers. Available online: https://www.retaileconomics. co.uk/top-10-retailers-uk-top-10-retailers (accessed on 12 May 2020).

Ropke, Inge. 2009. Theories of practice-new inspiration for ecological economic studies. Ecological Economics 68: 2490-97. [CrossRef]

Shell, Ellen Ruppel. 2009. Cheap: The High Cost of Discount. New York: Penguin.

Shove, Elizabeth, and Nicola Spurling. 2013. Sustainable practices: Social theory and climate change. In Sustainable Practices: Social Theory and Climate Change. Edited by Elizabeth Shove and Nicola Spurling. London: Routledge, pp. 1-14.

Tesco. 2018. Contributing to the Sustainable Development Goals. Available online: https://www.tescoplc.com/media/475526/contributing-to-the-un-sustainabledevelopment-goals_final.pdf (accessed on 11 May 2020).

United Nations. 2017. Summary Table of SDG Indicators. Available online: https://unstats.un.org/sdgs/files/meetings/iaeg-sdgs-meeting-06/Summary\%20Table_ Global\%20Indicator\%20Framework_08.11.2017.pdf (accessed on 4 June 2019).

United Nations. 2019a. Sustainable Development Goals. Available online: https://www.un. org/sustainabledevelopment/sustainable-development-goals/ (accessed on 19 May 2020).

United Nations. 2019b. Report of the Secretary-General on SDG Progress 2019. Available online: https://www.evalforward.org/sites/default/files/2019-09/2019\% 20Report_of_the_SG_on_SDG_Progress_2019.pdf (accessed on 12 May 2020).

United Nations Environment Programme. 2015. Sustainable Production and Consumption: A Handbook for Policy Makers. Available online: https://sustainabledevelopment.un.org/ content/documents/1951Sustainable\%20Consumption.pdf (accessed on 12 January 2018).

World Commission on Environment and Development. 1987. Our Common Future. Available online: https://sustainabledevelopment.un.org/content/documents/5987ourcommon-future.pdf (accessed on 16 May 2020).

Wynn, Martin. 2000. From E-Commerce to E-Business at HP Bulmer: Pioneering technologies in the drinks industry. Virtual Business 4: 18-21.

Wynn, Martin, and Peter Jones. 2020. The Sustainable Development Goals: Industry Sector Approaches. Abingdon: Routledge.

Zhang, Jing, Luis Luna-Reyes, Holly Jarman, and Giri Kumar Tayi. 2015. Information systems to support sustainable consumption and sustainable supply. Information Technology Management 16: $1-4$. [CrossRef]

(C) 2020 by the authors. Licensee MDPI, Basel, Switzerland. This article is an open access article distributed under the terms and conditions of the Creative Commons Attribution (CC BY) license (http://creativecommons.org/licenses/by/4.0/). 


\title{
Towards More Sustainability in Clothing Production and Consumption: Options, Opportunities, and Constraints
}

\author{
Silke Kleinhückelkotten and Horst-Peter Neitzke
}

\section{Introduction}

A large share of the world population still does not have the means to meet even their basic needs. On the other hand, more and more people are living in relative prosperity and their demands for energy and all kinds of goods are increasing (Kharas 2017; Lange and Meier 2009). From a social point of view, the latter development is welcome, but under the prevailing production conditions it implies increasing demand for already limited natural resources. The new emerging middle classes are not primarily responsible for the hitherto existing overutilization of natural resources and ecological capacities. The main responsibility for this lay, until now, with the people living in economically well-developed countries and their consumption attitudes and behaviors-which have unfortunately served as models for people in many emerging countries (Lange and Meier 2009; O'Neill et al. 2018; Simms et al. 2009). Equitable ways must be found to meet individual needs and desires within the ecological limits of the planet. More efficient production methods and better consistency in terms of natural processes are indispensable. However, this will not suffice. Consumption patterns must also be made more sustainable. This is the message of Sustainable Development Goal 12.

More sustainable methods of production and more sustainable consumption patterns are required for every field of supply. In this chapter, the focus is on clothing. On the production side, the field of clothing is characterized by globalized value-added chains, manufacturing sites mainly in least developed and threshold countries, inputs of large quantities of different materials and toxic and eco-toxic emissions (Chapagain et al. 2006; Ellen MacArthur Foundation 2017; Global Fashion Agenda and The Boston Consulting Group 2017; Mekonnen and Hoekstra 2010; Mukherjee 2015; Muthu 2017; Prentice and De Neve 2017). On the consumption side, it must be recognized that clothing is a basic need. Clothes protect the body from thermal, mechanical, biological, and other adverse impacts. Generally, a few pieces of clothing would be enough to obtain these protective functions. However, clothing is more than a protective cover. Clothing is a cultural good, a social differentiation 
and communication medium, a sign of social status, and, last but not least, a means to adorn oneself (Simmel 1995; Bourdieu 1992; Esposito 2014). These secondary functions of clothing constitute powerful fulcra for fashion marketing; and fashion marketing is very successful in using it.

Ever faster successions of fashion trends and collections strongly contribute to a steady increase of the demand for garments especially in the economically well-developed and emerging countries. This 'fast fashion' is only possible at the costs of the workers in the textile industry and the environment especially in the producing countries (Chapagain et al. 2006; Mekonnen and Hoekstra 2010; Mukherjee 2015; Muthu 2017; Prentice and De Neve 2017). The clothing production chains, and the clothing market are global. As the vocational skill requirements are low for many jobs in the textile industry, it is easy to take advantage of differences as regards wages, safety regulations, and workers' rights in different countries and to shift clothing production to the countries with the lowest manufacturing costs. Low environmental standards and a lack of environmental surveillance also help to keep production costs low.

Press reports about disasters in clothing factories, like the 2013 Rana Plaza garment factory collapse, when at least 1132 people were killed and more than 2500 injured, and pictures of rivers flowing through textile industrial areas, whose water show the 'it' color of the season, bring awareness of the serious social and ecological deficits along the textile chain to the public. However, the customers dismay does not last long, and the reactions of the global players in the clothing industry are fleeting. In the last years, more sustainably produced clothes have come onto the market, but their share is still marginal.

Are there chances to (a) lower the clothing consumption level and (b) substantially increase the demand for and the offer of more sustainably produced clothing? If so, what can be done to improve sustainability in the clothing market? These are the central questions of this chapter. After a short summary of the economic importance of the clothing sector in the global perspective, and the social and ecological problems associated with the production of clothes, the results of some recent empirical studies on drivers of clothing consumption and the social acceptability of more sustainable consumption alternatives are presented. Then, we give an outlook on possibilities to improve sustainability in the clothing sector, together with experts' ratings of the probability that these will be implemented by 2030 . 


\section{Economic, Social, and Ecologic Aspects of Clothing Production and Consumption}

Section 2.1 gives information on the development of the global clothing market and the countries with the greatest market shares. The social impacts of clothing production and consumption are discussed in Section 2.2, and the environmental effects in Section 2.3.

\subsection{Clothing Market and Clothing Consumption}

The demand for many consumer goods like clothing and mobile phones is increasing much faster than the world population or demands for food and energy (Figure 1). There are two strong drivers for the disproportionately high increase in the demand for clothing

- The fast fashion industry ejects new fashion collections in shorter and shorter time intervals.

- The middle classes with incomes well above subsistence level are growing in threshold and even in less developed countries.

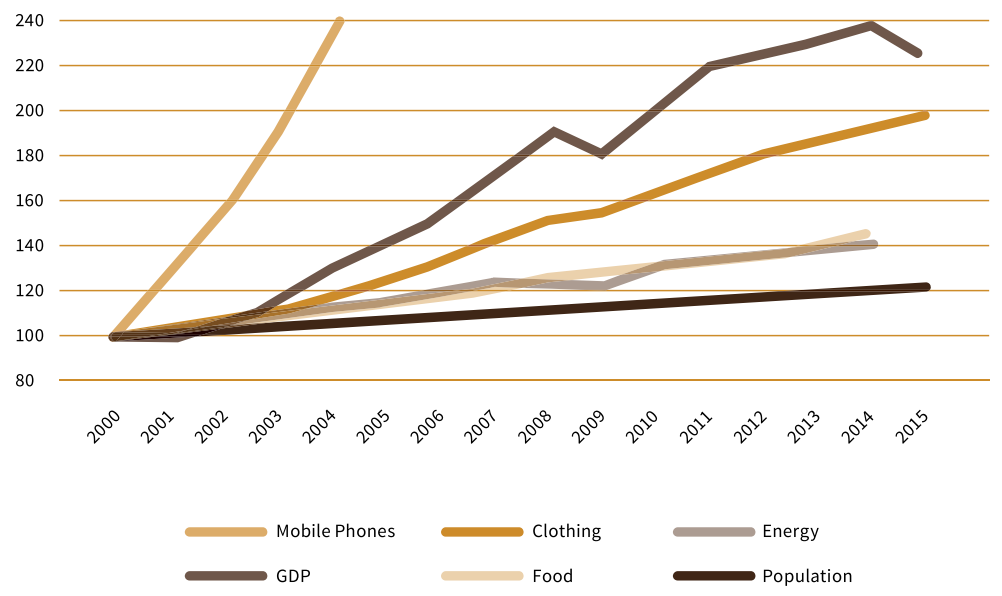

Figure 1. Development of the global population, the gross domestic product, and the consumption of clothing, mobile phones, food, and energy relative to the year 2000 (=100) (data: Ellen MacArthur Foundation 2017; International Telecommunication Union 2018; UN DESA (United Nations, Department of Economic and Social Affairs, Population Division); World Bank 2018). Source: Own illustration. 
A projection for 2025 shows percentage increases of per capita expenditures for clothing in threshold countries like Brazil, China, and India that are much higher than those in the developed market countries and regions (Figure 2). However, the consumption level is and will, in the years to come, continue to be much higher in the USA, Japan, and the European Union than in the rest of the world. For the latter, one must bear in mind that there exist large differences between the European countries with respect to clothing consumption: In Luxembourg and Austria, the annual average per capita expenditures for clothing and footwear added up to 1395 and 1025 EUR respectively in 2018 (Eurostat 2020a); in Bulgaria and Hungary, the two countries with the lowest expenditures on clothing, these only reached 123 and 180 EUR respectively. The expenditures for clothing directly reproduce the economic situation in these countries. In Luxembourg and Austria, the gross domestic products per capita come to about 100,000 and 44,000 EUR, in Bulgaria and Hungary only to 8000 and 14,000 EUR (Eurostat 2020b).

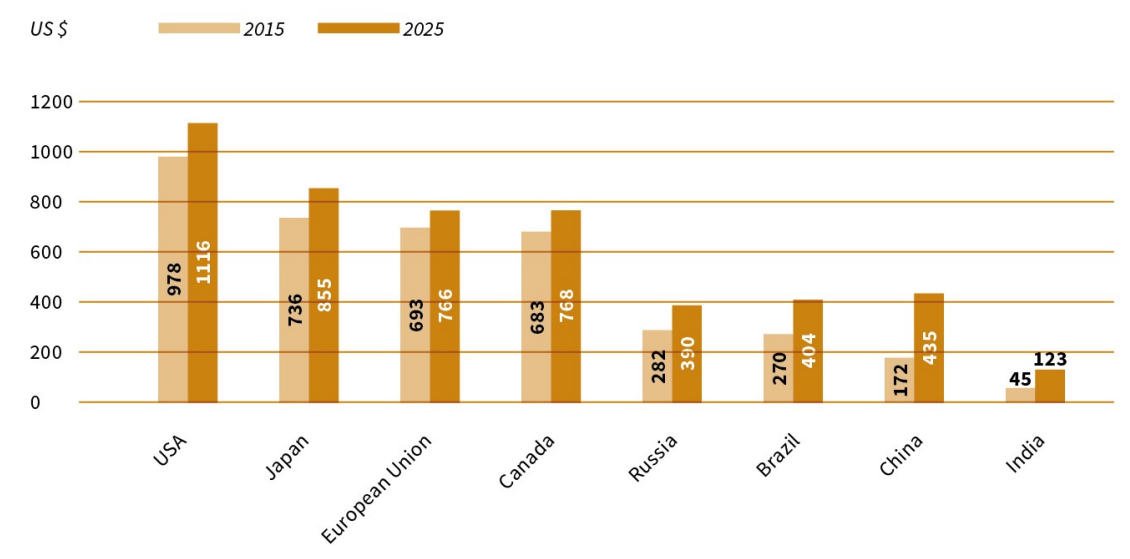

Figure 2. Per capita expenditure on apparel (data: Varun and Kanika 2017). Source: Own illustration.

Since the turn of the millennium the shares of different producing countries in the world clothing market have changed substantially. China increased from $18 \%$ in 2000 to 31\% in 2018, and Bangladesh and Viet Nam multiplied their percentages (Figure 3). The percent clothing export quota of the European Union remained almost constant. Here, it must be pointed out, that the extra EU (28) exports account for less than one fourth of all EU clothing exports. 


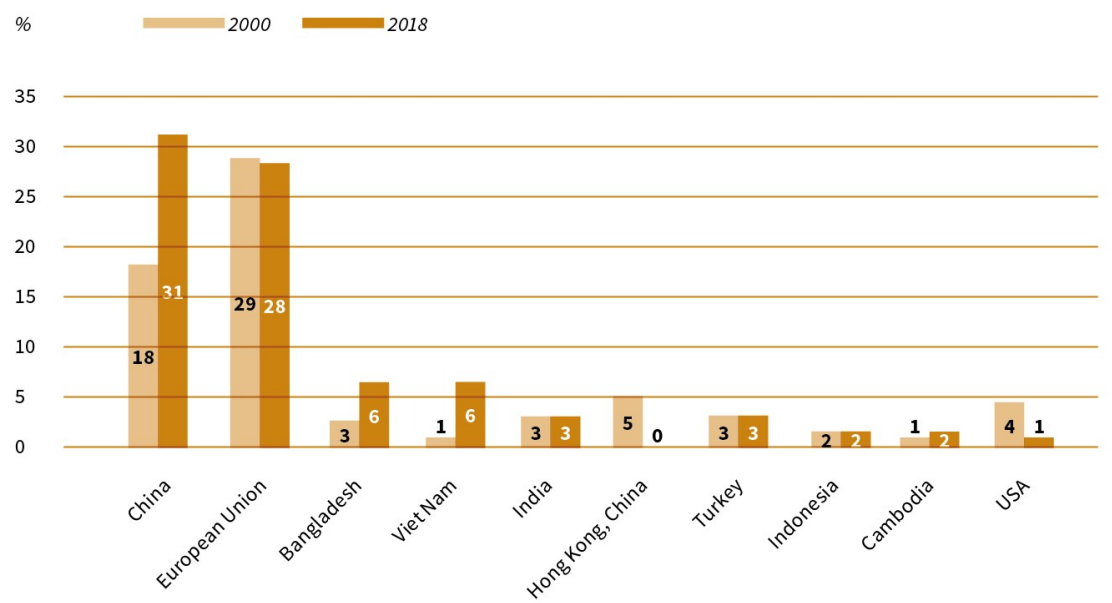

Figure 3. Top 10 exporters of clothing: Percentage of global exports (data: World Trade Organization 2019, rounded). Source: Own illustration.

\subsection{Social Impacts of Clothing Production and Consumption}

The fashion industry employs over 75 million people worldwide. Most of them work under poor conditions. The social evils elaborated on the following pages are widespread in the clothing industries, especially in Asia and Africa.

\subsubsection{Low Wages}

In some of the clothing exporting countries in Asia the minimum wages fixed for the clothing industry are even lower than the legal minimum wages (Table 1). In a number of countries, there exist great regional differences, since minimum wages are fixed in reference to the specific regional status of economic development (International Labour Office 2014).

\subsubsection{Long Working Times}

Some of the biggest clothing production countries have not ratified the Hours of Work (Industry) Convention, 1919 (No. 1), by which a maximum standard working time of $48 \mathrm{~h}$ per week and eight hours per day was introduced, with the exception of limited and well-circumscribed cases (International Labour Organization 2014b). In developing clothing producing countries excessive working hours are widespread (ibid.). Due to low wages, workers are compelled to work extremely long hours in order to supplement their basic earnings enough to feed themselves and their families. 
Table 1. Textile and clothing industry: Employment, value added, and wages (Countryeconomy 2020; European Parliament 2014; Fibre2Fashion 2019; International Labour Organization 2014a, 2014b; World Bank 2019a, 2019b).

\begin{tabular}{|c|c|c|c|c|c|}
\hline Country & $\begin{array}{l}\text { Employment in } \\
\text { the Textile } \\
\text { Industry: } \\
\text { Persons } \\
\text { [Million] }\end{array}$ & $\begin{array}{l}\text { Employment in } \\
\text { the Textile } \\
\text { Industry: } \\
\text { Percentage of } \\
\text { Total Labor } \\
\text { Force }\end{array}$ & $\begin{array}{l}\text { Textiles and } \\
\text { Clothes: } \\
\text { Percentage of } \\
\text { Value Added in } \\
\text { Manufacturing }\end{array}$ & $\begin{array}{l}\text { Minimum } \\
\text { Wages in the } \\
\text { Clothing } \\
\text { Industry } \\
\text { [USD per } \\
\text { month] }\end{array}$ & $\begin{array}{l}\text { Legal } \\
\text { Minimum } \\
\text { Wages } \\
\text { [USD per } \\
\text { month] }\end{array}$ \\
\hline China & $>10$ & $1.3 \%$ & $10.0 \%$ & $166-266^{\mathrm{b}}$ & $325.60^{c}$ \\
\hline Bangladesh & 4.0 & $5.7 \%$ & $37.6 \%{ }^{a}$ & $68-168^{b}$ & 97.20 \\
\hline Viet Nam & 2.2 & $3.8 \%$ & $15.4 \%$ & $90-128^{b}$ & \\
\hline India & 45.0 & $8.7 \%$ & $8.5 \%$ & $70-106^{b}$ & 54.5 \\
\hline Hong Kong & 0.0 & $0.1 \%$ & $4.7 \%$ & 805 & 821.90 \\
\hline Turkey & 0.9 & $2.7 \%$ & $17.1 \%$ & 494 & 485.90 \\
\hline Indonesia & 1.1 & $0.8 \%$ & $11.1 \%$ & $74-219^{b}$ & 137.80 \\
\hline Cambodia & 0.5 & $5.4 \%$ & $22.3 \%{ }^{a}$ & 100 & 80.71 \\
\hline Pakistan & 15.0 & $20.0 \%$ & $28.9 \%^{a}$ & $85-95^{b}$ & 152.70 \\
\hline
\end{tabular}

a last available data, possibly outdated; ${ }^{\mathrm{b}}$ depending on area of production; ${ }^{\mathrm{c}}$ high variability within the country.

\subsubsection{Bad Health and Safety Conditions}

The working conditions at many cotton production sites and in many factories along the whole value-added chain of clothing are unacceptable. The workers are exposed to fiber dust, toxic substances, and blasted sand. Many employees work in unsafe buildings without ventilation and emergency exits. Despite some improvements after disasters, like the collapse of the Rana Plaza building in 2013, 'fast fashion' is still putting the health and well-being of garment workers at risk (Prentice and De Neve 2017).

\subsubsection{Child Labor}

According to the International Labour Organisation 168 million children are engaged in child labor worldwide. This is defined by the UN as "work for which the child is either too young-work done below the required minimum age- or work which, because of its detrimental nature or conditions, is altogether considered unacceptable for children and is prohibited" (International Labour Office 2013). Because the clothing industry predominantly requires low-skilled labor, child labor is particularly common in this industry. Child labor is forbidden by law in most countries, but is still rife in some fiber and clothing producing countries, even those with ratified international conventions against child labor (Table 2). It is 
known, that the following countries tolerate child labor in clothing-related industries and agriculture: Argentina, Azerbaijan, Bangladesh, Benin, Brazil, Burkina Faso, Burma, Cambodia, China, India, Kazakhstan, Pakistan, Tajikistan, Thailand, Turkey, Turkmenistan, Viet Nam, and Zambia (Office of Child Labor et al. 2018).

\subsubsection{Forced Labor}

Two leading clothing producing countries, China and Viet Nam, have not ratified the Abolition of Forced Labour Convention (Table 2) and, as frequent press reports show, forced labor is a problem in these countries. Uzbekistan, one of the world's largest cotton exporters, is another extreme example. At harvest time, the government forces over one million people to leave their regular jobs and pick cotton. Children are taken out of school to harvest cotton. Besides the three countries mentioned, forced labor occurs in one or more stages of the value-added chain of clothing in Argentina, Benin, Brazil, Kazakhstan, Malaysia, Pakistan, Tajikistan, Thailand, and Turkmenistan (Office of Child Labor et al. 2018).

\subsubsection{Prohibition of Unions}

Over $90 \%$ of the workers in the global clothing industry have no possibility to negotiate their wages and working conditions (UK Parliament 2017).

\subsection{Environmental Impacts of Clothing Production and Consumption}

The production of clothing passes through many stages from the exploitation and preparation of the raw materials and their conversion to fibers, through yarn, grey fabric, and finished fabric preparation to apparel manufacturing. Although, the nature and the degree of the environmental impacts depend on the kind of executed processes, some specific ecological risks can be identified for the different stages of the supply chain (Kleinhückelkotten et al. 2018; Mukherjee 2015; Muthu 2017). 
Table 2. Ratfication of ILO conventions (data: International Labour Organization 2020).

\begin{tabular}{|c|c|c|c|c|c|c|c|c|}
\hline & China & Bangladesh & $\begin{array}{l}\text { Viet } \\
\text { Nam }\end{array}$ & India & Turkey & Indonesia & Cambodia & Pakistan \\
\hline ILO Member since & 1919 & 1972 & $\{1950\}$ & 1919 & 1932 & 1950 & 1969 & 1947 \\
\hline $\begin{array}{l}\text { C029-Forced Labour } \\
\text { Convention, } 1930\end{array}$ & n.r. & 1972 & 2007 & 1954 & 1998 & 1950 & 1969 & 1957 \\
\hline $\begin{array}{l}\text { C098-Right to Organise and } \\
\text { Collective Bargaining } \\
\text { Convention, } 1949\end{array}$ & n.r. & 1972 & (2019) & n.r. & 1952 & 1957 & 1999 & 1952 \\
\hline $\begin{array}{l}\text { C105-Abolition of Forced } \\
\text { Labour Convention, } 1957\end{array}$ & n.r. & 1972 & n.r. & 2000 & 1961 & 1999 & 1999 & 1960 \\
\hline $\begin{array}{l}\text { C111-Discrimination } \\
\text { (Employment and } \\
\text { Occupation) Convention, } \\
1958\end{array}$ & 2006 & 1972 & 1997 & 1960 & 1967 & 1999 & 1999 & 1961 \\
\hline $\begin{array}{l}\text { C138-Minimum Age } \\
\text { Convention, } 1973\end{array}$ & 1999 & n.r. & 2003 & 2017 & 1998 & 1999 & 1999 & 2006 \\
\hline $\begin{array}{l}\text { C182-Worst Forms of Child } \\
\text { Labour Convention, } 1999\end{array}$ & 2002 & 2001 & 2000 & 2017 & 2001 & 2000 & 2006 & 2001 \\
\hline
\end{tabular}

n.r.: not ratified. ( ) ratified yet not enforced. \{ \} Member from 1950 to 1976,1980 to 1985 and since 1992.

\subsubsection{Consumption of Material and Energetic Resources}

The conventional cultivation of fiber plants requires significant amounts of water. This is especially true for cotton, the most widely used natural fiber in clothing production. On average, the water input to produce one kilogram of cotton fabric is 10,000 L (Mekonnen and Hoekstra 2010, 2011). This represents a severe problem in countries with low water availability and/or insufficient rural water supply infrastructure and management for social, as well as for ecological, reasons. The diversion of water to cotton fields had and has severe impacts on major ecosystems such as the Aral Sea in Central Asia (Chapagain et al. 2006; UNEP 2017).

The other production step with a high water demand is dyeing. Here, the problem is not the 'disappearance' but the contamination of the used water (see below).

The production of clothing requires energy at all stages of the textile chain and, it must be kept in mind, also the frequent transport processes and long transportation routes in globalized supply chains. The necessary energy input strongly depends on 
the kind of fiber, and for synthetic fibers is very high. While the production of $1 \mathrm{~kg}$ of conventional cotton requires $60 \mathrm{MJ}$, and that of organic cotton requires $54 \mathrm{MJ}, 127 \mathrm{MJ}$ are needed in the case of polyester and $175 \mathrm{MJ}$ in the case of acrylic (Muthu 2014).

\subsubsection{Emissions of Greenhouse Gases}

As Table 3 shows, fiber and yarn production are the production steps with the greatest shares in the emission of greenhouse gases (GHG) along the production chain of clothes. The data given in Table 3 are derived from the results of a life cycle carbon mapping study (Business for Social Responsibility 2009). In this study, aggregated GHG emissions along the clothing life cycle are reported for different garments of one retailer's assortment. The values in Table 3 are the results of a recalculation omitting the use phase. Table 3 is meant to give an overall picture of aggregated GHG emissions by clothing. However, the actual GHG emissions profile will be different for any given garment.

Table 3. Contribution of the different production steps of clothing to total greenhouse gas emissions (data basis: see text).

\begin{tabular}{cc} 
Production Step & $\begin{array}{c}\text { Contribution to } \\
\text { GHG-Emissions [\%] }\end{array}$ \\
Fiber production & 30 \\
Yarn production & 26 \\
Preparation and blending & 8 \\
Fabric manufacture & 11 \\
Dyeing and finishing & 5 \\
Other raw materials & 8 \\
Garment manufacture & 3 \\
(making-up) & 7 \\
Packaging & 2 \\
Transportation & \\
\hline
\end{tabular}

\subsubsection{Toxic and Ecotoxic Pollution}

The conventional production of plant fibers is associated with extensive inputs of fertilizers and pesticides. About $10 \%$ of the entire production of agricultural chemicals are used for cotton production alone (Muthu 2014). Parathion, aldicarb, and methamidophos are among the top ten most widely used insecticides in cotton 
production. According to the World Health Organization (WHO) these are extremely hazardous to human health.

A second major cause of toxic and ecotoxic pollution are finishing processes such as singeing, desizing, scouring, souring, bleaching, mercerizing, dyeing, printing, sanforizing, calendering and the application of other special finishes (Muthu 2014). Large quantities of chemicals are used throughout the processes. On average, about $1 \mathrm{~kg}$ of chemicals and auxiliaries per $\mathrm{kg}$ of finished textile. The remainder reaches the environment mainly through sewage waters, but also through the air.

A problem recognized to its full extent only in recent years are micro-particles from clothes made of synthetic fibers. Micro-fibers are, on the one hand, released during production and use of textiles. On the other hand, they result from the fragmentation of larger items such as discarded clothing (Henry et al. 2019). Since these materials are generally resistant to biodegradation, micro- and nano-plastic particles accumulate in the environment, in terrestrial habits as well as in aquatic and coastal systems. Microplastics have been detected in a wide range of human food and beverages. Up to now, the ecological and human health effects of microplastics are poorly understood, but the evidence for noxious effects is increasing (ibid.).

\subsubsection{Waste}

When the use of a piece of clothing ends, either because the owner does not appreciate it any longer or because it has reached its material end-of-life, there are several options (Ellen MacArthur Foundation 2017; Global Fashion Agenda and The Boston Consulting Group 2017):

- Reuse;

- Recycling;

- Incineration;

- Disposal to landfill.

Normally, the best option from an environmental point of view is to reuse a garment that is still wearable, potentially after upgrading it. However, in an environmental assessment of secondhand clothes the impacts arising from transportation, collection, sorting, and reselling must be considered.

Recycling to recover the raw materials requires the input of energy and can lead to emissions harmful to health and/ or to the environment. It is, therefore, only the second-best option.

Incineration is not a good option due to the emissions and the problematic waste in the form of ashes. The environmental balance can be improved by recovery 
of the energy set free in the combustion process. The worst option is disposal to landfill because landfill space is running low and leachate as well as outgassing are problematic.

Waste also accrues along the production chain and when stocks exceed the demand.

\subsubsection{Environmental Impacts in the Use Phase}

In the preceding summary the focus was on environmental impacts occurring in the production and after-use phases of clothing. However, in the use phase, substantial amounts of energy, water, and chemicals, e.g., detergents, are applied. Irrespective of the type of textile, the use phase is responsible for up to $80 \%$ of the carbon footprint (Muthu 2014).

\section{Drivers of Clothing Consumption and Social Acceptability of More Sustainable Alternatives}

Whether or not the quantitative volume of clothing production will continue to increase with high growth rates and with negative implications for workers, societies, and the environment depend not least on customers' demands and behaviors. For economic valuations of the market chances of more sustainable clothing alternatives as well as for the design of (social) marketing campaigns to initiate and support more sustainable consumption behaviors, one has to know the drivers of clothing consumption and the motives behind buyers' decisions. These are the subject of this chapter. Selected results from a recent representative survey carried out in Germany (2000 German speaking participants, aged 18 years and above; for the methods and further results see: Kleinhückelkotten and Neitzke 2019a, 2019b) and findings from some similar studies are presented.

\subsection{Quantitative Level of Clothing Consumption}

Clothing serves not only protective purposes but also fulfills social, cultural, and emotional functions (Simmel 1995; Bourdieu 1992; Esposito 2014). It serves to express its wearers social status (distinction function) and/or individuality. It is used to signal social affiliation or differentiation. It is a means to express emotions and creativity. Figure 4 shows the importance of distinction and individuality in terms of the social attributes gender, age and income. There is a significant difference between women and men as regards the relevance of clothing to express individuality, but no gender difference as to the importance of the distinction function of clothing. The importance of the distinction function of clothing decreases 
continuously with increasing age but increases with income. For individuality there is no clear age-related effect and the increase with income is only by trend.

There can be many reasons to buy new clothes:

- The existing clothes are worn out and no longer wearable, or body dimensions have changed.

- Buying new clothes is associated with fun.

- A strong fashion orientation forces the buying of up-to-date clothing.

- Situational external stimuli, e.g., special offers or other buying incentives, lead to impulse buying.

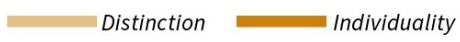

1.2

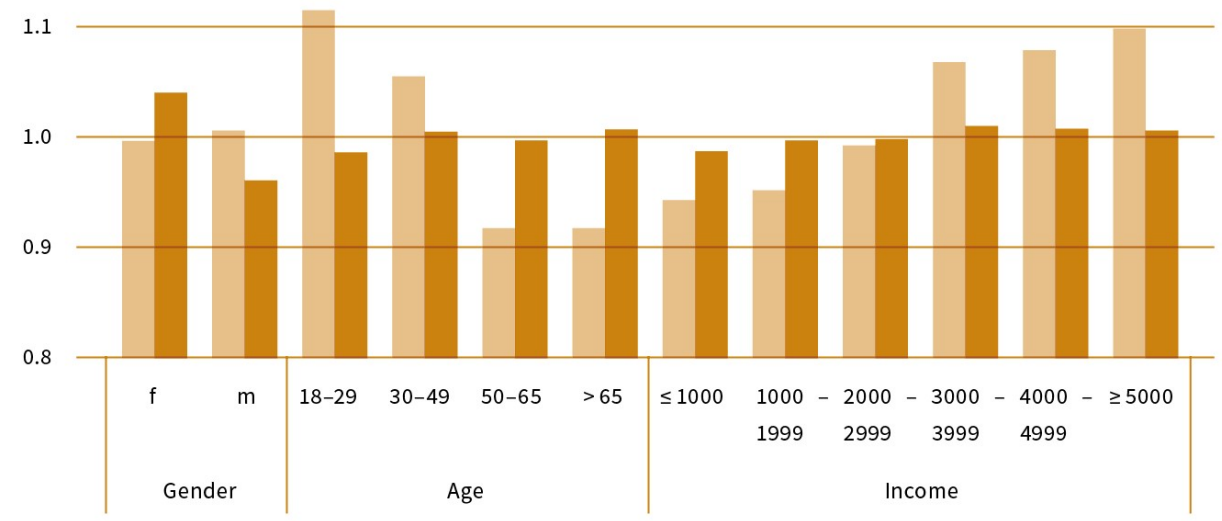

Figure 4. Social variability of importance of the distinction and individuality functions of clothing (index values, 1.0 corresponds to the population average). Source: Own illustration.

Figure 5 shows that the index for consumption orientation is highest in the youngest population segments, and higher for women than for men. The meta-variable 'consumption orientation' comprises the individual and collective fun of buying new clothes, the impulsive buying of clothes, the frequent buying of clothes without using them afterwards, and the clearing out of the wardrobe to make room for new things. The same population segments also show a high fashion orientation. The meta-variable 'fashion orientation' is an aggregate of several items 
representing, among other things, self-evaluation as part of the fashion avant-garde, those knowing what is 'in' and what is 'out', and the statement, that new bought outerwear must match the current fashion trend. Fashion orientation increases steadily with income.

The social patterns of consumption and fashion orientation are reflected in the quantitative level of clothing consumption (Figure 6). The quantitative level of outerwear consumption is calculated from the number of items bought in the last year, and weighted by rough factors for the respective resource input and expenditures in manufacturing. It is higher for women, decreases with age, and increases steeply with income. These results confirm the findings of other studies that income is a strong driver for clothing consumption (e.g., Moser and Kleinhückelkotten 2018; Wahnbaeck et al. 2015). The social differences in the wearing time of clothes, also depicted in Figure 6, are comparatively small.

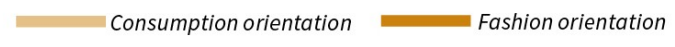

1.2

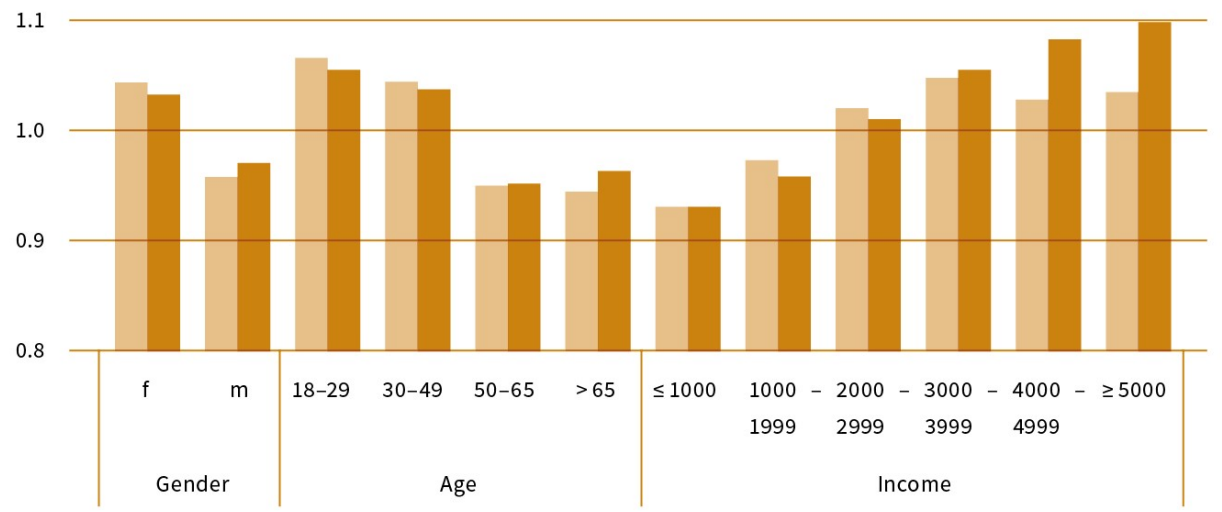

Figure 5. Social variability of consumption and fashion attitudes as regards clothing (index values, 1.0 corresponds to the population average). Source: Own illustration.

Correlation and regression analyses confirm that consumption and fashion orientation are strong, attitude-related, positive drivers for quantitative clothing consumption (Kleinhückelkotten and Neitzke 2019b). Another equally strong consumption stimulating effect is the importance of the clothing function to creativity, 
while the effects of distinction and individuality are somewhat weaker. Quality orientation has a weak positive effect; the likewise weak effects of price consciousness and of habitual buying behavior are negative. Consumption and fashion orientation are the strongest negative drivers for a long wearing time of clothes, followed by the factors 'creativity' and 'distinction'. The only significant positive effect, that supports a long wearing time, comes from price consciousness.

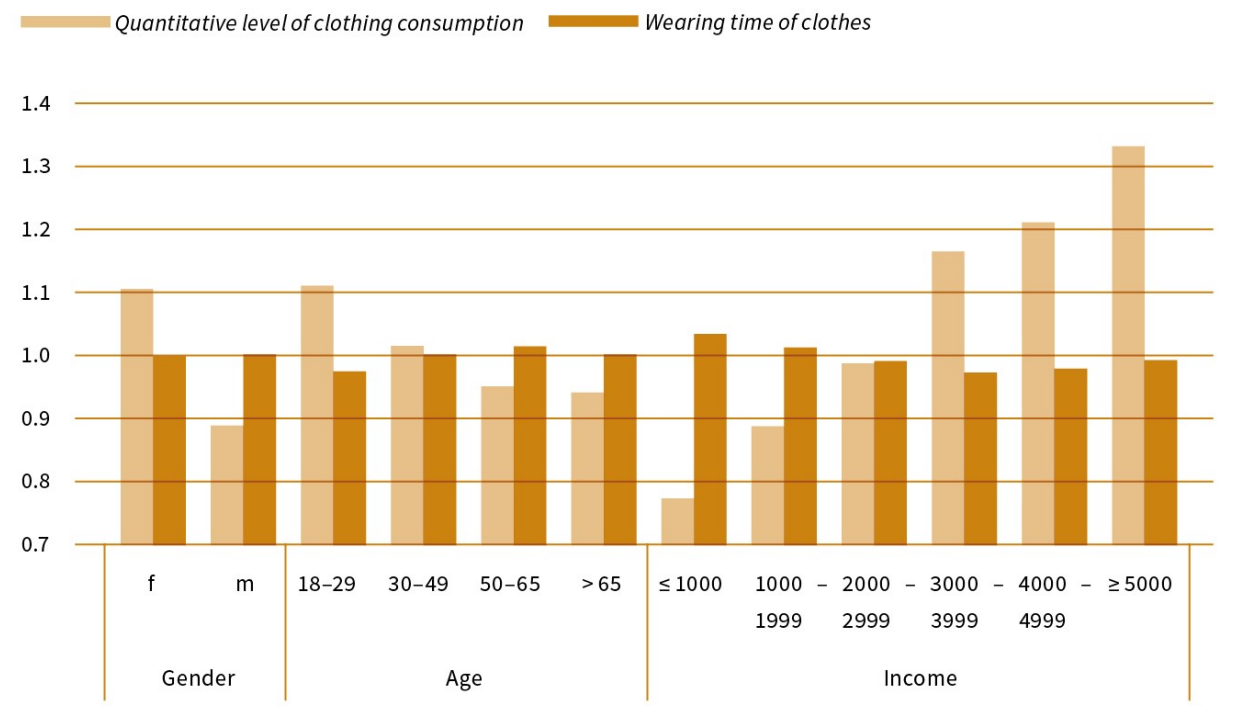

Figure 6. Social variability of the quantitative level of clothing consumption and of the wearing time of clothes (index values, 1.0 corresponds to the population average). Source: Own illustration.

\subsection{Demand for More Sustainably Produced Clothing}

The awareness of the problems associated with the production and consumption of clothes, as well as general sustainability awareness, has practically no influence either on the quantitative level of clothing consumption or the wearing time of clothes (ibid.). Both attitudes support the buying of more sustainably produced clothing (ibid.).

The problem, as well as the general sustainability awareness, is more pronounced in women compared to men, increases clearly with age, and by trend with income (Figure 7). The frequency of buying more sustainably produced clothing shows similar patterns (Figure 8). Women buy such clothes more often than men, older people 
more often than younger, and people with high incomes more often than low-income earners. A more detailed analysis, differentiated according to socio cultural milieu segments, show that more than $70 \%$ of people from the critical-creative milieus buy, at least sometimes, clothing produced under environmentally compatible conditions, and even more than $77 \%$ state to buy, at least sometimes, clothing produced under socially acceptable conditions (InNaBe 2019). These social milieus are characterized by higher education, a high level of information orientation, and higher-than-average incomes. In the precarious milieus with low incomes and low education levels the corresponding percentages are $35 \%$ and $39 \%$. Besides problem and sustainability awareness, quality orientation and the intent to underline one's individuality with appropriate clothes support the buying of more sustainably produced clothing (Kleinhückelkotten and Neitzke 2019b). With regard to promoting the demand for more sustainably produced clothing, it is relevant that the perceived social norm to prefer such clothes has a positive effect on the buying behavior (ibid.). The effect is somewhat stronger for men than for women.

The arguments (or reservations) that prevent people from buying more sustainably produced clothing are

- A too small assortment (stated by $75 \%$ of the interviewees: 'I fully agree', 'I agree', 'I rather agree');

- High prices $(67 \%)$;

- Not fashionable (44\%).

To make things worse, nearly $80 \%$ of the customers more or less strongly agree with the statement "I do not know, which clothing has been produced in a sustainable manner", and more than $80 \%$ state that they feel more or less uncertain whether they can trust the information given as regards production conditions. 


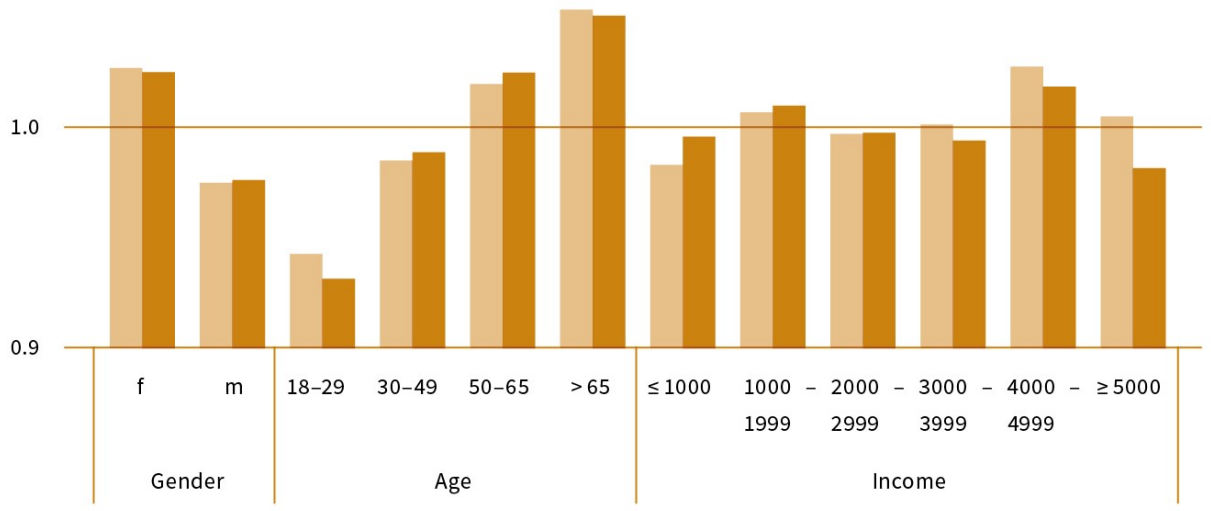

Figure 7. Social variability of problem and general sustainability awareness (index values, 1.0 corresponds to the population average). Source: Own illustration.

1.1

1.0

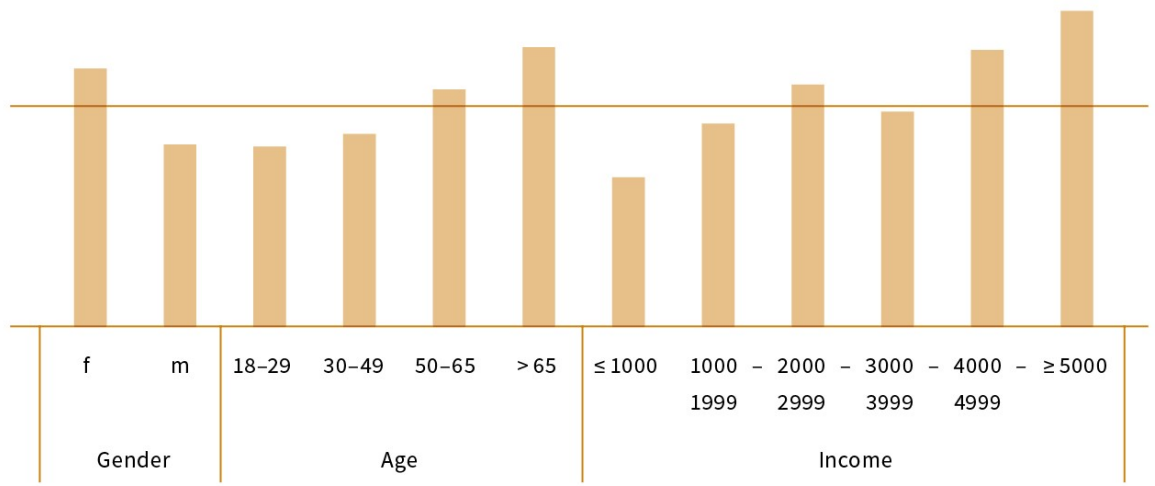

Figure 8. Social variability of the purchase of more sustainably produced clothing (index values, 1.0 corresponds to the population average). Source: Own illustration. 


\subsection{Second Life of Clothes}

There are some alternatives to the buying of newly produced clothes, that could be advantageous from an ecological point of view. They have in common that they allow a second life for sorted out clothing:

- Buying of secondhand clothes;

- Sharing, swapping, lending, renting, or leasing of clothing;

- Repairing of shopworn clothes;

- Makeover of clothing.

The results of the representative survey (Table 4) show that women's openness for the buying of secondhand clothing is greater than that of men. For about $50 \%$ of the male interviewees the buying of secondhand clothing is not an acceptable option. The corresponding percentage of the female interviewees is much lower (33.3\%). Reservations against secondhand clothes are widespread.

- The assortment of secondhand clothes is too small: $57 \%$.

- The quality of secondhand clothes is not so good: $40 \%$.

- Secondhand clothes are something for needy persons: $39 \%$.

- Secondhand clothes are not fashionable: $36 \%$.

Table 4. Use of second life of clothing options (percent of female (f) and male (m) interviewees who claimed to use the options often or at least sometimes or did not use the options until now but can imagine doing so in the future).

\begin{tabular}{ccccccc} 
Option & \multicolumn{2}{c}{ Often } & \multicolumn{2}{c}{ Sometimes } & \multicolumn{2}{c}{ Imaginable } \\
& $\mathrm{f}$ & $\mathrm{m}$ & $\mathrm{f}$ & $\mathrm{m}$ & $\mathrm{f}$ & $\mathrm{m}$ \\
Buy secondhand clothing & 7.7 & 2.8 & 32.7 & 19.2 & 24.1 & 26.3 \\
Swap clothing, internet & 2.6 & 1.3 & 7.3 & 7.2 & 28.5 & 20.8 \\
Swap clothing, event & 2.0 & 1.6 & 4.3 & 6.0 & 27.4 & 18.4 \\
Rent clothing for a short time & 1.1 & 1.7 & 5.0 & 7.1 & 34.6 & 29.5 \\
Rent clothing for a longer time & 1.1 & 1.4 & 4.0 & 6.3 & 20.8 & 19.0 \\
Have clothing repaired & 5.0 & 3.0 & 34.9 & 35.1 & 27.5 & 27.5 \\
Have clothing made over & 2.6 & 2.3 & 19.1 & 19.5 & 34.7 & 32.6 \\
\hline
\end{tabular}

About $42 \%$ of the polled women and $55 \%$ of the men stated that wearing secondhand clothing would make them feel uncomfortable. The feeling of discomfort is most widespread in the youngest population segment (18 to 29 years: $58 \%$ ). 
Nevertheless, the percentage of those who claimed to buy secondhand clothes often or at least sometimes is higher in the youngest population segment $(40 \%)$ than in the total population (32\%).

In the youngest population segment, we also have the greatest willingness to swap clothes. About $20 \%$ of the young do this already and for another about $30 \%$ this is at least imaginable. The openness for this option is more widespread among women than among men. For the other options listed in Table 4 the gender differences are only marginal. Regarding upcycling as a possibility to give a second life to clothing that has become out of date it is interesting to note, that the openness for the makeover of clothing is well above $50 \%$.

\section{Paths Towards More Sustainability in Clothing Production and Consumption}

This section deals with options to improve sustainability in the clothing sector by:

1. Efforts in the manufacturing industry;

2. Changes in consumption behavior;

3. Political and legal frame settings.

Estimates of the developments expected in the next ten years are given based on the results of an expert survey (Kleinhückelkotten et al. 2017). The expert survey was conducted to determine for the time horizon 2030 the probability of sustainability supporting changes in production conditions as well as in consumption trends. Eighty experts from industry, science, and nongovernmental organizations (NGOs) took part in the online survey. They were selected on the basis of a comprehensive actor analysis. The expert survey was complemented by twelve in-depth personal interviews with experts from enterprises, commercial and consumer protection organizations, authorities and five dialogue boards each with around 40 participants. About one half were personally invited due their expertise in the field of clothing production and consumption. It must be kept in mind that the expert survey has been undertaken for Europe, with a partial focus on Germany. Generalizations are limited to countries with similarly developed economies and public debates with respect to global social and environmental responsibilities. However, developments in these countries are of global importance due to the high levels of clothing consumption in these countries and the market power of the major fashion brands residing there. 


\subsection{Clothing Industry}

Important decisions with respect to the achievable degree of sustainability of a piece of clothing are already made in the design phase. Designers should integrate the following objectives into their work:

Long material usability of clothing, e.g., by

- Choosing hard-wearing materials;

- Avoiding potential weaknesses;

- Strengthening especially stressed parts;

- Using adjustable fasteners;

- Ascertaining good reparability.

High appreciation for and modish constancy of clothing, e.g., by

- Varying classical designs in innovative ways;

- Using timeless patterns and colors;

- Making garments multi-use.

Efficient use of material and energy, e.g., by

- Applying zero or minimal waste cuts;

- Allowing for easy disassembly to regain garment parts like hoods, sleeves or lapels for reuse;

- Reusing parts of garments;

- Using materials with good recycling characteristics;

- Ensuring biological circulating capability (cradle-to-cradle).

Environmentally compatible and socially acceptable production of clothing, e.g., by

- Choosing fibers from sustainably cultivated renewable sources.

Little environmental burdens in the use phase of clothing, e.g., by

- Applying soil-resistant and antimicrobial finishes;

- Reducing the energy demand for laundry, e.g., by using fast-drying fabrics;

- Modular design allowing the removal of parts that are easily soiled to wash them separately.

Designers have, at least in principle, a key position when it comes to achieving more sustainability along the textile chain. However, there are two problems: The first is that only a minority of those who create clothing are sensitized for 
and can appraise sustainability issues. There are only a few places around the world, where such issues are integrated in study courses (Educations.com 2020; Masterstudies 2020; The University Network 2018). However, if designers realize and acknowledge their responsibility, they need not be sustainability assessment experts because there are several tools available to help designers optimize their products in terms of sustainability (Colour Connections 2020; Kleinhückelkotten et al. 2018; Sustainable Apparel Coalition 2020a).

The second problem is that designer have a key position regarding product development but their influence on the choice of manufacturing locations, production conditions, and processes is limited (Grose 2017). These decisions are primarily made under economic points of view. They are far too often made on the basis of deficient information. An essential precondition to attain more sustainability in clothing production is the securing of the traceability of garments, including the raw, auxiliary, and working materials along the entire textile chain. This precondition is normally not given in the case of the major fashion vendors. However, there are good examples of smaller fashion labels that ensure full transparency for all stages of clothing production, which is important for their own management decisions and for their marketing. Some market leaders have also recognized the necessity of better information (Sustainable Apparel Coalition 2020b).

Better information and responsible decisions by the major clothing vendors as regards manufacturing sites and processes are needed to ensure that clothing is produced without the application of hazardous substances and production processes, which is important from an environmental point of view as well as for health reasons. We must also guarantee that clothing is produced under socially acceptable conditions, as explained in Section 2.2.

Table 5 lists the developments the experts in our survey expect to occur in the design and manufacturing process of clothing by 2030 (see Kleinhückelkotten et al. 2017). The developments are classified according to their contribution to more sustainability and their probability of occurrence.

According to the experts' ratings, clear improvements can be expected along the total textile chain as well as at particular stages, e.g., a higher degree of transparency along the supply and production chain and an increased input of sustainably produced natural fibers. There are also trends that could run contrary to sustainability, like increased percentages of fabrics made from chemical fibers, fiber blends, and genetically modified plants. The reduction of the potentially negative effects of chemical fibers requires substantial improvements in the production conditions and the recyclability of these fibers. Negative effects in connection with 
fiber blends can only be avoided by technical innovations in sorting and recycling. Table 5 also shows that uncertainties exist, as for alternative raw materials and fibers. Synthetic fibers made from cellulose, like viscose or rayon, are presumed to be a more sustainable alternative to cotton, but the environmental compatibility strongly depends on the kind of forest ecosystem management and the fiber production process. Hope is also placed in bio-degradable synthetic fibers, but meaningful environmental assessments are lacking. The environmental effects of new chemical-synthetic fibers optimized for special applications depend strongly on the nature of the materials and the production processes. Appropriate finishes could lower negative environmental effects in the use phase of clothes. On the other hand, additional chemicals could complicate recycling.

\subsection{Clothing Consumption}

"Buy less, choose well, make it last!" That is the advice given by the design visionary Vivienne Westwood. Customers should take this to heart to contribute to the achievement of SDG 12 in the field of clothing (BBC 2017). From an environmental point of view, the first challenge, namely the reduction of clothing consumption, is the one of greatest importance. "Choose well" means that the buying decision should not be made spontaneously-rather after an objective consideration of the arguments that militate in favor or against the purchase of a piece of clothing. However, it is not easy for customers to make rational decisions. On the one hand, they are hampered by the positive emotions connected with the buying of clothes. On the other hand, the information provided by many vendors is insufficient or misleading. The multitude of eco- and pseudo-eco-labels leads to uncertainty and confusion.

The expert ratings (see Table 5) of some consumption related developments in the period till 2030 are shown in Table 6. The prospects for a reduction of the quantitative level of clothing consumption are dismal. Especially in the young and higher income population segments as well as in the modern mainstream milieus a reduction of clothing consumption cannot be expected. The importance of sustainability issues and the demand for clothing produced under environmentally compatible and socially acceptable conditions will increase. However, the implementation of one standard sustainability label for clothing is not very likely. Increasing demand is also expected for high quality clothing, but this could only have a positive sustainability effect if the clothing is worn for a longer time and supersedes the buying of new items. 


\subsection{Political and Legal Frame Settings}

The dimensions of the environmental and social problems caused by the clothing industry outlined above and the fact that the efforts of the big players in the clothing industry to improve sustainability have been rather tentative so far or even slowed down in the recent past (Lehmann et al. 2019) suggest the conclusion that strict political and legal frame settings are necessary to reach the necessary speeding up of the imperative transformation processes. It is obvious that the clothing producing countries are challenged to ensure humane and environmentally compatible production conditions by their legislation and to control compliance with these regulations. However, they cannot be left alone in solving the problems. As the representative survey showed, most of the consumers, at least in Germany, support stricter regulations by their own authorities. The demand for binding legal provisions is even shared by many companies (Kleinhückelkotten and Neitzke 2019a). There is a broad spectrum of regulatory or incentivizing measures to improve sustainability in clothing production and consumption that can be taken on the part of the countries where the fashion companies are registered and/ or where they sell their products:

- $\quad$ Statutory obligations for executive care;

- Textile regulation with lists of banned chemicals and processes;

- $\quad$ Reporting commitments for all large- and medium sized enterprises;

- Obligation to label the production conditions;

- Reduced VAT and/or custom charges for clothing produced under environmentally compatible and socially acceptable conditions;

- $\quad$ Reduced VAT for repair and upcycling services;

- Obligatory recycling rates;

- Liability of certification bodies;

- Promoting the foundation of companies with innovative sustainability supporting business concepts;

- Funding of sustainability-oriented research in design, textile engineering, textile chemistry, recycling, and sustainability marketing. 
Table 5. Developments in the textile industry and their sustainability effects as expected by experts.

\begin{tabular}{|c|c|}
\hline $\begin{array}{l}\text { Sector } \\
\text { Development }\end{array}$ & Effect \\
\hline \multicolumn{2}{|l|}{ Value-added chain } \\
\hline $\begin{array}{l}\text { Most fashion vendors will disclose their supply relationships and the manufacturing conditions (high } \\
\text { transparency of the supply and production chain). }\end{array}$ & ++ \\
\hline $\begin{array}{l}\text { The major fashion companies will progressively accept only suppliers that guarantee the observance of high } \\
\text { environmental standards and at least the basic ILO working norms. }\end{array}$ & ++ \\
\hline \multicolumn{2}{|l|}{ Fashion and design } \\
\hline The number of annual collections will increase. & - \\
\hline \multicolumn{2}{|l|}{ Some sustainability aspects will be respected in the design process: } \\
\hline - Seasonal independence; & + \\
\hline - Multi-use; & + \\
\hline - Waste avoidance during cutting; & + \\
\hline - Low energy demand for laundry; & + \\
\hline - Cradle-to-cradle cyclability; & + \\
\hline - Reusability of yarn, fibers, and fiber materials; & + \\
\hline - Repairability; & $\mathbf{o}$ \\
\hline - Reusability of parts; & $\mathbf{o}$ \\
\hline The importance of timeless designs will increase. & + \\
\hline \multicolumn{2}{|l|}{ Raw material and fibers } \\
\hline The percentages of fabrics made from sustainably produced plant and animal fibers will increase. & ++ \\
\hline Solutions will be developed to reduce the abrasion of synthetic fibers (less microplastic). & ++ \\
\hline The percentage of cellulose-based (synthetic) fibers will increase. & ?? \\
\hline The percentage of fabrics made from bio-degradable synthetic fibers will increase. & ?? \\
\hline New chemical-synthetic fibers optimized for special applications will be developed. & ?? \\
\hline The percentage of fabrics made from fiber blends will increase. & - \\
\hline The percentage of fabrics made from chemical fibers will increase. & - \\
\hline The percentage of fibers from genetically modified plants will increase. & - \\
\hline \multicolumn{2}{|l|}{ Finishing } \\
\hline $\begin{array}{l}\text { Chemicals used in the finishing of clothes will be predominantly unproblematic as regards the environment } \\
\text { as well as the health of workers and users. }\end{array}$ & + \\
\hline The percentage of clothing with special chemical finishes will increase. & $?$ \\
\hline \multicolumn{2}{|l|}{ Recycling } \\
\hline The recyclability and usability of chemical-synthetic fibers will improve significantly. & ++ \\
\hline New sorting methods will allow for great quantities of the same or similar clothes for upcycling. & + \\
\hline
\end{tabular}

++ clear improvement expected/high probability for improvement; + slight improvement expected/medium probability for improvement; ?? high probability for development, effect unclear; ? medium probability for development effect, effect unclear; - clear worsening expected/high probability for worsening; - slight worsening expected/medium probability for worsening; o no change expected. 
Table 6. Developments in clothing consumption and their sustainability effects as expected by experts.

\begin{tabular}{|c|c|}
\hline $\begin{array}{l}\text { Sector } \\
\text { Development }\end{array}$ & Effect \\
\hline \multicolumn{2}{|l|}{ Public opinion } \\
\hline The percentage of customers concerned with sustainability issues will increase. & + \\
\hline The public pressure on fashion companies to make clothing production more sustainable will increase. & + \\
\hline \multicolumn{2}{|l|}{ Quantitative consumption } \\
\hline The present trend to buy more pieces of clothing with decreasing price per item will continue. & - \\
\hline $\begin{array}{l}\text { In population segments with higher education there will be an increasing trend towards less } \\
\text { clothing consumption. }\end{array}$ & + \\
\hline $\begin{array}{l}\text { A reduction of clothing consumption in young and higher income segments as well as in the modern } \\
\text { mainstream milieus is not very likely. }\end{array}$ & - \\
\hline \multicolumn{2}{|l|}{ Demand for more sustainable clothing } \\
\hline $\begin{array}{l}\text { The demand for clothing produced under environmentally compatible and socially acceptable conditions } \\
\text { will increase. }\end{array}$ & + \\
\hline The demand for clothing with ecological or social certification will increase. & + \\
\hline The willingness of customers to by clothing made from recycled natural fibers will increase. & + \\
\hline The demand for recyclable clothing will increase. & + \\
\hline The demand for high quality clothing will increase. & $?$ \\
\hline The demand for high-price secondhand clothing will increase. & + \\
\hline Changes in the demand for middle- and low-price secondhand clothing are not very likely. & $\mathbf{o}$ \\
\hline \multicolumn{2}{|l|}{ Repair and upcycling of clothes } \\
\hline There will be no large changes in the demand for repairing and upcycling services. & $\mathbf{o}$ \\
\hline $\begin{array}{l}\text { The demand for services to individualize clothing will increase, associated with the positive effect of greater } \\
\text { appreciation. }\end{array}$ & + \\
\hline \multicolumn{2}{|l|}{ Swapping and renting of clothing } \\
\hline \multicolumn{2}{|l|}{ The swapping of clothes } \\
\hline - via events will increase & + \\
\hline - via commercial platforms on the internet will increase & + \\
\hline - via non-profit platforms on the internet will increase & + \\
\hline \multicolumn{2}{|l|}{ Information } \\
\hline $\begin{array}{l}\text { The implementation of one standard sustainability label for clothing is not very likely, either as a state } \\
\text { controlled or as a common label of the clothing industry. }\end{array}$ & - \\
\hline
\end{tabular}

See Table 5 for the meanings of the signs used in the column 'effect'.

Promising developments are expected by the experts who took part in the survey (see above) regarding the tightening of the ecological, social, and health related requirements to be fulfilled in connection with the production of clothing for Europe (Table 7). 
Table 7. Developments in political and legal frame settings and their sustainability effects as expected by experts.

\begin{tabular}{ll}
\multicolumn{1}{c}{$\begin{array}{c}\text { Sector } \\
\text { Development }\end{array}$} & Effect \\
Regulations of production conditions & + \\
\hline $\begin{array}{l}\text { The requirements to be fulfilled in connection with clothing production will be } \\
\text { tightened by European regulations as regards: }\end{array}$ & + \\
\hline - environmental and climate protection; & + \\
\hline - warranty of employment rights; & - \\
\hline - health protection; & - \\
\hline Taxes and customs & + \\
\hline The introduction of reduced taxes for repair and upcycling services is not very likely. & + \\
\hline A reduced tax for the use of recycled fibers is not very likely. & \\
\hline Public procurement &
\end{tabular}

See Table 5 for the meanings of the signs used in the column 'effect'.

\section{Conclusions}

Most of the steadily increasing mass of clothing is produced and merchandized in globalized production and trade chains. That means that fashion trends and consumption decisions as well as public debates on human rights, climate and environmental protection in clothing importing countries have impacts on the economical state, the working conditions, the level of living of possibly large portions of the population, and the ecological situation in faraway countries. Whether or not the absolutely necessary transformation towards more sustainability in clothing production and consumption will be seriously initiated and will succeed depends largely on the management decisions in the market leading companies, which in turn are strongly influenced by the demand in their key markets. The latter depends on the prevalence of norms and attitudes related to clothing and consumption, but also on the suggestibility of the population by marketing measures.

The results presented in this chapter are based on empirical studies focusing on Germany and the frame settings by the European Union. They are not generalizable on a global scale, but they indicate the options, opportunities, and constraints for a shift towards more sustainability in clothing production and consumption in one of the leading selling markets. 
The message is that there is a widespread awareness of the ecological and social problems related with fast fashion, which together with a general, more diffuse sustainability awareness (a) actually stimulates the buying of more sustainably produced clothing and (b) pushes the demand for binding legal regulations that ensure humane working conditions in the textile industry and the observance of environmental standards regardless of the factories' locations.

The bad news on the consumption side is that fashion and consumption orientation are also strong drivers of buying behavior. Generally, they are not opposed to the buying of more sustainably produced clothing, but they impede a reduction of the quantitative level of consumption. Congruously, the polled experts expect the actual trend to buy more pieces of clothing with decreasing price per item will continue, at least in greater population segments. At first sight, one could think that this is good news for the clothing producing countries, because they can count on the preservation of jobs. However, the other side of the coin is the increasing pressure on the manufacturing costs with negative consequences for wages and working conditions as well as for investments in environmental protection measures.

However, some developments with positive effects on the production conditions are on the horizon.

First of all, major fashion companies are on track to improve transparency along the full textile chain. This is a big challenge due to the globalized and highly branched value-added chains. It is an indispensable requirement to meet the expectations of many customers and the stricter statutory provisions pending for the near future.

It can be expected that clothing production will become more environmentally compliant and that the working conditions in the textile industry will be improved-at least as far as clothing produced for the European and comparable markets. Another foreseeable, positive, development is the more consequent consideration of sustainability aspects in the design and product development process. However, it must be pointed out that meaningful sustainability assessments are lacking for many materials, chemicals, and processes that are discussed as potentially more sustainable alternatives.

In summary, it must be stated that though some developments contributing to more sustainability in clothing production and consumption are in sight, the pace of renunciation of unsustainable production methods and consumption patterns is far too low. In view of the dimensions of the problems, it is not adequate to rely primarily or solely on voluntary initiatives by the clothing industry. The states and the international community are challenged to speed up the necessary agricultural and industrial transformation processes by suitable political and legal frame settings. 
In parallel, educational institutions, authorities, non-governmental organizations, and other societal actors must intensify their engagement and strengthen social norms and attitudes that abet sustainable consumption behavior in an effort to encourage, support, and consolidate it. This is a Herculean task since nothing short of a cultural shift is required.

Author Contributions: All authors contributed equally to the research and to the preparation of the manuscript.

Funding: This research was funded by the German Federal Ministry of Education and Research.

Acknowledgments: The authors thank their colleagues in the InNaBe-project for the inspiring discussions and Nora Schmidt for assistance in data processing.

Conflicts of Interest: The authors declare no conflict of interest.

\section{References}

BBC. 2017. Vivienne Westwood Gives Her Advice on New Designers and Fashion Waste. Available online: http://www.bbc.co.uk/newsbeat/article/40260489/vivienne-westwoodgives-her-advice-on-new-designers-and-fashion-waste (accessed on 31 January 2020).

Bourdieu, Pierre. 1992. Die feinen Unterschiede. Kritik der Gesellschaftlichen Urteilskraft. Frankfurt am Main: Suhrkamp.

Business for Social Responsibility. 2009. Apparel Industry Life Cycle Carbon Mapping. Available online: http://www.bsr.org/reports/BSR_Apparel_Supply_Chain_Carbon_ Report.pdf (accessed on 31 January 2020).

Chapagain, Ashoka, Arjen Hoekstra, Huub Savenije, and Resham Gautam. 2006. The water footprint of cotton consumption: An assessment of the impact of worldwide consumption of cotton products on the water resources in the cotton producing countries. Ecological Economics 60: 186-203. [CrossRef]

Colour Connections. 2020. EcoMetrics. Available online: www.colour-connections.com/ EcoMetrics/ (accessed on 31 January 2020).

Countryeconomy. 2020. National Minimum Wages. Available online: https://countryeconomy. com/national-minimum-wageWTO2019 (accessed on 31 January 2020).

Educations.com. 2020. Education Abroad-Find Your Ideal Study Abroad Course. Available online: https://www.educations.com/search/ (accessed on 23 June 2020).

Ellen MacArthur Foundation. 2017. A New Textiles Economy: Redesigning Fashion's Future. Cowes: Ellen MacArthur Foundation.

Esposito, Elena. 2014. Originalität durch Nachahmung: Die Rationalität der Mode. In Modetheorie. Klassische Texte aus vier Jahrhunderten. Edited by Getrud Lehnert, Alicia Kühl and Katja Weise. Bielefeld: Transcript, pp. 198-210. 
European Parliament. 2014. Workers' Conditions in the Textile and Clothing Sector: Just an Asian Affair? Issues at Stake after the Rana Plaza Tragedy. Brussel: European Parliament Research Service.

Eurostat. 2020a. Final Consumption Expenditure of Households by Consumption Purpose. Available online: https://appsso.eurostat.ec.europa.eu/nui/submitViewTableAction.do (accessed on 31 January 2020).

Eurostat. 2020b. GDP and Main Components (Output, Expenditure and Income). Available online: https://appsso.eurostat.ec.europa.eu/nui/show.do?dataset=nama_10_gdp\&lang= en (accessed on 30 January 2020).

Fibre2Fashion. 2019. Cambodia Rising through the Horizon. Available online: https://www. fibre2fashion.com/industry-article/7357/cambodia-rising-through-the-horizon (accessed on 31 January 2020).

Global Fashion Agenda, and The Boston Consulting Group, eds. 2017. Pulse of the Fashion Industry. Copenhagen: Global Fashion Agenda, Boston: The Boston Consulting Group. Grose, Lynda. 2017. Fashion design education for sustainability practice. In Sustainabilty in Fashion and Textiles. Edited by Miguel Angel Gardetti and Anna Laura Torres. New York: Routledge, pp. 134-147.

Henry, Beverley, Kirsi Laitala, and Ingun Grimstad Klepp. 2019. Microfibres from apparel and home textiles: Prospects for including microplastics in environmental sustainability assessment. Science of The Total Environment 652: 483-94. [CrossRef] [PubMed]

InNaBe. 2019. Research and Praxis Cooperation 'Innovations for Sustainable Clothing'. In Slow Fashion: Gestalterische, Technische und Ökonomische Innovationen für Massenmarkttaugliche Nachhaltige Angebote im Bedarfsfeld 'Bekleidung'. Schlussbericht. Available online: http: //www.innabe.de/fileadmin/Innabe/Literatur/InNaBe_Schlussbericht.pdf (accessed on 31 January 2020).

International Labour Office. 2013. Marking Progress against Child Labour. Global Estimates and Trends 2000-2012. Geneva: International Labour Office.

International Labour Office. 2014. Minimum Wage Systems. General Survey of the Reports on the Minimum Wage Fixing Convention, 1970 (No. 131), and the Minimum Wage Fixing Recommendation, 1970 (No. 135). Geneva: International Labour Office.

International Labour Organization. 2014a. Minimum Wages in the Global Garment Industry. Geneva: ILO Regional Office for Asia and the Pacific.

International Labour Organization. 2014b. Wages and Working Hours in the Textiles, Clothing, Leather and Footwear Industries. Geneva: International Labour Organization.

International Labour Organization. 2020. Ratfication of ILO Conventions: Ratifications by Country. Available online: https://www.ilo.org/dyn/normlex/en/f?p=1000:11001:::NO::: (accessed on 30 January 2020). 
International Telecommunication Union. 2018. Mobile-Cellular Telephone Subscriptions. Available online: https://www.itu.int/en/ITU-D/Statistics/Pages/stat/default.aspx (accessed on 5 November 2018).

Kharas, Homi. 2017. The Unprecedented Expansion of the Global Middle Class. An Update. Global Economy \& Development Working Paper 100. Washington: Brookings.

Kleinhückelkotten, Silke, and Horst-Peter Neitzke. 2019a. Increasing sustainability in clothing production and consumption-opportunities and constraints. GAIA 28: 240-48. [CrossRef]

Kleinhückelkotten, Silke, and Horst-Peter Neitzke. 2019b. Social acceptability of more sustainable alternatives in clothing consumption. Sustainability 11: 6194. [CrossRef]

Kleinhückelkotten, Silke, Horst-Peter Neitzke, and Nora Schmidt. 2017. Kleidung 2030-Entwicklungen und Innovationen. InNaBe-Projektbericht 5.2. Hannover: ECOLOG-Institut.

Kleinhückelkotten, Silke, Horst-Peter Neitzke, and Nora Schmidt. 2018. Bewertung der Nachhaltigkeit von Innovationen Entlang der Textilen Kette. InNaBe-Projektbericht 7.1. Hannover: ECOLOG-Institut.

Lange, Hellmuth, and Lars Meier, eds. 2009. The New Middle Classes: Globalizing Lifestyles, Consumerism and Environmental Concern. Dordrecht, Heidelberg, London, New York: Springer. Lehmann, Morten, Gizem Arici, Sebastian Boger, Catharina Martinez-Pardo, Felix Krueger, Margret Schneider, Baptiste Carrière-Pradal, and Dana Schou. 2019. Pulse of the Fashion Industry: Update 2019. Copenhagen: Global Fashion Agenda.

Masterstudies. 2020. Masters Programs in Fashion Design in Europe 2020. Available online: https://www.masterstudies.com/Masters-Degree/Fashion-Design/Europe/ (accessed on 23 June 2020).

Mekonnen, Mesfin M., and Arjen Y. Hoekstra. 2010. The Green, Blue and Grey Water Footprint of Crops and Derived Crop Products. (Value of Water Research Report 47). Delft: UNESCO-IHE Institute for Water Education.

Mekonnen, Mesfin M., and Arjen Y. Hoekstra. 2011. The green, blue and grey water footprint of crops and derived crop products. Hydrology and Earth System Sciences 5: 1577-600. [CrossRef]

Moser, Stephanie, and Silke Kleinhückelkotten. 2018. Good intents, but low Impacts: Diverging importance of motivational and socioeconomic determinants explaining pro-environmental behavior, energy use, and carbon footprint. Environment Behavior 50: 626-56. [CrossRef]

Mukherjee, Sudeshna. 2015. Environmental and social impact of fashion: Towards an eco-friendly, ethical fashion. International Journal of Interdisciplinary and Multidisciplinary Studies 2: 22-35.

Muthu, Subramanian Senthilkannan. 2014. Roadmap to Sustainable Textiles and Clothing. Singapore: Springer. 
Muthu, Subramanian Senthilkannan. 2017. Sustainability in the Textile Industry. Singapore: Springer.

O’Neill, Daniel W., Andrew L. Fanning, William F. Lamb, and Julia K. Steinberger. 2018. A good life for all within planetary boundaries. Nature Sustainability 1: 88-95. [CrossRef] Office of Child Labor, Forced Labor, and Human Trafficking. 2018. 2018 List of Goods Produced by Child Labor or Forced Labor; Washington: US Department of Labor.

Prentice, Rebecca, and Geert De Neve. 2017. Unmaking the Global Sweatshop: Health and Safety of the World's Garment Workers. Philadelphia: University of Pennsylvania Press.

Simmel, Georg. 1995. Philosophie der Mode. In Georg Simmel. Gesamtausgabe, Bd. 10. Edited by Behr Michael, Volkhard Krech and Gert Schmidt. Frankfurt am Main: Suhrkamp.

Simms, Andrew, Victoria Johnson, Joe Smith, and Susanna Mitchell. 2009. The Consumption Explosion. The third UK Interdependence Report. London: New Economics Foundation.

Sustainable Apparel Coalition. 2020a. The Higg-Index. Available online: https: //apparelcoalition.org/the-higg-index/ (accessed on 30 January 2020).

Sustainable Apparel Coalition. 2020b. Transforming the Apparel, Footwear, and Textile Industry. Available online: https://apparelcoalition.org (accessed on 30 January 2020).

The University Network. 2018. Top 10 Sustainable Fashion Schools in the World. Available online: https://www.tun.com/blog/top-10-sustainable-fashion-schools-in-the-world/ (accessed on 23 June 2020).

UK Parliament. 2017. The Social Cost of Our Clothes. Available online: https://publications. parliament.uk/pa/cm201719/cmselect/cmenvaud/1952/report-files/195205.htm (accessed on 30 January 2020).

UN DESA (United Nations, Department of Economic and Social Affairs, Population Division). 2017. World Population Prospects: The 2017 Revision. Volume I: Comprehensive Tables. New York: United Nations.

UNEP. 2017. The Changing Aral Sea. Foresight Brief 003. Nairobi: United Nations Environmental Program, UNEP, Available online: http://uneplive.unep.org/media/early_ warning/foresight_brief_003_final (accessed on 12 May 2020).

Varun, Vaid, and Abrol Kanika. 2017. The Road to 2025. National Capital Region: Wazir Advisors Pvt. Ltd.

Wahnbaeck, Carolin, Kirsten Brodde, and Hanno Growth. 2015. Usage E Attitude Mode/Fast Fashion. Ergebnisbericht. Hamburg: Greenpeace.

World Bank. 2018. World Development Indicators. Available online: https://data.worldbank. org/indicator (accessed on 31 January 2020).

World Bank. 2019a. Textiles and Clothing (\% of Value Added in Manufacturing). Available online: https://data.worldbank.org/indicator/NV.MNF.TXTL.ZS.UN (accessed on 31 January 2020). 
World Bank. 2019b. Labor Force, Total. Available online: https://data.worldbank.org/indicator/ SL.TLF.TOTL.IN (accessed on 31 January 2020).

World Trade Organization. 2019. World Trade Statistical Review 2019. Geneva: World Trade Organization.

(C) 2020 by the authors. Licensee MDPI, Basel, Switzerland. This article is an open access article distributed under the terms and conditions of the Creative Commons Attribution (CC BY) license (http://creativecommons.org/licenses/by/4.0/). 



\title{
Socially Responsible Fashion Practice: Looking Good and Feeling Good
}

\author{
Elaine L. Ritch
}

\section{Introduction}

Information describing the impact that fast fashion production has upon the environment has accelerated over the last year, with numerous reports in the media and news (cf. Agerholm 2019; Seigle 2019). In 2019, the United Nations reported that the fashion industry is the second most polluting industry in the world (United Nations 2019a). As the United Nations Sustainable Development Goals (SDGs) seek to provide a better and more sustainable future for all (United Nations 2020), understanding how the fashion industry impacts upon the natural environment and resources offers only a partial response. To progress SDG 12 ('Ensure sustainable consumption and production patterns'), it is important to establish the barriers consumers experience in performing sustainable consumption and why current production patterns are unsustainable. For over a decade, the fashion industry has been criticised for not assuming socially responsible fashion production, nor encouraging consumers to adopt sustainable fashion consumption behaviours (Centre for Sustainable Fashion 2009; Hearson 2008); neglect for sustainable responsibility was also evident in the Raza Plaza factory collapse that killed 1134 workers (Safi and Rushe 2018). Although this forced Western brands and retailers to insist on health and safety implementations, it does not go far enough to rectify all the issues (Safi and Rushe 2018), such as overlooking neglect for the environment and worker conditions (Ritch 2019). Rather than addressing sustainability and using this as a way to create value, fashion retailers continue to compete with lower prices, endorsing normalised Western behaviours that encourage more consumption (United Nations 2019a).

In fact, it seems that the race to the bottom continues, with Misguided (UK online fashion retailer) marketing a bikini for GBP 1.00 in the summer of 2019 (Abraham 2019): this price does not represent the true cost of the impact that excavating materials and production has upon the environment, or the consequences for those involved in the supply chain (United Nations 2019a; Rivoli 2009). Although some high street retailers have introduced facets of sustainable production-such as H\&M's Conscious Collection, M\&S's responsibly sourced cotton and both M\&S and H\&M, along with 
Zara, encouraging unwanted garments to be recycled in store (United Nations 2019a; Ritch 2019) - this seems a small concession given the volume of fast fashion garments that are annually produced, sold, and discarded (United Nations 2019a); particularly, as vouchers are offered in exchange to encourage further consumption (Ritch 2019). Academic research has investigated how consumers deliberate fashion consumption from an ethical and sustainable position, and found that consumers are reluctant to sacrifice style over ambiguous allegations (Wiederhold and Martinez 2018; Ritch and Brownlie 2016a; McNeil and Moore 2015). As the fashion industry continues to skirt around the issues of sustainability, fashion-conscious consumers remain unable to express their preferences to avoid the detrimental consequences of fashion production, compromising their pleasure of fashion consumption.

The aim of this chapter is to examine the discord between fashion and sustainability, often referred to as an oxymoron (Black 2008). Framed within social identity theory, tensions between the use of fashion as an identity signaller and preferences to mitigate the detrimental impact fashion has on the environment are illuminated upon. The chapter will first establish the background context, examining the rise of sustainability within mainstream consciousness and the impetus for businesses, including the fashion industry, to address rising concerns. Accordingly, fashion-related behaviours that position the construction of self through commodity signalling and related emotive feelings are considered, along with the potential to link fashion, identity, and altruism within sustainable fashion consumption behaviours. Social identity theory is then introduced, followed by outlining the research agenda and presenting the findings. The chapter concludes with commentary on how the fashion industry can benefit from raising consumer awareness of the ways in which the fashion industry is unsustainable, and the efforts that can be made to adopt socially responsible fashion practice.

\section{Background Context}

Despite continued interest in sustainability, including that of academics who have examined numerous ways in which to advance the sustainably agenda, the scale of the issues continues to magnify. Whilst consumers report concern for the issues, this is not replicated in the sales of sustainably produced goods (Carrington et al. 2010). However, recent consumer activism, especially from younger people, has illustrated heightened concern, and activists are urging the government and businesses to do more to address sustainability (Read 2019; Wilson-Powell 2019). In this chapter, sustainability encapsulates the definition provided by the World Commission on Economic Development (1987), stating that international co-operation which 
prioritises sustainable development is underpinned by equal consideration for the environment, economy, and social wellbeing to ensure 'development that meets the needs of the present without compromising the ability of future generations to meet their own needs' (ibid: 34). This places equal importance on limiting environmental damage as well as ensuring that people have the ability to create economy and protect their wellbeing. As planetary resources are finite, continued excavation will compromise water supplies and growing crops (United Nations 2020; Rivoli 2009); the climate is already experiencing disruption, with fires, flooding, and draughts, and this has resulted in deaths, disease, reduced cognitive capacity, childhood stunting, and malnutrition (Carbon Brief 2019; Lyon 2019). Recent reports claim that urgent action is required in addressing climate change, as limited time (11 years) remains to halt irreversible damage (United Nations 2019b). To address this broad statement, the SDGs provide a framework to address the global challenges (United Nations 2020). Although the fashion industry is also a major contributor to the global economy, economic growth should not be at the cost of endangering the planet (United Nations 2020).

Recently, business leaders have been warned about the importance of addressing sustainability. At the Annual Meeting of the International Monitory Fund, Mervin King (former governor of the Bank of England) warned that the world economy is 'sleepwalking towards a fresh economic and financial crisis that will have devastating consequences for the democratic market system' and that recovery from the 2008-2009 recession was slower and less stable than after the Great Depression in the 1930s (Elliott 2019). Further, Mark Carney, the current Bank of England governor, cautioned businesses that unless they moved towards zero-carbon emissions, they would be punished by various stakeholders and would face bankruptcy. Like King, Carney also expressed fears that failure to 'tackle the climate crisis could result in an abrupt financial collapse' (Carrington 2019). There are three implications from those assertions: firstly, consumers remain price conscious as salaries have stagnated in relation to inflation, which has reduced their pricing threshold (Ritch and Brownlie 2016b) and is a consequence of continued financial instability since the recession (Rudawska et al. 2013); secondly, as the current dominant paradigm of production and consumption appears unsustainable for economic growth (Ritch 2016), neither benefiting people as consumers or employees (the race to the bottom and the erosion of workers' rights are now experienced in the United Kingdom-zero-hour contracts, the gig economy, etc. (MacDonald and Giazitzoglu 2019) reducing consumers' disposable income) and certainly not the planet as described previously; thirdly, 
this appears to be an opportunistic time for reconfiguring responsible production and consumption.

Despite the fashion industry falling behind the trend for sustainability, consumer awareness is increasing (Read 2019; Wilson-Powell 2019). Other consumption contexts appear more advanced, particularly the current nudge to reconsider single-use plastic (Howard et al. 2019), and more consumers now carry shopping bags, water bottles, and reusable coffee cups with lids to avoid plastic waste. Yet, fashion consumption is more complex; fashion constructs identity (Anand and Kaur 2017), indicating status, lifestyle, and belonging (Goldsmith and Clark 2008). Fashion sends symbolic signals to others that portrays social self (Anand and Kaur 2017) and Nash (2019) found that acquiring new fashion increased self-confidence. Hudson and Hudson (2003) postulate that marketing activities are positioned from the perspective that consumption increases personal satisfaction that contributes to feelings of wellbeing ( $\mathrm{O}^{\prime}$ Guinn and Faber 1989). This is evidenced in fashion marketing, which focuses on style, fashion consciousness, and how the consumer will look wearing the garment, improving self-esteem (Díaz-Meneses 2010; Richins 1999). Interest in fashion is a potent precursor to engaging with new styles, something that Díaz-Meneses (2010) explored along with the emotive complexity of fashion consumption; she found that fashion thought to be aesthetically pleasing and with a good fit provided pleasure and satisfaction related to self-actualisation. Niinimäki (2010) also identified that the hedonism experienced with fashion superseded ethical tendencies that were often applied in other consumption contexts. Further, Joy et al. (2012) and Ritch (2015) found that despite adopting sustainable behaviours in some consumption contexts (recycling, buying sustainable food), this did not transfer to fashion. The main differentiation is that fashion is akin to a language-it is a silent communication of identity and values. Although, research has exposed that tensions are experienced through a misalignment of socially responsible fashion practice and sustainability preferences (Wiederhold and Martinez 2018; Ritch and Brownlie 2016a; McNeil and Moore 2015), the industry remains unresponsive. As fashion-interested consumers prioritise fashion aesthetics over ethical or sustainable implications, Niinimäki (2010) believes that all fashion, including mainstream options, should be produced responsibly to satisfy appearance (looking good) and to ensure that consumers feel good about their consumption.

Status, belonging, and self-esteem are also traits that are linked with ethical and sustainability consumption (McGoldrick and Freestone 2008), particularly as social identity links with behaviours that can be influenced by others (Nash 2019; Richins 1999). Griskevicius et al. (2010) found that signalling status and wealth 
was experienced from purchasing a hybrid car because they are more expensive, yet have a reputation for lower performance; therefore, hybrid car owners illustrate their willingness to sacrifice comfort and efficiency for wider societal good. Griskevicius et al. (2010) refer to this as conspicuous conservation, which is pro-social in contrast to pro-self. However, often this is a mutual value purchase where sustainable options encompass both personal satisfaction as well as a response to social responsibility (Smith 1999, p. 154). Similarly, Cervellon et al. (2009) and Zabkar and Hosta (2012) identified elevated status linked to the purchase of organic produce, while Cherrier (2006) found that some consumers use green shopping bags rather than plastic bags to illustrate their commitment to environmental conservation. Therefore, being socially responsible is considered as good citizenship, increasing esteem and leading to altruism (Ritch and Brownlie 2016a, 2016b; Niinimäki 2010). For the fashion industry to assume responsibility for socially responsible production by creating enhanced value that is responsive to current concerns, there are similar advantages that increase consumers' sense of wellbeing and reduce the tensions currently experienced.

However, as the current marketing message to fashion consumers focuses more on enhancing appearance and status-values that are consumer orientated (pro-self) -than on wider social concerns that include production practice (pro-social) (Hudson and Hudson 2003), nudging consumers to consider sustainability is required. Fashion production is somewhat obscured, not only from being located in developing countries that are geographically distant and culturally diverse but also because consumers have limited understanding of what fashion production entails; for example, consumers are unaware that pesticide use to increase cotton production depletes the soil of fertility, that dye disposed of negligently impacts on water supplies (Rivoli 2009), or that the complexity of tracing supply chains means that allegations of exploitation cannot be rectified (Ritch 2019). When fashion brands are criticised for neglecting responsibility, the response is to blame the supply chain and purportedly rectify workers conditions/pay or apply a cultural context (Ritch and Brownlie 2016a). The facelessness of the garment workers dehumanises their experience (Lyon 2006), leading to consumer disconnect. This temporal gap is a consequence of overseas production, where cultural employment experiences and expectations are somewhat abstract; Western consumers struggle to relate to the workers' experience in developing countries, or make sense of what is an appropriate salary (Ritch and Brownlie 2016a). Additionally, sustainability can also be described as abstract, especially as the detrimental consequences of climate change seem futuristic and will be experienced more quickly in developing countries than for 
Western consumers (Stern 2006), who need to temper their consumption practice. Issues around sustainability are also complex; it is easier for consumers ignore the severity of the consequences, especially when a sacrifice of preferred consumer values is required.

Fashion consumers using mainstream markets have little option to prioritise their sustainable preferences, other than the small efforts of some high street brands or choosing sustainable fashion brands which are more expensive and less convenient to access. Other options are voice or exit (Hudson and Hudson 2003) but, again, this requires a sacrifice in appearance which would impact on esteem and confidence. Yet, there are many ways in which value can be created within production, from information on 'who made my clothes' (the annual Fashion Revolution campaign in response to the Rana Plaza disaster) to recycled fibres that 'close the loop' of production, consumption, and disposal; both of these offer aspects of socially responsible fashion practice that includes the emotive complexities of fashion and further endorse positive feelings of looking good and doing good. To explore the mutual benefits of socially responsible fashion production and consumption, social identity theory provides a framework to examine the values transmitted through commodity consumption. Although social identity theory has been previously applied to fashion, this has not included sustainable fashion.

\subsection{Social Identity Theory}

Upon reflection, it is unsurprising that social identity theory offers the opportunity to frame the findings; the sampling characteristics of this research captured a narrow demographic of social grouping (professionally working mothers). Social identity theory can explain the relationship between consumers and their social environment, as well as how they perceive their consumer group, emerging from attitudes and beliefs (Bartels and Hoogendam 2010); this could include whether sustainability attributes are deemed important for consumption practice and how fashion and appearance signal 'same social category' (Tajfel and Turner 1979, p. 59). Within this, identity formation relates to how someone chooses to place themselves within society, informing appearance, lifestyle, and practices that may include a political stance (Liu 2019; Badaoui et al. 2018). Social categorisation is a cognitive process that segments and classifies people, is used to inform self-reference and the construction of self, and offers a sense of belonging to the social world (Tajfel and Turner 1979). Belk (1988) illustrated the use of possessions as constructing self and signalling one's self-orientation to others. Social group membership (whether conscious or not) signals self-concept through efforts to belong within social identity 
groups and conform to expected practices and performances (Liu 2019). This will include fashion selection, linguistic articulation, ideology, and related cultural lifestyle attributes that indicate intergroup belonging (Badaoui et al. 2018; McNeill 2018).

The accepted culture and behaviour which is inherent to the chosen group (Badaoui et al. 2018) is also symbolic of social class and status (Belk 1988) that offer feelings of self-esteem (Stryker and Burke 2000). The emotive involvement found in belonging (Bartels and Hoogendam 2010) and the altruism experienced from being a socially responsible consumer (Moisander 2000) cannot be overlooked. For example, certain attributes are related to assumptions of mothering, such as being caring and nurturing (Ritch and Brownlie 2016b), and this might include educating children on being good citizens through caring for the environment and workers within the supply chain (Ritch and Brownlie 2016b). Furthermore, experiencing an inability to perform to the expected ideals of the social group can lead to reduced self-confidence (Liu 2019). Bartels and Hoogendam (2010) found that social environment was an important aspect of encouraging green (sustainable) consumerism, and that there was a modest relationship between different aspects of environmental behaviours; this infers that positive feelings for sustainable practices extend into other consumption contexts. They also found that compliance with sustainability was related to increased social mobility (Bartels and Hoogendam 2010). Therefore, understanding what motivates participation in social group settings and the meaning derived from social identity (McNeill 2018) offers marketing managers opportunities to create meaningful marketing activities. Moreover, a better understanding of how to comply with sustainable behaviours increases confidence, and altruism will help to better position social marketing.

\subsection{Research Agenda}

The research adopted a broad approach to better understand how sustainability is 'thought through' (Szmigin et al. 2009, p. 379) and how it is existentially experienced within families, with a specific focus on fashion. The premise was to examine how sustainability was perceived in theory and practice, as well as how this differentiated between consumption contexts. This approach was considered necessary as other contexts (the food industry, reusing plastic bags, recycling, etc.) are more advanced in addressing the sustainability agenda that the fashion industry (Ritch 2015). Although the previous literature has attempted to identify demographic and psychographic factors that increase the propensity for sustainability practice, there is little consensus regarding the defining characteristics that result in sustainability involvement (Bray et al. 2011). 
Nevertheless, lifestyles encapsulate similar characteristics which establish commonality (D'Souza et al. 2007). The extant literature has reported that sustainability was more important for certain social groups. Firstly, women are considered as being more proactive in implementing sustainability in the home (do Paço and Raposo 2010), which could be a consequence of women still carrying out a higher percentage of household tasks, including consumption, within some family dynamics (Cappellini and Yen 2016); secondly, motherhood has inspired consideration for the world in which children encounter (Prothero and Fitchett 2000), and as sustainably produced food is marketed as kinder towards the environment as well as providing a healthier diet, this has led to mothers reporting preferences for sustainable production, particularly organic, which is grown without the use of pesticides (Atkinson 2014; Cairns et al. 2013); finally, attainment of higher education is thought to increase the level of interest in current affairs, including concern for climate change and human rights (Kriwy and Mecking 2012). Therefore, the sampling approach of convenience and snowballing (Anderson et al. 2016) was adopted to focus on those three characteristics, seeking mothers who worked in a professional occupation as this determined higher education attainment. Initially, five participants were approached and interviewed, with each asked to recommend another five potential participants. In total, 28 participants were interviewed for between 60 and 90 minutes, all of whom lived in Edinburgh and the surrounding Lothians; however, some were originally from other countries and brought with them experience of different levels of sustainability practice.

After gaining ethical approval from Queen Margaret University, phenomenological interviews (Thompson et al. 1989) provided an opportunity for an exploratory inquiry to examine everyday lifeworlds (Smith et al. 2009). The aim of phenomenological interviews is to understand the phenomena 'as lived', beginning with a broad question to explore the lived experience (Thompson et al. 1989) that is not based on prior hypothesis (Guillard 2018). Therefore, the interviews began by asking "How does fashion come into the home, for you and your children, and what factors are important?" After this question had been discussed with additional probing questions, in order to manage the direction of the interview and encourage discussion around sustainability, garment labels that contained facets of sustainable production were introduced as primers (Pink 2005). This included fabric made from recycled plastic bottles (M\&S); fabric made in an eco-factory (M\&S); organic cotton (M\&S); enzyme-washed garments (John Lewis); t-shirts made from sustainable cotton sources, with the label and logo of the t-shirt in support of avoiding child labour in cotton production (Environmental Justice Foundation). The informants were contacted with 
a request for an interview, and basic demographic information that would support analysis was collected, including age, family structure, occupation, and weekly number of hours worked. Those factors were considered likely to impact on their ability or engagement to adopt sustainability.

The informants were all professionally working mothers, spanning accountants, lawyers, academics, and teachers; work patterns ranged from $12 \mathrm{~h}$ per week to full-time. They were aged between 28 and 48 years, and most cohabited with the fathers, with two being single mothers; the number of children in the household was between one and four. Data interrogation followed Interpretive Phenomenological Analysis (Smith et al. 2009), which included the data being considered through three lenses: descriptive, linguistic, and conceptual. To achieve this, a table was formulated with the participant's narrative before being analysed descriptively-unpacking what was said; linguistically — how it was said (for example, the participants sometimes whispered as though relaying a secret); and conceptually-what do they really mean (for example, a participant spoke at length about a furniture retailer who constantly advertised a sale, but what she really meant was that she was uncertain what the true price was, was it the pre-sale price or sale price, and she questioned the integrity of price tactics).

The process began with an in-depth analysis of two informants who were selected due to their reconceptualisation of value after becoming a mother. P-10 began to focus more on sustainability, in a similar way that Prothero (Prothero and Fitchett 2000 reacted after bringing a child into the world and questioning what kind of world the next generation would inherit. P-20 also was concerned about the health implications of pesticide use in food production, and the family followed an organic diet. Related to fashion and identity formation, it was provisioning that expressed values; immersed in the home while on her third maternity leave, P-20 was less concerned about her attire as most of her time focused on nurturing the children. This is unsurprising, as Giddens (1991, p. 11) suggests that familial change culminates in 'establishing a new sense of identity'. Familial change was also experienced by P-20, who had returned to study and found her time juxtaposed between part-time work, university, and the home. She considered her appearance for each activity, adopting the accepted norms for each activity to illustrate her sense of belonging. However, the financial restrictions she experienced meant she had to suspend her ethical values, and although previously a vegetarian, she found herself buying non-free-range chicken to provide nutritious meals for her children. Consequently, those two informants illustrate that fashion, identity and appearance are related to situational constructs: internal (invested in the home and child-rearing) and external 
(participation in external activities, such as work and study), and selected fashion that was appropriate for each activity. Once themes had been developed, the other transcripts were analysed for supporting narratives.

\section{Informant Perceptions and Discussion}

This chapter focuses on the themes around identity, appearance, fashion consumption, and misalignment of ideology. The analysis identified that the informants conceptualised their identity as threefold, as captured in Figure 1:

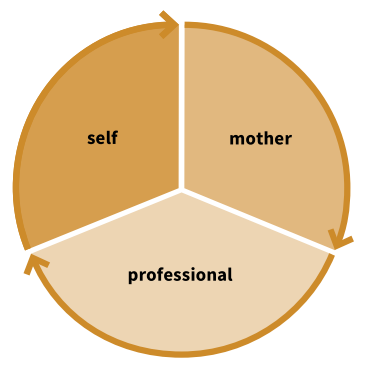

Figure 1. Conceptualisations of identity formation. Source: Own illustration.

Figure 1 not only describes concepts of identity formation, but also illustrates the main functions that constituted their everyday lifeworlds, as a point of reference to how they managed time, responsibility, and finances. As professionally working mothers, the informants expressed multiple identities, which, as found by Bartels and Hoogendam (2010), is unsurprising given their dual roles. In terms of time and managing a myriad of responsibilities (childcare, household duties, and work), this impacted on their ability to evaluate consumption, including sustainability implications. All of the participants had at least one child under 12 years for whom they were responsible for care giving and consumption. Although most of the participants were in a couple, from the interviews, they assumed main responsibility for their children. Often, as identified in other research (Carrigan and Szmigin 2006), this resulted in opting for practice that was convenient; for example, purchasing fashion in the supermarket as they were there purchasing food, despite allegations of garment worker exploitation. Even though the informants worked in professional occupations, money was still contentious, and their disposable income had to cover household management, fashion, and activities for themselves and their children. Therefore, they adopted a different approach to accessing fashion for themselves and their children; given the children's continuous growth, they sought value for money and the low prices of budget fashion retailers and supermarket 
fashion resulted in a reduced threshold of how much they were willing to pay (Ritch and Brownlie 2016a, 2016b).

Previous research has reported on how fashion and sustainability was perceived and managed for their children (Ritch 2019; Ritch and Brownlie 2016a, 2016b; Ritch 2015). Therefore, this chapter takes a different approach to focus on how the informants managed their own fashion consumption to align with their conceptualisations of self, mother, and professional. Social identity theory is utilised to examine how fashion signals family values, including status and ideology through consumption practice. The interviews began by asking the informants how fashion came into the home for themselves and their children. Those approaches to fashion consumption are considered first, as those discussions led the interviews. The analysis revealed that fashion involvement had been reduced, which is unsurprising given their multiple responsibilities; however, as a result of fashion shopping becoming less frequent, the experience provided heightened emotive hedonistic feelings (see Table 1 , column one). After this discussion had been exhausted, the sustainable fashion garment labels were introduced to guide the discussion towards sustainable fashion. It was clear that motherhood was already considered demanding; although this was accepted by the informants, it contributed to an unwillingness for further sacrifice (see Table 1, column two). However, despite the numerous barriers to sustainable fashion consumption (price, limited styles and sizes, not following fashion, lack of high street availability, and uncertainty regarding the implications), there was delighted surprise that some high street stores were addressing socially responsible fashion practice as well as feelings of guilt at the thought of contributing to exploitative practice (see Table 1, columns three and four).

\subsection{Approaches to Fashion Consumption}

The recognition that children's continued growth necessitated clothing consumption already put a strain on the household budget and, of course, the time to shop. Despite shopping in the supermarket for the children's clothes as a means of convenience and because of lower pricing, purchasing fashion for themselves led to preferences for a pleasurable shopping experience. Often, this was an activity around their birthday, Christmas, or when an event dictated a new garment (see quote 1). In this sense, fashion consumption is considered a self-indulgent treat, and due to the infrequency of such occasions, time was taken to enjoy the event and children were not included in the shopping trip. There was also a preference for upmarket fashion stores that sold higher quality garments, and had luxurious fitting rooms and sales staff that were more attentive, as also identified by Niinimäki (2010). 

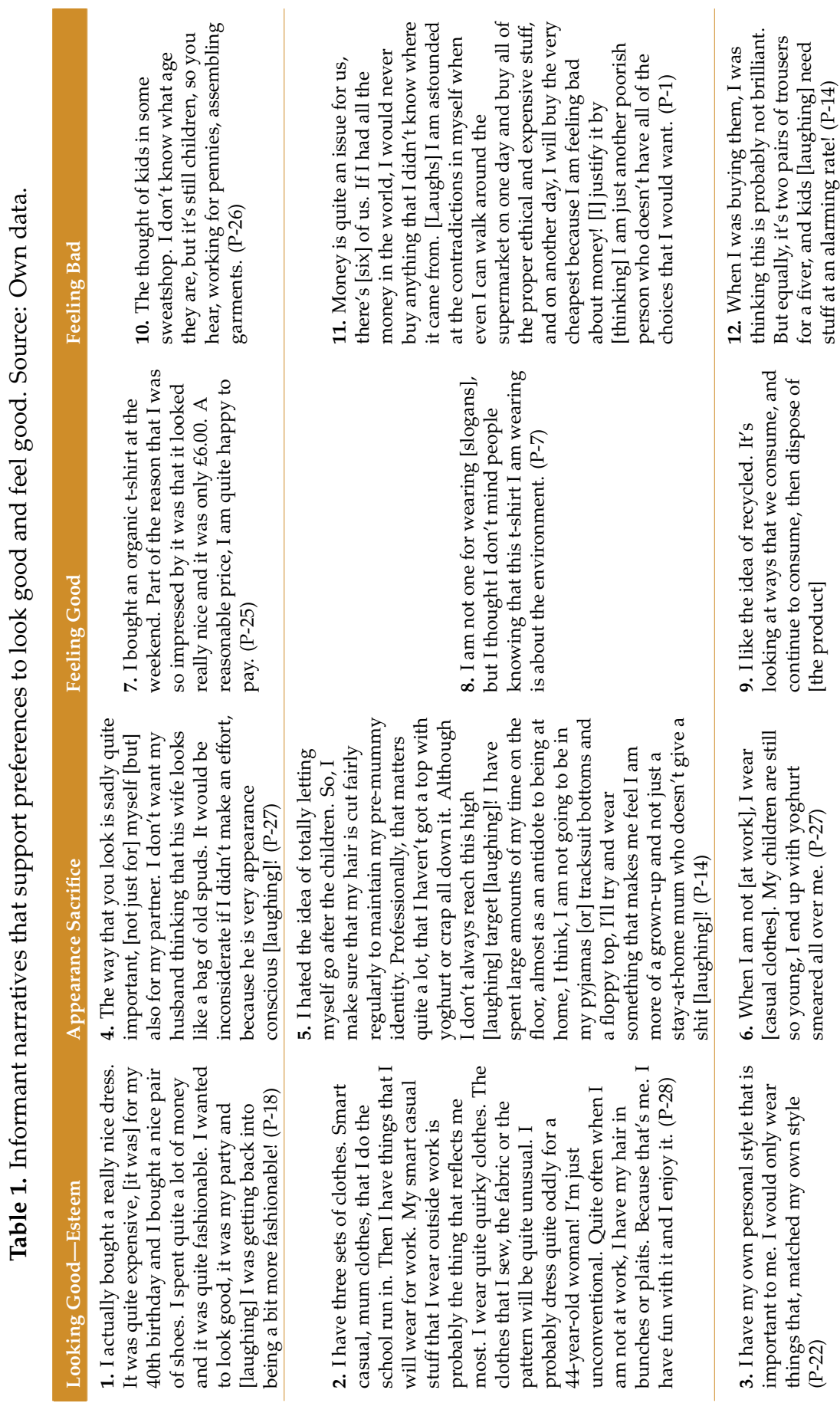

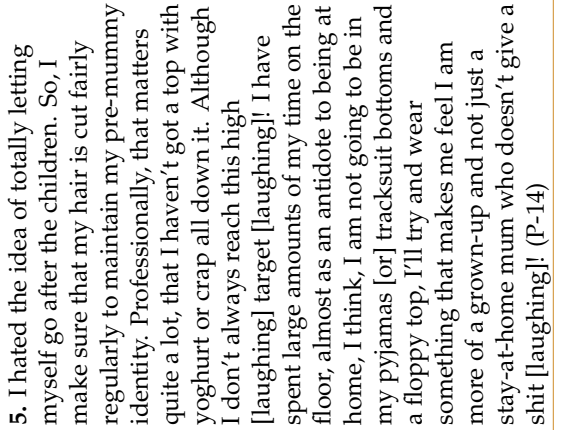

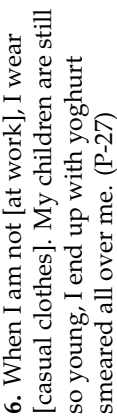

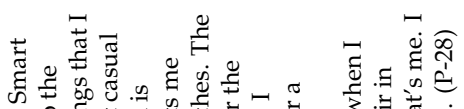

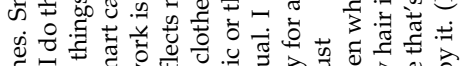

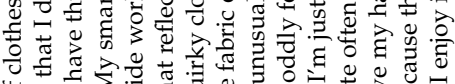

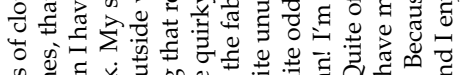

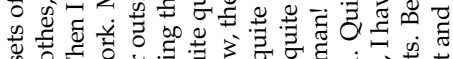

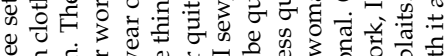

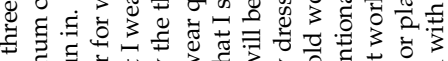

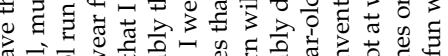

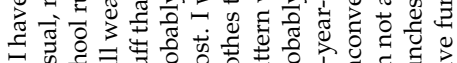

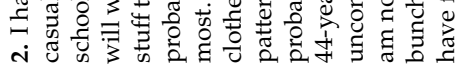

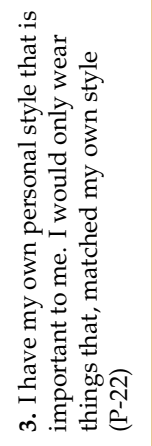


It was clear that the fashion shopping was considered an activity to focus on themselves, in contrast to work, chores, and childcare that constituted their everyday lifeworlds. Fashion shopping also evoked memories of a time when they could be self-indulgent and more carefree. For example, P-6 mentioned that she bought spiky heeled shoes that she could not walk in, but liked the idea of owning them. Shopping for fashion was reminiscent of a time when they participated in social occasions and had more excitement in their lives. Consequently, the informants pursued fashion consumption as a form of escapism from the mundanity of their everyday lifeworlds, resulting in them responding to stimuli in the marketplace and being aesthetically attracted to fashion which they perceived would enhance their appearance. In addition, it was important that their appearance reflected their personal style and work status (see quotes 2 and 3), not only enhancing belonging to social groups but also reflective of their capability and confidence.

This fashion from premium retailers was more expensive, which aligned with their status of having a professional occupation; the clothes had a superior design and increased quality, which meant that the garment lay on their bodies better (fit) and tended to last for longer. Longevity suited their needs as the frequency of their fashion consumption had reduced and they tended to wear clothes for longer (because they were 'hopefully not growing bigger', P-10!); this also led to preferences for more classic designs rather than fast fashion, especially for work. Fit was important, especially as their body shape had changed during and after pregnancy, multiple pregnancies for some; the lack of craftsmanship in inexpensive fashion often led to a poor fit (see quote 12) whereas higher quality garments fit their body shape, providing confidence, positive feelings, and comfort. A further rationale for spending more on fashion for work was that time at home with the children often involved messy activities, such as playing games on the floor or feeding small children (see quotes 4,5 , and 6 ). Therefore, garments which were more comfortable that they did not mind getting dirty were preferred.

Clothing for the day was dictated by the activities that were planned, with a different wardrobe for work, play, and socialising. For example, P-10 had returned to study, and was uncertain how a 'lady of a certain age' who was studying should dress, given that she was older than the student cohort and also a mother. She dressed less in professional work clothing and although she felt that some fashions were too young for her, she adopted a more casual approach which still differed from the clothing that she wore when playing with the children. She was also aware of the signal from her fashion-related commodities, stating that she selected a larger cotton tote bag to carry round her books and folders, but felt uncomfortable that this bag 
had the Primark logo on it; as this brand had alleged worker exploitation, it did not align with her awareness of social issues. Similarly, P-28 worked as a drama lecturer and led a creative industries business. She felt that her appearance should reflect her creative tendencies, as an expression of her character, but also required clothing that would allow comfort for drama expression (see quote 2). Again, this differed from the clothing she wore when with her children and she also felt that at the school gate, status was expressed through fashion, claiming that the 'yummy mummies' had a certain dress code.

\subsection{Reluctance to Sacrifice Self}

As described previosuly, fashion consumption for themselves had been reduced, and this was considered necessary given that their children's wellbeing and the household took precedence, as found by Carrigan and Szmigin (2006). In itself, this was considered a sacrifice, to ensure the children were well looked after, albeit a temporary one that would change as the children became more self-sufficient. This included the financial management that focused on putting the children foremost by providing clothing and experiences that would create family memories. Bettany et al. (2010) postulated that sacrifice within a caregiving or household management is socially expected from mothers, and this was not questioned by the informants; however, a further sacrifice to include sustainability implications was not entertained. Rationales were offered during the interview for this reluctance, covering infrequent consumption; work needs; the lack of supporting information; and, the lack of availability in their preferred fashion retailers. Connolly and Prothero (2003) situate sustainable consumption as 'giving up and losing out'; this was the opinion of all of the informants and the words they used to describe sustainable fashion included 'frumpy' (P-4), 'obscure' (P-13), 'arty-farty' (P-15), and 'comfy clothing' (P-18). This was not how the informants wanted to present themselves externally and, in particular, it was not suitable for work; this indicates that their social environment dictated adherence to certain norms of dress (as supported by Liu 2019; Badaoui et al. 2018; McNeill 2018; Bartels and Hoogendam 2010) and a sense of belonging within their multiple lifeworld identities.

In this sense, fashion depicts occupation. Those who worked in law or for the government felt that their attire related to their position and chose more formal wear. There was a sense of competing with, whilst also being influenced by, others in the workplace. From a similar perspective, it was important that the children were smart for school and wore the required uniform as this was a visible statement about complying with the school values, and that the children were cared for in the hope that 
this would increase the care that their children received in school. Another important aspect of looking good in the external world was a sense of still being part of society, reflecting current fashion trends provided a sense of relevance and keeping up with societal conformity. For example, many stopped purchasing fashion whilst they were pregnant, but had looked forward to playing with their appearance afterwards. As such, fashion represents participation in an external world that differentiates their internal world. Care for their appearance was evident in their self-preservation, as a reflective counteraction of the self-imposed stay-at-home activities of motherhood (see quotes 4, 5, and 6). In her study of the identity transition of motherhood, Smith (2007) found her participants began to review their lifeworlds five months after the birth. The evidence from the informants indicates this is ongoing as they emerge from their identity revolving around the home to focusing back to themselves when their children required reduced care. As the children became more independent, the informants began to turn their gaze back to themselves and external activities, often reinvesting in their career, such as increasing their working hours or seeking promotion. This reflects that fashion is also used for self-worth, as well as self-care and confidence, expanding social identity theory to be related to self-preservation and belonging to wider social consideration.

\subsection{Sustainability Ideology}

When evaluating the sustainable fashion labels, there were many positive comments (see quotes 7,8 , and 9). The increase in concern for sustainability led to feelings of belonging to a movement that was gaining traction and adopting sustainability preferences as practiced in other consumption contexts, such as Fairtrade and locally produced and organic food, along with recycling household waste. These behaviours were also influenced by peers, swapping stories about lifeworlds and sharing mothering tips. There was also surprise that fashionable garments in high street stores were produced in ways that were socially responsive. This increased their perception of the garments' value, and despite claiming previously that they had not purchased garments that were produced sustainably, many had purchased garments made from recycled or organic materials, as well as garments that indicated who made the clothes. They reflected back on those purchases, expressing altruism and pride (see quotes 7 and 8 ). These statements forged their moral ideology and were also used as a visual tool to construct self as caring, contributing to esteem by providing altruistic feelings, similar to previous findings (Zabkar and Hosta 2012; Griskevicius et al. 2010; Cervellon et al. 2009; Cherrier 2006; Moisander 2000; Smith 
1999). There was an expressed moral obligation to 'do my bit' that also reflected self-identity and accepting socially responsible practice.

This illuminates upon the transitioning of production and consumption norms as evolving to recognise that everyone plays a role in socially responsible actions. It also contrasts with the narratives around guilt and negative feelings when unable to practice consumption that was suspected to have derived from exploitative practice (see quotes 10,11, and 12). Fast fashion production is bereft of socially responsible practice, with little alternative to negate better provenance. Although consumers can opt for options of voice or exit (Hudson and Hudson 2003), consumption is still necessary especially for food and children's clothes, and the informants' narratives reflect their perception that sustainable production and consumption is a luxury that not everyone can afford (see quote 11). P-20 was an isolated case due to her focus on sustainable produce; however, she was on maternity leave with her entire focus on household provisioning. The other informants juggled work, children, and household management, leaving little time for consumption, never mind tracing production implications. Yet the evidence from quotes 10,11, and 12 as well as wider discourse was that their inability to follow through with socially responsible practice was incongruent with their social identity; it did not align with their knowledge of current affairs and related attitudes, beliefs, practices, and performance. It is here where fashion retailers and brands can encourage and enhance sustainability production processes.

\section{Concluding Comments}

Although this research reports on a narrow cohort, both geographically and demographically, the aim of existential phenomenology is to adopt a focused lens to better understand lived experiences (Thompson et al. 1989). The purpose of such an approach is to 'advance theoretical arguments' (Szmigin et al. 2009, p. 229) by focusing more acutely on specific contexts. Nevertheless, the findings may propose some generalisability to concurrent themes discussed by participants, similar to 'replication logic' found within experiential research (Creswell 2009, p. 193) or 'analytical generalisation' where consumer behaviour can be analysed to develop emerging themes or motivation or barriers (Stenbacka 2001). As Collis and Hussey $(2009$, p. 65) suggest, even a single case can be representative if the analysis 'capture[s] the interactions and characteristics of the phenomenon'. Therefore, it could be assumed that the findings may be applicable to professionally working mothers in Western countries, who will negate similar lifeworlds juxtaposed with managing work, family, and home, as well as expectations for mothering and professionalism 
that dictate conformity in certain settings. Comparability will come from exposure to similar media discourses around fashion production and sustainability, along with access to multinational fashion retailers alleged of exploitation (of both the environment and workers) in Western cities.

Consequently, this research contributes to wider debates around how to encourage consumers to engage with responsible consumption and production. Previous research has examined ethical/sustainable fashion behaviours and found there is a reluctance to sacrifice style when they are uncertain of how fashion production compromises social responsibility (Wiederhold and Martinez 2018; Ritch and Brownlie 2016a, 2016b; McNeil and Moore 2015). This contrasts with other consumption behaviours that respond to preferences to assume social responsibility practice (Ritch 2015; Joy et al. 2012; Niinimäki 2010), using production as a means to create value, such as Fairtrade, information on workers in the supply (Fashion Revolutions 'Who made my clothes?' campaign) and responsible disposal (that would help close the loop of the production and consumption cycle). As fashion marketing focuses on pro-self attributes that enhance identity, esteem, status, and belonging (Hudson and Hudson 2003), it is unsurprising that little consideration is given to pro-social attributes; rather, production and supply chain management are hidden behind a veil of mystery (Hudson and Hudson 2003). The chapter sought to consider if fashion identity and socially responsive practice can be aligned, and through adopting the theoretical lens of social identity, found that sustainable consideration emerges within social environments (Bartels and Hoogendam 2010), social categories (Tajfel and Turner 1979) and social identity groups (Liu 2019; Badaoui et al. 2018; McNeill 2018) with expected practices and performances (Liu 2019) that include an awareness of social issues (Kriwy and Mecking 2012) and efforts for social responsibility.

However, this research also illustrates that this cohort of professionally working mothers, who already an experience identity crisis with body and lifestyle change, are reluctant to further sacrifice the infrequent opportunities they have for self-preservation. That does not mean to say that they do not experience tension between the choice of looking good and feeling good (Wiederhold and Martinez 2018; Ritch and Brownlie 2016a; McNeil and Moore 2015). Tensions are indicative of wider protest, where consumers are clearly articulating their concern that governments and businesses are not doing enough to address socially responsible practice (Agerholm 2019; Seigle 2019; Read 2019; Wilson-Powell 2019). Consequently, consumers have to navigate a marketplace where there are few alternatives to deviate from production and consumption norms due to the prevalence of mainstream fashion retails and brands' continuation to focus on reducing production costs. The oxymoron 
of sustainable fashion (Black 2008) is perpetrated by the abstraction (Lyon 2006) and ambiguity of both fashion production (Ritch and Brownlie 2016a) and the consequences of continuing to ignore the effects of irresponsible practice. All of this indicates that consumers require education and support from fashion retailers and brands to determine how fashion production compromises socially responsible behaviours. Fashion retailers and brands could do more to present socially responsible practice that creates value through repositioning educational marketing that addresses the issues and providing information on responsive production. By introducing transparency of production through marketing, such as 'Who made my clothes', to provide information of the workers lifeworld's, and closing the loop of production and consumption, as evident in garments made from recycled materials, there is an opportunity to increase feelings of self-esteem and altruism (Moisander 2000; Stryker and Burke 2000). This could be promoted through videos on websites that provide an insight into supply chain management and harnessing mainstream media programmes, such as the BBC documentary 'Fashion's Dirty Secrets'.

Acknowledging concerns would go a long way to address the elephant in the room-because consumers are increasingly aware of production allegations and experience guilt in contributing through their consumption (Wiederhold and Martinez 2018; Ritch and Brownlie 2016a; McNeil and Moore 2015). Given the evidence from previous research that has identified consumers experiencing altruistic feelings from socially responsible consumption (Zabkar and Hosta 2012; Griskevicius et al. 2010; Cervellon et al. 2009; Cherrier 2006; Moisander 2000; Smith 1999); blending looking good with feeling good could emerge from knowing that fashion consumption has contributed to social and economically responsive practice. Given the momentum of expressing concern, it could be argued that it is somewhat fashionable to demand social responsibility from government and business. Surprisingly, the fashion industry has stagnated in being responsive to this new trend (Safi and Rushe 2018; Centre for Sustainable Fashion 2009; Hearson 2008), evident in the span of literature accessed for this chapter. Moreover, given both the alarm around the consequences of climate change and lack of recovery from the global economic crisis from over a decade ago (Elliott 2019; Carrington 2019), this presents a timely opportunity to consider value chains within production to transition into mainstream consciousness for socially responsible production and consumption. It is unsurprising that younger people are protesting, especially as they are responsible for addressing the impact of the economy and climate change (Read 2019; Wilson-Powell 2019); younger people are already disenfranchised with employment security, the stagnation of salaries and an inability to get on the housing market (MacDonald and Giazitzoglu 2019). This potentially 
could make them more discerning in holding businesses to account. Therefore, as King advocates, it is clear that more intelligent thinking is required to progress a socially responsible and responsive economy (Elliott 2019). This would involve a shift in fashion-related values from focusing on pro-self attributes to including pro-social contributions that enhance the social capital of fashion practice (Ritch and Brownlie 2016a; Niinimäki 2010; Moisander 2000).

Author Contributions: This chapter was authored solely by E.L.R., including the conceptualisation, literature reviewed, theoretical development, methodological design, data collection, analysis, writing and editing the draft, project administration.

Funding: This research was funded through a PhD scholarship from Queen Margaret University.

Conflicts of Interest: The author declares no conflicts of interest.

\section{References}

Abraham, Tamara. 2019. Missguided's £1 Bikini Is Deeply Problematic, It's Time for the Government to Step in on Fast Fashion. The Telegraph. Available online: https://www.telegraph.co.uk/fashion/brands/missguideds-1-bikini-deeplyproblematic-time-government-step/ (accessed on 9 July 2019).

Agerholm, Harriet. 2019. Fast fashion: Should we change how we think about clothes? BBC News. Available online: https://www.bbc.co.uk/news/uk-48682493 (accessed on 9 July 2019).

Anand, Sahiba, and Harsandaldeep Kaur. 2017. Fashion self-congruity: scale development and validation. Journal of Fashion Marketing and Management 22: 158-75. [CrossRef]

Anderson, Stephanie, Kathy Hamilton, and Andrea Tonner. 2016. Social labour: Exploring work in consumption. Marketing Theory 16: 383-400. [CrossRef]

Atkinson, Lucy. 2014. Green moms: the social construction of a green mothering identity via environmentally advertising appeals. Consumption Markets $\mathcal{E}$ Culture 17: 553-72.

Badaoui, Khafid, Anne-Marie Lebrun, Che-Jen Su, and Patrick Biuchet. 2018. The influence of personal and social identity on the clothing consumption of adolescents. Canadian Journal of Administrative Sciences 35: 65-78. [CrossRef]

Bartels, Jos, and Karen Hoogendam. 2010. The role of social identity and attitudes toward sustainability brands in buying behavior for organic product. Journal of Brand Management 18: 697-708. [CrossRef]

Belk, Russell W. 1988. Possessions and the extended self. Journal of Consumer Research 15: 139-68. [CrossRef]

Bettany, Shona, Susan Dobscha, Lisa O'Malley, and Andrea Prothero. 2010. Moving beyond binary opposition: Exploring the tapestry of gender in consumer research and marketing. Marketing Theory 10: 3-28. [CrossRef]

Black, Sandy. 2008. Eco-Chic. The Fashion Paradox. London: Black Dog. 
Bray, Jeffery, Nick Johns, and David Kilburn. 2011. An exploratory study into the factors impeding ethical consumption. Journal of Business Ethics 98: 597608. [CrossRef]

Cairns, Kate, Josée Johnston, and Norah MacKendrick. 2013. Feeding the 'organic child': Mothering through ethical consumption. Journal of Consumer Culture 13: 97-118. [CrossRef]

Cappellini, Bernadetta, and Dorothy Ai-wan Yen. 2016. A space of one's own: spatial and identity in an online community of mothers. Journal of Marketing Management 32: 1260-83. [CrossRef]

Carbon Brief. 2019. Mapped: How Climate Change Affects Extreme Weather around the World. Carbon Brief. Available online: https://www.carbonbrief.org/mapped-how-climatechange-affects-extreme-weather-around-the-world (accessed on 18 October 2019).

Carrigan, Marylyn, and Isabelle Szmigin. 2006. Mothers of invention": maternal empowerment and convenience consumption. European Journal of Marketing 40: 1122-42. [CrossRef]

Carrington, Damien. 2019. Firms Ignoring Climate Crisis Will Go Bankrupt, Says Mark Carney. The Guardian. Available online: https://www.theguardian.com/environment/2019/oct/13/ firms-ignoring-climate-crisis-bankrupt-mark-carney-bank-england-governor (accessed on 21 October 2019).

Carrington, Michal J., Benjamin A. Neville, and Gregory J. Whitwell. 2010. Why ethical consumers don't walk their talk: Towards a framework for understanding the gap between the ethical purchase intentions and actual buying behaviour of ethically minded consumers. Journal of Business Ethics 97: 139-58. [CrossRef]

Centre for Sustainable Fashion. 2009. Tactics for Change. London College of Fashion. Available online: http://www.sustainable-fashion.com/wp-content/uploads/2009/09/ CSF\%20Volume\%203_Tactics\%20for\%20Change.pdf (accessed on 28 June 2010).

Cervellon, Marie-Cécile, Helena Hjerth, Sandrine Ricard, and Lindsey Carey. 2009. Green in fashion? An exploratory study of national differences in consumers concern for eco-fashion. Paper presented at Ethical Design Conference, Cattolica, Italy, May 7-8.

Cherrier, Helene. 2006. Consumer identity and moral obligations in non-plastic bag consumption: a dialectical perspective. International Journal of Consumer Studies 30: 515-23. [CrossRef]

Collis, Jill, and Roger Hussey. 2009. Business Research. A practical Guide for Undergraduates and Postgraduate Students, 3rd ed. London: Palgrave MacMillan.

Connolly, John, and Andrea Prothero. 2003. Sustainable consumption: Consumption, consumers and the commodity discourse. Consumption, Markets and Culture 6: 275-91. [CrossRef]

Creswell, John W. 2009. Research Design. Qualitative, Quantitative and Mixed Methods Approaches, 3rd ed. Thousand Oaks: Sage. 
D'Souza, Clare, Mehdi Taghian, Peter Lamb, and Roman Peretiako. 2007. Green decisions: demographics and consumer understanding of environmental labels. International Journal of Consumer Studies 31: 371-76. [CrossRef]

Díaz-Meneses, Gonzalo. 2010. The ethics of consumer involvement with fashion: A freedom under social pressure. Textile Research Journal 80: 354-64. [CrossRef]

do Paço, Arminda M. F., and Mário L. B. Raposo. 2010. Green consumer market segmentation: empirical findings from Portugal. International Journal of Consumer Studies 34: 429-36. [CrossRef]

Elliott, Larry. 2019. World economy is sleepwalking into a new financial crisis, warns Mervyn King. The Guardian. Available online: https://www.theguardian.com/business/2019/oct/ 20/world-sleepwalking-to-another-financial-crisis-says-mervyn-king (accessed on 21 October 2019).

Giddens, Anthony. 1991. Modernity and Self-Identity. Self and Society in the Late Modern Age. Stanford: Stanford University Press.

Goldsmith, Ronald E., and Ronald A. Clark. 2008. An analysis of factors affecting fashion leadership and fashion opinion seeking. Journal of Fashion Marketing and Management 12: 308-22. [CrossRef]

Griskevicius, Vladas, Joshua M. Tybur, and Bram Van den Bergh. 2010. Going green to be seen: Status, reputation, and conspicuous conservation. Journal of Personality and Social Psychology 98: 392-404. [CrossRef]

Guillard, Valérie. 2018. Anticonsumption Consciousness in Pursuit of Sustainability. Journal of Public Policy \& Marketing 37: 274-90.

Hearson, Martin. 2008. Let's Clean up Fashion. 2008 Update. Company profiles. Labour Behind the Label [Online]. Available online: www.cleanupfashion.co.uk (accessed on 15 November 2009).

Howard, Brian C., Sarah Gibbens, Elaina Zachos, and Laura Parker. 2019. A running list of action on plastic pollution. National Geographic. Available online: https:// www.nationalgeographic.com/environment/2018/07/ocean-plastic-pollution-solutions/ (accessed on 7 October 2019).

Hudson, Ian, and Mark Hudson. 2003. Removing the Veil? Commodity Fetishism, Fair Trade, and the Environment. Organiztion Development 16: 413-30.

Joy, Annamma, John F. Sherry Jr., Alladi Venkatesh, Jeff Wang, and Ricky Chan. 2012. Fast fashion, sustainability and the ethical appeal of luxury brands. Fashion Theory 18: 273-96. [CrossRef]

Kriwy, Peter, and Rebecca-Ariane Mecking. 2012. Health and environmental consciousness, costs of behaviour and the purchase of organic food. International Journal of Consumer Studies 36: 30-37. [CrossRef]

Liu, Chihling. 2019. Men and their groomed body. European Journal of Marketing 53: 1015-34. [CrossRef] 
Lyon, Sarah. 2006. Evaluating fair trade consumption: Politics, defetishisation and producer participation. International Journal of Consumer Studies 30: 452-64. [CrossRef]

Lyon, Kate. 2019. Climate crisis already causing deaths and childhood stunting, report reveals. The Guardian. Available online: https://www.theguardian.com/environment/2019/jul/31/ climate-crisis-already-causing-deaths-and-childhood-stunting-report-reveals (accessed on 21 October 2019).

MacDonald, Robert, and Andeas Giazitzoglu. 2019. Youth, enterprise, and precarity: or, what is, and what is wrong with, the 'gig economy'? Journal of Sociology. Forthcoming. [CrossRef]

McGoldrick, Peter J., and Oliver M. Freestone. 2008. Ethical product premiums: antecedents and extent of consumers' willingness to pay. International Review of Retail, Distribution and Consumer Research 18: 185-201. [CrossRef]

McNeill, Lisa. 2018. Fashion and women's self-concept: A typology for self-fashioning using clothing. Journal of Fashion Marketing and Management 22: 82-98. [CrossRef]

McNeil, Lisa, and Rebecca Moore. 2015. Sustainable-Fashion Consumption and the Fast Fashion Conundrum: fashionable consumers and attitudes to sustainability in clothing choice. International Journal of Consumer Studies 39: 212-22. [CrossRef]

Moisander, Joanne. 2000. Group Identity, Personal Ethics and Sustainable Development: suggesting new directions for social marketing Research. In Society, Behaviour, and Climate Change Mitigation. Edited by Eberhard Jochem, Jayant A. Sathaye and Daniel Bouille. Dordrecht: Kluwer Academic Publisher, pp. 127-56.

Nash, Jill. 2019. Exploring how social media platforms influence fashion consumer decisions in the UK retail sector. Journal of Fashion Marketing and Management 23: 82-103. [CrossRef]

Niinimäki, Kirsi. 2010. Eco-clothing, consumer identity and ideology. Sustainable Development 18: 150-62. [CrossRef]

O'Guinn, Thomas C., and Ronald J. Faber. 1989. Compulsive buying: A phenomenological exploration. Journal of Consumer Research 16: 147-57.

Pink, Sarah. 2005. Doing Visual Ethnography, 2nd ed. London: Sage.

Prothero, Andrea, and James A. Fitchett. 2000. Greening capitalism: Opportunities for a green commodity. Journal of Macromarketing 20: 46-55. [CrossRef]

Read, Bridget. 2019. Climate Change Protests Disrupt London Fashion Week. Vogue. Available online: https:/www.vogue.co.uk/article/climate-change-protests-disruptlondon-fashion-week (accessed on 4 October 2019).

Richins, Marsha L. 1999. Possessions, materialism, and other-directedness in the expression of self. In Consumer Value A Framework for Analysis and Research. Edited by Morris B Holbrook. London: Routledge, pp. 85-105.

Ritch, Elaine L. 2015. Consumers interpreting sustainability: Moving beyond food to fashion. International Journal of Retail and Distribution Management 43: 1162-81. [CrossRef] 
Ritch, Elaine L. 2016. Fashion brand management: Fashioning value through CSR. In Handbook of Research on Global Fashion Management and Merchandising. Edited by Alessandra Vecchi and Chitra Buckley. Hershey: IGI Global, pp. 560-91.

Ritch, Elaine L. 2019. 'From a Mother to Another': creative post-consumption experiences of used children's clothing underpinned by sustainability. Journal of Marketing Management 25: 770-94. [CrossRef]

Ritch, Elaine L., and Douglas Brownlie. 2016a. Everyday dramas of conscience: Navigating identity through creative neutralisation. Journal of Marketing Management 32: 1012-32. [CrossRef]

Ritch, Elaine L., and Douglas Brownlie. 2016b. Doing it for the kids: the role of sustainability in family consumption. International Journal of Retail and Distribution Management 44: 1100-17. [CrossRef]

Rivoli, Pietra. 2009. The Travels of a T Shirt in the Global Economy. An Economist Examines the Markets, Power, and Politics of World Trade, 2nd ed. Hoboken: John Wiley \& Sons.

Rudawska, Edyta, Renko Sanda, and Bilan Yuriy. 2013. Sustainable development: concept, interest groups, benefits and global challenges. International Journal of Academic Research 5: 83-86. [CrossRef]

Safi, Michael, and Dominic Rushe. 2018. Rana Plaza, five years on: Safety of workers hangs in balance in Bangladesh. The Guardian. Available online: https://www.theguardian.com/global-development/2018/apr/24/bangladeshi-policetarget-garment-workers-union-rana-plaza-five-years-on (accessed on 21 October 2019).

Seigle, Lucy. 2019. Fast fashion is on the rampage, with the UK at the head of the charge. The Guardian. Available online: https://www.theguardian.com/fashion/2019/jun/21/fastfashion-is-on-the-rampage-with-uk-at-the-head-of-the-charge (accessed on 9 July 2019).

Smith, N. Craig. 1999. Ethics and the typology of consumer value. In Consumer Value: A Framework for Analysis and Research. Edited by Morris B. Holbrook. London: Routledge, pp. 147-58.

Smith, Jonathan A. 2007. Identity development during the transition to motherhood: An interpretative phenomenological analysis. Journal of Reproductive and Infant Psychology 17: 281-99. [CrossRef]

Smith, Jonathon A., Paul Flowers, and Michale Larkin. 2009. Interpretive Phenomenological Analysis: Theory, Method and Research. London: Sage.

Stenbacka, Caroline. 2001. Qualitative research requires quality concepts of its own. Management Decision 39: 551-55. [CrossRef]

Stern, Nicholas. 2006. Stern Review on the Economics of Climate Change. Office of Climate Change [Online]. Available online: http://webarchive.nationalarchives.gov.uk/+/http: /www.hm-treasury.gov.uk/sternreview_index.htm (accessed on 24 June 2013).

Stryker, Sheldon, and Peter J. Burke. 2000. The Past, Present, and Future of an Identity Theory. Social Psychology Quarterly 63: 284-97. [CrossRef] 
Szmigin, Isabelle, Marylyn Carrigan, and Morven G. McEachern. 2009. The conscious consumer: Taking a flexible approach to ethical behaviour. International Journal of Consumer Studies 33: 224-31. [CrossRef]

Tajfel, Henri, and John C. Turner. 1979. An integrative theory of intergroup conflict. In Organisational Identity. Edited by Mary Jo Hatch and Majken Schultz. Oxford: Oxford University Press, pp. 56-65.

Thompson, Craig J., William B. Locander, and Howard R. Pollio. 1989. Putting consumer experience back into consumer research: The philosophy of existential phenomenology. Journal of Consumer Research. 16: 133-46. [CrossRef]

United Nations. 2019a. UN Launches Drive to Highlight Environmental Cost of Staying Fashionable. Available online: https://news.un.org/en/story/2019/03/1035161 (accessed on 3 June 2020).

United Nations. 2019b. Only 11 Years Left to Prevent Irreversible Damage from Climate Change, Speakers Warn during General Assembly High-Level Meeting. Available online: https://www.un.org/press/en/2019/ga12131.doc.htm (accessed on 4 October 2019).

United Nations. 2020. About the Sustainable Development Goals. United Nations. Available online: https://www.un.org/sustainabledevelopment/sustainable-development-goals/ (accessed on 3 June 2020).

Wiederhold, Marie, and Luis F. Martinez. 2018. Ethical Consumer Behaviour in Germany: The attitude-behaviour gap in the green apparel industry. International Journal of Consumer Studies 42: 419-29. [CrossRef]

Wilson-Powell, Georgina. 2019. If You Think Individuals' Actions Can't Solve Our Environmental Crisis, You're Wrong-Here's Why. The Independent. Available online: https://www.independent.co.uk/voices/climate-change-student-strikesenvironment-consumerism-sustainability-schoolchildren-a8816651.html (accessed on 4 October 2019).

World Commission on Economic Development. 1987. Our Common Future. Oxford: Oxford University Press.

Zabkar, Vesna, and Maja Hosta. 2012. Willingness to act and environmentally conscious consumer behaviour: can prosocial status perceptions help overcome the gap? International Journal of Consumer BEHAVIOUR 37: 257-64. [CrossRef]

(C) 2020 by the author. Licensee MDPI, Basel, Switzerland. This article is an open access article distributed under the terms and conditions of the Creative Commons Attribution (CC BY) license (http://creativecommons.org/licenses/by/4.0/). 


\title{
Consumer Choice and Food Waste:
}

\section{A Demand-Side Perspective to Address the Challenge of Sustainable Consumption Models}

\author{
Luca Secondi and Ludovica Principato
}

\section{Introduction}

Food waste (FW) is a global problem whose political and social importance has grown in recent years (Corrado et al. 2019), which is why its reduction has been included within the Sustainable Development Goals of the UN Agenda 2030 in its 12th goal "Ensure sustainable consumption and production patterns" with the aim of halving per capita overall food waste at both retail and consumer levels and of reducing losses of food throughout production and food supply chains (FSCs) including post-harvest losses, by 2030 (UNDP 2016).

Although there is not yet a single methodology to measure it, and the accessible data are different, current estimates indicate that globally about a third of food produced for human consumption is wasted or lost (Gustavsson et al. 2011). Food is a precious commodity and its production requires many resources. The overall cost of FW amounts to about 2.6 trillion US dollars a year if we consider the economic, environmental and social costs associated with it (FAO 2013).

Food losses, meaning the waste that happens in the first phases of the FSC, are mainly an issue in developing countries due to a lack of investments and inadequate infrastructures. Meanwhile, FW, the waste that occurs at the retail and consumption level is a typical problem of western countries and happens as a result of consumer's specific behavioral issues and habits (Gustavsson et al. 2011; Parfitt et al. 2010; Secondi et al. 2015; Principato 2018).

Considering the waste per type of food, the Food and Agriculture Organization (FAO) estimates that, globally, up to $30 \%$ of cereals, $20 \%$ of dairy, $35 \%$ of fish and seafood, $45 \%$ of fruits and vegetables, $20 \%$ of meat, $20 \%$ of oilseeds and pulses, and $45 \%$ of roots and tubers get lost or are wasted along the FSC (Gustavsson et al. 2011). According to research conducted in Italy (Waste Watchers 2017), if we consider the wasted food within the household, we waste $31 \%$ of fruit and $29 \%$ of salad $(29 \%)$, followed by other vegetables $(19 \%)$, bread $(17 \%)$, cold cuts $(16 \%)$, cheese and dairy 
products (respectively $16 \%$ and $14 \%$ ). Scrolling down the list we find yogurt $(12 \%)$, milk $(10 \%)$, cooked pasta $(9 \%)$, cooked meat $(7 \%)$ and raw meat $(6 \%)$. At the end of the list are other foods (like eggs and sauces) (5\%), and desserts (4\%).

In terms of socio-economic status, as acknowledged by Principato (2018), the literature debate is still open. Indeed, if we consider the level of education of individuals, the more educated they are, the higher the quantities of wasted food (Visschers et al. 2016; Secondi et al. 2015). Household composition also plays a role: bigger households tend to waste more than smaller ones (Quested et al. 2013), although it has been seen that the amount of FW per capita decreases as the members of a family increase (Parizeau et al. 2015). In any case, it has been seen that families with children tend to waste more than all-adult households of the same size because of picky eating and food safety (Quested and Luzecka 2014). Considering gender, some researches showed that females waste more than males (Visschers et al. 2016); however, a number of other studies revealed that men waste more than women (Gallo 1980; Buzby and Guthrie 2002). In terms of income, most of the findings suggest that higher-income households waste more than those with lower-incomes (Buzby and Guthrie 2002; Van Garde and Woodburn 1987; Osner 1982; Koivupuro et al. 2012; Stefan et al. 2013). On the other hand, some demonstrated the opposite (Stefan et al. 2013; Cox and Downing 2007; Thi Thuy Trang et al. 2017).

The purpose of this study is to investigate-from the demand side-consumers' choice in terms of wasted (edible and not consumed) food at the domestic level. Through data collected on a sample of consumers in Italy, this research aims to: (i) analyze types of food most wasted at the household level, according to socio-economic characteristics of families; and (ii) evaluate, by means of the Working-Leser (WL) demand equation models, if and to what extent propensity and responsiveness to wasted food vary according to both weekly expenditure for food and household living standards as measured by total annual household income.

To our knowledge, studying the connection between FW generation and demand elasticity represents a new and original approach for addressing consumer behavior towards FW. The results obtained provide new data on food purchasing behavior and the FW phenomenon at the consumer level, thus a novel contribution to ensuring sustainable consumption patterns.

The remainder of the chapter is structured as follows: Section 2 describes the data collection process and the methodological approach used for the estimation of consumers' elasticity towards FW. Section 3 reports the obtained results both in terms of descriptive analysis and estimated elasticity. Section 4 provides a discussion 
starting from the results obtained by highlighting the possible contributions of this study to the literature and to the possible uses by policy makers. In the same section, some concluding remarks are drawn by focusing on further development of the research.

\section{Materials and Methods}

\subsection{The Data Collection Process}

In order to obtain information on the FW produced and, specifically, on the categories of food (types of food) wasted by households, as well as their distribution in the overall generated FW, an ad-hoc questionnaire was implemented and structured with the following six sections: (i) knowledge of the phenomenon of FW in terms of dissemination and awareness of the economic, social and environmental impacts of FW (questions with a Likert response scale); (ii) behavior and purchasing habits in terms of the overall weekly food expenditure, frequency, and type of distribution channel generally chosen for the purchase of food; (iii) FW behavior and habits in terms of distribution among different categories of food, meal planning, methods for reducing waste, and reasons for which FW is generated in the family; (iv) awareness of FW behaviors by means of a set of questions regarding, for example, the influence of the aesthetic aspect of food or the offers and disposition of food in supermarkets on the family; (v) preventive actions that would reduce food waste, such as, for example, greater awareness of the meanings of product labels or availability in stores of packages with less food (set of questions with Likert-type answer); (vi) socio-demographic characteristics of the head of household responsible for purchases (specifically her/his gender, age, level of education, marital status, and residence) as well as her/his family characteristics in terms of overall economic situation (household living standard as measured by the declared total annual income), number of family members and presence of children within the nucleus.

The core questions of the questionnaire, contained in Section 3-and on which the analyses reported below are based-focus on the distribution of FW (in percentages) among the following categories of food: (i) pasta, rice and cereals; (ii) meat and cured meat; (iii) vegetables and legumes; (iv) fruit; (v) bread and pizza; (vi) cheese and eggs; (vii) fish and derived products; (viii) milk, yogurt and other dairy products; (ix): sauces and condiments; $(x)$ sweets and desserts.

The data were collected in the period October 2017-January 2018 from a sample of respondents located mainly in the Lazio and Tuscany regions. The adopted sampling scheme started with the voluntary participation of university students 
who were asked to involve their families in the filling out of the questionnaire and, specifically, to involve the family member responsible for food purchases.

Once they agreed, the questionnaire could be accessed through a Web Based Survey (WBS) system characterized by a self-administration of the responses by the participants. By adopting this procedure, we obtained answers from 268 families (as represented by the household member responsible for food purchase) whose controlled and validated responses were considered for the descriptive analyses and statistical modeling reported in the following sections.

\subsection{The Demand Modeling Estimation Approach}

The empirical model applied to study the propensity of consumers towards FW and, therefore, their responsiveness to FW with regards to both total food expenditure and household living standards is the WL model, introduced by Working (Working 1943) and Leser (Leser 1963) and further developed by Deaton and Muellbauer (Deaton and Muellbauer 1980a, 1980b), as presented in the general Equation (1). This model was used to estimate the food waste expenditure elasticity (hereon FWE2) with reference to the 10 categories of food presented in the previous section.

The basic equation of the WL model is presented in a log-linear form in which the share of waste of each food product is a linear function of the logarithm of prices and the logarithm of total weekly expenditure of all the foods considered. In our study, the socio-demographic characteristics of households were also considered as control factors. Therefore, the single estimated equation can be expressed as:

$$
w_{\text {in }}=\alpha_{0 i}+\alpha_{i} \log x_{n}+\beta_{i} \log p_{i}+\sum_{j \neq i} \beta_{j} \log p_{j}+\sum_{k} \gamma_{k j} H_{k n}+\varepsilon_{i n}
$$

where $i(i=1, \ldots 10)$ represents the index of the product category considered for the estimation, while $n(n=1, \ldots 268)$ refers to the $n$-th family considered. In Equation (1) $w_{\text {in }}$ represents the share of FW generated for the i-th product category by the $n$-th family, $x_{n}$ represents the average weekly expenditure for food, while $p_{i}$ represents the price of the products of the $i$-th studied category and $p_{j}$ the prices of the other products (for $i \neq j)$. Furthermore, $\mathrm{H}_{\mathrm{kn}}$ represents the $k$-th $(k=1, \ldots K)$ socio-demographic characteristic of the $n$-th family introduced as a control factor in the estimated regression models. Lastly, $\varepsilon_{\text {in }}$ is the error component of the model.

As underlined by Landry and Smith (2019) who used the WL specification for the overall estimation of FW elasticity in the context of the Household Food Consumption Survey for US households, the advantage of the WL specification is that it suits utility-maximization with the assumption of constant returns to scale 
and separability, and that it is possible to calculate expenditure elasticity consistent with consumer theory.

It is worth noting that the WL specification in its log-linear form does not give a direct interpretation of expenditure elasticity. Therefore, the FW expenditure elasticity (FWE2) for the i-th product category can be obtained from the parameter estimates as:

$$
\mathrm{FWE} 2_{i}=1+\left(\frac{\alpha_{i}}{w_{i}}\right)
$$

whose computed value according to whether it is less than, equal to, or greater than 1 , can provide indications of the lower or higher sensitivity of consumers to FW as their weekly food expenditure increases. In this sense, values of FWE2 less than (or greater than) the unit-which, in the classic consumer microeconomic approach, provide references for necessary goods or luxury goods-provide information on the speed with which FW grows with overall increasing expenditure on food. Therefore, it provides evidence of less or more tendency to throw away food when food expenditure increases.

In estimating the equations reported in the general form in Equation (1), the different household living standards of the respondents were taken into account by considering the estimate of two separate sets of equations based on the answers provided by the participants in the survey regarding total annual family income. Since the questionnaire includes information about classes of total annual income, the median category (total family income between 15 and 25 thousand Euros) was considered to have two subgroups of households-defined as households with a low-medium level of income and household with a high level of income-by which to investigate the propensity and tendencies towards FW.

With reference to the variables considered, food expenditure $\left(x_{i}\right)$ refers to the average household expenditure incurred weekly for the purchase of food. Considering the price vector $\mathbf{p}(i=1, \ldots 10)$ we referred to the average published prices of the various categories of products by the Price Observatory of the Italian Ministry of Economic Development and referred to the month during which the interview was conducted.

As regards the socio-economic characteristics considered, the following variables were introduced in the WL specification: head of the family gender, age, marital status, and educational qualification, as well as information about the nuclear family in terms of number of family members, presence of children, and residence area (also by distinguishing between rural and urban areas). 


\section{Results}

\subsection{A Descriptive Analysis: Respondents and Their Purchase Habits}

The sample of respondents was composed of 268 individuals, aged between 18 and 69 with family compositions ranging from one to seven people. It emerged that the task of food supply is carried out by majority women $(81 \%)$, and the remaining part by men $(19 \%)$. A total of $80.96 \%$ of individuals were domiciled in the Lazio region while $19.04 \%$ of respondents resided in Tuscany.

The average weekly expenditure for the purchase of food incurred by households was approximately EUR 98.77 (standard deviation equal to 66.55), with empirical quartiles observed at $\mathrm{Q}_{1}=50, \mathrm{Q}_{2}=85$ and $\mathrm{Q}_{3}=125$ Euros.

The supermarket was the most cited place to purchase food ( 222 responses out of 268 respondents equal to a percentage value of $82.84 \%$ ). Indeed, respondents were asked to indicate the two places their family generally makes food purchases and the second most frequently cited purchase location was a small retail store (117 out of 268 respondents, corresponding to 43.66\%). Discount (69 respondents) and hypermarkets (56 respondents with a total incidence percentage of $20.9 \%$ of respondents) followed, as reported in Figure 1. It should be noted that the percentages in Figure 1 do not sum 100 because respondents could choose at most two places where food shopping was carried out. Therefore, for each place of purchase, the percentage indicates the proportion of individuals that used this channel independently to the preference order and to the total number of places selected.

Regarding the frequency of purchases, "two/three times per week" was the modal category observed for the respondents (approximately 51.1\%) followed by "once a week" (26.5\%), while 18.9\% declared to purchase food "every day".

Regarding the FW generated, about $88 \%$ of the sample claimed to throw away less than $15 \%$ of food purchased and not consumed weekly, while only $1.5 \%$ threw out more than $30 \%$ of food weekly.

\subsection{FW by Categories, the WL Model Estimation and the Obtained FWE2}

The three most wasted types of food (referring to the specific food category) were fruit (18.15\%), vegetables and legumes (16.54\%) and bread and pizza (16.38\%), as shown in Figure 2, thus confirming the ranking published by the Waste Watcher (Lmm/Swg) observatory regarding to the most wasted foods in Italy in 2016. The categories least subject to be wasted were sweets $(3.91 \%)$ and fish $(3.52 \%)$. 


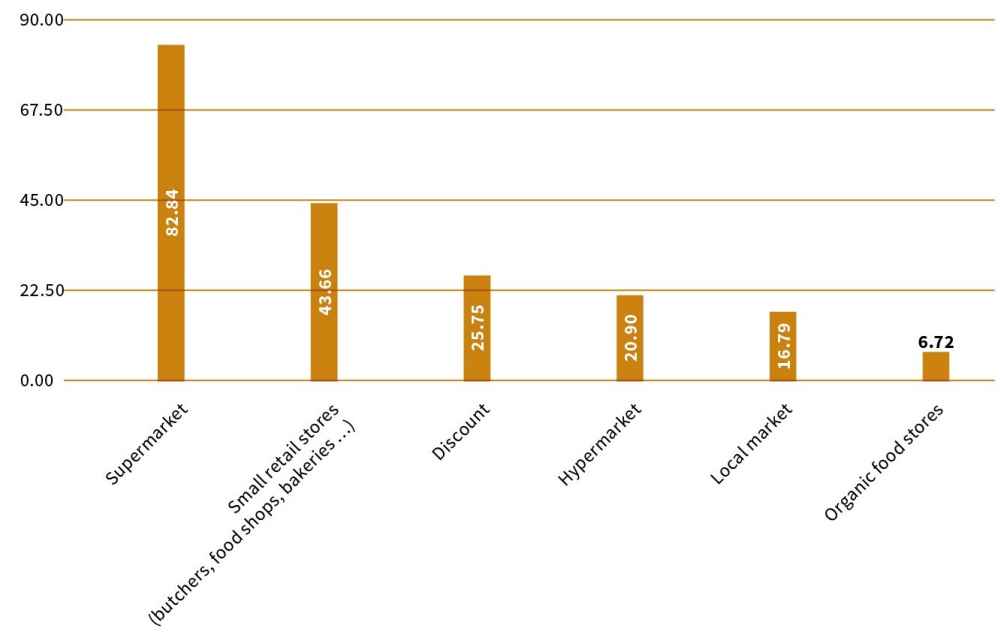

Figure 1. Places where food shopping is usually carried out (note: multiple choice question). Source: Own illustration.

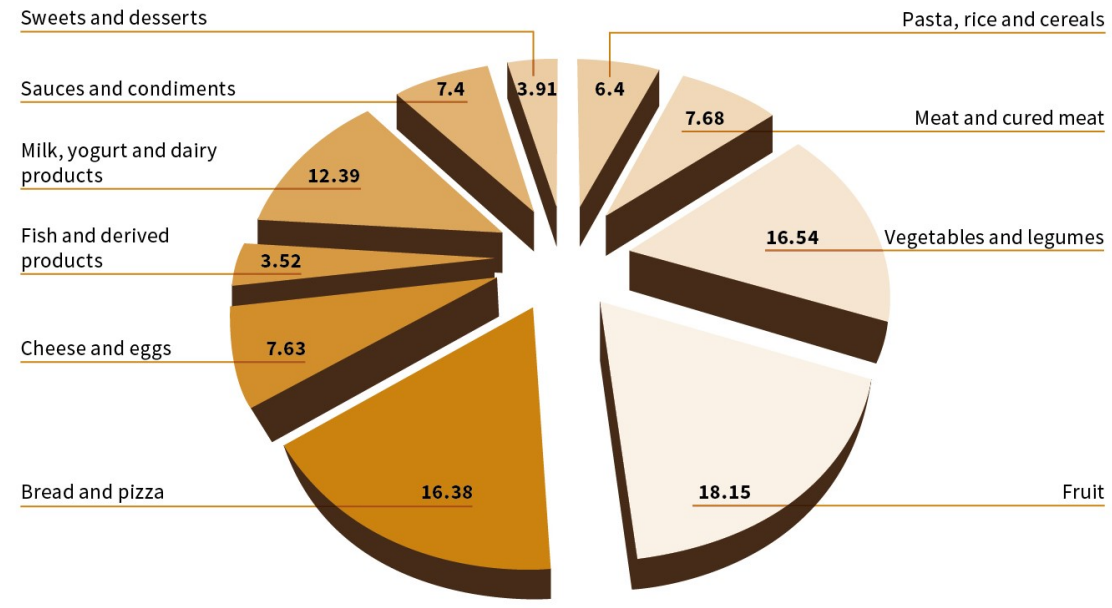

Figure 2. Food waste (FW) distribution across the 10 studied categories. Source: Own illustration.

On the other hand, Figure 3 shows, for each food category, the empirical overall distribution of responses thus highlighting both the range (in terms of minimum 
and maximum observed values) and the mid-range variability as measured by the dispersion between first and third quartiles.

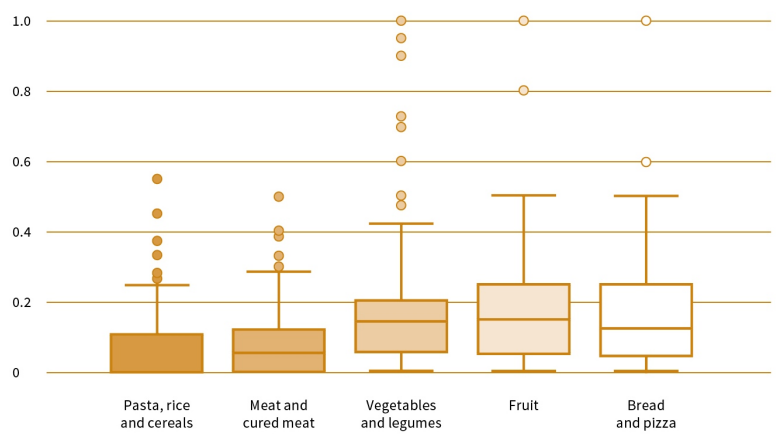

(a)

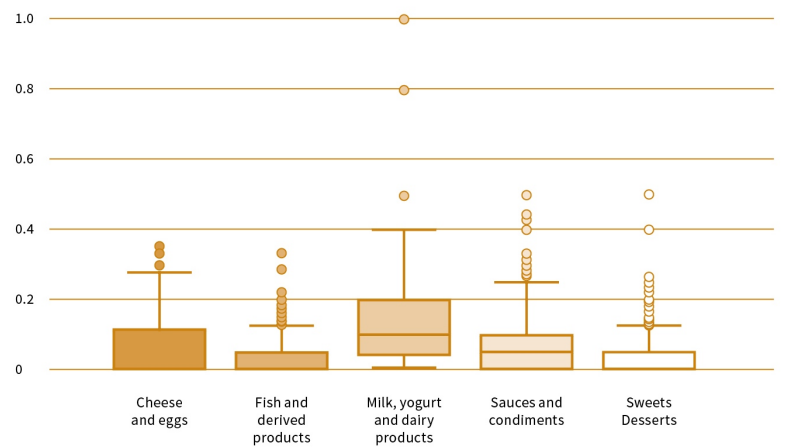

(b)

Figure 3. Box-plot of FW per food category: (a) pasta, rice and cereals; meat and cured meat; vegetables and legumes; fruit; bread and pizza; (b): cheese and eggs; fish and derived products; milk, yogurt and dairy products; sauce and condiments; sweets and desserts. Source: Own illustration.

In order to understand any differences in the propensity to waste food according to the total expenditure and households' standard of living, we estimated the WL model by distinguishing families according to the median household income declared in the interview. Aware of the bias that a declared income could generate, the goal was to understand if and to what extent there were differences in the propensity to waste between households whose income was less than 25 thousand Euros (this category represents the median category based on respondents) and households with an annual income of 25 thousand Euros or more. 
We estimated two different subsets of FW share equations based on the specification proposed in Equation (1). Figure 4 shows the values of the FWE2 for the two groups of families and highlighted a cut-off of 1 , which distinguishes the level of growth of FW as less proportional (if the elasticity is less than 1) or more than proportional (if the elasticity is greater than 1) as the overall weekly spending increases.

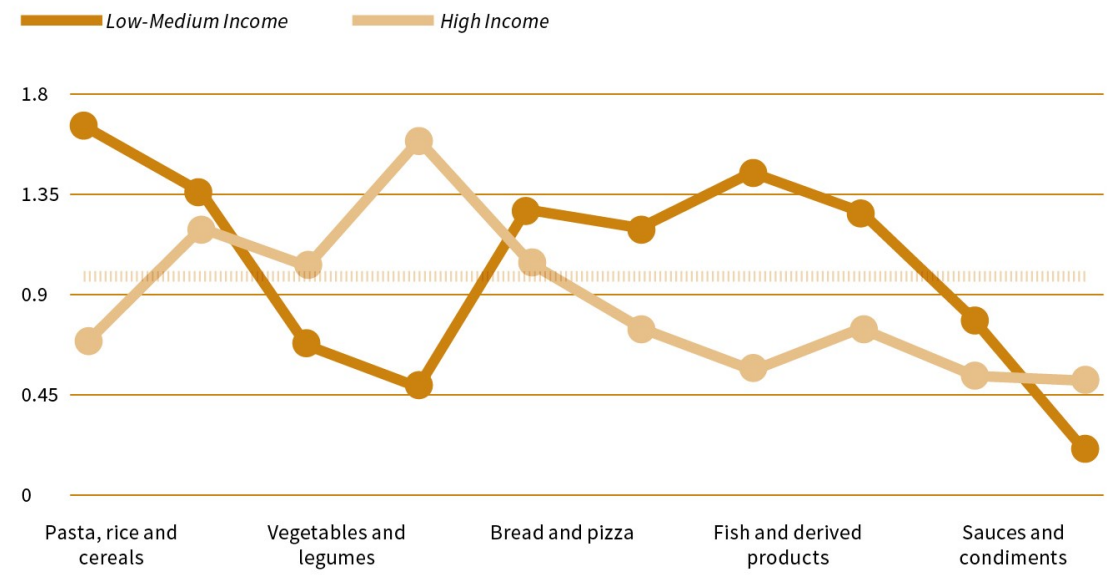

Figure 4. Food waste expenditure elasticity (FWE2) for the studied food categories: values of the FW expenditure elasticity distinguished for low-medium and high household incomes (red line equal to 1 for the distinction between necessary and luxury food categories). Source: Own illustration

Table 1 shows the estimates of the parameters (with the related level of statistical significance) used for the computation of FW expenditure elasticity.

The elasticities were computed-according to Equation (2) - by considering the average share of the i-th food category.

As usual in microeconomic theory of elasticities, at first evaluation of the elasticity values it was noted that all estimated elasticities were positive, proving that all the categories of products considered represented "normal goods" towards FW. Therefore, these were categories of products, for which as food expenditure increases the quantity (in percentage) of FW increases. If, on the other hand, we had obtained negative values of FWE2, we would have found ourselves faced with "lower goods", for which as spending increased the amount of FW produced would have decreased (Varian 2002). 
Table 1. Working-Leser parameter and FWE2 estimates.

\begin{tabular}{|c|c|c|c|c|c|c|}
\hline & \multicolumn{3}{|c|}{ LOW-INCOME } & \multicolumn{3}{|c|}{ MEDIUM-HIGH INCOME } \\
\hline & Alpha & $\begin{array}{l}\text { Significanci } \\
\text { Level }\end{array}$ & FWE2 & Alpha & $\begin{array}{l}\text { Significanc } \\
\text { Level }\end{array}$ & FWE2 \\
\hline Pasta, rice and cereals & -0.018 & & 0.711 & 0.043 & $* *$ & 1.647 \\
\hline Meat and cured meat & 0.014 & & 1.197 & 0.030 & $*$ & 1.369 \\
\hline Vegetables and legumes & 0.007 & & 1.038 & -0.047 & * & 0.665 \\
\hline Fruit & 0.103 & $* * *$ & 1.598 & -0.097 & $* * *$ & 0.491 \\
\hline Bread and pizza & 0.008 & & 1.048 & 0.047 & & 1.284 \\
\hline Cheese and eggs & -0.019 & & 0.745 & 0.015 & & 1.200 \\
\hline $\begin{array}{c}\text { Fish and derived } \\
\text { products }\end{array}$ & -0.016 & & 0.583 & 0.014 & & 1.456 \\
\hline $\begin{array}{l}\text { Milk, yogurt and dairy } \\
\text { products }\end{array}$ & -0.025 & & 0.764 & 0.041 & & 1.285 \\
\hline Sauces and condiments & -0.036 & $* *$ & 0.538 & -0.015 & & 0.789 \\
\hline Sweets and desserts & -0.019 & & 0.529 & -0.031 & $* *$ & 0.202 \\
\hline
\end{tabular}

Notes: ${ }^{*} p$-value $<0.10 ;{ }^{* *} p$-value $<0.05 ;{ }^{* *} p$-value $<0.01$. Source: Own data.

For some categories of goods, values of elasticity higher than one were observed. In this sense, for the usual so-called luxury goods, FW increased more than proportionally compared to the increase in food expenditure.

By combining the elasticity values with the relative significance levels, and also by considering the distinction between household living standards (low-medium and high levels of income), we noticed elasticity values higher than the unit for fruit ( $p$-value $<0.01$ ) in the low-income households. Therefore, by an increase of 1 percentage point of food expenditure, the value of FW for fruit increased by 1.5 percentage points. On the contrary, elasticity, statistically significant and lower than 1 , was observed for sauces and condiments ( $p$-value $<0.05)$, meaning that as spending increased there was a tendency to observe a less than proportional increase in the waste of this category of products.

Considering families with medium-high income, we noted values of elasticity higher than the unit for pasta, rice and cereals ( $p$-value $<0.05)$, meat and cured meat ( $p$-value $<0.10$ ) indicating that these foods were considered "luxury goods" and, therefore, their waste increased disproportionately to the expense. On the other hand, FWE2 values lower than unity-which showed a less than proportional growth in FW compared to overall food expenditure-were observed for vegetables and legumes ( $p$-value $<0.10)$, fruit $(p$-value $<0.01)$ and for sweets and dessert $(p$-value $<0.05)$. 


\section{Discussion and Conclusions}

Much has been written about FW at the domestic level in recent years, focusing attention on consumer awareness of the impacts of FW, the causes of FW and the measures to be implemented in order to be able to reduce FW in practice to achieve the 2030 objective set by SDG 12-to halve FW (Corrado et al. 2019; Gustavsson et al. 2011; Secondi et al. 2015; Waste Watchers 2017; Quested et al. 2013; Koivupuro et al. 2012; Mondéjar-Jiménez et al. 2016; Principato et al. 2015; Secondi 2019).

In this study, we attempted to address a new perspective of analysis to understand-given the centrality of the role of FW in the entire production chain (Principato et al. 2019; Secondi et al. 2019a) and the possibilities of FW recovery within a circular economy perspective - the propensity of consumers towards FW and, in particular, to understand if and to what extent this propensity varied for different categories of products and household living standards. To answer this research question, a topic on which literature is right now emerging, we started an exploratory investigation involving a sample of Italian families located mainly in the Lazio region and southern Tuscany. We made an effort to have the person in charge of family purchases be directly involvedin logging the percentage of FW for 10 categories of products (the sum of these categories was required to be $100 \%$ ). The collected data were then analyzed within the perspective of consumer FW demand and in terms of FW expenditure elasticity (for which we introduced the acronym FWE2) which, like the classical elasticity with respect to expenditure (expenditure elasticity) enables analysts and researchers to provide information with greater or lesser proportional growth in FW generation in relation to the expenditure.

In order to highlight behavioral differences, we distinguished the families interviewed on the basis of their standard of living and estimated two separate WL type equations. This allowed us, in the first stage of research, to estimate two separate FWE2s distinguished by level of total household income and, therefore, to obtain a different level of households responsiveness in generating FW, according to the amount spent on food. It is important to emphasize that the computed elasticity reflects the elasticity of producing FW and is not directed towards "consumer goods", as they usually are. This evidence can be the starting point for a deep reflection concerning economic meaning and interpretation.

This first exploratory analysis produced interesting results for the discussion. First of all, for all categories of food we obtained a positive elasticity value, thus confirming these products as normal goods for which FW varies in a positive sense as spending increases. This result is in line with the one recently observed for the 
U.S. by Landry and Smith (2019), where FW was considered for luxury goods with values between 1.1 and 1.4 .

In this regard, and by distinguishing positive values lower (or greater) than unit in order to identify necessary (or luxury) categories of food, we noted the presence of goods considered "luxury food" for a group of families, while necessity goods for others. This is the case, for example, with fruit. In fact, if fruit represents a "luxury food" for the generation of FW for low-medium income families, the waste grows more than proportionally with respect to expenditure. For families with a higher level of income, the wasted food of this category grows less than proportionally. The result obtained must certainly be investigated further, but in our opinion can be related to both the promotional offer, which leads consumers (above all, consumers with a low-medium level of income) to purchase quantities of food (in this case fruit) that they will not be able to consume in time (before their physiological drop) as well as to the importance of linking FW generation with a nutritional balanced and correct diet by consumers. Distinctly, higher income families also buy and consume more fruit but, in their diet—as is the case for the Mediterranean diet, for example-such fruits (and vegetables) are actually consumed and therefore wasted to a lesser extent. As a result, it is also important, at the policy level, to jointly address the issue of food well-being and health, thus helping the dissemination of good food practices (consumption of fruit and vegetables for example) as well as helping low-income families guarantee a balanced diet. from a nutritional point of view, which may require greater economic effort (Benedetti et al. 2018).

From this perspective, the estimates of demand elasticities for commodity groups and household characteristics can help with planned interventions aimed at addressing selected categories of consumers, thus contributing to minimized FW, sustainable consumption models and the ultimate reduction of FW related impacts. In this sense, a method to reduce fruit waste would be to implement targeted consumer educational campaigns on fruit consumption that emphasize the role of fruit in pursuing our health and well-being, and at the same time bring attention to perishability so that clusters, like the low-income population, buy the correct daily amount. For these interventions, digital innovations and applications could be of use (Secondi et al. 2019b) in achieving the desired results more effectively.

Further research must be carried out on the implementation of more flexible demand equation systems (such as the Almost Ideal Demand System) as well as with more structured survey methods (i.e., a larger sample survey on a representative sample of Italian consumers), which would enable academics and, therefore, policy makers to analyze this vital issue with a deeper, more detailed, and targeted approach. 
Author Contributions: Conceptualization, L.S. and L.P.; methodology, L.S.; Software, L.S.; validation, L.S. and L.P.; formal analysis, L.S.; writing-original draft preparation, L.S. and L.P.; writing-review and Editing, L.S. and L.P.; supervision L.S. and L.P. All authors have read and agreed to the published version of the manuscript.

Funding: This research received no external funding.

Acknowledgments: The authors thank C. Allegrini for data collection and first analysis on this issue.

Conflicts of Interest: The authors declare no conflict of interest.

\section{References}

Benedetti, Ilaria, Tiziana Laureti, and Luca Secondi. 2018. Choosing a healthy and sustainable diet: A three-level approach for understanding the drivers of the Italians' dietary regime over time. Appetite 123: 357-66. [CrossRef] [PubMed]

Buzby, Jean C., and Joanne Frances Guthrie. 2002. Plate Waste in School Nutrition Programs. Final Report to Congress; ERS E-FAN-02-009; Washington, DC: USDA.

Corrado, Sara, Carla Caldeira, Mattias Eriksson, Ole Jørgen Hanssen, Hans-Eduard Hauser, Freija van Holsteijn, and Gang Liu. 2019. Food Waste Accounting Methodologies: Challenges, Opportunities, and Further Advancements. Global Food Security 20: 93-100. [CrossRef] [PubMed]

Cox, Jayne, and Phil Downing. 2007. Food Behaviour Consumer Research: Quantitative Phase. Banbury: WRAP.

Deaton, Angus, and John Muellbauer. 1980a. An Almost Ideal Demand System. American Economic Review 70: 312-26.

Deaton, Angus, and John Muellbauer. 1980b. Economics and Consumer Behavior. London: Cambridge University Press.

FAO. 2013. Food Wastage Footprint: Impacts on Natural Resources. Available online: http://www.fao.org/docrep/018/i3347e/i3347e.pdf (accessed on 17 January 2020).

Gallo, Anthony E. 1980. Consumer Food Waste in the U.S. Consumer Research. Food Review/ National Food Review, 13-16. [CrossRef]

Gustavsson, Jenny, Christel Cederbergand, and Ulf Sonesson. 2011. Global Food Losses and Food Waste. Gothenburg: Swedish Institute for Food and Biotechnology (SIK).

Koivupuro, Heta-Kaisa, Hanna Hartikainen, Kirsi Silvennoinen, Juha-Matti Katajajuuri, Noora Heikintalo, Anu Reinikainen, and Lotta Jalkanen. 2012. Influence of socio-demographical, behavioural and attitudinal factors on the amount of avoidable food waste generated in Finnish households. International Journal of Consumer Studies 36: 183-91. [CrossRef]

Landry, Craig E., and Travis A. Smith. 2019. Demand for Household Food Waste. Applied Economic Perspectives and Policy 41: 20-36. [CrossRef] 
Leser, Conrad Emanuel Victor. 1963. Forms of Engel Functions. Econometrica 31: 694-703. [CrossRef]

Mondéjar-Jiménez, Juan Antonio, Guido Ferrari, Luca Secondi, and Ludovica Principato. 2016. From the table to waste: An exploratory study on behaviour towards food waste of Spanish and Italian youths. Journal of Cleaner Production 138: 8-18. [CrossRef]

Osner, Robin. 1982. Food wastage. Nutrition and Food Science 82: 13-16. [CrossRef]

Parfitt, Julian, Mark Barthel, and Sarah Macnaughton. 2010. Food waste within supply chains: Quantification and potential for change to 2050. Philosophical Transactions of the Royal Society B: Biological Sciences 365: 3065-81. [CrossRef]

Parizeau, Kate, Mike von Massow, and Ralph Martin. 2015. Household-level dynamics of food waste production and related beliefs, attitudes, and behaviours in guelph, ontario. Waste Management 35: 207-17. [CrossRef] [PubMed]

Principato, Ludovica. 2018. Food Waste at Consumer Level. A Comprehensive Literature Review. Cham: Springer.

Principato, Ludovica, Luca Secondi, and Carlo Alberto Pratesi. 2015. Reducing food waste: An investigation on the behaviour of Italian youths. British Food Journal 117: 731-48. [CrossRef]

Principato, Ludovica, Luca Ruini, Matteo Guidi, and Luca Secondi L. 2019. Adopting the circular economy approach on food loss and waste: The case of Italian pasta production. Resources, Conservation and Recycling 144: 82-89. [CrossRef]

Quested, Tom, and Paulina Luzecka. 2014. Household Food and Drink Waste: A People Focus. Banbury: WRAP.

Quested, Tom, Emma Marsh, Daniel Stunell, and Andrew D. Parry. 2013. Spaghetti soup: The complex world of food waste behaviours. Resources, Conservation and Recycling 79: 43-51. [CrossRef]

Secondi, Luca. 2019. Expiry Dates, Consumer Behavior, and Food Waste: How Would Italian Consumers React If There Were No Longer "Best Before" Labels? Sustainability 11: 6821. [CrossRef]

Secondi, Luca, Ludovica Principato, and Tiziana Laureti. 2015. Household food waste behaviour in EU-27 countries: A multilevel analysis. Food Policy 56: 25-40. [CrossRef]

Secondi, Luca, Ludovica Principato, Luca Ruini, and Matteo Guidi. 2019a. Reusing Food Waste in Food Manufacturing Companies: The Case of the Tomato-Sauce Supply Chain. Sustainability 11: 2154. [CrossRef]

Secondi, Luca, Ludovica Principato, and Giovanni Mattia. 2019b. Can digital solutions help in the minimization of out-of-home waste? An analysis from the client and business perspective. British Food Journal 122: 1341-59. [CrossRef]

Stefan, Violeta, Erica van Herpen, Ana Alina Tudoran, and Liisa Lähteenmäki. 2013. Avoiding food waste by Romanian consumers: The importance of planning and shopping routines. Food Quality and Preference 28: 375-81. [CrossRef] 
Thi Thuy Trang, Pham, Huynh Quoc Dong, Dinh Quang Toan, Nguyen Thi Xuan Hanh, and Nguyen Thi Thu. 2017. The Effects of Socio-economic Factors on Household Solid Waste Generation and Composition: A Case Study in Thu Dau Mot, Vietnam. Paper presented at the 3rd International Conference on Energy and Environment Research, Porto, Portugal, July 17-20.

UNDP. 2016. United Nations Development Programme, Sustainable Development Goals. Available online: http://www.undp.org/content/undp/en/home/sustainabledevelopment-goals/goal-12-responsible-consumption-and-production/targets/ (accessed on 17 January 2020).

Van Garde, S. J., and Margy J. Woodburn. 1987. Food discard practices of householders. Journal of the American Dietetic Association 87: 322-29.

Varian, Hal R. 2002. Microeconomia. Venezia: Cafoscarina.

Visschers, Vivianne HM, Nadine Wickli, and Michael Siegrist. 2016. Sorting out food waste behaviour: A survey on the motivators and barriers of self-reported amounts of food waste in households. Journal of Environmental Psychology 45: 66-78. [CrossRef]

Waste Watchers. 2017. Osservatorio sullo Spreco di cibo in Italia. Available online: https: //www.sprecozero.it/waste-watcher/ (accessed on 17 January 2020).

Working, Holbrook. 1943. Statistical Laws of Family Expenditure. Journal of the American Statistical Association 38: 43-56. [CrossRef]

(C) 2020 by the authors. Licensee MDPI, Basel, Switzerland. This article is an open access article distributed under the terms and conditions of the Creative Commons Attribution (CC BY) license (http://creativecommons.org/licenses/by/4.0/). 



\title{
From Open to Closed-Cycle Fast Moving
} Consumer Goods (FMCG) Packaging Systems: An Overview of Potential Avenues for Progress

\author{
Robert Hamlin
}

\section{Introduction}

The twelfth UN Sustainable Development Goal ('4rfResponsible Consumption and Production'), calls for significant change in how we view both production and consumption norms (UNGA 2015). The production and consumption norm for fast moving consumer goods (FMCG) packaging, up to 2017, was to treat them as single-use disposable items. Large quantities of used packaging were sent to landfills. Some packaging was 'recycled', but much of this material was actually exported to third countries, where it persisted as a significant but largely invisible challenge (EEA 2019). Progress in glass, steel, aluminium and paper recycling was offset by a massive increase in the use plastics in packaging and landfilling/exporting of plastic waste (USEPA 2017). In developing economies, the direct move to plastics as the primary FMCG package component meant that the situation was rapidly deteriorating in these countries (Tisserant et al. 2017). Public discussion of waste was increasing prior to 2017, but not to the point of mass mobilisation.

This situation changed abruptly in many countries with the screening of a single TV series, 'Blue Planet II' by the British Broadcasting Corporation (BBC) in 2017, and specifically one episode, Our Blue Planet (Episode 7, 10 Dec.) that dealt with effectively indestructible plastic waste in the oceans. The 'Blue Planet Effect' (Gell 2019) has led to the elimination of single use plastic bags in many countries and their severe curtailment in many others (Taylor 2019). While these massive developments appear to be out of proportion to the seemingly minor triggering event, these 'marketing earthquakes' are quite common in marketing where, as in an earthquake, substantial movement to a new equilibrium occurs as an outcome of a small triggering event for the release of pre-existing market pressures (Hamlin et al. 2015). At the same time, many countries that had acted as a convenient destination for both unrecyclable and supposedly recyclable FMCG waste refused to accept any more imports from developed economies and started 
to aggressively police these policies amid considerable publicity (Brooks et al. 2018; McNaughton and Nowakowski 2019).

These developments, along with the public revelation that the majority of 'recycling' in developed countries actually meant export dumping, have triggered a very rapid move to a much higher level of consumer awareness, sensitivity and scepticism towards FMCG packaging waste. Despite the passage of three years since 'Blue Planet II' screened, this awareness does not seem to be declining, and is thus becoming both a political and commercial issue (Webster 2019). Such rapid and irreversible movements between stable states in consumer awareness and sentiment are a feature of FMCG markets, where they are described as 'marketing earthquakes' (Hamlin et al. 2015). This appears to be a classical marketing earthquake, and the FMCG packaging environment is now a very different place to what it was three years ago. Anybody claiming in 2016 that single use supermarket plastic bags would be illegal in my home country of New Zealand by 2019 would have been met with disbelief. Yet, it is now so (Ministry for the Environment (NZ) 2019).

In this new environment it is now possible for the first time to consider a proposal that is core to any circular economy (Stahel 2016): How might a national-level system be set up to create a closed-cycle system for FMCG packaging manufacture, distribution, consumption and disposal in which 'at source' FMCG package design and standardisation is used alongside government regulation to reduce package waste to a small amount of unavoidable loss?

This chapter presents a commentary on how progress may be usefully made towards this end. It is a conceptual and pioneering discussion because almost no research has been published on such systems up to this point. Consequently, it is very difficult to fund and publish empirical research on any aspect of such systems due to the absence of any coherent conceptual basis. This chapter seeks to contribute to the creation of such a basis by providing an initial published platform for research in the area by starting with some basic definitions, and moving on to examine how the current situation might be usefully modified by national-level waste minimisation systems. A variety of approaches that might act as a basis for such a national level system are then described.

The discussion concludes that there appears to be no insurmountable technical barriers to the implementation of such a system. There is a considerable convergence between systems that are based on package recycling and those that depend upon package reuse when they are deployed on a national scale. The barriers to the establishment of any system are largely social and political. Any such system will require aggressive regulation to establish and maintain it. Such regulation will require 
a high degree of consensus between the population, business and government if it is to be politically feasible. As a consequence, social, commercial and political matters have to be taken into account from the outset when designing such a system so that the necessary consensus/acquiescence can be achieved.

\section{Definitions}

The literature in this area has an issue with varying terminology. In order to avoid confusion, the three key terms that are used throughout this chapter are defined here:

Reuse: $\quad$ A package is used and is then cleaned and otherwise prepared for reuse without any further transformation. It is then reused for its original purpose, e.g., returnable glass milk bottles.

Recycling: A package is used and is then reprocessed into its original components. These are then used to remanufacture a package of an identical or similar type with equivalent value, e.g., aluminium cans reduced to aluminium, then remanufactured as aluminium cans.

Repurposing: A package is used and is then reprocessed into a form where either it or its components may be used in a role of lower unit value, e.g., composting, remanufacturing PET bottles into a component of insulating cement building blocks, remanufacturing plastic bags into park benches.

\section{The Current Situation in FMCG Packaging}

The current situation in FMCG packaging in a developed economy is shown in Figure 1. In a developed economy such as the United States, the system is predominantly linear, with packaging inputs coming in at the top of the system, and proceeding through stages of manufacturing distribution, sale, consumption and disposal. Upon disposal, the majority of packaging ends up as waste in landfills, or exported to an uncertain destination and fate. A minority of packaging material may be repurposed, in which case the material is remanufactured and used for an alternative purpose rather than being returned to the system. Much smaller volumes are truly recycled, in that they are remanufactured and returned to the system at the same point from which they came. An equivalently small proportion are reused, a process in which they are returned to the system in their original form (USEPA 2017). In addition to revelations with regard to the degree to which 'recycled' materials quoted in these figures is actually exported and dumped (Dobush 2019), official figures of this type display some peculiarities. For example, (USEPA 2017) claims 
that in 2017 c. $15 \%$ of all glass waste was burnt and its energy recovered. As glass is a non-flammable/exothermic material, this claim has some issues of credibility.

It should be noted that 'repurposing' is not recycling, although it is often described as such (e.g., Keramitsoglou and Tsagarakis 2018). While some materials such as elemental aluminium may be freely and repeatedly repurposed, most polymers and organic materials are complex compounds that are not as amenable to remanufacture, and the process consequently usually involves a degree of functional downgrading, which destroys the circularity that is the primary characteristic of recycling (Rahimi and García 2017). A good example of this repurposing is the common activity where soft plastics such as single-use supermarket carrier bags are 'recycled' into park benches (Righter 2019). As such, the bags are not truly recycled back into the packaging system, and presumably after a passage of a few years the faded and warped bench becomes a yet more intractable disposal problem. Similarly composting of 'organic' packaging is not recycling, but repurposing-the result cannot be reused for its original purpose.

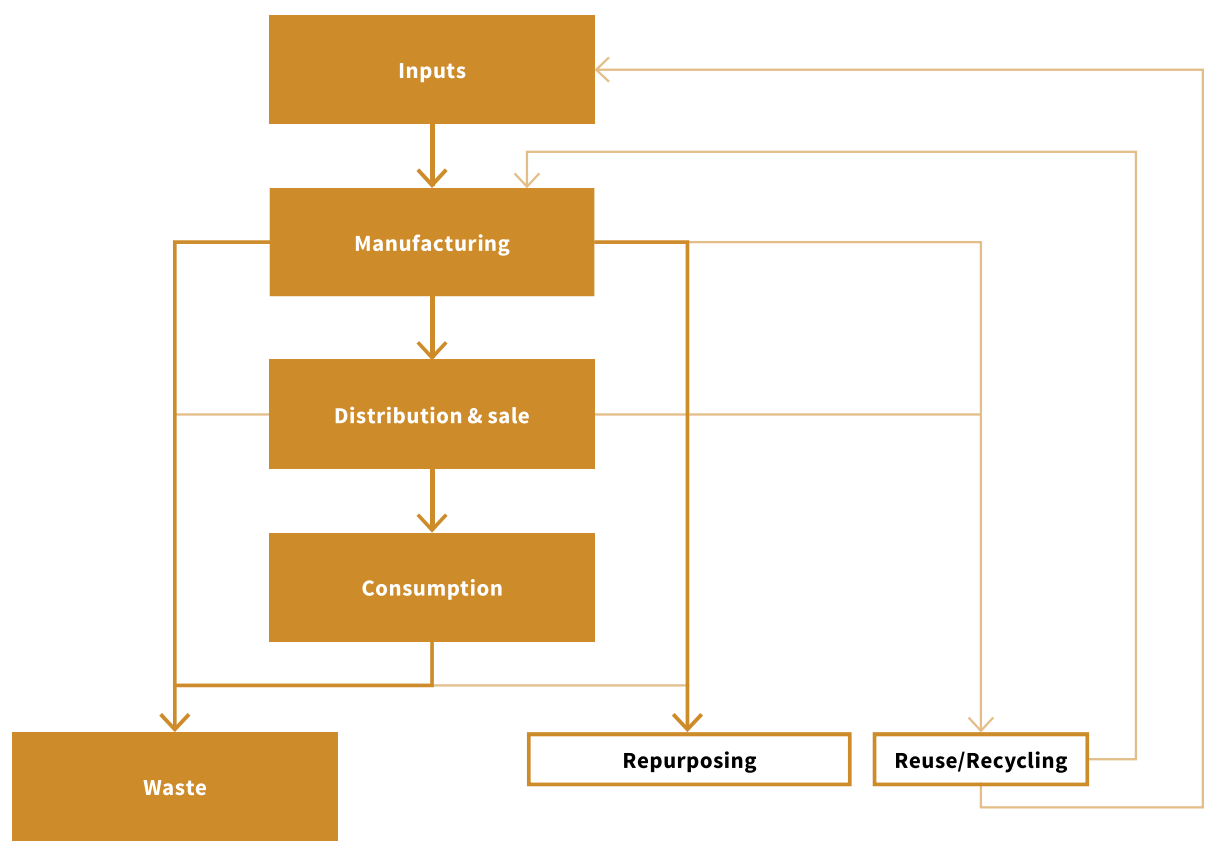

Figure 1. Linear 'open-cycle' fast moving consumer goods (FMCG) packaging system (the current situation). 
A further aspect of the current situation that cannot be expressed in Figure 1 is the degree of fragmentation within the system. Given that any individual supermarket has around 30,000 products on its shelves and a large hardware store around the same number, any developed economy has hundreds of thousands of individual FMCG products, and tens of thousands of unique packages containing thousands of unique and discrete constituents. These constituents are combined and recombined as they pass through multiple participants at the various stages of the process, and they arrive at their eventual destination after disposal via an equally wide variety of routes. As a result, their eventual destinations are unknown to any consumer or statutory authority, which reduces motivation to change (Barnes 2019).

A good example of this is the coffee capsules popularised by Nespresso ${ }^{\circledR}$. The capsules are now sold worldwide via an enormous variety of outlets (Brem et al. 2016). They are also manufactured by a large number of companies using a wide variety of materials (de Oliveira and Rodrigues 2015). The original Nespresso ${ }^{\circledR}$ capsules are aluminium; others are made from combinations of various plastics, biodegradable polymers and organic materials. While many have the advertised potential to be repurposed, and Nescafe and others aggressively promote their products on this basis (Fox 2019), the degree to which they actually achieve this status is impossible to ascertain.

The same can be said about the FMCG packaging system in its current fragmented situation. While it can be stated with some confidence that the amount of packaging that is repurposed, recycled or reused is only a minority of the total (Hoornweg et al. 2015), the exact size of that proportion, and whether that proportion is increasing, static or decreasing, is not known.

\section{The Aspirational Situation for FMCG Packaging}

An aspirational situation for FMCG packaging in a developed economy is shown in Figure 2. This design, specifically for FMCG packaging, is derived from the closed-cycle system developed by Meherishi et al. (2019), which encompasses all activity within an economy. The linear structure from manufacture to consumption from Figure 1 remains, but there are now feedback loops at each stage that return packaging material to the manufacturing process. This feedback can be via recycling, reuse, or a combination of the two, but repurposing has no role in the process unless the component in question is a renewable resource.

This position on repurposing is not compatible with Meherishi et al.'s (2019) concept of circular supply chain management (CSCM) where repurposed material can be moved between industries, but the example given by these authors shows 
the issue of functional and value downgrading that is implicit with repurposing within CSCM:

"In practice, CSCM endeavor [sic] to produce zero waste through system-wide innovations to recover value from what was traditionally called 'waste'. For example, recycled PET bottles may be used for construction; light concrete is added to the bottles, creating isolated walls for houses." (Meherishi et al. 2019, p. 885)

The issue with this example is that the PET/concrete block will also come to the end of its useful life, at which point the large lumps of concrete/PET combination are likely to represent a completely economically intractable repurposing/recovery problem. They will then become open-cycle waste-like the 'recycled' benches mentioned earlier. In most cases repurposing merely kicks the open-cycle 'can' down the road. If it is kicked far enough, then it may perhaps become invisible to the original user, but this does not mean that it has disappeared!

Figure 2 shows that an input into the system remains, but at a greatly reduced level that is balanced by unavoidable loss at the other end of the process. Even an aspirational situation has to accept that some loss will occur. This also departs from the aspiration outlined by Meherishi et al. (2019). This loss may come about by actual physical loss, dispersion, permanent retention by the consumer, destruction or defilement beyond the capacity to recycle or manufacture and the minority of situations where a closed-cycle system cannot be sensibly applied to either a package or a functional component of it.

A good example of unavoidable loss is the colorants used as a component of inks and dyes in packaging. Colorants are present in tiny quantities that are often fully integrated with an individual package. As a consequence, these are rarely if ever recovered, even though when measured on a system wide scale, this loss of colorant by irreversible dispersion may be significant. This loss is not an issue if the colorant is either a biological product or is synthesised from common elements that cycle within the biosphere, but it is an issue if the colorant incorporates a rare element derived from mining of finite deposits that have been concentrated over a geological time period (e.g., copper) (Sverdrup et al. 2019). 


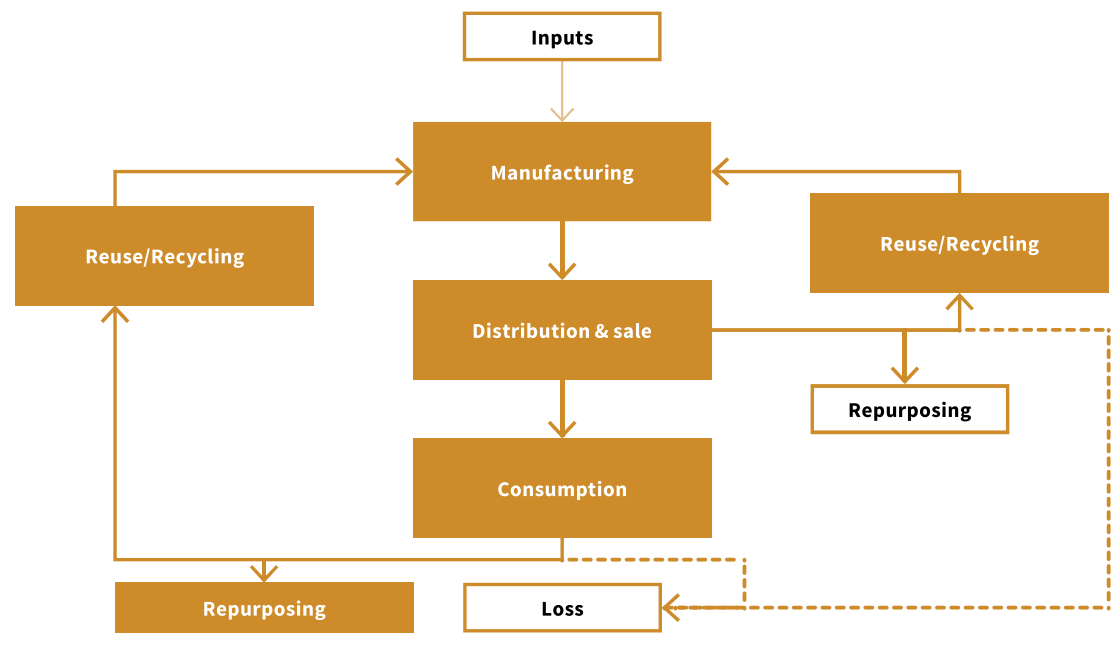

Figure 2. Circular 'closed-cycle' FMCG packaging system (aspirational situation).

Clearly the system shown in Figure 2 represents a radical departure from that shown in Figure 1. Can this situation be achieved or even approached within the political, commercial and social parameters of a developed society? The global closed-cycle system developed by Meherishi et al. (2019) encompasses an entire economy and it represents such a massively complex scenario that it is hard to envision how a single strategy could be developed to achieve it. This is not the case in the situation under discussion here. FMCG packaging is a substantial industry; however, it is only a small, consistent component of any economy with a well delimited waste stream. It does therefore represent an environment within which a coherent national level strategy and plan for moving towards an aspirational scenario could be developed.

\section{Current Developments towards Closed-Cycle FMCG Packaging Systems}

\subsection{Overview}

The reviews by Meherishi et al. (2019) and Nemat et al. (2019) represent a comprehensive overview of academic research in closed-cycle FMCG packaging. The vast majority of studies on current closed-cycle FMCG packaging initiatives reported by these reviews are restricted to single products or single companies, and as such reflect the high degree of fragmentation that exists within the field. 
Closed-cycle initiatives based on packaging reuse are heavily concentrated in the manufacturing and distribution steps of the FMCG packaging systems, primarily secondary and tertiary packaging (e.g., Battini et al. 2016; Baruffaldi et al. 2019). ${ }^{1}$ Many studies have reported significant cost advantages for the reusable systems studied (e.g., Silva et al. (2013)), but the majority of secondary and tertiary packaging is still either disposed of or repurposed at the present time (Chung et al. 2018).

\subsection{Reusable Systems}

Those initiatives that involve reusable primary packaging are predominantly single companies, such as small independent dairy product manufacturers, that offer reusable glass milk bottles (Levitt 2019). In some cases, these individual initiatives are sufficiently similar and sufficiently numerous that they represent significant industry-scale movements. One example of such a movement would include the move to allowing reusable coffee cups by a wide number of foodservice providers (Romeo 2018; Winter 2019b), although this particular example has not been without its problems and public relations disasters (Gabbitas 2018). Nevertheless, the majority of retail coffee cups remain single-use items with a structure that predetermines that they go to landfill (Poortinga and Whitaker 2018).

While not a package in the strict use of the term, the movement towards reusable supermarket shopping bags has had a far greater impact on behaviour in many countries than many other initiatives (Parker 2019). In many cases this movement has been backed by legislation (Nielsen et al. 2019), with legislators reacting to and leveraging the rapid development of a strong market sentiment (Knoblauch et al. 2018). The outcome has been that, in many countries, a product that was once produced and discarded by the billions has been massively reduced. This was the case in the UK, for instance, within a very short time period (Woodcock 2019). This offers an encouraging illustration that mass changes in consumer sentiment and behaviour towards packaging are possible—given the right social conditions.

One interesting development, which involves an attempt to consolidate FMCG reusability among multiple suppliers, is the Loop ${ }^{\circledR}$ concept, in which reusable

1 Primary packaging is the packaging that is bought with the product and forms part of an integrated 'offer' (e.g., the wrapper on a bar of chocolate). Secondary packaging is present at the point of sale (POS) and is used to present the package to the consumer (e.g., the open-top box in which the chocolate products are presented to the consumer in the shop). Tertiary packaging is rarely present at the POS, and is used to transport the product (e.g., the cardboard carton containing several open-top boxes of chocolate and the pallet on which a number of cartons may be transported by sea or land). 
packages with an expected life of 100 cycles are supplied by major FMCG companies via a privately held Internet platform (Cheng 2019). Loop is only available in restricted areas of North America and Europe at the present time. The system has garnered considerable publicity, but reviews of the system have been equivocal with regard to price (Bratskeir 2019). Whether this price reflects a high margin, or simply the cost of manufacturing and refilling a portfolio of unique branded packages, has yet to be established, as has the fate of the packages if they reach their end of use point.

One reusable closed-cycle FMCG packaging system that has been fully operational in the soft drinks category worldwide for over 50 years is the system pioneered by Sodastream ${ }^{\circledR}$. This system relies upon a consumer owned carbonation machine with reusable bottles for both carbonating gas and the water that is carbonated. Concentrated syrups for flavour are available in a standard single-use pack. Despite its undoubted effectiveness as a package reduction system and its clear economic advantages to consumers, this system has had little impact upon the vast quantities of soda that are sold in single-use PET bottles each year (Osland and Luo 2019).

This lack of impact appears to be an outcome of hostility to the system within distribution channels for soft drinks. It must be remembered that a packaging innovation that is economically advantageous to consumers may be economically disadvantageous to those who supply them. The author was employed by an American investor in the late 1980s to examine the feasibility of introducing a similar system into the United States. After considerable investigation, the conclusion reached was that the level of hostility among established suppliers of soft drinks meant that the only large-scale point of access to the market was via chain retail outlets (hardware stores) that were not at present selling soft drinks.

Thirty years later in my home town of Dunedin, New Zealand, this situation does not seem to have changed. The local hardware multiple does not sell soft drinks, but it does have a very large and prominent display of Sodastream ${ }^{\circledR}$ machines along with a wide range of good quality syrups and gas bottles. None of this is available via the mainstream supermarkets. One striking feature is the complete absence of branded after-market syrups for this system. This is in contrast to the coffee capsule markets where nearly all the major coffee brands have multiple coffee capsule products available in supermarkets. The point to be made by this example is that the attitude of channels to any proposed package reduction innovation, and the reasons for that attitude, must form a component of any research related to the development of that innovation if it is to have any hope of large-scale success. 


\subsection{Repurposing and Recycling Systems}

Repurposing and recycling, with the former often described as the latter, have a very much larger presence in both the academic literature and in practice (Han et al. 2018). Unlike reuse, repurposing initiatives include large-scale (public) systems that encompass an entire FMCG package waste stream. Large scale repurposing systems (usually described as recycling) now have a strong presence in many developed economies (Khandelwal et al. 2019). Many systems of refuse sorting are now established at a civic collection level with organic waste, paper, glass, plastics and aluminium all identified as separate repurposing streams (Keramitsoglou and Tsagarakis 2018).

Of these only that for aluminium seems to be largely problem free with a strong commercially viable market for the stream and no issues with repurposing to the same level, thus establishing a true recycling scenario (Dando 2019). The other three streams, plastic in particular, all have serious issues with identifying an end use for the repurposed product, and establishing a commercially viable market/logistics system to access that end use (Brooks et al. 2018).

Contamination remains a serious issue, not only with foodstuffs and other items that are foreign to that particular stream, but also with 'paper' and 'plastic' packages that are not repurposable because they are not entirely as they seem. This can be because either they are not made from a repurposable material or because the package consists of a variety of intimately incorporated components which cannot be separated for repurposing (Schmidt 2018). Tetra-pacs and multi-layer plastic bottles are examples of this multi-component package issue (Ma 2018). Complex 'hi-tec' packages of any sort that are developed to address specific problems higher up the distribution chain can present serious issues when it comes to repurposing them after final use (Kaiser et al. 2018). As there is considerable investment and activity in the development of such 'hi-tec' FMCG packages (e.g., Idumah et al. 2019), this 'designed in' unrecyclability problem is likely to become more significant in the future.

Glass, while seemingly an easily repurposable commodity, suffers from the fact that there are many types of glass, and it only takes a small amount of contamination of an inappropriate but very similar looking glass (e.g., lead crystal), or anything else for that matter, to make an entire batch of food-grade glass unfit for recycling back to its original purpose. As a consequence, most glass packages that are not reused in the existing form are either landfilled or repurposed (Majdinasab and Yuan 2019).

These issues with repurposing have recently led to a number of unfortunate and high-profile incidents. These very public failures, and the undertones of deceit 
that have coloured many of them, have led to a certain loss of public confidence in large scale repurposing initiatives despite the significant achievements that can be attributed to them (Laville 2018).

\subsection{Reduction Systems}

The predominant reduction system at present is the bulk or 'bin' product retail format, which eliminates retail packaging altogether as consumers bring and fill their own containers (Beitzen-Heineke et al. 2017). Bin retailers are usually smaller independent retailers, although recently, larger retailers have started to offer restricted services in this area (Flaws 2019). Bin retailing certainly eliminates packaging, and thus closes the cycle. However, it faces considerable challenges in transitioning to a mainstream format because of issues with food contamination, difficulty in handling some foods, and potential liability in jurisdictions where tort is an active legal sector (Vanne 2019).

Bin retailing also represents a major challenge to large FMCG manufacturers and retailers due to the loss of brand intellectual property (IP) and capital value as the majority of these brands communicate with the consumer via the package at the point of sale in FMCG markets (Hamlin 2010). It also creates major issues with apportionment and pricing, which are both key marketing tools in this industry (Ellickson and Misra 2008). As a consequence, major FMCG companies are likely to actively resist any significant expansion of this format. Given the resources available to them, this resistance is likely to be effective.

\subsection{Progress towards a Closed-Cycle}

It is not currently possible to state with any confidence if progress is being made with moving to a closed-cycle for FMCG packaging. Progress in new closed-cycle packaging formats is matched by 'progress' in new FMCG packaging formats and technologies that are incorrigibly open-cycle and single use.

Perhaps no example expresses this situation better than the 'coffee pod' market cited previously. This market relies upon a consumer owned machine that takes single-use pre filled coffee pods-one for each drink. The disposable pods are small and attractively styled items - each an FMCG package in its own right-that may be made of either metal or plastic. Coffee pods have grown to be a global industry in the last twenty years. The pioneering brand Nespresso ${ }^{\circledR}$ still dominates the market, and has made very high-profile attempts to ameliorate the obvious 'throw away' aspect of this product via stressing the use of aluminium as a key component in the pods, and a series of high-profile re-purposing exercises for the aluminium. 
Nevertheless, the small size of the pod and consumer habit dictates that, even though repurposing opportunities exist, the majority of pods end up being flicked into the consumer's kitchen bin, and from thence to landfill. The exact proportion of coffee pods that make this particular journey is unknown.

The situation is aggravated by the large number of competing after-market pods that are now available. These use an enormous variety of alternatives to aluminium, including plastic and compostable versions. All these of course require their own dedicated repurposing systems, thus losing any opportunities for economies of scale and consumer communication.

It is not disputed by any manufacturer that pods create more direct waste than the coffee making systems that they have displaced. The counter argument put forward by these companies and others is that the environmental impact of this waste is offset by the reduced requirement for coffee, and a concomitant reduction in the environmental impact of this crop globally (Gunther 2015). This may be so, but one possibility that is not widely discussed is the potential for reusable pods to capture this desirable efficiency without generating the undesirable waste stream. Reusable pods are readily obtainable on the Internet, but not from the major players (e.g., Coffee Lovers New Zealand 2019)—which indicates that there is no particular barrier to the wider scale deployment of reusable pods or the design of a reusable pod chamber into the machine in the first place.

The reason for the lack of enthusiasm for reusable or 'designed in' pods among the market incumbents may well be related to commercial imperatives similar to those that oppose the Sodastream ${ }^{\circledR}$. A coffee pod system comprises a machine and a dedicated consumable product, the pod. As with colour printers and ink cartridges the bulk of the lifetime profit of such a system is in the large number of consumable pods, not the single durable machine, which may be sold at or below cost in order to establish the consumable purchase stream (Dhebar 2016). In the case of Nescafe Nespresso ${ }^{\circledR}$ pods, the coffee in them is priced at NZ $\$ 124$ per kilogram in my local supermarket. This scale of value added, compared to other retail presentation formats such as packaged ground coffee, generates an understandable reluctance to introduce anything to the market that might interfere with the continued consumer take up of the consumable pod product. $^{2}$

2 Countdown, Mosgiel, New Zealand, 20/12/19. A sixteen-capsule box of Nescafe pods, \$9.99. Assuming $5 \mathrm{~g} /$ capsule (Caffeininformer.com 2019) gives a value of $\$ 124 / \mathrm{kg}$ for the coffee. Nescafe Instant $100 \mathrm{~g}$ $\$ 7.00$, assuming an extraction yield from beans of 1:3 (Pfluger 1975) gives a value of $\$ 25 / \mathrm{kg}$ for the coffee. Package ground coffee (Hummingbird) $200 \mathrm{~g} \$ 7.00$ gives value of $\$ 35 / \mathrm{kg}$ for the coffee. 


\subsection{The Case for a National Level Approach to Closed-Cycle FMCG Packaging}

There appears to be little dispute that an open-cycle FMCG packaging system is not viable in the long term. However, it cannot be stated that any significant net progress is being made towards closing the cycle in this sector. At present, the majority of closed-cycle initiatives based on reuse and recycling are too small, isolated, symbolic and/or ephemeral to make a significant difference. The same can be said of reduction systems based on the elimination of consumer packaging at the point of sale. Large-scale initiatives based on repurposing of FMCG packaging waste do not close the cycle in the required manner, and the outwards channels for repurposing captured waste streams have proven to be very difficult to establish and maintain, leading to a series of damaging high-profile scandals.

It would appear that the only avenue to progress towards a closed system in this area is the consideration of national level closed-cycle systems that are able to capture economies of strategic coherence, design, scale and communication. Such systems are unlikely to consist of a single solution, and will only succeed if they have a high degree of consumer support with complete government commitment, along with a degree of commercial incumbent acquiescence within the FMCG industry itself.

\section{Developing Closed-Cycle FMCG Packaging Systems on a National Scale}

\subsection{The Advantages of National Level Systems}

To this point no country has attempted to introduce a closed-cycle system of FMCG packaging at a national level. This is perhaps not surprising as the political and fiscal obstacles do appear to be daunting, and any such system requires definitive regulation on a level that has not been fashionable in developed economies since the 1970s (Bloom 2017). Nevertheless, national level systems that are set up as such from the outset do offer advantages over the current process of undirected development via a series of unconnected micro-initiatives.

The most obvious of these advantages is scale. A closed-cycle packaging process that may not be economically or technically viable on the scale of a local or individual channel participant level may be perfectly viable when applied on a national scale.

The second major advantage is that regulation can be more easily applied on a national scale, thereby achieving compliance and uniformity across an economy.

Compliance is a necessity for any closed system initiative to succeed. Humans are notoriously unwilling to accept constraints upon their behaviour, even when it is in their interests to do so. A good example of this is the issue of non-compliance with the European Union's ban on incandescent lightbulbs, despite the fact that LED 
lightbulbs are not only a collective environmental benefit but also an individual economic benefit given their much lower lifetime costs-even for the most fiscally constrained citizens (United Nations Environment 2017). Nevertheless, loopholes were actively identified and developed that allowed incandescent light bulbs to be imported into the EU, and they were then (perversely) purchased on a large scale (Schieß1 2012). These loopholes had to be aggressively 'shut down' by the authorities (Hickman 2012). It is possible that certain sectors of society and industry would react in a similar manner to any closed-cycle packaging initiative.

Uniformity is also a necessity if advantages of scale are to be fully realised. Once again, uniformity is not a feature of unrestrained societies, even if it is advantageous. As a result, uniformity can only be achieved in the majority of cases by regulation. The coffee pod industry cited earlier is a good example of this type of perverse behaviour and the need for regulation to suppress it. The principle drawback of the coffee pod is its manifest wastefulness. It would be in the individual interests of the industry participants to standardise certain aspects of the pods so that a standardised waste disposal solution could be applied to this undesirable aspect of the product. This has not happened. There are now a wide variety of pods that each require their own system to deal with them, none of which really have the scale to be viable. It is an undesirable situation that appears to be getting worse rather than better as new 'solutions' enter the market.

The third advantage of a national scale initiative is the capacity for the deployment of social investment. Any closed-cycle system is likely to require a considerable up-front investment. There are barriers to this investment coming from the private sector. Firstly, the return from any such system may take a considerable time to materialise. Secondly, the returns and benefits may not accrue to the same area/investor as where the investment was made, and they may not be a single bottom line return either (Walker et al. 2008). While triple bottom line accounting has been around for several decades (Slaper and Hall 2011), there are no examples of private investors embracing it on the scale that would be required here. There is also an issue with the incompatibility of private investment in a regulated environment, and the capacity for monopolistic behaviours as has been seen in privatised water (Lobina 2019).

\subsection{The Convergence between Reuse and Recycling in National Scale Systems}

Up to this point in the literature reuse and recycling have been normally considered to be discrete alternative approaches to the developing closed-cycle systems for FMCG packaging. However, when applied to national level systems, the 
difference between the two approaches converge, and the differences between them become much more nuanced. In a closed-cycle system run on a national scale that is based on reusable FMCG packages, it is important that a reusable package also has the capacity to be recycled to the same level of functionality. A reusable package may be reusable, but it will have a more or less precisely predictable life. For example, glass milk bottles have a theoretically indefinite lifespan; but in practice, they have a very specific life expectancy (WRAP 2010). If a reusable package does not have the capacity for recyclability then once again it is simply a slower-burning repurposing exercise, and it is not a closed-cycle system.

The difference between a national level recyclable system and a national level reusable system is thus merely how many cycles the package will make though the system before it is recycled. This is a logistic rather than a paradigmatic level of difference.

\subsection{The Role of 'Upstream' and 'at Source' Design and National-Scale Standardisation}

One of the main reasons why existing large-scale FMCG packaging repurposing systems have run into such difficulties is that they have employed the 'ambulance at the bottom of the cliff' approach to treating this particular environmental ailment, and the role of upfront design has only recently become a focus of research (Rezaei et al. 2019). It is impossible to say how many unique FMCG packages exist in a developed economy, but the number certainly runs into the millions, and the specific material component and technology types run into the thousands. These material components and technologies are also frequently intimately incorporated with each other in a single package. Every week, more packaging innovations of ever more complex types join this population (Wyrwa and Barska 2017). All of this variety then has to be sorted into a small number of 'waste streams' - creating an insoluble technical and logistic nightmare.

If a closed-cycle system is to be successfully applied to FMCG packaging, then the FMCG packaging will have to be designed from the outset to fit the closed-cycle system and not the other way around. If it is deployed on a national scale, 'the system' is also a singular not a plural entity, and all FMCG packaging will have to be designed from the outset to fit the requirements of this single system. The coffee pod example noted earlier indicates that such compliance is only likely to be achieved by regulation.

The level of design standardisation imposed by such regulation could vary quite significantly. At a minimum, packages might be restricted to a set number of non-combined components with proven recyclability, and the most extreme level of the entire FMCG sector could be restricted to a minimum number of fully standardised 
packages. Preliminary design studies undertaken by this writer have indicated that the 20,000 food items found in the average supermarket in New Zealand could be presented with less than 20 standard reusable package types incorporating less than four technologies.

\subsection{The Requirements and Role of the Consumer}

Any closed-cycle FMCG packaging system has to conform to the requirements of its constituents, who also each have a specific role to play in its implementation. The retail consumer will have legitimate expectations of any such system. These include core functions of economic efficiency, ease of decision/purchase, containment, protection, transportability and (reasonable) preservation. However, it is extremely unlikely that a closed-cycle packaging system will match the existing open-cycle system in all regards. This may create some local and specific problems, but such consumer problems are also commercial opportunities. For example, coffee pod consumers are likely to be denied coffee pods in their current form as part of any closed-cycle scenario, but this represents an opportunity to the first company to create an equivalent system that does comply with the system's parameters. It is important to note that a closed-cycle system defined by regulation will not necessarily suppress innovation in the manner assumed by much of the literature (e.g., Trubnikov 2017), and that a proactive regulatory system may well act as a disruptive innovation in its own right, thus increasing rather than decreasing the overall rate of innovation in a market, as has been the case with domestic lighting.

\subsection{The Requirements and Role of Business}

The primary requirement that business has of any closed-cycle system is that it will permit them to continue to operate in a manner that allows an adequate return on the capital invested in them. How this occurs will vary in accordance with the position of the business within the system. Clearly some specialist packaging businesses that are heavily invested in non-compliant plants and technologies may face particular issues in this regard, and some form of compensation for irrevocably committed capital may be the only redress.

For many manufacturers and retailers, their capital issues may relate more strongly to intangible capital assets, mainly brand IP, which in many cases represents the dominant portion of the capital value of any FMCG company (Winter 2019a). No research exercises on alternative FMCG packaging systems have touched on this key issue. Any system that significantly interferes with the effectiveness of FMCG brand assets is likely to encounter well-funded and highly organised resistance from 
industry players. As consumers form relationships with brands and also rely on them to assist with their decision making, this resistance may well also strike a significant chord with them (Elbedweihy et al. 2016).

Generally it could be expected that large incumbent FMCG businesses would resist any closed-cycle system as it represents a change to a status-quo that is currently highly advantageous to them. Medium and smaller companies may well take an opposite viewpoint, in that anything that significantly disrupts the status-quo is potentially to their advantage (Christensen et al. 2015).

The role of business is fairly straightforward: to comply with the closed-cycle system, and to invest, operate and innovate within its spirit and parameters. Whether this happens will depend upon the degree to which any proposed closed-cycle system meets the requirements outlined above. Not everybody in the FMCG industry will be comfortable with any proposed closed-cycle system, but it is essential to its success that a critical mass of them are. Collectively businesses within the FMCG industry have considerable fiscal resources and a high level of skill in public communication. If the FMCG industry were to reach a consensus to actively deploy these capacities against any proposed system in a free-market democracy, it would greatly reduce the chances of that system coming into operation, whatever its benefits might be. The case of Sodastream ${ }^{\circledR}$ demonstrates this capacity clearly, even when applied at a passive level.

\subsection{The Requirements and Role of Government}

The principle requirement for government at all levels is to reduce the amount of waste going to landfill, which is both a major communal cost and a politically troublesome issue. However, this has to be achieved in a manner that is consistent with public health, social sensibilities and economic well-being. Public waste disposal was initially motived by public health rather than private convenience. It dates back to 1750 in London, and for the first 150 years the process was self-funding as the communal waste streams largely consisted of ash, urine, dung and organic waste, all of which had value and an accessible repurposing market (Velis et al. 2009). Only since 1900 has the increasingly large and diverse stream of private household consumer waste become a net communal cost, which has been exploited by the FMCG industry among others. Governments would very much like to return to the pre-1900 position!

The principal role for national government in this situation is one of leadership. Perhaps the most important aspect of this is to make the communal cost of open-cycle FMCG items more publicly apparent, and to then act accordingly and with public 
support. The private profitability of open-cycle FMCG packaging goods relies upon the partial or complete socialisation and apparent dispersal of the cost/impact of their disposal. Disposable nappies, while not strictly a package, are a good example of this exploitation of public waste streams. Disposable nappies are a very high percentage all nappies used. Used disposable nappies are a particularly undesirable landfill input, and they represent a considerable proportion of waste going to landfill (Mendoza et al. 2019).

Reusable nappy systems that offer good performance are now available, and at an economically very advantageous cost to the consumer compared to disposables. They will never be quite as convenient to the individual as the disposable version, but the disposable nappy is a highly destructive and expensive item in a communal landfill, and even minor changes brought about by incentives to use reusables have generated significant communal savings (Warner et al. 2015). Disposable nappies, like coffee capsules, are very easy to use and profitable to manufacture and sell, and disposable nappy systems still dominate retail displays and public advertising. It is thus very unlikely that their use will cease unless government either taxes them to properly reflect the social cost of disposal, prohibits their sale or ceases to allow them to enter the communal waste stream at any point. The perverse importation and purchase of incandescent lightbulbs in Europe in the face of regulation indicates that only the second two more drastic options, requiring great political courage, would be likely to succeed.

It is likely that no closed-cycle system for FMCG packaging will ever be established without such leadership by government. That leadership will have to come via justified regulation if we continue with the disposable nappy example. If the management of one of the major disposable nappy manufacturers unilaterally chose to sacrifice their position in the disposable market by moving towards reusables, they could quite justifiably be accused of destroying shareholder value, especially as their competitors predictably moved to exploit their loss of position in the disposable nappy market. It is very likely that the management in question would be removed and the initiative reversed. Any executive that was interested in their own self-preservation is therefore very unlikely to do this, and the same will apply to the management of any other FMCG company that operates in a market where the communal cost of open-cycle FMCG packaging is not properly recognised.

If, by contrast, the government told all nappy manufacturers that sale of disposables would be prohibited after three years as an outcome of the costs that they represent to the government, no market position or capital is lost to that company through that ruling relative to its competitors. It would only be lost if the company 
failed to innovate in response to that ruling as effectively as its competitors over the following three years.

Thus, the primary role of government is leadership by regulation, but regulation that is the minimum to achieve the objective, fully justified and judiciously developed and applied in order to avoid the generation of a critical degree of resistance within the FMCG industry and the consuming public.

\subsection{The Requirements and Role of Trans-National Organisations and Treaties}

A wide variety of trans-national organisations exist to improve environmental outcomes, and such organisations play a part encouraging governments to take a leadership role, and assisting them when they choose to do so. Thus, the acquisition and dissemination of experience and information relating to best practice in closed-system FMCG packaging systems is an obvious role for such organisations so that such best practices are consistently applied.

A rather less obvious but equally important role for trans-national organisations is the mitigation of the negative effects of trans-national treaties in the development of closed-cycle FMCG packaging systems. Many free trade agreements that are coming into force go well beyond free trade and significantly constrain national governments in their policy development if a company or nation can demonstrate that such regulations will affect their property rights. The legal platforms on which such cases may be made by third parties against local laws and regulations are in many cases set up within the treaty itself and they can fall well short of what would be considered a satisfactory legal platform for governments to defend their position (Kelsey 2019).

Just how these can impact on government FMCG packaging policy can be clearly demonstrated by the experience of Australia's attempts to ban branding on retail cigarette packages. This policy was challenged by the international tobacco companies on the basis of loss of intellectual property rights under just such an international treaty, a case that the Australian government eventually won (O'Dowd 2018). However, the potential for such international treaties to allow commercial interests to strike down domestic government policy on FMCG packages, especially in smaller countries that are committed to treaties in which redress can be pursued by third parties in treaty pseudo-courts, was clearly demonstrated. A role therefore exists for trans-national organisations to oppose treaties that, either by accident or design, give third parties the power to overrule regulations put in place by democratically elected governments. 


\subsection{Potential Structures for a National Scale Closed-Cycle FMCG Packaging System}

Any closed-cycle system for FMCG packaging will have to satisfy the requirements of the constituents identified above, and it will also rely upon them to fulfill their roles if it is to have any chance of long-term success at a national level. The development of such a system will require a considerable amount of negotiation and compromise between these stakeholders, coupled with consistent leadership from government. It is likely that the system that would emerge from the end of these negotiations would differ significantly from the one that the constituents had individually in mind when they started out. This process will require that participants not become overly committed to any specific technical platform as it is the outcomes, not the means towards those outcomes, that will determine the eventual success or failure of a system. It is also possible that a single national system may consist of a small number of discrete solutions.

With this caveat in mind, the three approaches outlined below, all of which require point of origin design, may represent viable starting points for this process.

Restricted component recycling: The current efforts at recycling rarely achieve recycling to the same level, with repurposing at varying levels of success being the normal outcome. A national level system that aims to achieve a closed-cycle system based on recycling is unlikely to succeed unless packaging manufacture is regulated so that only component materials that can be recycled to the same level indefinitely are used, and that these component materials are easy to identify and separate from each other (Figure 3).

This system has the advantage that it is closest to the present open-ended arrangements from all stakeholders' points of view. In addition, many of the components that might be used have existing recycling codes, such as PET (Polyethylene Terephthalate) $=1$ (EC 1997). Industry participants would be free to do as they pleased within the parameters of the component content regulation. Current consumer and government arrangements would remain largely unchanged. The drawback of this system is that the requirement for the indefinite recycling to the same level is an extremely demanding one if packages remain single use. Almost the only material that could meet this requirement at present is aluminium.

Consumer controlled reusable packaging: The rise of bin retailers, where consumers bring their own packaging to be filled from bulk containers, was discussed earlier (Figure 4). These retail formats still have a small market share in most developed economies, but they are growing fast. The principal drawbacks of these systems relate to food safety and cross-contamination at retail and in the home, 
and handling at retail. Loss of retailer and manufacturing IP along with control of the package are also significant issues for industry stakeholders.

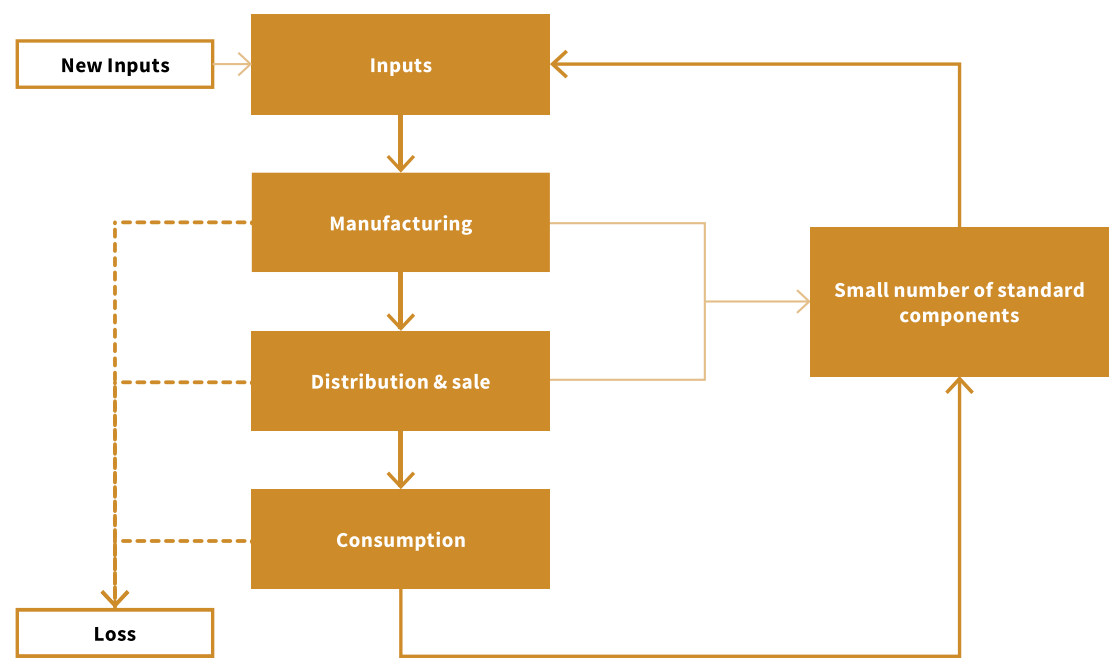

Figure 3. Restricted component recycling.

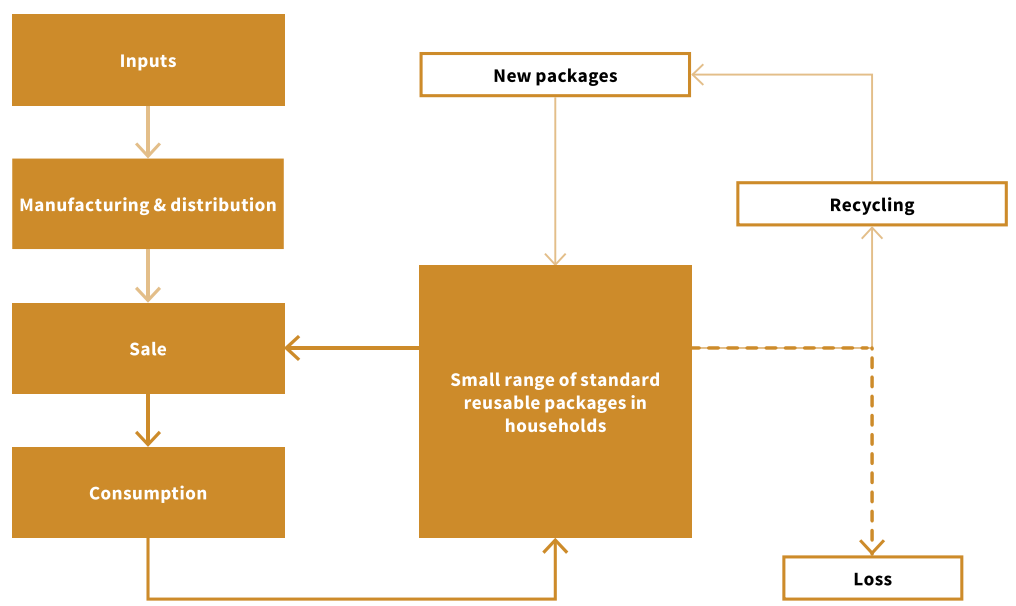

Figure 4. Consumer controlled reusable packaging. 
Many of the handling and safety issues can be addressed by mandating the use of a restricted range of recyclable 'approved' containers to purchase retail items. The containers would remain the property and responsibility of the consumer. Such regulations have precedent with the use of approved containers for purchasing petrol. Even with careful design, it is unlikely that systems of this type represent a wide-ranging solution for closed system FMCG packaging. A variant of this, where the retailer rather than the consumer owns the package, may work in such circumstances, but smaller retailers may be systemically disadvantaged by such a system.

Third party controlled reusable packaging: In a third party reusable system a small range of standard reusable packages is also used, but this time they are controlled by a third party that processes them for reuse, and recycles them at the end of the useful reusable life of the package, on a national scale (Figure 5). In this system a package would be purchased from the third party by a manufacturer, who would then use it to send their product down the channel to retail. The consumer would then purchase the product, consume it and return the package to the third party by a regular domestic bin pick up. The third party would then reprocess the package and sell it out for reuse. Thus a package may go from city ' $A$ ' to city ' $\mathrm{B}$ ' full of beer, be reprocessed and return from city ' $\mathrm{B}$ ' to city ' $\mathrm{A}$ ' full of milk, to then be sent to city 'C' full of tomato ketchup.

This approach has a number of advantages for most stakeholders. Apart from the use of a more restricted range of packages, the normal patterns remain unchanged for the consumer. They buy the items packed and dispose of them in a bin that can be collected in a similar manner to current weekly bin pickups. As industry controls the containers through manufacturing, distribution and sale, most of their safety, apportionment, pricing, handling and IP issues can also be mitigated. The exceptions to this are the packaging manufacturers who lose heavily if this system is introduced. This would need to be factored into the politics of any such initiative. A government that successfully deployed such a system would achieve its objective of reducing FMCG packaging waste to landfill, and if they control the third-party reuse/recycling process, then the system could be self-funding or even profitable. The regulatory monopoly issues that are inherent to this system would make any private ownership or control of this part of the system an extremely risky proposition. 


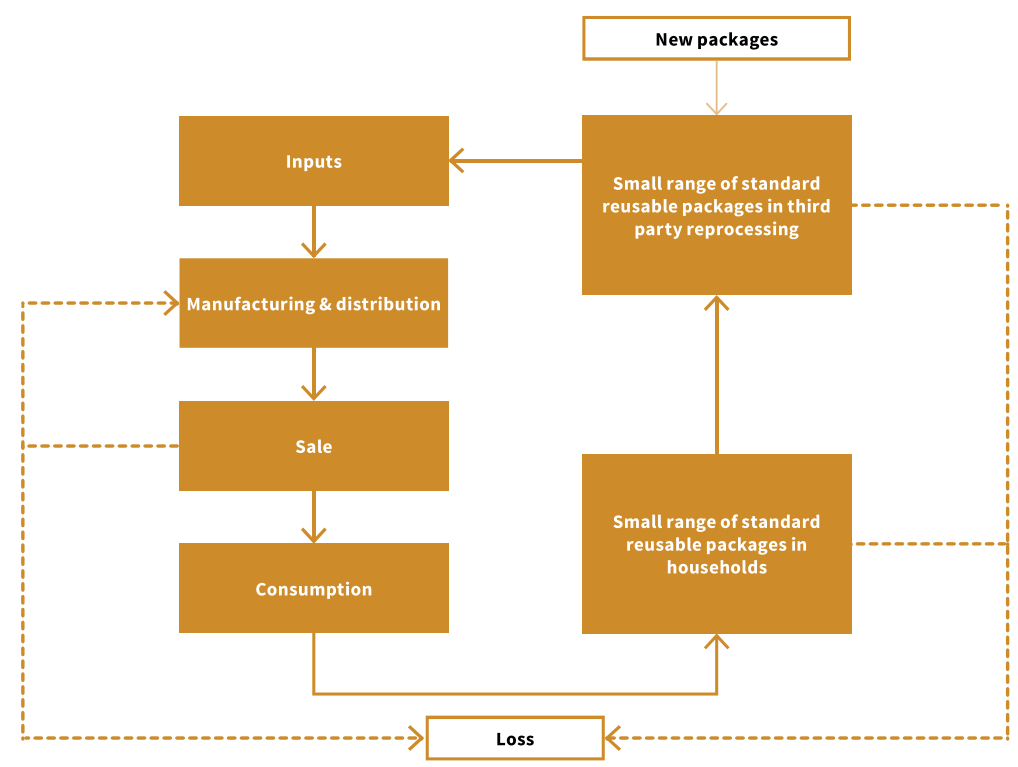

Figure 5. Third party controlled reusable packaging.

\section{Progressing to a Closed-Cycle FMCG System: Future Steps}

Achieving a closed-cycle FMCG packaging system on a national scale appears to be a depressingly enormous task. Yet, given widely known issues of pollution and resource depletion, achieving it also appears to be obligatory. The discussion presented here is by no means a comprehensive one, and the three approaches outlined above are only preliminary concepts.

The research team of which I am a member favours third party controlled reusable packaging as an initial avenue for development as it appears to have the capacity to meet all stakeholder requirements. The first step appears to be to develop the concept to the point where it can be presented as a service blueprint for large-format retailers via the following steps:

(1) Identify the minimum range (number) of packages that are necessary to present all packaged products in a large format retailer.

(2) Create a set of consumer performance specifications for each package type.

(3) Create a set of industry performance specifications for each package type.

(4) Identify which existing technologies (if any) would be able to meet these consolidated performance specifications in addition to being fully recyclable. 
(5) Develop a computer logistics programme to model flows of the packaging though a third-party reprocessing and remanufacturing system.

The outcome of this work, which in our estimation will take a minimum of three years and cost in excess of three million New Zealand dollars, will be a basic service blueprint for the system that would form a starting point for preliminary evaluation and negotiation between the stakeholders noted previously.

The main objective of any national scale closed-cycle system is reduction by 'before the event' design and supporting regulation. This requires very careful research to inform design that addresses the interests and concerns of all stakeholders, but particularly those of business. The capacity of business to bless or blight an initiative, independently of its merits to consumers, government and the environment, is amply demonstrated by the differential trajectories of Sodastream ${ }^{\circledR}$ and Nespresso ${ }^{\circledR}$ in our FMCG markets.

Funding: This research received no external funding.

Conflicts of Interest: The author declares no conflict of interest.

\section{References}

Barnes, Stuart J. 2019. Out of sight, out of mind: Plastic waste exports, psychological distance and consumer plastic purchasing. Global Environmental Change 58: 101943. [CrossRef]

Baruffaldi, Giulia, Riccardo Accorsi, Luca Volpe, Riccardo Manzini, and Fredrik Nilsson. 2019. Sustainable operations in reusable food packaging networks. In Sustainable Food Supply Chains. Cambridge: Academic Press, pp. 293-304.

Battini, Daria, Martina Calzavara, Alessandro Persona, and Fabio Sgarbossa. 2016. Sustainable packaging development for fresh food supply chains. Packaging Technology and Science 29: 25-43. [CrossRef]

Beitzen-Heineke, Elisa F., Nazmiye Balta-Ozkan, and Hendrik Reefke. 2017. The prospects of zero-packaging grocery stores to improve the social and environmental impacts of the food supply chain. Journal of Cleaner Production 140: 1528-41. [CrossRef]

Bloom, Peter. 2017. The Ethics of Neoliberalism: The Business of Making Capitalism Moral. Abingdon: Routledge.

Bratskeir, Kate. 2019. Loop Review: A Waste-Free Packaging Service for Returning Containers. Huffpost, October 28. Available online: https://www.huffpost.com/entry/loop-review-pl astic-free-delivery_n_5db35e42e4b006d4916e7f79 (accessed on 21 April 2020).

Brem, Alexander, Maximilian Maier, and Christine Wimschneider. 2016. Competitive advantage through innovation: The case of Nespresso. European Journal of Innovation Management 19: 133-48. [CrossRef] 
Brooks, Amy L., Shunli Wang, and Jenna R. Jambeck. 2018. The Chinese import ban and its impact on global plastic waste trade. Science Advances 4: eaat0131. [CrossRef]

Caffeininformer.com. 2019. Nespresso Original Line Caffeine, "Each Standard Arabica Capsule Contains 5 grams of Coffee". Available online: https://www.caffeineinformer.com/caffein e-content/nespresso-coffee-capsules (accessed on 23 December 2019).

Cheng, Karen. 2019. Sustainable Packaging Approaches for Current Waste Challenges. Ph.D. dissertation, Massachusetts Institute of Technology, Cambridge, MA, USA.

Christensen, Clayton M., Michael E. Raynor, and Rory McDonald. 2015. What is disruptive innovation? Harvard Business Review 93: 44-53.

Chung, Sai Ho, Hoi Lam Ma, and Hing Kai Chan. 2018. Maximizing recyclability and reuse of tertiary packaging in production and distribution network. Resources, Conservation and Recycling 128: 259-66. [CrossRef]

Coffee Lovers New Zealand. 2019. Retail Description of Reusable Nespresso Pod. Available online: https://www.coffeelovers.co.nz/products/nespresso-stainless-steel-refillable-co ffee-capsule-coffee-tamper-reusable-coffee-podC (accessed on 23 December 2019).

Dando, Tansy. 2019. European Aluminium Can Recycling Rate Reaches 74.5 per cent. Resource.co, October 15. Available online: https://resource.co/article/european-alumini um-can-recycling-rate-reaches-745-cent (accessed on 21 April 2020).

de Oliveira, Elizabeth Real, and Paula Rodrigues. 2015. The importance of corporate social responsibility in the brand image-The "Nespresso" case study. International Journal of Engineering and Industrial Management 4: 77-87.

Dhebar, Anirudh. 2016. Razor-and-Blades pricing revisited. Business Horizons 59: 303-10. [CrossRef]

Dobush, Grace. 2019. The brutal reality of being the World's 'best' recycler. Huffington Post, July 19. Available online: https://www.huffpost.com/entry/germany-recycling-reality_n_ 5d30fccbe4b004b6adad52f8 (accessed on 21 April 2020).

European Community (EC). 1997. Commission Decision of 8 January 1997 Establishing the identification system for packaging materials pursuant to European Parliament and Council Directive 94/62/EC on packaging and packaging waste. Official Journal of the European Communities, L50/28. Available online: https://eur-lex.europa.eu/legal-content/ EN/TXT/PDF/?uri=CELEX:31997D0129\&from=EN (accessed on 19 February 2020).

EEA (European Environment Agency). 2019. The Plastic Waste Trade in the Circular Economy (Briefing). October 28. Available online: https://www.eea.europa.eu/themes/waste/resou rce-efficiency/the-plastic-waste-trade-in (accessed on 21 April 2020).

Elbedweihy, Alaa M., Chanaka Jayawardhena, Mohamed H. Elsharnouby, and Tamer H. Elsharnouby. 2016. Customer relationship building: The role of brand attractiveness and consumer-brand identification. Journal of Business Research 69: 2901-10. [CrossRef]

Ellickson, Paul B., and Sanjog Misra. 2008. Supermarket pricing strategies. Marketing Science 27: 811-28. [CrossRef] 
Flaws, Bonnie. 2019. Countdown's BYO container scheme goes nationwide. Stuff, July 29. Available online: https://www.stuff.co.nz/business/114556623/countdowns-byo-containe r-scheme-goes-nationwide (accessed on 23 December 2019).

Fox, Hannah. 2019. Which Coffee Pod Brands Are the Most Eco-Friendly? Which, April 22. Available online: https://www.which.co.uk/news/2019/04/which-coffee-pod-brands-are-t he-most-eco-friendly/ (accessed on 21 April 2020).

Gabbitas, Josh. 2018. Campaigners Call for Starbucks to Honour Pledge to Bring in ' $100 \%$ Recyclable' Cup. The Independent, March 6. Available online: https://www.independent.co.uk/news/business/news/starbucks-recyclable-co ffee-cup-pledge-disposable-campaigners-call-late-levy-a8237246.html (accessed on 21 April 2020).

Gell, Fiona. 2019. The Blue Planet effect: The plastics revolution is just the start. The Guardian, March 29. Available online: https://www.theguardian.com/commentisfree/2019/mar/25/ plastics-revolution-marine-life (accessed on 21 April 2020).

Gunther, Marc. 2015. The good, the bad and the ugly: Sustainability at Nespresso. The Guardian, May 27. Available online: https://www.theguardian.com/sustainable-business/2015/ma y/27/nespresso-sustainability-transparency-recycling-coffee-pods-values-aluminum (accessed on 21 April 2020).

Hamlin, Robert P. 2010. Cue-based decision making. A new framework for understanding the uninvolved food consumer. Appetite 55: 89-98. [CrossRef]

Hamlin, Robert P., David Bishop, and Damien W. Mather. 2015. 'Marketing earthquakes' A process of brand and market evolution by punctuated equilibrium. Marketing Theory 15: 299-320. [CrossRef]

Han, Jia-Wei, Luis Ruiz-Garcia, Jian-Ping Qian, and Xin-Ting Yang. 2018. Food packaging: A comprehensive review and future trends. Comprehensive Reviews in Food Science and Food Safety 17: 860-77. [CrossRef]

Hickman, Leo. 2012. Light goes out for incandescent bulbs. The Guardian, August 31. Available online: https://www.theguardian.com/environment/2012/aug/31/lightbulbs-incandesc ent-europe (accessed on 21 April 2020).

Hoornweg, Daniel, Perinaz Bhada-Tata, and Christopher Kennedy. 2015. Peak waste: When is it likely to occur? Journal of Industrial Ecology 19: 117-28. [CrossRef]

Idumah, C. I., M. Zurina, J. Ogbu, J. U. Ndem, and E. C. Igba. 2019. A review on innovations in polymeric nanocomposite packaging materials and electrical sensors for food and agriculture. Composite Interfaces 27: 1-72. [CrossRef]

Kaiser, Katharina, Markus Schmid, and Martin Schlummer. 2018. Recycling of polymer-based multilayer packaging: A review. Recycling 3: 1. [CrossRef]

Kelsey, Jane. 2019. The Trans-Pacific Partnership Agreement and the Regional Comprehensive Economic Partnership: A Battleground for Competing Hegemons? In Free Trade Agreements. Singapore: Springer, pp. 11-34. 
Keramitsoglou, Kiriaki M., and Konstantinos P. Tsagarakis. 2018. Public participation in designing the recycling bins to encourage recycling. Sustainability 10: 1240. [CrossRef]

Khandelwal, Harshit, Hiya Dhar, Arun Kumar Thalla, and Sunil Kumar. 2019. Application of life cycle assessment in municipal solid waste management: A worldwide critical review. Journal of Cleaner Production 209: 630-54. [CrossRef]

Knoblauch, Doris, Linda Mederake, and Ulf Stein. 2018. Developing countries in the lead-What drives the diffusion of plastic bag policies? Sustainability 10: 1994. [CrossRef]

Laville, Sandra. 2018. UK plastics recycling industry under investigation for fraud and corruption. The Guardian, October 19. Available online: https://www.theguardian.com/environmen $\mathrm{t} / 2018 /$ oct/18/uk-recycling-industry-under-investigation-for-and-corruption (accessed on 21 April 2020).

Levitt, Tom. 2019. Cut the wrap! UK dairy farm aims to be first to go single-use plastic-free. The Guardian, November 28. Available online: https:/www.theguardian.com/environment/2019/nov/28/scottish-dairy-farmaims-to-become-uks-first-to-go-single-use-plastic-free-mossgiel-ayrshire (accessed on 21 April 2020).

Lobina, Emanuale. 2019. UK: Strong and Weak Lock-in of Water Governance Outcomes in England. In Facing the Challenges of Water Governance. Cham: Palgrave Macmillan, pp. 155-88.

Ma, Yuhui. 2018. Changing Tetra Pak: From waste to resource. Science Progress 101: 161-70. [CrossRef]

Majdinasab, Alireza, and Qiuyan Yuan. 2019. Post-consumer cullet and potential engineering applications in North America. Resources, Conservation and Recycling 147: 1-9. [CrossRef]

McNaughton, Sean, and Kelsey Nowakowski. 2019. How China's plastic waste ban forced a global recycling reckoning. National Geographic, June. Available online: https://www.nationalgeographic.com/magazine/2019/06/china-plastic-waste-ba n-impacting-countries-worldwide/ (accessed on 21 April 2020).

Meherishi, Lavanya, Sushmita A. Narayana, and K. S. Ranjani. 2019. Sustainable packaging for supply chain management in the circular economy: A review. Journal of Cleaner Production 237: 117582. [CrossRef]

Mendoza, Joan Manuel F., Francesco D’Aponte, Diego Gualtieri, and Adisa Azapagic. 2019. Disposable baby diapers: Life cycle costs, eco-efficiency and circular economy. Journal of Cleaner Production 211: 455-67. [CrossRef]

Ministry for the Environment (NZ). 2019. Phase out of Single-Use Plastic Shopping Bags. Available online: https://www.mfe.govt.nz/consultation/plasticshoppingbags (accessed on 21 April 2020).

Nemat, Babak, Mohammad Razzaghi, Kim Bolton, and Kamran Rousta. 2019. The role of food packaging design in consumer recycling behavior-A literature review. Sustainability 11: 435. [CrossRef] 
Nielsen, Tobias Dan, Karl Holmberg, and Johannes Stripple. 2019. Need a bag? A review of public policies on plastic carrier bags-Where, how and to what effect? Waste Management 87: 428-40. [CrossRef]

O'Dowd, Adrian. 2018. Latest legal challenge to tobacco plain packaging is rejected by the World Trade Organization. BMJ: British Medical Journal (Online) 361: k2878. [CrossRef]

Osland, Asbjørn, and Lori Luo. 2019. Environmental Sustainability, Sugar Consumption, and Sodastream. Thousand Oaks: SAGE Publications.

Parker, Laura. 2019. Plastic bag bans are spreading. But are they truly effective? National Geographic, April. Available online: https://www.nationalgeographic.com/environment/2 019/04/plastic-bag-bans-kenya-to-us-reduce-pollution/ (accessed on 21 April 2020).

Pfluger, Richard. A. 1975. Soluble coffee processing. In Solid Wastes: Origin, Collection, Processing, and Disposal. Edited by Charles. L. Mantell. New York: Wiley.

Poortinga, Wouter, and Louise Whitaker. 2018. Promoting the use of reusable coffee cups through environmental messaging, the provision of alternatives and financial incentives. Sustainability 10: 873. [CrossRef]

Rahimi, AliReza, and Jeannette M. García. 2017. Chemical recycling of waste plastics for new materials production. Nature Reviews Chemistry 1: 0046. [CrossRef]

Rezaei, Jafar, Athanasios Papakonstantinou, Lori Tavasszy, Udo Pesch, and Austin Kana. 2019. Sustainable product-package design in a food supply chain: A multi-criteria life cycle approach. Packaging Technology and Science 32: 85-101. [CrossRef]

Righter, Catalina. 2019. Green seats: Benches made from recycled bags debut at South Carroll High. Carroll County Times, June 18. Available online: https://www.baltimoresun.com/maryland/carr oll/news/cc-bags-to-benches-20190617-story.html (accessed on 21 April 2020).

Romeo, Peter. 2018. Restaurants rethink the disposable coffee cup. Restaurant Business, December 13. Available online: https://www.restaurantbusinessonline.com/beverage/re staurants-rethink-disposable-coffee-cup (accessed on 2 July 2020).

Schießl, Michaela. 2012. Dictatorship of the Bureaucrats' Light-Bulb Ban Casts Shadow over EU Democracy. Spiegel Online, August 31. Available online: https://www.spiegel.de/international/e urope/eu-light-bulb-ban-illuminates-power-struggle-in-brussels-a-852931.html (accessed on 21 April 2020).

Schmidt, Anthony T. 2018. Keep it Simple: Making it easy is the key to recycling success. Waste+ Water Management Australia 45: 2.

Silva, Diogo Aparecido Lopes, Gece Wallace Santos Reno, Gustavo Sevegnani, Tacila Berkenbrock Sevegnani, and Oswaldo Mário Serra Truzzi. 2013. Comparison of disposable and returnable packaging: A case study of reverse logistics in Brazil. Journal of Cleaner Production 47: 377-87. [CrossRef]

Slaper, Timothy F., and Tanya J. Hall. 2011. The triple bottom line: What is it and how does it work. Indiana Business Review 86: 4-8.

Stahel, Walter R. 2016. The circular economy. Nature 531: 435-38. [CrossRef] 
Sverdrup, Harald Ulrik, Anna Hulda Olafsdottir, and Kristin Vala Ragnarsdottir. 2019. On the long-term sustainability of copper, zinc and lead supply, using a system dynamics model. Resources, Conservation and Recycling X: 100007.

Taylor, Rebecca L. C. 2019. Bag leakage: The effect of disposable carryout bag regulations on unregulated bags. Journal of Environmental Economics and Management 93: 254-71. [CrossRef]

Tisserant, Alexandre, Stefan Pauliuk, Stefano Merciai, Jannick Schmidt, Jacob Fry, Richard Wood, and Arnold Tukker. 2017. Solid waste and the circular economy: A global analysis of waste treatment and waste footprints. Journal of Industrial Ecology 21: 628-40. [CrossRef]

Trubnikov, Dmitrii. 2017. Analysing the impact of regulation on disruptive innovations: The case of wireless technology. Journal of Industry, Competition and Trade 17: 399-420. [CrossRef]

United Nations General Assembly (UNGA). 2015. Transforming Our World: The 2030 Agenda for Sustainable Development. A/RES/70/1. New York: UNGA. Available online: http s://www.un.org/ga/search/view_doc.asp?symbol=A/RES/70/1andLang=E (accessed on 21 April 2020).

United Nations Environment. 2017. Accelerating the Global Adoption of Energy Efficient Lighting. Paris: United Nations Environment.

USEPA (United States Environmental Protection Agency). 2017. Containers and Packaging: Product-Specific Data. USEPA. Available online: https://www.epa.gov/facts-and-figure s-about-materials-waste-and-recycling/containers-and-packaging-product-specific-data (accessed on 21 April 2020).

Vanne, Karine. 2019. The problem with America's bulk food bins. Eater, October. Available online: https://www.eater.com/2019/10/29/20938213/bulk-food-grocery-store-supermar ket-environmental-impact-plastic-packaging (accessed on 21 April 2020).

Velis, Costas A., David C. Wilson, and Christopher R. Cheeseman. 2009. 19th century London dust-yards: A case study in closed-loop resource efficiency. Waste Management 29: 1282-90. [CrossRef]

Walker, Helen, Lucio Di Sisto, and Darian McBain. 2008. Drivers and barriers to environmental supply chain management practices: Lessons from the public and private sectors. Journal of Purchasing and Supply Management 14: 69-85. [CrossRef]

Warner, Charles, Hilary Vick, Paul Phillips, and Andrew Lappage. 2015. The 'Real Nappies for London' Scheme 2007-2012: Key findings to drive a future waste prevention agenda through landfill reduction. The Journal of Solid Waste Technology and Management 41: 28-40. [CrossRef]

Webster, Ben. 2019. Britain sends plastic waste to countries with heavily polluted rivers. The Times, December 13. Available online: https://www.thetimes.co.uk/article/rivers-of-w aste-plastic-created-by-britains-exported-rubbish-7r2wlxbf8 (accessed on 21 April 2020). 
Winter, Daniel. 2019a. Top 100 global brands 2019: The full ranking. Financial Times, June 11. Available online: https://www.ft.com/content/3a3419f4-78b1-11e9-be7d-6d846537acab (accessed on 21 April 2020).

Winter, Lydia. 2019b. 10 best reusable coffee cups. The Independent, February 7. Available online: https://www.independent.co.uk/extras/indybest/house-garden/coffee/best-reu sable-coffee-cup-a7510606html (accessed on 21 April 2020).

Woodcock, Andrew. 2019. Plastic bag usage in supermarkets down 90 per cent since introduction of $5 p$ charge in 2015. The Independent, July 31. Available online: https://www.independent.co.uk/news/uk/politics/plastic-bag-charge-supermarkets -figures-reduction-a9029996.html (accessed on 21 April 2020).

WRAP (Waste and Resources Action Programme). 2010. Life Cycle Assessment of Example Packaging Systems for Milk. Banbury: WRAP.

Wyrwa, Joanna, and Anetta Barska. 2017. Innovations in the food packaging market: Active packaging. European Food Research and Technology 243: 1681-92. [CrossRef]

(C) 2020 by the author. Licensee MDPI, Basel, Switzerland. This article is an open access article distributed under the terms and conditions of the Creative Commons Attribution (CC BY) license (http://creativecommons.org/licenses/by/4.0/). 


\title{
Smell and Sustainability: Can Odour Shorten the Life Span of Clothing?
}

\author{
Rachel McQueen, Jennifer Kowton and Lauren Degenstein
}

\section{Introduction}

Under Sustainable Development Goal 12, the UN Economic Programme noted a rapid increase in both worldwide material consumption and per capita material footprint, with the latter jumping from 7.3 tonnes per person in 1990 to 10.9 tonnes in 2015 (UN Secretary General 2019). Consequently, landfilled clothing and textile waste pose significant environmental problems, as textile waste has increased considerably over the last few decades due to the increased consumption of clothing (Morgan and Birtwistle 2009; Tokatli et al. 2008). Incineration and landfilling have accounted for about $84 \%$ of textile disposal in the US for more than a decade; both the volume of this waste and the cost to manage it on a per tonne basis are growing across the country (Johnson and Adler 2017). Clothing made from petroleum sources does not biodegrade, which adds to the growing problem of non-biodegradable waste (Geyer et al. 2017). Carbon dioxide is also produced during decomposition of organic materials, and methane, a potent greenhouse gas, is produced due to its incomplete biodegradation within landfills in the absence of oxygen (European Commission 2010). Despite methane capture technology and utilisation of landfill gas as a fuel source, it is still estimated that methane emissions from Canadian landfills make up 20\% of the total national methane emissions (Government of Canada 2017). Incinerating textiles as an alternative to landfilling can also pose detrimental environmental and health impacts. If appropriate capture technology is not used, persistent organic pollutants such as dioxins can be released during incineration, and the ash from the incineration process still needs to be landfilled (Rabl et al. 2008; European Commission 2010).

In the USA, it is estimated that 21 billion pounds (9.5 million tonnes) of textile waste ends up in the landfill each year (Council for Textile Recycling 2017). In the UK, government initiatives aimed at improving the sustainability of the fashion and textiles industry, including focusing on consumer use, have resulted in reductions of 50,000 tonnes of textiles ending up in household waste since 2012 (WRAP 2017). While this is an encouraging start, 300,000 tonnes of clothing still enter household waste that is destined for landfilling or waste-to-energy initiatives (WRAP 2017). According to Value Village's State of Reuse Report (Value Village 2018), the average 
North American consumer disposes of approximately $37 \mathrm{~kg}$ of used clothing each year. As such, textile waste accounts for $5 \%-10 \%$ of all materials in Canadian landfills annually (Weber 2015). Therefore, in order to keep clothing out of the waste stream, it is necessary to understand motivations for why consumers choose to throw clothing in the trash rather than use routes that may extend the life of clothing (Norum 2017).

Clothing disposal in the literature refers to the process of getting rid of an item of clothing that the consumer no longer wants to wear (Laitala 2014). Jacoby et al. (1977) describe three options available to consumers when they decide to dispose of a product: to keep the product, permanently dispose of it, or temporarily dispose of it. Repurposing the item may extend the life of the garment considerably. Through the process of upcycling, unwanted clothing can continue to be worn or reconstructed as something else. Alternatively, damaged or otherwise undesirable clothing could be used as rags (i.e., downcycled), both of which more closely align with the UNEP's Sustainable Development Goal 12.5 recommendation (UN Sustainable Development Goals n.d.). Most disposal methods involve permanent disposition, which may include selling it, giving it away, donating it, or throwing it in the trash (Laitala 2014). The choice of disposition option is influenced by many intrinsic (e.g., recycling behaviour, environmental awareness, fashion consciousness) and extrinsic factors (e.g., convenience of recycling/donating facilities, condition/quality of clothing) (Bianchi and Birtwistle 2010; Laitala and Boks 2012). Clothing disposal behaviours such as selling, giving away (usually to friends and family) or donating to charity are considered positive environmental behaviours as they keep unwanted clothing out of landfills (Bianchi and Birtwistle 2010). Furthermore, if the extension of the lifetime of an old garment leads to the displacement of the production, processing and disposal of another garment, then even further environmental savings are possible (WRAP 2017).

Discarding a garment directly in the trash is considered the least environmentally sustainable option that a consumer can make. Consumers may be more likely to throw away items that are damaged or deemed to be of "no use" to anyone else, perhaps due to poor quality materials or unfashionable items (Bianchi and Birtwistle 2010). When "laundering has not fulfilled its purpose" and odours are not effectively removed, Laitala et al. (2014, p. 142) state that consumers may use this as a reason to throw the garment away. Yet, the clothing disposal literature has rarely addressed the potential impact of odour and, if mentioned, it is often grouped with other changes that can occur to the garments during use (e.g., holes, fading) and prompt disposal (Laitala and Klepp 2011). This may be that persistent odour within clothing plays only a minor role in clothing disposition as a whole; however, 
exploratory research has suggested that odour can lead to early disposal, even when the clothing is otherwise deemed functional or wearable (Ehnes et al. 2011) and, therefore, merits further investigation.

Consumers make decisions everyday about the clothing they are going to wear and how that clothing item is going to meet their functional and/or aesthetic needs. Although consumers usually assess clothing on sensorial properties related to appearance (e.g., colour, design) and handle (e.g., softness, texture) or performance attributes (e.g., durability, resiliency), clothing fabrics can pick up odours during use or storage that may become perceptible to the wearer. This odour may then become another attribute impacting how a person assesses clothing. Clothing-related odours can come from a variety of sources, both internal and external to the human body (McQueen and Vaezafshar 2020). Odour perception is considered to be problematic because "olfaction intersects with social, cultural, and moral order" and, therefore, evokes judgments about the person, place or situation in which the perceiver finds themselves (Waskul and Vannini 2008, p. 53). North American consumers often develop cultural odour definitions formed through contextual relationships; therefore, the detection of odour, especially one that is seemingly out of context, can generate positive or negative assumptions about its source (Waskul and Vannini 2008). Clothing should not smell or, if it does, should smell of fresh scents associated with laundry detergent, indicative of cleanliness (Shove 2003). Yet, clothing that retains smells of sweat, becomes musty and stale, or picks up other environmental odours can generate a negative association and may impact the wearer's satisfaction with the garment.

Cooper (2005) argues that extending the life of a product is essential in moving toward sustainable consumption, as products will less likely be disposed of due to quality issues. Drawing upon scholarship in product satisfaction and consumer-product attachment, Niinimäki (2017) argues that a positive or pleasurable use experience deepens attachment to clothing items, making it less likely that specific clothing items will be discarded. Schifferstein and Zwartkruis-Pelgrim (2008) describe the degree of consumer-product attachment as "the strength of the emotional bond a consumer experiences with a durable product" (p. 1). Due to the emotional bond with a product, the owner will experience a sense of loss if the object is lost and is unlikely to want to dispose of it (Schifferstein and Zwartkruis-Pelgrim 2008). Enjoyment related to using the product and memories formed with the product were both associated with strong levels of attachment, whereas life-vision, self-identity, market value, reliability and utility were not (Schifferstein and Zwartkruis-Pelgrim 2008). From a sustainability point of view, developing and maintaining product attachment is 
important in order to avoid products being disposed of. Niinimäki (2017) positions her argument in sustainable clothing design toward extending the lifetime of clothing through the creation of positive or pleasurable use experiences with clothing, where enjoyment is experienced with wearing the clothing item. As described in an earlier article examining the emotional connection between a wearer and their clothing, Niinimäki and Armstrong (2013) demonstrate how experiential attachment could potentially prevent early disposal:

Clothing has a strong impact on our emotions, and it can elevate the wearer's mood. People feel attached to clothes because of their aesthetic beauty as well as through beauty experiences over time that develop in social situations and through positive multi-sensorial use experiences (p. 196).

In relation to our study, we are most interested in that "positive multi-sensorial" experience, as it provides justification for how odour perception applies to decreased use. Although Niinimäki and Armstrong (2013) discuss the importance of a pleasurable use experience in relation to continued ownership, it could also be concluded that a connection between odour detection and a particular item could facilitate a negative use experience that might initiate a premature disposal process.

In the present study, we explore Canadian consumers' experiences and perceptions of odour in clothing through focus group interviews and an online survey. We aimed to discover how prevalent the perception of odour in clothing was among textile consumers and how odour perception could influence their experience with clothing and impact their behaviours, particularly as it related to clothing disposal. We asked what types of odour consumers experience within their clothing and whether there were characteristics of clothing items they identified as being more susceptible to collecting and retaining odour. Through the perspective of odour as a negative use experience, we address the issues related to consumer dissatisfaction with odorous garments and the likelihood of premature clothing disposal.

\section{Materials and Methods}

A mixed-methods approach was taken, where qualitative and quantitative data were collected through focus group interviews and an online survey, respectively. This triangulation of data allowed for a more holistic examination of the research problem.

\subsection{Focus Group Interviews}

The topic of odour in clothing could be a potentially uncomfortable topic to discuss due to the personal and intimate nature of some odours. However, focus group 
interviews were considered to be suitable as a means to collect data on a subject that have seldom been previously reported (Morgan 1997). Furthermore, the use of humour and laughter through conversations in focus groups has been recognized as an effective means to elicit information about intimate topics that may border on the "taboo" and how it may impact sustainable practices (Browne 2016).

Between 2014 and 2017, the research team conducted eight focus group interviews. Each focus group had both female and male participants and ranged from a minimum of six to a maximum of ten participants. A total of 58 participants (41 females, 17 males) were involved. The interviews ranged from 60 to $90 \mathrm{~min}$ in length. Each focus group was moderated by two researchers, with the primary moderator $(\mathrm{JK})$ leading the discussion for all eight focus group interviews. At the beginning of the interviews, the participants completed a brief survey regarding general experience with odour in clothing. Guiding questions for the interviews began with participants being asked to recall and describe an item of clothing that they perceived to be odorous. Further questions related to discovering how odour in that clothing item made them feel; whether they had noticed if there were specific types of clothing that could become odorous; what they do with clothing if the odour persists; and what type of disposal methods are used when getting rid of odorous clothing.

Focus groups were audio-recorded with participant consent and transcribed verbatim. Two researchers analysed the transcripts and coded the data in order to identify common themes (Breen 2006).

\subsection{Survey}

We used quantitative survey data to assess whether consumers perceived odour in clothing and whether this led to premature disposal of clothing items. The survey also addressed the avenues of disposal for odorous versus non-odorous clothing items. The survey offset the qualitative focus group data as a larger group of Canadian consumers could be included in the study; however, the data elicited from the survey results were not as rich and detailed as the focus group interviews.

Quantitative data were collected using an online survey administered by Survey Monkey. A non-probability sample was selected using snowball sampling methods. People were asked whether they had ever disposed of clothing because it became too odorous to wear; people were then asked about what disposal methods they used for non-odorous clothing and then again for odorous clothing for six specific garment types (i.e., T-shirt, button-up shirt, sweater, jeans, athletic shirt, athletic pants). There were seven options for disposal methods: "keep the item but stop 
wearing it"; "sell it"; "give it to a friend/family member"; "donate it to charity"; "repurpose it (make it into something new)"; "use it as a rag"; or "put it in the trash". The majority of responses were scored based on a 5-point Likert-type scale: 1 "never"; 2 "rarely"; 3 "sometimes"; 4 "often"; 5 "always or almost always".

Clothing disposal data were analysed by comparing the method of clothing disposal for each clothing item for (1) non-odorous clothing and (2) odorous clothing. Multiple paired t-tests were carried out to compare means within each disposal method group. Since there were multiple t-tests conducted, differences among disposal methods were deemed to be significant if $p<0.001$.

\section{Results}

\subsection{Focus Group Interviews}

The survey completed by participants at the beginning of the focus group interviews indicated that the majority (i.e., 57 out of $58(98 \%)$ ) perceived odour within various clothing items they have owned. From the interviews it became apparent that (i) odour could come from different sources, but that body odour, particularly from the underarm region, was the most common; (ii) certain types of clothing can be more likely to pick up and retain odour; and (iii) persistently odorous clothing could lead to negative use experience and, consequently, premature disposal. These items were less likely to be disposed of in a way that would extend the life of the clothing item.

\subsubsection{Sources of Clothing Odour}

When discussing the different types of smell trapped in their clothing, participants in all eight focus groups agreed that body odour was of particular concern. This was not surprising given the close proximity of clothing to the body. All but one participant referenced body odour in their own clothing; however, perceptions of the frequency and/or intensity of the garment odour varied among participants. Frequent reference to the armpit region made it clear that underarm odour was the most common type of body odour and is considered unacceptable. Concerns with underarm odour were associated with work, formal and casual clothing as well as sportswear. Many participants also cited foot odour as being problematic, while a few also discussed genital odour. A number of other smells were presented as displeasing throughout the series of focus groups, these included food and spice smells; must from vintage clothing, cigarette or campfire smoke; odours present in specific workplaces (e.g., poultry farms, meat packing, oil rigs) and the odour of wet wool. Although participants in all focus groups declared these types 
of odour, the experiences were noted only by specific individuals, not the group as a whole.

Despite it being evident that odour on clothing was usually perceived to be unpleasant and generated negative associations with odorous clothing, there were a few participants who referred to odours on specific clothing items as pleasant. Two participants in the same focus group described how they enjoyed the smell of their scarves during winter as the fabric retained the smell of their own fragrances. Furthermore, some inherently unpleasant smells were considered to be pleasant, or at least not completely offensive, due to positive memory associations. For example, one female participant described the "endearing" smell of her vintage clothing:

I have some vintage kind of grandma clothes that, yeah, the smell doesn't really come out and it's almost, like, endearing. It's not really a good smell but it's kind of like, like a car that my grandpa gave me when I was 18-his old car. It's like, that grandpa smell wasn't coming out. It's not necessarily a good smell, but it's kind of like an endearing smell. So, like, some of my grandma's pieces are like, you just accept that they have a, a vintage smell to them (FG2).

\subsubsection{What Types of Clothing Smell?}

Our study revealed a trend in the types of clothing most often associated with odour retention. In relation to underarm body odour, participants acknowledged persistent odour in tops constructed from synthetic fibres, heavier knitted fabrics, and clothing designed to hug the underarm area. Participants described their negative experiences with synthetics; for example, one female participant stated that "synthetic fabrics, fibres annoy me ... they seem to absorb smells faster" (FG1). Whereas another described certain types of lightweight polyester shirts:

I also have experienced whenever I wear, you know those kind of sheer, polyester kind of chiffon shirts that are in fashion? Whenever I wear one of those, I can only wear that once before I have to wash it again because it definitely smells. And even if I take it off and I personally don't smell, it's like the fabric smells (FG4).

Her vivid description that the smell was a result of the interaction between her body and the sheer polyester fabric, and not her body alone, emphasised the role the synthetic fibre can play in intensifying odour. A third female participant claimed that she had learned from such experiences and is now 
a little bit better in my choices, but I think I remember some shirts that contained polyester in my early twenties that I would, you know, feel embarrassed to be wearing after a few hours. I'm like, ugh, what's wrong with this? (FG1)

These sentiments were held by the majority of participants, and it became apparent that even without knowing why, participants understood synthetic fibres extenuated odour. Some other participants specifically mentioned cheap polyester, such as the free polyester tops that were provided for entering sporting events, as being particularly problematic. Whereas, some participants commented that clothing made from natural fibres in general, or more specifically those made from wool, were far less odorous and did not emit strong body odours during or after being worn.

Other garment and fabric properties were also identified as significant in how much body odour may be picked up by the garment. An association between body odour and heavier, knitted fabrics was noted: "I perceive that the heavier the knit will absorb the smell ... it just makes me uncomfortable and I feel unclean" (FG2), highlighting the negative feeling associated with odorous clothing. This sense of anxiety, felt when a person wears clothing that they perceive to smell, was also expressed by another participant in relation to clothing that fit close to the underarm:

I wear cardigans a lot to work and I find those are the worst. I don't know if it's 'cause they hug your armpits, you know, they're really close to your skin and that's when I'm always like, oh god, do I stink? Do other people smell me? (FG3).

The relationship between odour and tight-fitting clothing was expressed by others, for example: "I think it's especially when, like the t-shirt or whatever you're wearing is especially close to your armpit, that's what I've noticed, the tightness" (FG6). Identifying particular characteristics of their smelly clothing resulted in some participants seeking out certain types of garments, and avoiding other types, in future purchases: "I'm now buying looser because I find the more, like the closer they fit to your skin, I think that's when it starts smelling a lot more. So, the looser the top is, I'm finding that it's better" (FG2). Similarly, another participant stated, "I will buy natural fibres and I will avoid anything that is a, um, unnatural" (FG3).

Throughout the focus group interviews, a number of participants raised certain clothing stores or clothing brands, sometimes comparing them with another, with which they had experienced odour developing quickly and persisting within certain types of garments. Such bad experiences had the potential to influence their 
future shopping purchases, exemplified in one participant's statement following a description about two cardigans she purchased from an online store: "I don't know what the specific fabric is or what it is, but I'm just not going to buy their cardigans anymore" (FG3).

Second-hand clothing was another category of clothing that a few participants mentioned throughout the focus group interviews. A specific musty smell associated with some types of vintage clothing was described, as well as the smell of a previous owner that may not come through until it was worn. Participants who mentioned such odours arising from second-hand clothing were not necessarily deterred from buying second-hand clothing, but it did alter their behaviour when it came to laundering, storing and even what occasions to wear the offending clothing item.

\subsubsection{Options for Dealing with Persistently Odorous Clothing}

The focus group interviews confirmed that many people have experienced odour building up within certain items of clothing to the point that the odour could not be removed and/or was perceived to return quickly when the freshly laundered item was worn again. Participants then dealt with persistently odorous clothing in a variety of ways. These decisions can be viewed as potential life-extending behaviours (e.g., keep, donate or give away the item) or life-shortening behaviours (e.g., make into rags, put into the trash).

When persistent odour was present, participants were generally not inclined to extend the life of odorous clothing. Giving away an odorous item of clothing to someone they knew was never an option, nor was reselling it. However, a few participants stated that they would include odorous clothing in clothing piles intended for donation along with other non-odorous clothing. As one female participant said, "I'm just lazy, I'll throw everything in one bag. And if it's stained too. I'll donate that too because I can't resale it" (FG2), indicating the role that convenience plays in this sorting decision. Others felt that it was up to the organization they donated their clothing to make the decision about whether it was acceptable for resale. As another female participant stated:

I probably would [donate it], 'cause when I donate it I would wash it and it would smell okay and if that person who purchased it or got it found out it did that, hopefully they would get rid of it (FG3).

Even though specific items of clothing may have been deemed annoyingly odorous to wear, some recognised that this odour might not be perceptible to others. As one individual explained, she had donated an odorous curling jacket "because I thought maybe it was just me that was, you know, holding onto a memory of a 
scent or something like that, so I did donate that one" (FG5). Therefore, although an individual may have detected odour in their clothing, the smell could simply be considered in the mind of the wearer and unnoticeable to others.

Despite a few participants admitting they would donate clothing they perceived as odorous, a higher proportion indicated that donation was not an option as they would not donate clothes that they "can't handle the smell of" (FG1). Generally, this was because many felt if clothing was too smelly for them, then it would be too smelly for someone else. As one participant put it, "if I think it smells really bad, I don't think anyone else should have to deal with the smell" (FG1). However, that same participant explained that there could be some exceptions:

well, sometimes I'll ask if someone, like someone else if it stinks that bad and if they say no, then I'll consider donating it, 'cause I've seen, like I think I have a strong sense of smell (FG1).

Her reflection about determining where an odorous clothing item should go supports the earlier statement that some people may donate clothing they perceive as odorous because others will not detect it.

Some participants also explained that they would keep clothing they perceived to be odorous because they could not bring themselves to get rid of it. When this occurred, participants would keep the clothing item in their possession but not wear it, or delegate it to another purpose where persistent odour was less of a concern. Motivations for keeping these items included guilt about throwing them in the trash, because it was a waste of money to throw them out, or because the clothing item had sentimental value. Some participants would use an odorous clothing item for another specific purpose, in a sense, repurposing the garment. If the item was suitable, participants would use the garment to exercise in, do yard work, camp or wear for occupations which were by nature dirty and odorous (e.g., underneath coveralls in the oil rig). Despite the perception that odour development was a negative attribute, some participants described their attachment to specific clothing items that prevented them from getting rid of the garment. One participant described her attachment to a dress she had worn heavily for weeks while travelling:

I remember getting home with this dress and being like, I think we're done now. I don't think I can. I think it's absorbed so much odour at this point, that I, and, but that was four years ago and I still wear the dress sometimes (FG3). 
A dress that she wore when she was "so happy" could not be discarded and she would continue to wear it again when on holiday. Despite the smell she could justify why she could still wear it:

So that's why I call it my camping dress so that it's understood that it's my dirty, comfy dress. Nobody can judge me because I'm making this conscious choice to wear this thing (FG3).

Another participant expressed her strong attachment to, and unwillingness to part with, an odorous shirt:

I like the look and the cut of it and that, like there's so many things that I like about it, that I'm reluctant to give up on it yet ...... it's such a lovely shirt and it was a freakin' lot of money so I'm, you know, I think it needs a little more time from the price tag to when I can actually throw it away (FG3).

The design and cut of the shirt, as well as the financial cost created a level of attachment influencing her decision to hold onto the shirt for longer, despite its persistent smell.

Repurposing odorous clothing into rags was an option explored by many of the participants.

If I find something has a persistent odour and I'm done with it, then I assume no one's going to want it so I cut it up and use it for rags at work to wipe oil off things and stuff like that (FG2).

However, there was often a caveat that the fabric needed to be suitable as a rag. As one participant stated when explaining how she dealt with odorous clothing, "I'd probably turn it into a rag or throw it out if it wasn't rag-able" (FG3). More specifically participants offered insight into what fabrics they deemed unacceptable as rags. For example, in relation to a cotton/polyester work uniform, one participant expressed "it's also not made of really a nice fabric for using for rags because it'll actually scratch up a lot of surfaces" (FG1). In another instance, a participant stated, "I found that with polyester shirts I don't like to repurpose them as a cloth because they don't really soak up water very well. So, I end up chucking them" (FG4). Towels, however, were deemed appropriate for such a purpose.

Throughout the focus group discussions, it became clear that if odour became persistent- to the point that the person no longer wanted to wear it-the most common disposal method was to throw them into the trash. As one participant explained: "Garbage, usually garbage because I don't want to pass that on to someone 
else, you know, if it's not in nice condition, I don't want to donate it even" (FG5). A few participants did acknowledge that the trash would be their choice of disposal 'in theory' but had never actually had to throw out odorous clothing as, for them, laundering was sufficient to remove odour.

\subsection{Survey Results}

A total of 240 usable responses were received for this survey after removal of responses from outside of Canada. Of this, $85 \%$ of the respondents were female and $15 \%$ male. Over half of the respondents were ranged between 18 and 35 years old (percent of age in years: $18-25=20.4 \%, 26-35=33.8 \%, 36-45=22.1 \%, 46-55=10.0 \%$, $56-65=10.0 \%, 66+=3.8 \%)$. The majority of respondents (97.5\%) indicated they had noticed odour in an article of clothing they owned after wear or use. Of the 234 respondents who detected odour in their clothing, approximately half $(49.6 \%)$ reported that they had, at some time, gotten rid of an item of clothing because it became too odorous to wear. The most common type of odour was sweat-related body odour, followed by food odour (Table 1).

Table 1. Level of frequency at which different types of odours are perceived in clothing $(n=234)$.

\begin{tabular}{cc} 
Types of Odour & Mean ${ }^{1}$ (SE) \\
Body odour (sweat) & $3.52(0.23)$ \\
Food odour (cooking smells) & $2.65(0.17)$ \\
Musty odour (earthy/stale/damp) & $2.28(0.15)$ \\
Musky odour (pungent, sweet, heady, musk) & $2.20(0.14)$ \\
Body odour (e.g., unwashed hair, illness) & $2.12(0.14)$ \\
\hline${ }^{1}$ Scale: 1 = never; 2 = rarely; $3=$ sometimes; $4=$ often; $5=$ always or almost always.
\end{tabular}

The greatest number of respondents disposed of athletic shirts $(n=80)$ at some time, as they became too odorous to wear. This number represented one-third of the total number of respondents. Slightly less than one-third of respondents noted having experienced T-shirts $(n=72)$ becoming too odorous to wear, followed by button-up shirts $(n=44)$ and sweaters $(n=29)$. Fewer respondents reported choosing to stop wearing athletic pants $(n=19)$ or jeans $(n=11)$ due to a persistent build-up of odour. The methods of disposal that respondents used on clothing without odour compared to odorous clothing are shown for the two clothing types that the highest proportion 
of respondents indicated they have disposed of due to persistent odour. Figure 1 shows the results for T-shirts and Figure 2 shows the results for athletic shirts.

The most common method for disposing of non-odorous T-shirts and athletic shirts was donation. However, for athletic shirts, donating to charity did not differ significantly from being thrown in the trash $(\mathrm{t}(158)=1.63, \mathrm{NS})$; whereas, donation and putting in the trash did differ for T-shirts $(\mathrm{t}(142)=6.74, p<0.001)$. The next most common method for disposing of a T-shirt was to downcycle the item into a rag. Selling or repurposing these items of clothing were the least common methods of disposal for the non-odorous clothing categories. When a T-shirt or athletic shirt had a persistent odour on it, the clothing was more likely to be thrown in the trash. This option differed significantly from the other methods of disposal.

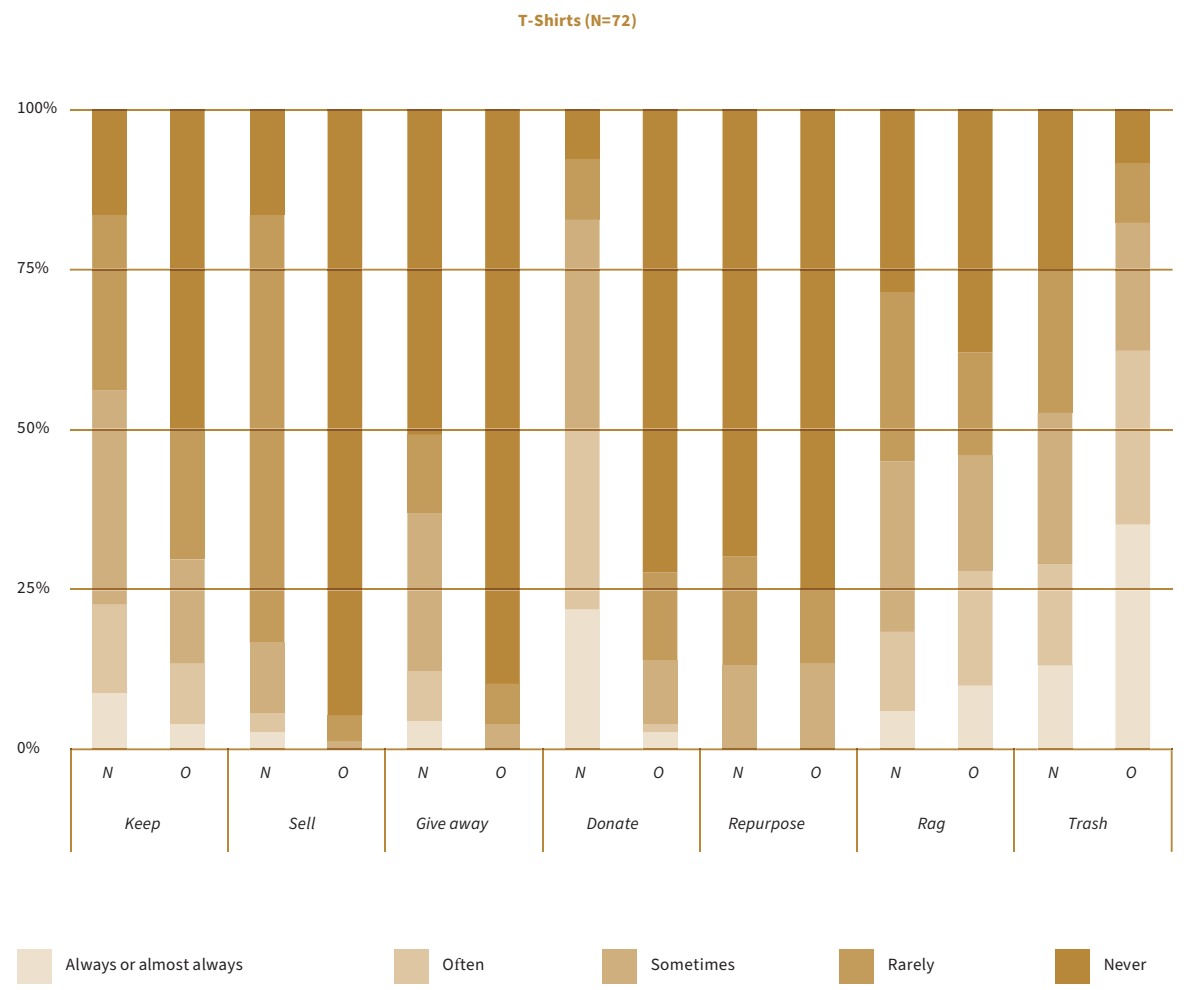

Figure 1. Frequency of disposal method for non-odorous (N) T-shirts and odorous (O) T-shirts. Source: Own illustration. 


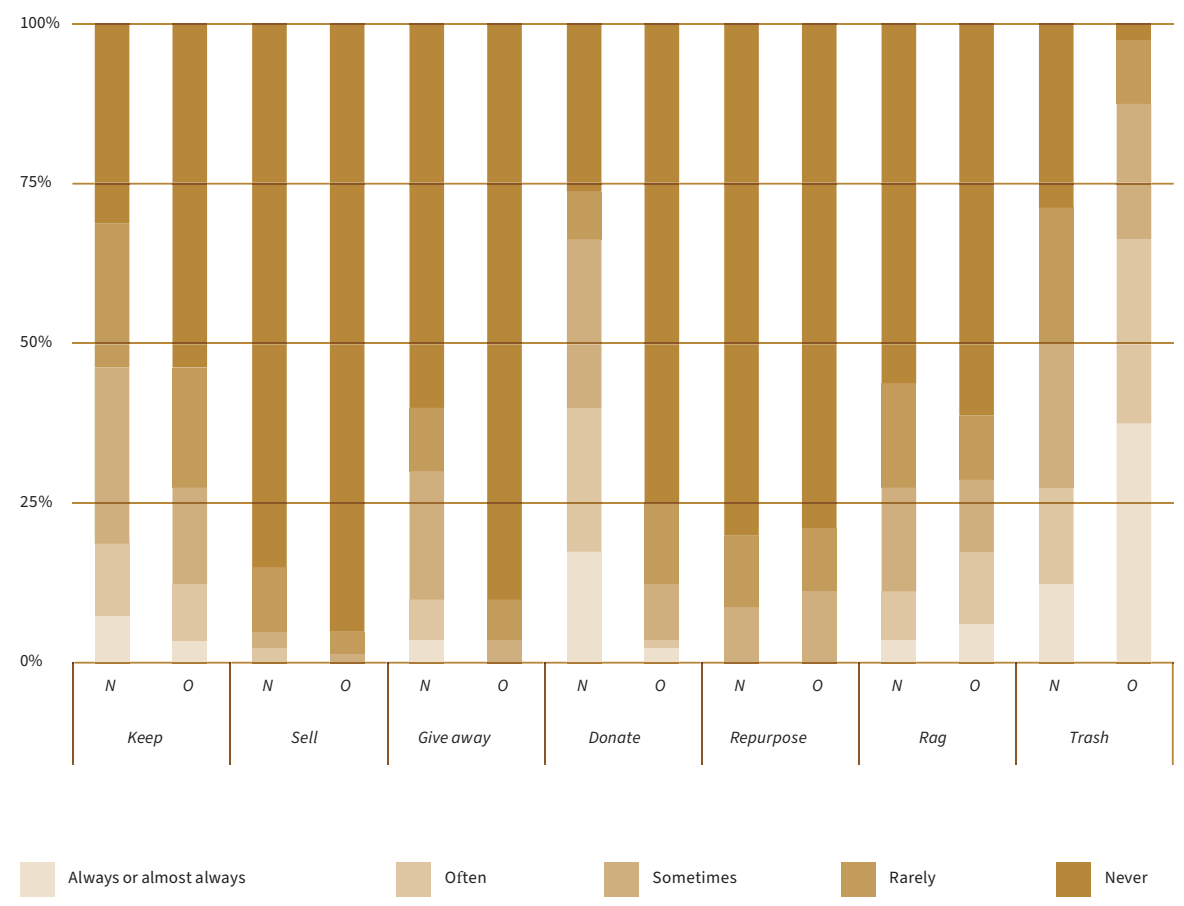

Figure 2. Frequency of disposal method for non-odorous (N) athletic shirts and odorous (O) athletic shirts. Source: Own illustration.

The method of disposal for non-odorous $(\mathrm{N})$ clothing differed significantly from disposal methods for odorous $(\mathrm{O})$ clothing for six of the seven disposal categories for T-shirts and five of the disposal categories for athletic shirts. Respondents were less likely to keep, sell, give away, donate or repurpose odorous T-shirts and were more likely to put odorous T-shirts directly in the trash. Respondents were just as likely to make an odorous clothing item into a rag as they were if it did not have any perceptible odour on it. Athletic shirts were unlikely to be repurposed even when odour was not present, which may explain why there was no change in this disposal method when odour was present.

Respondents also indicated that they were likely to have kept the item of clothing if it was still in good condition but had not become odorous (T-shirt: $4.28 \pm 0.84$; Athletic shirt: $4.24 \pm 0.93$ ), with the majority of respondents stating they would "often" 
or "always or almost always" have kept their odorous clothing. All respondents were asked whether they had ever disposed of clothing. Of those who responded yes $(n=220)$, odour was one of the least common reasons for disposing of clothing, with clothing being worn out/having rips, never wearing it, no longer suiting their taste or no longer fitting being far more common methods for disposing of clothing (Table 2).

Table 2. Level of frequency for reasons why respondents dispose of clothing $(n=220)$.

\begin{tabular}{cl} 
Reason for Disposal & Mean ${ }^{1}(\mathrm{SE})$ \\
Worn out (holes, rips, etc.) & $3.76(0.25)$ \\
Never wear & $3.55(0.24)$ \\
No longer suits my tastes & $3.33(0.22)$ \\
Doesn't fit & $3.31(0.22)$ \\
Found a better substitute & $2.94(0.20)$ \\
Need the storage space & $2.60(0.17)$ \\
Clothing is odorous & $2.07(0.14)$ \\
Negative memory associations & $1.72(0.12)$ \\
\hline${ }^{1}$ Scale: $1=$ never; 2 = rarely; 3 = sometimes; $4=$ often; $5=$ always or almost always.
\end{tabular}

\section{Discussion}

Odours can arise from a multitude of different sources. The most common source of clothing-related odour was body odour associated with sweat and, more specifically, odour arising from the underarm region. Not all odours may be considered unpleasant; nevertheless, there was a consensus that most odours picked up during wear were unacceptable and may even have become a source of embarrassment, particularly if the wearer thought others might also smell them. This embarrassment, or self-consciousness of wearing clothing that has become smelly, aligns with the findings of Waitt (2014) where "the aroma of sweat often prompted strong visceral reactions of embarrassment and discomfort" (p. 476). Wearing clothes that do not smell, or smell of "fresh" laundry scents indicating cleanliness, is an important societal norm where cleanliness is tied closely to good moral conduct and hygiene (Shove 2003; Waskul and Vannini 2008). Conversely, wearing clothes that smell stale and of sweat indicate a person not looking after oneself, poor moral conduct and invites judgement from others (Low 2005). 
Another goal of our study was to understand whether there may be common types of clothing that are problematic when it came to retaining odours, particularly those emanating from the body. Fibre type was suspected to play a major role, given the scientific literature showing that polyester tends to be more odorous following use than natural fibres such as cotton and wool (Callewaert et al. 2014; Klepp et al. 2016; McQueen et al. 2014, 2007). Our study confirmed that many consumers have identified the odour-extenuating properties of synthetic fibres. For some, this translated into actively seeking out clothing made of natural fibres and avoidance of synthetics when making decisions about what to buy or wear from within their wardrobes. This supports Stanes and Gibson (2017) who also found that some participants in their study would avoid polyester, as its connection with "sweat, odour and plastic have made the very idea of wearing polyester taboo" (p. 33). Persistent odour could make the idea of donating or giving away an odorous garment inappropriate. Furthermore, polyester garments are not well-suited to be turned into rags due to the lack of absorbency, nor do these garments biodegrade in the landfill (Fedorak 2005; Li et al. 2010). Therefore, polyester poses a problem at the disposal stage, and this problem is compounded when odour makes a garment unsuitable for garment extension options.

Heavier knits and clothing that "hugged" the underarms were other garment characteristics identified as prone to picking up and retaining odours. Although these characteristics were usually raised independently, there is likely to be an interaction between the two. That is, if a heavier-weight knit fabric does not come into contact with an odoriferous part of the body, then it is less likely to smell. This assumption appears to be supported by the survey findings where far fewer respondents reported having ever disposed of a sweater because it had become too odorous to wear compared with a T-shirt. The survey results did not elicit further details about the fibre content or the garment design, but it is likely that the additional layer of fabric often between a sweater and underarm, and/or a naturally looser fit of many sweaters, may have contributed to sweaters being less prone to absorbing sweat and odours. However, as one participant put it, tight-fitting cardigans that may be worn "really close to your skin" also posed a problem, reinforcing the importance of garment fit.

Recognition of certain clothing brands, styles, fabrics and fibre types may compel some consumers to shop in different stores or avoid certain brands altogether. The connection between odour and second-hand clothing was identified by some participants as a potential concern, consequently altering their behaviour and satisfaction with such second-hand purchases. We did not delve deeply into the smell 
of second-hand clothing from the perspective of consumers who wore these clothes, only touching upon it briefly with the few participants who chose to describe their own second-hand clothing odour experiences. The potential problem of past odours released from second-hand clothing may be a barrier for second-hand shopping (Laitala and Klepp 2018) and is worth pursuing in future investigations as it relates to other life-extension strategies. For example, the issue of odour may arise as a reason to deter consumers from participating in collaborative consumption practices such as clothing libraries or leasing. In a clothing library, individual clothing items would be worn by multiple users throughout their lifetime (Zamani et al. 2017), and depending on the clothing design, fabric and fibre type, perceptible odour could indeed become a barrier.

Persistent odour within clothing creates negative associations with such items, and, therefore, negative use experience, rather than the pleasurable use experience described by Niinimäki and Armstrong (2013), which generates satisfaction with the garment and has the potential to extend its life. Sometimes, strong attachment can still be experienced with odorous clothing, as in the example of the participant from the third focus group who described her "camping dress". The negative attribute of odour on the dress did result in her wearing it less often, but the strong emotional attachment to the dress generated through memories of enjoyable times she had spent wearing it meant she could not part with it. Here, her pleasurable use experience could override the negative use experience of unpleasant odour, although she would wear it less and under very particular circumstances. Yet, instead of extending the life of clothes, persistent odour more often results in behaviours that shorten the life of the clothing. The dissatisfaction and frustration consumers can feel with persistently odorous clothing results in these items being directly discarded in the trash, rather than being given away or sold. Embarrassment related to personal body odour, or other sources of odour that could result in judgement from others (e.g., musty clothing), likely prevents people giving odorous clothing to others they know; the smell also devalues the clothing item, making it unacceptable for sale.

Although not as common as trash disposal, donation was one potential life-extension strategy that some participants would still use, despite persistent odour. The anonymity of placing odorous items amongst other unwanted clothing pieces and dropping them off at a charity store, recycling bins or for doorstep collection makes donating odorous clothing an easy option. As well, donating reduced the guilt some people felt when disposing of odorous clothing that was otherwise in good condition. Participants believed it could be possible that someone else could want the item if the smell was only detectable by them, or, at least, they had passed on the 
decision to another about whether to throw out the garment or potentially extend its life.

Despite donation still being a viable method of disposal of odorous clothing for some focus group participants, the survey data indicated a considerable shift from donation of T-shirts and athletic shirts compared with their non-odorous counterparts. Subsequently, throwing odorous shirts into the trash was far more likely to occur than for non-odorous clothing items. Poor physical condition or stains are common reasons for discarding clothing into the trash (Birtwistle and Moore 2007; Degenstein et al. 2020; Norum 2017). Intimate clothing items, such as underwear, or other types that may be considered 'dirty' were also more likely to be thrown into the trash (Birtwistle and Moore 2007; Norum 2017). The survey results indicated that non-odorous athletic shirts were less likely to be donated and more likely to be put in the trash than non-odorous T-shirts (that were more likely donated and less likely trashed). Many respondents may feel that even just the process of having sweated in the clothing made the clothing unacceptable to pass onto others. If the disgust and shame people have with respect to their own sweat (Waitt 2014) extends to the clothing that was worn during exercise, then even when there is no detectable odour people may still believe nobody else would want their old exercise clothing. Another reason that the trash could be a common destination for athletic clothing is that it may be so heavily used that it gets worn out and, therefore, relegated to the trash can. As previously mentioned, worn out or poor-quality clothing can cause consumers to opt for trash disposal, rather than donation (Bianchi and Birtwistle 2010; Fisher et al. 2008).

Some participants extended the life of their odorous garments using them for another purpose where odour may be less of a concern. Although at some point the clothing item may end up in the trash following its use in this other life, it may by this time have become so dirty, stained and/or worn out that it was not prematurely disposed of. Its use for another purpose where the activity itself could result in further odour developing and adhering to the garment may prevent another garment from becoming extensively odorous. However, this option can only work for clothing items that still fulfil a necessary purpose. For instance, a dress shirt would not be worn underneath coveralls worn on an oil-rig; a chiffon blouse would not be appropriate for yard work. Likewise, a second life for clothing, as cleaning cloths or rags, was an option for some participants only when the fabric type was suitable. Such downcycling of odorous clothing for rags may only briefly extend the life of clothing and, therefore, is more likely classified as a life-shortening option 
(McNeill et al. 2020). Converting odorous clothing to rags suggests that premature disposal is occurring, particularly if the clothing is in otherwise good condition.

It is necessary to note that, in spite of the finding that odour can lead to premature disposal as well as potentially less sustainable methods for clothing disposition, persistent odour is not a major determining factor leading to clothing disposal. In fact, odour was one of the least common reasons cited for disposing of clothing. Hence, persistent odour within clothing does not have a major impact on consumers' overall sustainable behaviour when it comes to clothing disposition. Instead, reasons such as being "worn out", "no longer suits my tastes", or "doesn't fit" are far more common reasons for disposition. These latter reasons are consistent with those identified in other studies (Laitala 2014). Nonetheless, working on solutions toward odour control within clothing may benefit some consumers who find persistent odour does develop in garments. Life cycle assessments of the environmental benefit of odour-control technologies have been conducted based on the assumption that laundering will be reduced (Walser et al. 2011). Reduced laundering has the potential to also extend the useful life of clothing (McQueen et al. 2017). However, there is no evidence that consumers change their laundering habits due to the presence of odour-controlling agents (Hicks et al. 2015), or that these technologies effectively control odour compared with fabrics composed of natural fibres (Klepp et al. 2016). A better understanding of the inherent fibre, fabric and garment characteristics that enhance, or reduce, odour build-up within clothing will help inform consumers about clothing purchase decisions they may be able to make to reduce the likelihood of clothing-related odour.

\section{Conclusions}

This study explores the perspectives and behaviours of consumers in relation to their experiences with odour in clothing. We found that perceptible odour within clothing is commonly experienced by people during wear. Persistent odour, where the odour can no longer be washed out or returns rapidly during wear, is less common, but it is an unpleasant experience when it does occur. Although odour can arise from many different sources and be noticeable in different types of clothing, we found there were some common types reported. Odour development within clothing during wear, in particular persistent odour, created a negative association with the odorous clothing items. This negative use experience typically resulted in wearers wanting to dispose of the clothing item before they may have otherwise done so (premature disposal). Additionally, although there were varying methods chosen for disposal, designating the odorous clothing item to the trash was common; 
thus impeding sustainability efforts. Although odour is not a common motivator for disposal, it can lead to dissatisfaction with a garment when detected, leading to less environmentally sustainable disposal practices and also premature disposal.

Author Contributions: Conceptualization of the research: R.M. and J.K.; focus group interviews: R.M., J.K., and L.D.; survey data collection: R.M.; writing-original draft preparation, R.M. and J.K.; writing - review and editing: R.M., J.K. and L.D. All authors have read and agreed to the published version of the manuscript.

Funding: This research received no external funding.

Acknowledgments: We gratefully acknowledge the assistance of Cassandra Cunningham and Lori Moran in their involvement in developing the survey. We also thank our focus group participants for their time and contribution toward better understanding odour in clothing.

Conflicts of Interest: The authors declare no conflicts of interest.

\section{References}

Bianchi, Constanza, and Grete Birtwistle. 2010. Sell, Give Away, or Donate: An Exploratory Study of Fashion Clothing Disposal Behaviour in Two Countries. The International Review of Retail, Distribution and Consumer Research 20: 353-68. [CrossRef]

Birtwistle, Grete, and Christopher M. Moore. 2007. Fashion Clothing-Where Does It All End Up? International Journal of Retail \& Distribution Management 35: 210-16. [CrossRef]

Breen, Rosanna L. 2006. A Practical Guide to Focus-Group Research. Journal of Geography in Higher Education 30: 463-75. [CrossRef]

Browne, Alison L. 2016. Can People Talk Together about Their Practices? Focus Groups, Humour and the Sensitive Dynamics of Everyday Life. Area 48: 198-205. [CrossRef]

Callewaert, Chris, Evelyn De Maeseneire, Frederiek-Maarten Kerckhof, Arne Verliefde, Tom Van de Wiele, and Nico Boon. 2014. Microbial Odor Profile of Polyester and Cotton Clothes after a Fitness Session. Applied and Environmental Microbiology 80: 6611-19. [CrossRef] [PubMed]

Cooper, Tim. 2005. Slower Consumption: Reflections on Product Life Spans and the 'Throwaway Society'. Journal of Industrial Ecology 9: 51-67. [CrossRef]

Council for Textile Recycling. 2017. The Facts about Textile Waste. Available online: http://www.weardonaterecycle.org/about/issue.html (accessed on 29 September 2019).

Degenstein, Lauren M., Rachel H. McQueen, and Naomi T. Krogman. 2020. 'What Goes Where'? Characterizing Edmonton's Municipal Clothing Waste Stream and Consumer Clothing Disposal. Submitted to the Journal of Cleaner Production.

Ehnes, Briana, Rachel McQueen, and Lori Moran. 2011. An Exploratory Study on the Perception of Odor on Clothing. In International Textiles \& Apparel Association (ITAA) Proceedings. Philadelphia: ITAA, vol. 68. 
European Commission. 2010. Being Wise with Waste: The EU's Approach to Waste Management. Luxembourg: European Commission. [CrossRef]

Fedorak, Phillip M. 2005. Microbial Processes in the Degradation of Fibers. In Biodegradable and Sustainable Fibres. Edited by Richard S. Blackburn. Cambridge: Woodhead Publishing Limited.

Fisher, Tom, Tim Cooper, Sophie Woodward, Alex Hiller, and Helen Goworek. 2008. Public Understanding of Sustainable Clothing A Research Report Completed for the Department for Environment, Food and Rural Affairs; London: DEFRA.

Geyer, Roland, Jenna R. Jambeck, and Kara Lavender Law. 2017. Production, Use, and Fate of All Plastics Ever Made. Science Advances 3: 1-5. [CrossRef]

Government of Canada. 2017. Solid Waste and Greenhouse Gases. Available online: https://www.canada.ca/fr/environnement-changement-climatique/services/gestionreduction-dechets/solides-municipaux/gaz-effet-serre.html. (accessed on 23 June 2020).

Hicks, Andrea L., Leanne M. Gilbertson, Jamila S. Yamani, Thomas L. Theis, and Julie B. Zimmerman. 2015. Life Cycle Payback Estimates of Nanosilver Enabled Textiles under Different Silver Loading, Release, and Laundering Scenarios Informed by Literature Review. Environmental Science \& Technology 49: 7529-42. [CrossRef]

Jacoby, Jacob, Carol K. Berning, and Thomas F. Dietvorst. 1977. What about Disposition? Journal of Marketing 41: 22-28. [CrossRef]

Johnson, Anne, and Marisa Adler. 2017. Let's Talk: Textile Waste. Available online: https://recycle.com/textile-recycling/ (accessed on 29 September 2019).

Klepp, Ingun Grimstad, Madeline Buck, Kirsi Laitala, and Marit Kjeldsberg. 2016. What's the Problem? Odor-Control and the Smell of Sweat in Sportswear. Fashion Practice 8: 296-317. [CrossRef]

Laitala, Kirsi. 2014. Consumers' Clothing Disposal Behaviour-A Synthesis of Research Results. International Journal of Consumer Studies 38: 444-57. [CrossRef]

Laitala, Kirsi, and Casper Boks. 2012. Sustainable Clothing Design: Use Matters. Journal of Design Research 10: 121-39. [CrossRef]

Laitala, Kirsi, and Ingun Grimstad Klepp. 2011. Environmental Improvement by Prolonging Clothing Use Period. Paper presented at Towards Sustainability in the Textile and Fashion Industry Conference, Copenhagen, Denmark, 26-27 April 2011; pp. 1-22. Available online: https://pdfs.semanticscholar.org/2189/ 1571d3165a7fc9698be61b857e1c20ae6a70.pdf (accessed on 13 July 2020).

Laitala, Kirsi, and Ingun Grimstad Klepp. 2018. Motivations for and against Second-Hand Clothing Acquisition. Clothing Cultures 5: 247-62. [CrossRef]

Laitala, Kirsi, Marthe H. Austgulen, and Ingun G. Klepp. 2014. Responsibility without Means. In Roadmap to Sustainable Textiles and Clothing. Textile Science and Clothing Technology. Edited by Subramanian S. Muthu. Singapore: Springer. 
Li, Lili, Margaret Frey, and Kristie J. Browning. 2010. Biodegradability Study on Cotton and Polyester Fabrics. Journal of Engineered Fibers and Fabrics 5: 42-53. [CrossRef]

Low, Kelvin E. Y. 2005. Ruminations on Smell as a Sociocultural Phenomenon. Current Sociology 53: 397-417. [CrossRef]

McNeill, Lisa S., Robert P. Hamlin, Rachel H. McQueen, Lauren Degenstein, Sarah Wakes, Tony C. Garrett, and Linda Dunn. 2020. Waste Not Want Not: Behavioural Intentions toward Garment Life Extension Practices, the Role of Damage, Brand and Cost on Textile Disposal. Journal of Cleaner Production 260: 121026. [CrossRef]

McQueen, Rachel H., and Sara Vaezafshar. 2020. Odor in Textiles: A Review of Evaluation Methods, Fabric Characteristics, and Odor Control Technologies. Textile Research Journal 90: 1157-73. [CrossRef]

McQueen, Rachel H., Raechel M. Laing, Heather J. L. Brooks, and Brian E. Niven. 2007. Odor Intensity in Apparel Fabrics and the Link with Bacterial Populations. Textile Research Journal 77: 449-56. [CrossRef]

McQueen, Rachel H, James J. Harynuk, Wendy V. Wismer, Monika Keelan, Yin Xu, and A. Paulina de la Mata. 2014. Axillary Odour Build-up in Knit Fabrics Following Multiple Use Cycles. International Journal of Clothing Science and Technology 26: 274-90. [CrossRef]

McQueen, Rachel H., Jane C. Batcheller, Lori J. Moran, Han Zhang, and Peter M. Hooper. 2017. Reducing Laundering Frequency to Prolong the Life of Denim Jeans. International Journal of Consumer Studies 41: 36-45. [CrossRef]

Morgan, David L. 1997. Qualitative Research Methods: Focus Groups as Qualitative Research, 2nd ed. Thousand Oaks: SAGE Publications.

Morgan, Louise R., and Grete Birtwistle. 2009. An Investigation of Young Fashion Consumers' Disposal Habits. International Journal of Consumer Studies 33: 190-98. [CrossRef]

Niinimäki, Kirsi. 2017. Sustainable Consumer Satisfaction in the Context of Clothing. In Product-Service System Design for Sustainability. Sheffield: Greenleaf Publishing, pp. 218-37. [CrossRef]

Niinimäki, Kirsi, and Cosette Armstrong. 2013. From Pleasure in Use to Preservation of Meaningful Memories: A Closer Look at the Sustainability of Clothing via Longevity and Attachment. International Journal of Fashion Design, Technology and Education 6: 190-99. [CrossRef]

Norum, Pamela S. 2017. Towards Sustainable Clothing Disposition: Exploring the Consumer Choice to Use Trash as a Disposal Option. Sustainability 9: 1187. [CrossRef]

Rabl, Ari, Joseph V. Spadaro, and Assaad Zoughaib. 2008. Environmental Impacts and Costs of Solid Waste: A Comparison of Landfill and Incineration. Waste Management and Research 26: 147-62. [CrossRef] [PubMed]

Schifferstein, Hendrik N. J., and Elly P. H. Zwartkruis-Pelgrim. 2008. Consumer-Product Attachment: Measurement and Design Implications. International Journal of Design 2: 1-13. 
Shove, Elizabeth. 2003. Laundering: A System of Systems. In Comfort, Cleanliness and Convenience: The Social Organization of Normality. London: Bloomsbury Academic, pp. 117-38.

Stanes, Elyse, and Chris Gibson. 2017. Materials That Linger: An Embodied Geography of Polyester Clothes. Geoforum 85: 27-36. [CrossRef]

Tokatli, Nebahat, Neil Wrigley, and Ömür Kizilgün. 2008. Shifting Global Supply Networks and Fast Fashion: Made in Turkey for Marks and Spencer. Global Networks 8: 261-80. [CrossRef]

UN Secretary General. 2019. Special Edition: Progress towards the Sustainable Development Goals. Available online: https://undocs.org/E/2019/68. (accessed on 23 June 2020).

UN Sustainable Development Goals. n.d. Goal 12: Ensure Sustainable Consumption and Production Patterns. Available online: https://www.un.org/sustainabledevelopment/ sustainable-consumption-production/ (accessed on 23 June 2020).

Value Village. 2018. State of Reuse Report. Available online: https://www.valuevillage.com/ sites/default/files/reuse_report_2018-vv.pdf (accessed on 29 September 2019).

Waitt, Gordon. 2014. Bodies That Sweat: The Affective Responses of Young Women in Wollongong, New South Wales, Australia. Gender, Place \& Culture 21: 666-82. [CrossRef]

Walser, Tobias, Evangelia Demou, Daniel J. Lang, and Stefanie Hellweg. 2011. Prospective Environmental Life Cycle Assessment of Nanosilver T-Shirts. Environmental Science E Technology 45: 4570-78. [CrossRef]

Waskul, Dennis D., and Phillip Vannini. 2008. Smell, Odor, and Somatic Work: Sense-Making and Sensory Management. Social Psychology Quarterly 71: 53-71. [CrossRef]

Weber, Sabine. 2015. How Consumers Manage Textile Waste. Master's thesis, University of Waterloo, Waterloo, ON, Canada.

WRAP. 2017. Valuing Our Clothes: The Cost of UK Fashion. Available online: http://www.wrap.org.uk/sites/files/wrap/valuing-our-clothes-the-cost-of-ukfashion_WRAP.pdf (accessed on 29 September 2019).

Zamani, Bahareh, Gustav Sandin, and Greg M. Peters. 2017. Life Cycle Assessment of Clothing Libraries: Can Collaborative Consumption Reduce the Environmental Impact of Fast Fashion? Journal of Cleaner Production 162: 1368-75. [CrossRef]

(C) 2020 by the authors. Licensee MDPI, Basel, Switzerland. This article is an open access article distributed under the terms and conditions of the Creative Commons Attribution (CC BY) license (http://creativecommons.org/licenses/by/4.0/). 



\title{
.

Repairing Fashion Cultures:

From Disposable to Repairable

\author{
Kirsi Niinimäki and Marium Durrani
}

\section{Introduction}

The fashion and textile industry has large environmental impacts throughout its long and scattered supply chain. The activities of this industry have an impact on water, air and soil, and it uses large amounts of material, energy, water and chemicals. It has local impacts on areas where cotton is cultivated, where polyester is manufactured and where textile wet processes are done, but it also extends to areas where clothes are used and where textile waste is deposited. Moreover, it has global impacts through $\mathrm{CO}_{2}$ emissions affecting climate change, causing damage to ecosystems and even creating risks to human health (Global Fashion Agenda 2017; Sajn 2019; Niinimäki et al. 2020a).

The linear economic model (take-make-dispose) and the fast fashion business logic behind it is based on effective and large-scale mass manufacturing in lower-cost countries, mainly in Far-East and Asian countries. This model is based on fast-changing trends that have caused very short use times of garments and increased waste problems in all Western countries. The yearly textile waste amounts per person have a direct connection to the consumption rates in different countries; for instance, they are $13 \mathrm{~kg}$ in Finland (Dahlbo et al. 2017), $16 \mathrm{~kg}$ in Denmark (Watson et al. 2014) and $30 \mathrm{~kg}$ in the UK (Allwood et al. 2006). A study done in Norway found that $20 \%$ of textile waste items were nearly unused (Laitala and Klepp 2015). Lacy and Rutqvist (2015) state that we waste the lifecycle of a product if the product has an artificially short lifetime, and products are disposed even if they still function. This is called early disposal.

Moreover, studies estimate that existing levels of clothing consumption and production rates might even increase if the fashion system remains unaltered. Textile production has doubled its volume between the years 1975 and 2018 (Peters et al. 2019); subsequently, the use time of garments has decreased by $36 \%$ compared to the situation 15 years ago (Ellen MacArthur Foundation 2017). Garments are even produced in such high volumes that some part of the production stays unsold. Markets are oversaturated, and brands even burn unsold garments while trying to safeguard the brand value (Hendriksz 2017). 
The current consumption-production paradigm and the unsustainability in this industrial sector have to change, and we have to create a new balance in the fashion sector. One part of this transformation process is the new product lifetime understanding and approach to extend the use time of garments. This is essential while trying to lower the environmental impact of garments and the fashion industry. Moreover, building this new paradigm in the fashion sector includes not only change in consumers' consumption habits, but companies also have to be involved in this change. Sustainable fashion business models have to include the aspects of producing less, extending the use time of garments and including these principles in a new business understanding. In this way, a new balance can be achieved, and the fashion culture could potentially be "repaired" to create a better balance while slowing down the material throughput in the system.

This chapter approaches this paradigm shift in fashion cultures from two angles: firstly, from the consumer viewpoint and secondly from the company viewpoint. The text aims to build on the emerging phenomena of communal repair activities and on business examples, and through this approach it provides an understanding of the need to change the fashion culture from disposing to repairing. Through this knowledge, the chapter contributes to the discussion of transformation in the consumption-production paradigm from a narrowly framed view, i.e., repair. The text is grounded on earlier studies and literature, and through this base it aims to construct a conceptual understanding of this phenomenon under study, i.e., transforming fashion culture towards sustainability through the practice of repair.

\section{Replace or Repair}

As elaborated in the previous section, problems associated with the fashion and textile industry are plenty and quite perplexing. Yet, the quest to bring forth solutions that could address the aforementioned issues has continued to remain active and vibrant. In particular, extending the use time of garments has repeatedly been quoted within academic research as a viable solution when tackling the ever-increasing rates at which garments get disposed (Fletcher 2008; Birtwistle and Moore 2007; WRAP 2012; Gwilt 2014; Durrani 2018a, 2018b, 2018c; McLaren and McLauchlan 2015). According to The Waste and Resources Action Programme (WRAP 2012) report, it is estimated that using garments for a minimum of over three years has the potential to save 5 billion pounds worth of resources in one year alone. The significance of extending the use of garments is further resonated in the works of several academics that have mentioned the adoption of various techniques in an attempt to extend garment use. Some of these recommendations include encouraging users to purchase 
garments from charity or thrift stores, minimize laundering practices and opting for airing garments like wool and silk, re-designing or altering garments so that they fit better and/or repairing garments that have suffered breakages to avoid binning and be able to keep clothing in use for an extended period of time (WRAP 2012; Gwilt 2014; Durrani 2018a, 2018b, 2018c; McLaren and McLauchlan 2015; Laitala 2015; Twigger 2016; Lapolla and Sanders 2015; Norum 2013). For the purpose of this chapter, we will primarily focus our attention on garment repair, an increasingly growing area of discussion within the field of sustainable fashion. As it is our intention to contribute to the existing body of literature on clothing repair research, we will discuss the role garment repair could play in addressing sustainable practices of clothing use, but we also further the discussion on how the aspect of repair could change fashion business practices.

While mending garments is by no account a new practice (see Durrani 2018a), its significance for sustainable fashion consumption has only just caught the attention of researchers. Though the majority of earlier work recognized the benefits that can be reaped from mending garments, research has also identified various barriers to repair (see McLaren and McLauchlan 2015; Laitala 2015; Twigger 2016; Lapolla and Sanders 2015; Norum 2013; Gwilt 2014). These barriers include users not having enough time to mend, lacking knowledge on how to fix garments and relative cost of repairing falling in favor of buying new garments than opting for paid repair services (often offered by tailors or seamstresses; see ibid). With these challenges at play, 'altering' or 'steering' user practices has been placed at the center of sustainability around which various recommendations have set into motion. On the production front this has meant pushing for design-led solutions such as using quality materials or modular designs that can be repaired easily and potentially kept in use for a long time (Gwilt 2014). Additionally, offering paid-for repair services as part of designers' business models has also been suggested as one way to encourage garment mending (Gwilt 2014). Alternatively, the introduction of sewing classes in schools (Norum 2013) and the 'dissemination' of information via media campaigns on the benefits of mending (Dombek-Keith and Loker 2011) have been suggested as would-be means to bring change in user practices towards garment repair.

Recommendations such as those stated above could be useful; however, whether they address the triadic time-skill-cost challenge to encourage repair in its entirety remains an open question. It can be argued that when faced with time constraints, perhaps opting for repair services could be a useful option. However, if a fee for repair services is charged by local businesses, will it still be possible to overcome the 'cost' barrier to repair? Additionally, and linked to this, is the 'skill' challenge, 
wherein garments could get repaired if people were to utilize these repair services. Yet, the 'skill' needed to repair clothing by users themselves will not have been gained, resulting in depreciation of the practice we aim to increase. Moreover, even if informative videos on how to mend garments are available online, Gwilt (2014) notes that it does not automatically lead to users mending. Furthermore, Fletcher (2012) highlights that repair of garments is not always linked to the design of the garment. Thus, even if clothing designs were to become modular, the repair of garments is not always guaranteed, for practices of garment use are usually tied strongly to and impacted by social relations (Durrani 2018a, 2018b, 2018c). It is this social aspect, as the following section will illustrate, that stands as the third front running parallel to mainstream production and consumption practices that has, of late, worked towards addressing some of the barriers to garment repair in an unconventional manner.

\section{Alternative Cultures of Garment Use}

Recent research has shown that mending garments not only redirects waste flows but could also enable consumers to reduce making new purchases altogether (Laitala and Klepp 2018; Durrani 2018c). The relationship people often share with their garments is one that is deeply tied to social and material factors (Durrani 2018a, 2018b, 2018c). Clothing practices of use, such as how garments get cared for or are maintained, are often learned through lived experiences that are very much entangled with the social world (Durrani 2019). When discussing altering practices of garment use it becomes not only relevant but also imperative to move towards approaches where user practices are understood as an interlinked web of social, material and economic elements tied to larger political infrastructures as well (Durrani 2019). In doing so, attention could be better placed onto alternative practices that challenge present capitalistic regimes of mass production and mass consumption. One area where this can be seen occurring lies within community-based collective action where active participation in repair at the grassroots level is emerging.

Exemplified in what has now been termed as the 'Fixer Movement' (see Charter and Keiller 2019) is a global network of repairers that have been challenging mainstream capitalistic ethos of mass production and consumption practices. Taking root in the works of the Repair Café Foundation (Repair Café Foundation 2012) based in the Netherlands lies a concept that has given birth to an entire global 'repair eco-system' (Charter and Keiller 2019). Frustrated by the pre-mature expiration of most consumer products due mainly to planned obsolescence designed within products (Charter and Keiller 2019), the RCF began hosting free-of-charge public repair events in 2011. Their aim was to extend the life of products through 
encouraging acts of repair by inviting the general public where they could collectively learn first-hand how to repair various consumer products from expert volunteer menders without charging a fee (thus addressing the 'cost' and 'skill' barrier). With this in mind, the Foundation began hosting public events in local neighborhoods where repair experts helped people to learn how to fix various items from broken bicycle chains to ripped denim jeans. Over the years, this has resulted in various off-shoot organizations and/or designers to host events that focus entirely on the repair of garments and textiles as well (see Durrani 2018a, 2018b, 2018c). Some examples of this phenomenon from the UK include Middleton's 'Sock Exchange' (Middleton 2010), Tom of Holland's Visible Mending Programme (2017) and The Remakery (2011). Similarly, various communal mending events have begun emerging in Finland as well. In particular, Korjaussarja (2014), Repair-a-thon (2016) and REMAKE (2009) are examples of groups hosting public garment mending events in the city of Helsinki. In this section, we will briefly describe the activities of these three Helsinki-based groups before advancing discussion on how they are aiding in the mobilization of alternative garment use practices.

Common to all three groups is the desire to reduce textile waste, assist in the creation and proliferation of closing material loops, extend the use time of garments and share knowledge by engaging and re-skilling local communities through participation in repair practices (Durrani 2018b). Each of the three examples from Helsinki, Finland hosts public events where the organizers assist in the garment repairs of individuals (Durrani 2018b). These events are often hosted at varying locations such as cafes, public libraries, design museums and so forth, depending upon the availability of space. During the events the organizers provide various materials, sewing machines, threads, scrap fabrics and other haberdasheries needed to repair garments (Durrani 2018b).

Korjaussarja (2014) and Repair-a-thon (2016) in particular can be understood as craft-activists that aim to foster change in clothing use practice through collaborative public engagement. Consisting of a group of six craft teachers, Korjaussarja began a series of pop-up repair events in 2014 in Helsinki. In their public events they often mend using visible mending techniques as a means of fighting off cultural and historic connotations attached to wearing mended garments (Niinimäki et al. 2020b). Repair-a-thon (2016) is the initiative of a fashion designer Sasa Nemec who single-handedly has hosted various ad hoc mending events in the city (Durrani 2018b). To the events she brings a sewing machine and both repairs for and assists participants to mend their own garments. 
While Korjaussarja (2014) and Repair-a-thon (2016) do not charge any fee for participation in their events, REMAKE (2009) has in recent years began asking for a small fee for their repair workshops. REMAKE's primary source of income is generated from up-cycling post-consumer textile waste that is collected from thrift stores to create new clothing that they sell in their atelier. This is supported with the provision of repair workshops where they teach various ways to mend garments, a service that they charge for. As REMAKE operates as a social enterprise, its operations are still interlaced within a business logic of profit and loss. In doing so, their practices often mirror product-service system business models (see Armstrong et al. 2015) where they are both providers of products while also offering services to the public. Although their activities are reflective of circular economic models aimed at closing the loop on material waste, as stated by earlier research, one of the key barriers to repair is the relative cost of getting garments fixed as opposed to purchasing new ones. It, therefore, remains questionable whether charging and profiting from repair workshops/services could truly encourage the proliferations of repair practices.

In light of this, Charter and Keiller (2019) place significant emphasis on supporting free-of-charge communal repair events, as they are vital to addressing most barriers to repair (in particular the cost and skill barriers). They note that participants of free repair cafes or events are more likely to feel encouraged to continue to mend their garments while also sharing feelings of connectedness to their communities. Such communal spaces also offer rich learning opportunities for individuals who have never mended before (Durrani 2018b). It has been noted that through participation in communal repair events, people learn to recognize differences in the quality of garments, connect better the relationship between extending use time of garments and the ecological footprint of use whilst becoming more aware of their clothing maintenance practices (Durrani 2018c). Participation in events also encourages people to learn first-hand and get customized attention from more expert menders on the specifics of their respective garment breakages that they encounter. Many participants also state that, although mending videos are often available online on YouTube, following instructions from videos is not very easy, and they prefer having someone in person to guide them. Simultaneously, several participants claim that, through mending at the public events, the practice itself turns into a leisurely activity, and the time demands often felt if left to mend alone at home are no longer felt when mending in the company of others (see Durrani 2018b, 2018c). In this way, this inadvertently addresses the 'time' barrier to repair practices as mentioned in earlier scholarship. 
While the activities of communal repair events are still growing, they have certainly contributed towards mobilization of an alternative system running parallel to mainstream ideals of fast fashion where slow and extended garment use is encouraged and community participation is nurtured (Durrani 2018c). Through collaborative learning spaces such as these, various skills are shared with feelings of altruism and care circulating among locals (Durrani 2018c; Charter and Keiller 2019). However, in order to address the multiple challenges of the fashion system in a potentially holistic manner, perhaps we also need to explore other arenas and avenues through which to begin to pivot the system in a more ecological direction. The next section will take this discussion further to explore if there is room for ecological businesses in support of repair practices.

\section{Repair as a Part of the Fashion Business}

Recent years have experienced a rise in consumers' concern over the environmental impact of the fashion industry. Conscious consumption is increasing, and consumers are interested to support companies that aim to change their practices and business logic towards more sustainable ones. The public discussion on climate change has aided in making visible the questionable socio-environmental practices of the fashion and textile industry. Fashion businesses and the industry at large are now faced with increased pressure to change their 'business as usual' logic and practices (e.g., Global Fashion Agenda 2019). Some companies are taking this challenge seriously as they begin to create change in their own business model. Some companies have begun offering repair services to extend the use time of garments. Through this approach, these companies could contribute to transformation towards a more sustainable fashion culture by inviting consumers to change their consumption habits, from frequently buying new garments to taking good care of already owned garments. The following are examples of clothing companies that have included repair into their business model.

Arela is a small-scale company that offers a maintenance service for their knits to extend their use time (Arela 2019). A part of their collection includes cashmere knits, which are high quality and often need special care. In response to their customer worries of ruining their valuable knits, Arela developed a care service to complete their customer experience. The service they offer covers a range of practices needed to maintain knits and includes de-pilling, washing and steaming the knits and, if needed, mending holes. Additional services offered include elbow patch sewing and alterations. This service makes visible the company's philosophy, which is sustainability, and it also supports the extended use time. Arela also 
collects used and broken knits and recycles them for new products like sleep masks and elbow patches. From a business point of view, the service lowers the customer's consideration to invest in a high-quality knit and it also builds trust towards the quality of garments and also trust towards the business and its value base (Niinimäki 2018; Arela 2019).

Another example in support of extending the use time of clothing comes from Nudie Jeans who offers free repair services to their customers in some of their shops (Nudie Jeans 2019). The repair service count is placed in the front of the shop showing openly the values of the company. The message is repairing old jeans are as valuable activity to the company than selling a new pair of jeans. Nudie Jeans is a premium price level company, and their jeans can be seen as an investment and something consumers want to use for a long time. Nudie Jeans has even taken the next step and begun to re-sell their second-hand jeans (Nudie Jeans 2019). This shows a new kind of value of the garment but also shows an example of how to transform the business from linear thinking towards more sustainable thinking and including this approach even to a business model.

Reima is a clothing company that produces high-quality, expensive and durable children's wear items. Clothing for children often undergoes hard wearing conditions; therefore, even if they are made from durable materials and produced for durability, sometimes some repair is needed. While the garments are made from quite special fabrics (e.g., overall for winter use, with special print and textile material with waterproof finishing), Reima sells this material as batches for repair purposes (Reima 2019). This is a service for consumers to extend the use time of garment through repair and through their own actions. These actions also create an opportunity to form a more active role for a consumer through repairing their garments.

Such offerings can open space for customers to form better relations of trust with companies, where the responsibilities of the aftercare that come with the use of garments are shared equitably between both users and businesses. Providing another offering (such as repair, durability, high quality) can then be understood not only as a sustainability approach, but also a way for companies to stand out amidst the tight fashion competition. This could be one way to separate the sustainable businesses from the mainstream fashion offerings.

\section{Discussion: Repairing Fashion Culture}

Grounding on earlier discussion and the presented examples gives us a conceptual path to discuss further how to repair current unsustainable fashion cultures of consumption and production. We can start the discussion from a consumer's 
viewpoint. Repairing fashion culture from the consumer's viewpoint means a new appreciation of materials, products and garments, and through this appreciation they are given a longer life. This new understanding of use provides an opportunity towards lowering the purchase rate and slowing down consumption.

Repairing and selling second-hand items also changes the aesthetics of fashion. This could be seen as a "new aesthetics", meaning a visual and material world, which is far from mass manufactured "sameness". Acts of repair provides us an opportunity to express our individuality, our own "visual voice" through mending. If accepted widely, this approach could mean a big change in the fashion culture. Earlier studies have shown that social acceptance is an important element when we are choosing a garment, and accordingly our appearance is "built" to reflect our identity in a social context (Niinimäki 2009, 2014; Freeburg and Workman 2010). Perhaps the ethos of sustainability needs also a new kind of aesthetic understanding and aesthetic appreciation, where the repaired and used outlook is accepted based on a sustainable value base (Niinimäki 2014). Perhaps it is socially accepted to show your value base through your appearance.

Using garments to reflect one's identity might be one element that could explain cultures of clothing, but various other factors are at play that go beyond the point of purchase and impact the use of garments. One of which is the influence social relations play on determining the longevity of garments more than the design or aesthetics of the garment (Fletcher 2012). The hold that social ties have on harnessing relations with alternative use practices is further exemplified in the examples of social repair events. Not only do these platforms allow users to learn from their peers, but they also provide spaces where bonds between people and their communities take place (Durrani 2018c; Hirscher et al. 2018). Moreover, through participating in communal events such as these, users can be seen actively appropriating garments and fighting off ideals of garments as 'closed' objects to be merely used and prematurely disposed. Instead, through their collective actions, users can be seen caring for their garments. Moreover, garments begin to be more open products towards consumers' alterations and actions.

The more active role of a consumer could lead to growing self-esteem, and even being happier, by doing it yourself and doing it with others (Hirscher et al. 2018). This could mean even bigger changes in the fashion power balance. Being an active consumer creates a source of power for consumers. In the linear model, consumers are only a value user (using the product), and all power and value creation is situated on the fashion business side, but if the consumer's role is changing, they begin to be 
a value creator (Bilton and Cummings 2019). This means that some part of the power for the transition needed will be shared and moved to the shoulders of consumers.

From industry and business points of view, changing the focus from one-time selling to extended use phases drastically changes the current business logic in fashion. Through this shift it is possible to invest in better materials, manufacturing work, quality and durability, and it also leads to better customer relationships. Offering repair services also provides companies with an important channel to get customer feedback from the use phase and also valuable feedback about the product and its durability limits. This could be understood as a new way to collect user-centered information while aiming towards better customer satisfaction and also better understanding of quality.

Durability and quality of garments has to be in the core functions when aiming towards a more sustainable business. These attributes open opportunities to organize second-hand business. High-quality garments and luxury items already have second-hand value, but this approach could also be brought to all clothes, providing an extended value-harvesting possibility to the fashion business.

\section{Conclusions-Transformation through Repairing}

Repairing the fashion culture from consumer and business points of view is a big task. These transformations in mindset and in actions requires a new understanding of the value of garments, materials and work, but also it needs new creativity and skills and even new business understanding. The emerging phenomena of communal repair and repair-centered businesses was the focus of this study. This phenomenon is growing both in consumer culture and in business culture, and this gives us hope and also sign that a bigger shift in understanding the new consumption-production paradigm might be on the way. We have to cultivate our consumer mind to see garments as investments and shift our interest towards loving clothes we own, taking good care of them and extending their life. In this, the change in consumer culture towards the repair approach is essential just as is the change in business thinking. Changing the focus from one-time selling (linear model) to the use phase means a big change in the mindsets of business and industry. This shift means a change in the business model and taking into account the use phase and user experiences before beginning to offer services, like repair, to consumers. Moreover, if the material value aspect in fashion is changing, even second-hand business might begin to be an important part of the sustainable fashion industry. 
While studying the phenomena of repair, we have opened the discussion on how to transform the fashion culture towards a slower and more sustainable one. To lower the environmental impact of this industry, it is important to notice that we have to slow down the system as a whole. The material throughput, from manufacturing to consumption to end of product life, needs critical attention. We have to consume less and we have to produce less. We have to create material appreciation and invest in better quality and durability. We have to gain new skills to extend the use time of products through better maintenance and repair. The fashion industry must construct a new understanding on how to extend the use time of garments and include this aspect in their business model. Therefore, the phenomenon of repair can really start the path to repair the current unsustainable fashion culture.

Author Contributions: Conceptualization, K.N. and M.D; methodology, K.N.; investigation, K.N. and M.D.; writing-original draft preparation, K.N. and M.D.; writing-review and editing, K.N. and M.D.

Acknowledgments: This research was supported by the Academy of Finland's Strategic Research Council, grant number 327299/FINIX consortium. The authors want to thank Fashion/Textile Futures research group and Design Research of Aalto University for their support for this research.

Conflicts of Interest: The authors declare no conflicts of interest.

\section{References}

Allwood, Julian M., Soren Ellebaek Laursen, Cecilia Malvido de Rodriguez, and Nancy M. P. Bocken. 2006. Well Dressed? The Present and Future of Sustainability of Clothing and Textiles in the UK. Cambridge: Cambridge University, Institute of Manufacturing.

Arela. 2019. Available online: https://www.arelastudio.com/collections/arela-care/products/ basic-care-hole-mending (accessed on 14 September 2019).

Armstrong, Cosette M., Kirsi Niinimäki, Sari Kujala, Essi Karell, and Chunmin Lang. 2015. Sustainable product-service systems for clothing: exploring consumer perceptions of consumption alternatives in Finland. Journal of Cleaner Production 97: 30-39. [CrossRef]

Bilton, Chris, and Stephen Cummings. 2019. Creative Strategy. Reconnecting Business and Innovation. Chichester: John Wiley.

Birtwistle, Grete, and Christopher M. Moore. 2007. Fashion clothing-where does it all end up? International Journal of Retail \& Distribution Management 35: 210-16.

Charter, Martin, and Scott Keiller. 2019. Repair cafes: Circular and social innovation. In Designing for the Circular Economy. Edited by Martin Charter. London: Routledge, vol. 1, pp. 270-84. 
Dahlbo, Helena, Kristiina Aalto, Hanna Eskelinen, and Hanna Salmenperä. 2017. Increasing textile circulation-consequences and requirements. Sustainable Production and Consumption, Sustainable Utilisation of Waste 9: 44-57. [CrossRef]

Dombek-Keith, Kathleen, and Suzanne Loker. 2011. Sustainable Clothing Care by Design. In Shaping Sustainable Fashion: Changing the Way We Make and Use Clothes. Edited by Alison Gwilt and Timo Rissanen. London: Routledge, pp. 101-16.

Durrani, Marium. 2018a. The becoming of repair: Understanding garment mending through a practice theory perspective. In Eco-Friendly and Fair: Fast Fashion and Consumer Behaviour. Edited by Carolin Becker-Leifhold and Mark Heuer. London: Routledge, vol. 1, pp. 101-11.

Durrani, Marium. 2018b. Designers by any other name: exploring the sociomaterial practices of vernacular garment menders. In Design Research Society International Conference: Catalyst. DRS International Conference Series; London: Design Research Society, vol. 4, pp. 1731-46.

Durrani, Marium. 2018c. "People Gather for Stranger Things, So Why Not This?" Learning Sustainable Sensibilities through Communal Garment-Mending Practices. Sustainability 10: 2218. [CrossRef]

Durrani, Marium. 2019. Through the Threaded Needle: A Multi-Sited Ethnography on the Sociomateriality of Garment Mending Practices. Aalto University Publication Series DOCTORAL DISSERTATIONS, 204/2019. Aalto: Aalto University.

Ellen MacArthur Foundation. 2017. A New Textile Economy; Redesigning Fashion's Future. Available online: https://www.ellenmacarthurfoundation.org/assets/downloads/ publications/A-New-Textiles-Economy_Full-Report.pdf (accessed on 1 January 2019).

Fletcher, Kate. 2008. Sustainable fashion $\mathcal{E}$ textiles: Design Journeys. London: Earthscan.

Fletcher, Kate. 2012. Durability, Fashion, Sustainability: The Processes and Practices of Use. Fashion Practice Journal 4: 221-38. [CrossRef]

Freeburg, Beth Winfrey, and Jane E. Workman. 2010. A method to identify and validate social norms related to dress. Clothing and Textile Research Journal 28: 38-55. [CrossRef]

Global Fashion Agenda. 2017. Pulse of the Fashion Industry. Available online: https:/www.globalfashionagenda.com/wp-content/uploads/2017/05/Pulse-of-theFashion-Industry_2017.pdf (accessed on 1 January 2019).

Global Fashion Agenda. 2019. CEO Agenda 2019; Eight Sustainability Priorities for the Fashion Industry. Available online: https://www.globalfashionagenda.com/ceo-agenda-2019/ (accessed on 1 January 2019).

Gwilt, Alisson. 2014. What prevents people repairing clothes?: An investigation into community-based approaches to sustainable product service systems for clothing repair. Making Futures Journal 3. 
Hendriksz, Vivian. 2017. H\&M Accused of Burning 12 Tonnes of New, Unsold Clothing. Fashion United. Available online: https:/fashionunited.uk/news/fashion/h-m-accusedof-burning-12-tonnes-of-new-unsold-clothing-per-year/2017101726341 (accessed on 1 January 2019).

Hirscher, Anja-Lisa, Kirsi Niinimäki, and Cosette Armstrong. 2018. Social Manufacturing in the Fashion sector: New value creation through alternative design strategies? Journal of Cleaner Production 172: 4544-54. [CrossRef]

Korjaussarja. 2014. KORJAUSSARJAKOLLEKTIIVI. Available online: https:// korjaussarjakollektiivi.wordpress.com/ (accessed on 29 September 2019).

Lacy, Peter, and Jakob Rutqvist. 2015. Waste to Wealth. The Circular Economy Advantage. Hampshire: Palgrave Macmillan.

Laitala, Kirsi. 2015. Applicability of social practice theory for sustainable clothing consumption research. Paper presented at the Global Cleaner Production and Sustainable Consumption Conference, Sitges, Spain, November 1-4.

Laitala, Kirsi, and Ingun Grimstadd Klepp. 2015. Age and active life of clothing. In PLATE, Product Lifetimes and the Environment 2015 Conference. Edited by Tim Cooper, Naomi Braithwaite, Mariale Moreno and Giuseppe Salvia. Nottingham: Nottingham Trent University: CADBE, pp. 182-86. Available online: http://www.plateconference.org/ pdf/plate_2015_proceedings.pdf (accessed on 29 September 2019).

Laitala, Kirsi, and Ingun Grimstadd Klepp. 2018. Care and Production of Clothing in Norwegian Homes: Environmental Implications of Mending and Making Practices. Sustainability 10: 2899. [CrossRef]

Lapolla, Kendra, and Elizabeth B-N Sanders. 2015. Using cocreation to engage everyday creativity in reusing and repairing apparel. Clothing and Textiles Research Journal 33: 183-98. [CrossRef]

McLaren, Angharad, and Shirley McLauchlan. 2015. Crafting Sustainable Repairs: Practice-Based Approaches to Extending the Life of Clothes. Paper presented at the PLATE Conference, Delft, The Netherlands, June 17-19.

Middleton, Jonnet. 2010. Sock Exchange, Cork 2010. Available online: https://futuremenders. wordpress.com/projects/sock-exchange-cork/ (accessed on 29 September 2019).

Niinimäki, Kirsi. 2009. Consumer Values and Eco-Fashion in the Future. Future of the Consumer Society. Paper Presented at the Conference "Future of the Consumer Society", Tampere, Finland, May 28-29. Edited by Marileena Koskela and Markus Vinnari. pp. 125-34. Available online: https://www.utupub.fi/handle/10024/147587 (accessed on 1 January 2019).

Niinimäki, Kirsi. 2014. Green Aesthetics in Clothing: Normative Beauty in Commodities. Artifact 3: 3.1-3.13. [CrossRef] 
Niinimäki, Kirsi. 2018. Sustainable Fashion in a Circular Economy. Available online: https: //aaltodoc.aalto.fi/handle/123456789/36608 (accessed on 1 January 2020).

Niinimäki, Kirsi, Cindy Kohtala, and Marium Durrani. 2020a. Emerging DIY Activities to Enable Well-being and Connected Societies. International Journal of Craft Research.

Niinimäki, Kirsi, Peters Gregory, Helena Dahlbo, Patsy Perry, Timo Rissanen, and Aliso Gwilt. 2020b. Paying the environmental price for fast fashion. Nature Reviews: Earth and Environment 1: 189-200.

Norum, Pamela. S. 2013. Examination of apparel maintenance skills and practices: Implications for sustainable clothing consumption. Family and Consumer Sciences Research Journal 42: 124-37. [CrossRef]

Nudie Jeans. 2019. Free Repairs for Life. Available online: https://www.nudiejeans.com/page/ free-repairs-for-life (accessed on 14 September 2019).

Nudie Jeans. 2019. Reuse. Available online: https://www.nudiejeans.com/page/re-use (accessed on 14 September 2019).

Peters, Gregory M., Gustav Sandin, and Björn Spak. 2019. Environmental prospects for mixed textile recycling in Sweden. ACS Sustainable Chemistry \& Engineering 13: 11682-90.

Repair Café Foundation (RCF). 2012. Available online: https://repaircafe.org/en/ (accessed on 1 January 2018).

Reima. 2019. Tuotteen käyttö ja elinkaari. [Reima, The use and lifetime of a product]. Available online: https://www.reima.com/fi/tuotteen-kaytto-ja-elinkaari (accessed on 29 September 2019).

REMAKE. 2009. REMAKE-Eco Design Atelier. Available online: http://remake.fi/ (accessed on 29 September 2019).

Repair-a-thon. 2016. Available online: https://www.facebook.com/GingerHeads/?hc_ref= SEARCH (accessed on 29 September 2019).

Sajn, Nikolina. 2019. Environmental Impact of the Textile and Clothing Industry; What Consumers Need to Know. European Union. EPRS European Parliamentary Research Service. Available online: http://www.europarl.europa.eu/thinktank/en/ document.html?reference=EPRS_BRI\%282019\%29633143 (accessed on 1 August 2019).

The Remakery. 2011. Repair Surgery, The Remakery. The Remakery. Available online: https://www.edinburghremakery.org.uk/about-us/ (accessed on 29 September 2019).

Tom of Holland's Visible Mending Programme. 2017. Available online: https://tomofholland. com/about/ (accessed on 29 September 2019).

Twigger, Holroyd, A. 2016. Perceptions and practices of dress-related leisure: shopping, sorting, making and mending. Annals of Leisure Research 19: 275-93. [CrossRef] 
Watson, D., N. Kiørboe, B. Kjær, B. Lindblad, K. Dammand, and R. Nielsen. 2014. Mindre Affald og Mere Genanvendelse i Tekstilbranchen: Idéer fra Aktørerne på Tekstilområdet. København: The Danish Environmental Protection Agency. (In Danish)

WRAP. 2012. Valuing Our Clothes: The evidence Base. A Technical Report for WRAP: London. Available online: http://www.wrap.org.uk/sites/files/wrap/10.7.12\%20VOC-\%20FINAL. pdf (accessed on 29 September 2019).

(C) 2020 by the authors. Licensee MDPI, Basel, Switzerland. This article is an open access article distributed under the terms and conditions of the Creative Commons Attribution (CC BY) license (http://creativecommons.org/licenses/by/4.0/). 



\title{
The Role of Young Consumers in Moving to a Sustainable Consumption Future
}

\author{
Leah Watkins and Rob Aitken
}

\section{Introduction}

Our growing and increasingly urbanising human population and its concomitant need for greater levels of production and consumption, is driving rapid global environmental and social change (Whitmee et al. 2015). Current consumption habits and continuing rates of (over) consumption are considered to be, "the root cause of un-sustainability" (Ansari and Stibbe 2009, p. 322) and pose one of the greatest threats to sustainable development (Jackson and Michaelis 2003; Michaelis and Lorek 2004; Ash et al. 2010). Global consumption levels and patterns are driven at the most fundamental level by rapid global population growth, the rise in global affluence and associated consumption, and, by an increasingly universal culture of consumerism/materialism, especially among higher income groups, who account for the greatest per capita share of global consumption (Kasriel-Alexander 2016). The depletion of natural resources and the disruption of the planet's natural processes are a direct result of what and how much gets produced and consumed. In addition, the humanitarian, health and social crises we face are, to a large degree, due to unequal access to these resources and the opportunities they provide to satisfy needs and wants. Work on planetary boundaries (Rockström et al. 2009) and social justice (Raworth 2012) demonstrate the urgent need (particularly in light of our rapidly growing population) to review our current system of production and consumption and the socio-cultural context within which consumerism is embedded, to mitigate its effects on the health and well-being of people and the planet. In short, dealing successfully with sustainable development requires transformational change to systems and practices of production and to the privileges and patterns of consumption.

The urgent need to promote more sustainable consumption behaviours has been prominently reaffirmed in the 2016 United Nation's Sustainable Development Goals (SDGs), featuring specifically as SDG 12, "Ensure Sustainable Consumption and Production Patterns". According to the UN, "sustainable consumption and production aims at 'doing more and better with less', increasing net welfare gains from economic activities by reducing resource use, degradation and pollution along the whole life cycle, while increasing quality of life" (UNGA 2015). To meet this goal, 
attention must be paid to encouraging key stakeholders to engage in the processes of change necessary to achieve sustainable and healthy consumption practices that improve public and planetary health for present and future generations. A first step in the process of change is to understand the motivations and attitudes that underpin present consumption behaviours. Consumer behaviour is motivated by a number of complex factors that are deeply embedded in, and heavily influenced by, social, psychological, cultural and institutional contexts (Jackson 2005; Joshi and Rahman 2018). In addition to these factors and their effects on deliberative choice about what to consume, there are also a number of pragmatic barriers to making sustainable consumption choices and these all contribute to a recognised gap between consumers' sustainability attitudes and their sustainable consumption behaviours (McDonagh and Prothero 2014). While the consumer behaviour literature has widely investigated patterns of sustainable behaviour and the factors that motive them (including, for example, values, moral foundations, political ideology, perceived behavioural control and social norms), there has been little work, which focuses on young consumers.

Young consumers are a key stakeholder group in conceptualisations of sustainable living, and represent the future of our society: they are the future citizens, consumers, workers and innovators (Hume 2010). As 'tomorrow's leaders' (Emanuel and Adams 2011, p. 90), young consumers are not only likely to have the opportunity to contribute to decisions determining the nature of a post-consumption future, but also to be the ones most committed to its achievement (Emanuel and Adams 2011). Further, as attitudes towards, and patterns of, consumption are formed in childhood which provide the basis for long-term behaviour (Connell et al. 2014), childhood offers an opportunity to influence future consumer socialisation norms that are more conducive to long-term sustainability. As Donovan (2016, p. 562) suggests, "children have the capacity to adopt active roles as citizens and are crucial contributors to explorations of contemporary consumption practices and a sustainable future".

In this chapter, we present the results from three separate research studies that explore the relationship between young people, consumption and sustainability: specifically these studies address building sustainable consumption and production literacy, limiting advertising, and eliciting visions for a sustainable future. The aim of the chapter is to draw attention to the role of young people in the move towards a sustainable future and to provide strategies to inform, empower and enable them to enact the changes necessary for its achievement. In addition to presenting the results from these three key areas, we also aim to promote a research agenda that encourages further studies involving sustainability and young people and which use different methodologies to explore a range of sustainable consumption perspectives. 


\section{Building Sustainable Consumption and Production Literacy}

While young people have the capacity to be crucial contributors to a sustainable consumption future, changes to more sustainable consumption patterns are dependent upon them acquiring complex interdisciplinary understandings to help them become informed and responsible consumers. Such understanding includes recognising the symbolic value of commodities, insight into the systems and processes which produce and market commodities and services, awareness of the impact consumer lifestyles have on the environment and society, and the analytical and reflective thinking skills to decode commercial messages. Further, education for sustainable consumption requires young people to develop not just knowledge about sustainability in its widest sense, but also the ability to link this knowledge to their everyday practices and behaviours. This will help them see their consumption choices as powerful decisions shaping markets and production patterns, and recognise and understand the impact of their own and others' consumption behaviours on the natural and social environment.

Research indicates that young people are often positively disposed towards sustainability but lack the knowledge and direction needed to exercise this desire (Elizabeth Francis and Davis 2014), thus the foundations for change must focus on building their sustainable consumption literacy by developing knowledge and competencies to enable them to make informed decisions regarding consumption. Thus it is not only the development of factual knowledge ('knowing-that') but also procedural knowledge ('knowing-how') that is important to provide young people with the ability to take active steps towards building a more sustainable consumption future (Barth et al. 2012). This includes the literacy objectives outlined in the UNESCO Tbilisi principles of: awareness, knowledge, attitudes, skills and participation (McBeth and Volk 2009). Surprisingly, given the support and encouragement of major institutions such as the UN, the evidence based on educational approaches to promoting sustainable consumption remains limited, and progress in this field has been hampered by a lack of sophisticated research instruments capable of measuring sustainable consumption attitudes and behaviours, particularly with young people (Zwickle et al. 2014; Fischer et al. 2017). While there is some promising work in higher education, for example, the online sustainability literacy programme, Sulitest, (Sulitest.org 2016), and the BINK programme (Barth et al. 2012), there is little available to measure or support younger children in building sustainable consumption and production (SCP) literacy. According to UNEP's "Here and Now" report, there is "a pressing need for more systematic investigation focusing on how to teach education for sustainable consumption" (Thoresen 2010, p. 16). 
As a first step towards further work with young consumers, we conducted a pilot study to evaluate measures of children's Sustainable Consumption and Production (SCP) knowledge, attitudes and behaviour, and develop and test intervention content aimed at improving literacy in this area. In total, 21 Year Eight (12-13 year old) New Zealand children participated in one-hour focus groups where they completed previously established scales to measure their sustainable consumption attitudes and behaviours. Attitudes were measured using the Major Environmental Values Survey (2-MEV), and behaviours using the Middle School Environmental Literacy Survey (MSELS). Given the absence of a validated SPC knowledge scale, and the need to correlate the measure with the final intervention content, we designed an original, and appropriately targeted, set of knowledge questions. A bank of questions was generated based on Consume This! Buying that Matters, a Canadian Centre for Pollution Prevention (C2P2) resource. In total, 14 questions with five multiple-choice options (including 'I don't know') comprised the final questionnaire. The final intervention booklet was 11 pages long and contained a mix of text, images, diagrams and thought activities. Parts One and Two addressed the Tbilisi objectives of raising awareness, imparting knowledge (through introducing terms and concepts), and changing attitudes. Part Three, 'Making Smarter Choices', addressed the Tbilisi objectives of developing skills and increasing participation by offering specific tips and achievable behaviours and suggesting wider advocacy roles appropriate for children. In the focus group, the children participated in discussion to evaluate the SCP knowledge intervention booklet and completed the multi-choice knowledge questions before and after reading it. Results show children's (prior) SCP knowledge score was highly correlated with their attitudes, and attitudes were highly correlated with both sustainable consumption intention and behaviour scores. Paired $t$ tests demonstrating a significant increase in the scores for pre $(\mathrm{M}=7.05, \mathrm{SD}=2.52)$ and post $(\mathrm{M}=8.5, \mathrm{SD}=2.98)$ intervention knowledge scores $t(19)=3.56, p=0.002$ (Watkins et al. 2019a).

The significant increase in children's knowledge scores following the intervention content provides support for this type of content, and the style of delivery, in successfully improving children's knowledge. The strong correlations in the expected direction for knowledge, attitudes and behaviour provide support for the face validity of the scales adopted for this study, as well as representing promising initial findings that improving children's knowledge about SCP can lead to changes in behaviour. The information booklet provided children with terminology, knowledge and a framework that developed their understanding and improved their ability to recognise the more complex and integrated nature of the wider issues associated 
with sustainable consumption and production. While the learning was largely definitional, giving children the language to open up new ways of thinking about the complex interrelationships between what they need and want, the processes of production and disposal that accompany these choices, and the much wider economic, social and environmental impacts of those decisions is a critical first step in building their knowledge and awareness. Whether this knowledge and awareness impacts their decisions in the long term is, of course, a complex and important next step. However, the children in the study agreed that they now saw some concrete strategies/actions that they could take and these early steps could provide the basis for more sustained behaviours.

\section{Summary}

In order to develop the necessary analytical and reflective thinking skills that will help young people become informed, responsible and empowered consumers, sustainable consumption literacy interventions need to provide them with the understanding necessary to address a range of complex issues. The development of a range of age appropriate and engaging resources to develop a more integrated and informed understanding, and the adoption of measures to evaluate their effectiveness, is a critical step in empowering children to make sustainable consumption choices. Further development of measures and intervention content, such as that piloted in this study, can enable the establishment of a research platform and tools conducive to children becoming informed consumers and responsible citizens better able to contribute to shaping tomorrow's world into a more sustainable one.

\section{Changing Over-Consumption Norms through Limiting Advertising}

The above literacy study highlights a possible route to informing and empowering young people to make the changes needed to present practices of production and consumption that will lead to a more sustainable future. However, in addition to providing proactive strategies to encourage behaviour change, there is also a need to consider the wider landscape within which existing behaviours are situated and future ones are formed. The role of the mass media in providing blueprints for behaviour, is particularly important in this regard and especially the influence of commercial advertising. Advertising provides a pervasive medium not only for explicitly promoting specific products, but also for implicitly promoting the values of consumerism (Smart 2010) that have broader and more wide-ranging social and cultural and planetary health impacts. Research has shown that advertising prompts young people's immediate desires and informs 
their brand preferences (Nairn et al. 2007); however, advertising also shapes and influences their broader consumption values, including their attitudes towards materialism, which in turn has negative impacts on their psychological wellbeing (Opree 2014; Buijzen and Valkenburg 2003; Dávila and Casabayó 2013; Kasser 2005; Rose and DeJesus 2007; Opree 2014). Given that commercial society is largely and systematically dependent on the insatiability of needs, one of advertising's roles is to foster consumer's desires and encourage and reinforce beliefs in the positive individual and social outcomes of continued consumption. Regardless of the particular products being promoted, these wider pro-consumption messages have implications for the development of young people's consumption norms and their well-being. For example, the assumption that the achievement of success and happiness is dependent on, and represented by, the acquisition of material possessions, privileges a pattern of behaviour and a cycle of consumption underpinned by consumerist values and legitimised by social expectations. The normalisation of such values and their consequential behaviours are inimical to sustainability and social well-being. In response, attention must be paid to reducing both the amount and the ubiquity of commercial advertising, which plays such an influential role in establishing and perpetuating the normalisation of material acquisition and over-consumption.

While it is widely quoted in industry and popular culture that consumers may come into contact with up to 5000 brand messages a day, this figure is unsubstantiated (Choice Behaviour Insights 2007). In the rapidly changing marketing environment, research on the actual amount of advertising to which young people are exposed is considered, "woefully out of date and incomplete" (Common Sense Media 2014). Methods to date only provide figures for single media (e.g., TV), or a limited product category (primarily food). Consequently, there have been calls for new methodologies and more accurate metrics to quantify young people's exposure to advertising and examine the messages inherent in it (Kunkel and Castonguay 2012; Valkenburg and Peter 2013). It is timely and critical that a more robust and objective estimate of total marketing exposure across media is established, as a starting point to inform public policy decisions about the ubiquity and impact of advertising on children.

In a recent study, we used data from Kids'Cam, a cross-sectional observational study of 168 randomly selected Year 8 children (aged 11-13 years) from sixteen schools in the Wellington region of New Zealand, to examine their daily exposure to advertising. Children in this age group, commonly referred to as 'tweens' spanning the pre-adolescent years of 8-12 (Lindstrom 2004), are an appropriate age group to examine in relation to consumer experience due to their increasing purchasing power and affection for brands, and their representation on the cusp between the analytic and 
reflective stages of consumer socialisation (John 1999). Participants in the Kids'Cam study were asked to wear an automated digital camera ${ }^{1}$ for every waking hour for two weekdays and two weekend days (four days total) and only remove them during periods of exercise, swimming, bathing and in situations requiring individual privacy. The camera captures a passive, 180 degree angle image of the scene ahead of the wearer, approximately every seven seconds, and produces and stores between 2000 and 5000 images per day. To examine the marketing environment, captured images were manually coded in accordance with a protocol for marketing exposure based on the WHO definition of marketing as, "any form of commercial communication or message that is designed to, or has the effect of, increasing recognition, appeal and/consumption of particular products and services. It comprises anything that acts to advertise or otherwise promote a product or service" (World Health Organisation 2012, p. 9). Further, coding was based on a four-tier framework, including brand name, setting of exposure, marketing medium and product category. For our pilot study, 12 students (aged 11-12) were purposively selected from the wider study to examine the feasibility of coding all marketing exposure for one school day (Thursday). Only children with full data sets for the chosen day were included and participants were selected to represent a range of ethnicities, socio-demographic features, gender and locations (schools).

Our results showed that the children were exposed to 638 (95\% CI 492 to 783) individual marketing messages a day (Watkins et al. 2019b). The majority of these exposures occurred in school (54\%), followed by home $(18 \%)$ and in-store $(12 \%)$. The most prominent marketing media were brand labels (31\%), followed by product packaging and signage accounting for $19 \%$ and $12 \%$ of marketing exposures, respectively. The top three product categories were food and beverages (15\%), clothing $(9 \%)$ and electronics $(7 \%)$. The most prevalent brands were Nike (3\%), Adidas ( $2 \%)$ and Apple (2\%). In total, the children were exposed to 976 different brands over the 1 day period. The 683 exposures recorded on average per day is significantly higher than the existing estimates available for adult exposure, and the first to provide an objective measure of children's exposure. Although the figure undoubtedly underestimates children's total exposure (given limitations with what the camera can capture), the extrapolated 233,000 yearly exposures are more than five times greater than the highest evidence-based estimate to date $(40,000)$ (Common Sense Media 2014). It also demonstrates the overriding presence of commercial messages in a range of

1 See Autographer. Available online: http://www.autographer.com (accessed on 17 December 2019). 
children's environments and provides evidence of the leading product categories and brands to which children are exposed. This documentary evidence of the extent of children's everyday exposure to marketing, draws attention to the commercially saturated nature of their environment and further analysis with a bigger sample can inform debates concerned with the ubiquity and the nature of marketing messages to children, and contribute to reviews of policy and industry practice.

\section{Summary}

Childhood is a unique period during which lasting consumer behaviours and norms are established, and this study provides evidence of the nature and extent to which these behaviours and norms are represented through marketing in children's everyday environment. We suggest that the cycle of over-consumption is based, in part, on the normalisation of consumption values promoted by advertising that provide social legitimisation for non-sustainable consumption norms, patterns and behaviours. Restricting the ubiquity and reach of marketing may be an effective way to change (over) consumption norms (Whitmee et al. 2015). A sustainable consumption future requires rethinking patterns of consumption and production, and the role of marketing in promoting both over-consumption generally and, the consumption of products harmful to the individual, society and the planet. Breaking the cycle of (over) consumption, then, begins by understanding the advertising experience of those upon whom the continuation of the cycle depends: young people. In addition, this area requires further research in relation to its implications for policy, regulation and industry practice.

\section{Realising Young People's Vision of a Sustainable Consumption Future}

However, while it is necessary to address the normalisation of over consumption through advertising, and equip children with sustainable consumption literacy, it is also important to understand what a sustainable future would look like and the particular pathways needed to achieve it. As Elgin (1991, p. 57) suggests, "we cannot build a future we cannot imagine" - it would seem reasonable, therefore, to enable young people to make a contribution to this future's imagination and realisation. To address this, we used the projective technique of backcasting in a further pilot study to explore young people's visions of a sustainable future. Backcasting is a form of envisioning that can be defined as "generating a desirable future, and then looking backwards from that future to the present in order to strategize and to plan how it could be achieved" (Vergragt and Quist 2011, p. 747). Unlike more conventional approaches to forecasting, such as trend and scenario analysis that 
predict change from the present and project it to the future, the determining feature of backcasting is its reverse analysis from the future back to the present. Typically, this involves imagining an ambitious and aspirational societal vision that is followed by the development of agendas, strategies and pathways to realise it. In addition to enabling people to consider better ways of observing situations, problems and obstacles, envisioning also encourages them to take ownership of and responsibility for working towards their visions (Tilbury and Wortman 2004; Robinson et al. 2011).

The technique of backcasting is especially useful when dealing with complex problems, where there is a need for radical change and when the status quo is not sustainable. Backcasting is particularly appropriate for younger participants whose imaginations may be more easily triggered by the opportunity offered by this 'empty canvas' approach than by older people whose canvases are already coloured. While there is a wide range of literature on the use of backcasting to envision sustainable futures in areas such as urban planning, power generation and transport systems, its use in relation to imaginings of a consumption future is limited. In response, we conducted a qualitative study with 18-19 year old students $(n=36)$ to investigate what a sustainable future would look like.

Drawing from a range of literature, an integrative framework comprising housing, clothing, travel, leisure and food provided the structure for 6 separate focus group discussions. Thematic analysis identified three key characteristics of a sustainable consumption future, namely the importance of efficiency, sharing and community; and three critical elements necessary for its achievement, comprising government, education and technology (Aitken et al. 2019). In relation to efficiency, the importance of conserving and utilising resources and the generation of new ones was emphasised, as was the importance of the localised nature of this resource generation and usage. This included visions of independent, micro systems of power generation and the collection and reticulation of water. As an important characteristic of sustainability, the significance participants attached to efficiency reflected an informed understanding of its role in achieving and maintaining a sustainable future.

The future they envisioned was also characterised by an emphasis on sharing. This was represented both by examples of sharing physical resources, such as bicycles and clothes, and, in the sharing of intellectual resources such as experience and expertise. Shared social, working and recreational space, including communal gardens and workshops was envisioned as providing opportunities for increased engagement and closer and more meaningful interactions. Closely associated with sharing, was the emphasis placed by participants on the importance of community. This was reflected in the overriding vision of communal living in high-rise apartments, 
the production and distribution of food, the localised generation of power and the neighbourhood collection and reticulation of water. Interestingly, the vision of an international network of water distribution suggests that notions of community were not restricted to physical proximity or geographical distance. It was also assumed that the communities would be inclusive and this would encourage the sharing of resources to enable the meeting of needs.

Perhaps not surprising, given the nature of the participants, the critical role of education was prioritised as an essential contributor to the achievement of a sustainable future. Educating people both about the macro issues related to sustainability and the macro and micro behaviours necessary to achieve it was envisioned at all levels in the formal education system. The role of government in driving change was also strongly emphasised in students' visions for change. While celebrating the resilience and efficacy of local communities and their potential to drive innovation and change, there was recognition that this needed to be complemented by strong central leadership and legislative and regulatory support. Respondents imagined leading the move to a sustainable future should also be encouraged and enabled through the provision of government subsidies and incentives and balanced by restrictions and penalties. The final critical factor mentioned, and one strongly related to the theme of efficiency, was technology. Technology was expected to drive and enable change and provide solutions to problems both actual (e.g., water reticulation systems) and virtual (e.g., holographic actors). Interestingly, visions of a sustainable future comprised few disruptive technologies other than those required to generate power, produce food and enhance recreation. Of greater emphasis was the role of technology in developing localised, micro-systems that would more easily enable sharing and collaborative enterprise.

In addition to these characteristics and critical factors, a number of underlying assumptions were identified. For example, the emphasis on community and sharing represented an ideological vision of a society based more on collective action to achieve common goals than on the importance attached to prevailing notions of individual effort and success. It also suggested greater appreciation of the importance of developing and maintaining relationships and their role in creating a more equitable and responsible society. These relationships were seen to comprise social as well as economic and government organisations and based on a shared set of communal values. The resulting vision of a collective commitment to a shared purpose is both idealistic and aspirational but perhaps one that is necessary to negotiate the fundamental changes that will be required to achieve a sustainable consumption future. 


\section{Summary}

The backcasting project identified a number of important elements that characterised young people's vision of a sustainable future. In addition to practical components such as shared provisioning systems and alternative forms of protein production, there was an emphasis on more holistic, integrated and communal approaches to living. More emphasis was also placed on the role that government was expected to play in leading change and providing incentives for, and the quality control mechanisms necessary to ensure, its success. Results also suggest that, in addition to central government providing more proactive leadership, education was seen as having an important role to play in identifying and addressing the challenges related to sustainability and in preparing students to meet them. A number of insights elicited by the technique of backcasting also provided support for earlier suggestions that young people could play an increasingly active role in leading and advocating for change. Encouraging young people to consider and share their visions of an alternative future provides a range of competing alternatives that form the basis for continued discussion. It also enables young people to engage more meaningfully in discussions that may have direct consequences for their future. As a novel method for eliciting the ideas and inspirations of young people, we encourage researchers to apply it to a wider range of ages than those presented here.

\section{Discussion}

The aim of drawing together the studies presented in this chapter is to focus attention on the important but often neglected role of young people in considerations of and movement towards a sustainable future. The results from three key areas, building sustainable consumption and production literacy, limiting advertising, and eliciting visions for a sustainable future suggest that young people are both vulnerable to the influence of the media, but receptive to engaging with leading change. In presenting different approaches and methodologies to help us understand the relationship between young consumers and the changes necessary for a sustainable future, we hope to encourage further studies that will inform, empower and enable them to enact the changes necessary for its achievement.

Many of the current disruptions to the Earth's natural systems, including climate-change, environmental degradation, resource scarcity, and income and economic growth inequality, are contingent on and directly affected by the perpetuation of entrenched and prevailing patterns of consumption. Achieving a sustainable consumption future will require systemic change, and a fundamentally different understanding of the relationship between business and society, including rethinking 
patterns of consumption and production, and the role of marketing in promoting (over) consumption. For example, restricting the ubiquity and reach of marketing could reduce the opportunities for advertisers to prime and reinforce those consumption behaviours which are not conducive to long term sustainability. In particular, advertising to young people is problematic both to public health directly (through the promotion of environmentally harmful products), and through its pervasiveness, which drives materialism and a culture of consumerism (over-consumption), which is a direct threat to sustainability. To break this cycle of consumerism and promote more sustainable consumption practices, it is important to consider public policy interventions to reduce advertising's impact on the next generation. Disrupting the cycle also requires a change in the normalisation of consumption values promoted by advertising that provide social legitimisation for non-sustainable consumption norms, patterns and behaviours and which underpin unsustainable lifestyles (Whitmee et al. 2015). Norms and patterns of consumer socialisation established early in life are the basis for long term consumption behaviours. If we are to address over-consumption and its impacts on planetary health it is vital to re-align these norms and re-orientate the patterns.

The achievement of sustainable lifestyles is influenced by a number of complex factors that operate at both individual and social levels. Individual psychology, affective disposition and personal values, for example, strongly affect attitudes, intentions and behaviours, and these individual characteristics are deeply embedded in social norms and institutions (Jackson 2005). Increasingly, the need for a comprehensive and integrative approach linking these different factors together is compelling. Educating young people about this complex interplay to understand the wider issues as well as providing practical knowledge of the changes they can make to their personal consumption lifestyles are an important focus for ongoing research.

Behaviour change is only likely where attitudes are positively disposed to sustainable consumption, where this is supported by social norms, and where individuals feel that change is both possible and effective (Yazdanpanah and Forouzani 2015; Yadav and Pathak 2016). Given that the encouragement and achievement of sustainable lifestyles cannot rely solely on current incremental approaches to innovation and an ad hoc increase in the supply of sustainable goods, there needs to be progress towards a shared, holistic and integrated vision of the future (Tilbury and Wortman 2004). Young people have an important role in creating and realising this future.

In summary, creating the context for change, must begin by changing existing social norms by creating positive attitudes towards the need and possibilities for 
change, and building consumer agency amongst the next generation. In addition to focussing on individual choice, it is also necessary to change the consumption environment to constrain choices and to re-orientate and reset the automatic processes that underpin conventional consumption norms and behaviours. Thus the foundations for change must focus on building young people's sustainable consumption literacy, understanding their vision, and reducing the pro-consumption messages and environment, that will allow sustainable alternatives to flourish.

\section{Conclusions and Future Research}

The method of backcasting proved to be an effective technique for eliciting useful insights from young people. Given the importance of understanding what a sustainable future would look like, using the method more widely, especially with younger children, might provide a number of aspirational blueprints for the future that could encourage and inform the process and direction of change. In addition to identifying and understanding what a sustainable future would comprise, its achievement could be helped by adopting more proactive approaches to young people's socialisation. This is particularly appropriate in relation to the development of more integrated, systematic and comprehensive approaches to and provision of sustainability literacy programmes throughout the education system. In addition to further research into their development, there also needs to be comprehensive system of evaluation of these programmes. Researching the role of parents in encouraging more positive approaches and attitudes to sustainability in the socialisation of their children's consumption behaviour is also an important area that requires further attention. Further research to understand how young people could be encouraged to become more active agents for change is also needed as is an overall focus on their experiences, aspirations and attitudes towards a sustainable future.

Finally, it is clear from the literature that young people are an under-researched population in relation to sustainability. Given that they are the ones most likely to experience the changes necessary to achieve a sustainable consumption future, we suggest that they feature more centrally in future research on sustainable consumption.

Author Contributions: L.W. and R.A. were jointly and equally responsible for the conceptualization, development and writing of this chapter.

Funding: This research received no external funding.

Conflicts of Interest: The authors declare no conflicts of interest. 


\section{References}

Aitken, Rob, Leah Watkins, and Sophie Kemp. 2019. Envisioning a Sustainable Consumption Future. Young Consumers 20: 299-313. [CrossRef]

Ansari, Walid El, and Arran Stibbe. 2009. Public Health and the Environment: What Skills for Sustainability Literacy-And Why? Sustainability 1: 425-40. [CrossRef]

Ash, Neville, Hernán Blanco, Claire Brown, Keisha Garcia, Thomas Henrichs, Nicolas Lucas, Ciara Raudsepp-Hearne, R. David Simpson, Robert Scholes, Thomas P. Tomich, and et al. 2010. Ecosystems and Human Well-Being: A Manual for Assessment Practitioners. Washington: Island Press.

Barth, Matthias, Daniel Fischer, Gerd Michelsen, Claudia Nemnich, and Horst Rode. 2012. Tackling the Knowledge-Action Gap in Sustainable Consumption: Insights from a Participatory School Programme. Journal of Education for Sustainable Development 6: 301-12. [CrossRef]

Buijzen, Moniek, and Patti M. Valkenburg. 2003. The Effects of Television Advertising On Materialism, Parent-Child Conflict, and Unhappiness: A Review of Research. Journal of Applied Developmental Psychology 24: 437-56. [CrossRef]

Choice Behaviour Insights. 2007. The Myth of 5000 Ad's. Available online: http://cbi.hhcc. com/writing/the-myth-of-5000-ads (accessed on 25 April 2017).

Common Sense Media. 2014. Advertising to Children and Teens: Current Practices. In $A$ Common Sense Media Research Brief. New York: Common Sense Media.

Connell, Paul M., Merrie Brucks, and Jesper H. Nielsen. 2014. How Childhood Advertising Exposure Can Create Biased Product Evaluations That Persist Into Adulthood. Journal of Consumer Research 41: 119-34. [CrossRef]

Dávila, Juan Francisco, and Mònica Casabayó. 2013. Influences in Children's Materialism: A Conceptual Framework. Young Consumers 14: 297-311. [CrossRef]

Donovan, Doreen. 2016. How Children Represent Sustainable Consumption Through Participatory Action Research and Co-Design of Visual Narratives. International Journal of Consumer Studies 40: 562-74. [CrossRef]

Elgin, Duane. 1991. Creating a sustainable future. ReVision 14: 77-79.

Elizabeth Francis, Julie, and Teresa Davis. 2014. Exploring Children's Socialization to Three Dimensions of Sustainability. Young Consumers 15: 125-37. [CrossRef]

Emanuel, Richard, and J. N. Adams. 2011. College Students' Perceptions of Campus Sustainability. International Journal of Sustainability in Higher Education 12: 79-92. [CrossRef]

Fischer, Daniel, Tina Böhme, and Maria Geiger Sonja. 2017. Measuring Young Consumers' Sustainable Consumption Behavior: Development and Validation of the YCSCB Scale. Young Consumers 18: 312-26. [CrossRef]

Hume, Margee. 2010. Compassion without Action: Examining the Young Consumers Consumption and Attitude To Sustainable Consumption. Journal of World Business 45: 385-94. [CrossRef] 
Jackson, Tim. 2005. Motivating Sustainable Consumption: A Review of Evidence on Consumer Behaviour and Behavioural Change. In A Report to the Sustainable Development Research Network. Guildford: University of Surrey.

Jackson, Tim, and Lauri Michaelis. 2003. Policies for Sustainable Consumption: A Report to the Sustainable Development Commission. London: Sustainable Development Commission.

John, Deborah Roedder. 1999. Consumer Socialization of Children: A Retrospective Look at Twenty-Five Years of Research. Journal of Consumer Research 26: 183-213. [CrossRef]

Joshi, Yatish, and Zillur Rahman. 2018. Determinants of Sustainable Consumption Behaviour: Review and Conceptual Framework. In Green Initiatives for Business Sustainability and Value Creation. Hershey: IGI Global, pp. 239-62.

Kasriel-Alexander, Daphne. 2016. Top 10 Global Consumer Trends for 2016. London: Euromonitor International.

Kasser, Tim. 2005. Frugality, Generosity, and Materialism in Children and Adolescents. In What Do Children Need to Flourish? Conceptualizing and Measuring Indicators of Positive Development. Edited by Kristin Anderson Moore and Laura H. Lippman. Boston: Springer, pp. 357-73.

Kunkel, Dale, and Jessica Castonguay. 2012. Children and Advertising: Content, Comprehension, and Consquences. In Handbook of Children and the Media. Edited by Dorothy G. Singer and Jerome L. Singer. Los Angeles: Sage, pp. 395-418.

Lindstrom, Martin. 2004. Brandchild: Remarkable Insights into the Minds of Today's Global Kids and Their Relationships with Brands. Edited by Patricia B. Seybold. London: Kogan Page Publishers.

McBeth, William, and Trudi L. Volk. 2009. The National Environmental Literacy Project: A Baseline Study of Middle Grade Students in the United States. The Journal of Environmental Education 41: 55-67. [CrossRef]

McDonagh, Pierre, and Andrea Prothero. 2014. Sustainability marketing research: Past, present and future. Journal of Marketing Management 30: 1186-219. [CrossRef]

Michaelis, Laurie, and Sylvia Lorek. 2004. Consumption and the Environment in Europe-Trends and Futures. Environmental Project No. 904 2004. København: Danish Environmental Protection Agency.

Nairn, Agnes, Jo Ormrod, and Paul Andrew Bottomley. 2007. Watching, Wanting and Wellbeing: Exploring the Links-A Study of 9 to 13 Year-Olds. London: National Consumer Council.

Opree, Suzanna J. 2014. Consumed By Consumer Culture? Advertising's Impact on Children's Materialism and Life Satisfaction. Ph.D. Thesis, Faculty of Social and Behavioural Sciences (FMG), Amsterdam School of Communication Research (ASCoR), Amsterdam, The Netherlands.

Raworth, Kate. 2012. A Safe and Just Space for Humanity: Can we live within the doughnut. Oxfam Policy and Practice: Climate Change and Resilience 8: 1-26. [CrossRef] 
Robinson, John, Sarah Burch, Sonia Talwar, Meg O'Shea, and Mike Walsh. 2011. Envisioning sustainability: Recent progress in the use of participatory backcasting approaches for sustainability research. Technological Forecasting and Social Change 78: 756-68. [CrossRef]

Rockström, Johan, Will Steffen, Kevin Noone, Åsa Persson, F. Stuart Chapin, Eric Lambin, Timothy M. Lenton, Marten Scheffer, Carl Folke, Hans Joachim Schellnhuber, and et al. 2009. Planetary Boundaries: Exploring the Safe Operating Space for Humanity. Ecology and Society 14: 32. [CrossRef]

Rose, Paul, and Stephanie P. DeJesus. 2007. A Model of motivated cognition to account for the link between self-monitoring and materialism. Psychology \& Marketing 24: 93-115. [CrossRef]

Smart, Barry. 2010. Consumer Society: Critical Issues and Environmental Consequences. London: SAGE Publications Ltd.

Sulitest.org. 2016. Building a Sustainable World Together. Available online: https://www. sulitest.org/en/index.html (accessed on 17 December 2019).

Thoresen, Victoria. 2010. HERE and NOW! Education for Sustainable ConsumptionRecommendations and Guidelines. United Nations Environment Program, Marrakech Task Force on Education for Sustainable Consumption United Nations Decade on Education for Sustainable Development. Elverum: Hedmark University College.

Tilbury, Daniella, and David Wortman. 2004. Engaging People in Sustainability. Gland: Commission on Education and Communication. Cambridge: IUCN.

United Nations General Assembly (UNGA). 2015. Transforming Our World: The 2030 Agenda for Sustainable Development. Resolution Adopted by the General Assembly on 25 September 2015. New York: United Nations General Assembly.

Valkenburg, Patti M., and Jochen Peter. 2013. Five Challenges for the Future of Media-Effects Research. International Journal of Communication 7: 197-215.

Vergragt, Philip J., and Jaco Quist. 2011. Backcasting for Sustainability: Introduction to the Special Issue. Technological Forecasting and Social Change 78: 747-55. [CrossRef]

Watkins, Leah, Rob Aitken, and Jess Ford. 2019a. Measuring and Enhancing Children's Sustainable Consumption and Production Literacy. Young Consumers 20: 285-98. [CrossRef]

Watkins, Leah, Robert Aitken, Ryan Gage, Moira B. Smith, Tim J. Chambers, Michelle Barr, James Stanley, and Louise N. Signal. 2019b. Capturing the Commercial World of Children: The Feasibility of Wearable Cameras to Assess Marketing Exposure. Journal of Consumer Affairs. [CrossRef]

Whitmee, Sarah, Andy Haines, Chris Beyrer, Frederick Boltz, Anthony G. Capon, Braulio Ferreira de Souza Dias, Alex Ezeh, Howard Frumkin, Peng Gong, Peter Head, and et al. 2015. Safeguarding Human Health in the Anthropocene Epoch: Report of the Rockefeller Foundation-Lancet Commission on Planetary Health. The Lancet 386: 1973-2028. [CrossRef] 
World Health Organisation. 2012. A Framework for Implementing the Set of Recommendations on the Marketing of Foods and Non-Alcoholic Beverages to Children. Geneva: WHO.

Yadav, Rambalak, and Govind Swaroop Pathak. 2016. Young Consumers' Intention towards Buying Green Products in a Developing Nation: Extending the Theory of Planned Behavior. Journal of Cleaner Production 135: 732-39. [CrossRef]

Yazdanpanah, Masoud, and Masoumeh Forouzani. 2015. Application of the Theory of Planned Behaviour to Predict Iranian Students' Intention to Purchase Organic Food. Journal of Cleaner Production 107: 342-52. [CrossRef]

Zwickle, Adam, Tomas M. Koontz, Kristina M. Slagle, and Jeremy T. Bruskotter. 2014. Assessing sustainability knowledge of a student population: Developing a tool to measure knowledge in the environmental, economic and social domains. International Journal of Sustainability in Higher Education 15: 375-89. [CrossRef]

(C) 2020 by the authors. Licensee MDPI, Basel, Switzerland. This article is an open access article distributed under the terms and conditions of the Creative Commons Attribution (CC BY) license (http://creativecommons.org/licenses/by/4.0/). 



\title{
12 \\ 12 consumprion \\ $\infty$
}

\section{Justice Concerns in SDG 12: The Problem of Missing Consumption Limits}

\author{
Katia Vladimirova
}

\section{Introduction}

The adoption of Agenda 2030 and the Sustainable Development Goals (SDGs) in 2015 represents an important step taken by humanity towards conceptualizing the vision of future development. Agenda 2030 is the most recent global attempt to flesh out a normative concept of 'sustainability' (Jacob 1994; Griessler and Littig 2005; Amsler 2009) that outlines the different dimensions and priorities of global development. At the heart of Agenda 2030, as well as Agenda 21 before it, are normative aspirational ideas that reflect how we as humans want to see our world evolve in the future. A result of political negotiations, consultations with civil society and other stakeholders, and relying on decades of preceding legal frameworks, this vision essentially builds on assumptions that are deeply intertwined with our morality and values, our understandings of what is good and bad, right and wrong. Agenda 2030 and the SDGs propose nothing less than a pathway to transform the world, and it is critical to have these documents examined, questioned, and challenged, if needed, from an ethical perspective. To date, however, ethical examinations of Agenda 2030 are limited in number and scope (Vasconcellos Oliveira 2018; Klimková 2017).

SDG 12 draws attention to consumption and production patterns as one of the priority areas in sustainable development. Globally, material consumption increased from 27 billion tonnes in 1970, to 87 billion tons in 2015 (the year Agenda 2030 was adopted) and further to 92.1 billion tonnes only two years later, in 2017 (United Nation 2019). The global consumption of natural resources more than tripled over the course of forty-five years, during which the world population only about doubled, from 3.7 billion people in 1970 to 7.3 billion people in 2015 (World Bank 2020). The material footprint per capita continues to grow, from 7.3 tonnes of natural resources 'to satisfy a person's need' in 1970, to 8.1 tonnes in 1990 and to 12 tonnes in 2015 (United Nation 2019, p. 18).

These numbers also mask vast inequalities. While, on average, citizens of developed countries consume 16 tonnes of key resources per capita (ranging up to 40 tonnes in some countries), a person in India consumes on average 
only 4 tonnes of the same resources (UNEP 2011). The rate of extraction has accelerated since 2000 and it is projected that, by 2060, global resource extraction could reach 190 billion tonnes if, according to the UN, "no urgent and concerted political action is taken" (United Nation 2019, p.18).

SDG 12 represents an important goal for systemic change to align consumption and production patterns with a normative vision for a sustainable future. A shift towards more sustainable consumption and production patterns has the transformative power to "decouple economic growth from resource use and environmental degradation through improved resource efficiency, while improving people's well-being" (United Nations Statistics Division 2018; UNEP 2011). However, the academic literature suggests that mere resource efficiency improvements are not enough and that the profound large-scale transformation that is required should go beyond the narrowly construed pathway of decoupling (e.g., Alexander et al. 2017; Fletcher and Rammelt 2017).

Questions of allocation - who should be entitled to consume what, how, and, most importantly, how much-are all essentially questions of fair distribution. The reconfiguration of consumption and production patterns is bound to exacerbate existing matters of inequality and wealth distribution and to create new trade-offs and moral dilemmas. To navigate these complex issues, we need to have guidance from our moral theories, among others. Moral philosophers could contribute to the work on changing consumption and production patterns by engaging more actively into discussing matters of (re)distribution associated with this transformation. This position piece suggests several avenues to explore through further ethical inquiries.

\section{Consumption and Morality}

For centuries, morality played an important role in shaping how and what we consume. According to Trentmann's (2016) seminal work on the history of consumption, at different times morality, embedded in ideology and religion, determined what societies considered frugal or conspicuous, sufficient or excessive, acceptable or unacceptable. Moreover, as one ideological or religious paradigm succeeds the other throughout history, views of how and what we consume may change significantly.

For example, bans on luxury display in the form of dress, carriages or lavish feasts existed in Italy throughout most of the Middle Ages. The Church prescribed that the rich were to look and act modestly in public so as not to ignite envy and cause civil unrest. The morality of the Renaissance era in Italy, however, started to accept and encourage large scale consumption by the rich—with public good as its 
final goal. Acts of 'good consumption' at that time were understood as those that transcended the lifetime of the consumer (owner), resulting in the construction of palaces and public infrastructures, such as fountains and squares and the production of exquisite artwork that people still enjoy today (Trentmann 2016, p. 32).

Morality continues to shape our consumption patterns. Initially, the growth of consumer society was defined by considerations of restoring economic systems after a devastating world war. Maintaining peace, while improving the lives of people affected by global humanitarian and economic crises, was the key development priority. After half a century, however, priorities have changed. We are on the cusp of a paradigm shift, as has happened in the past. Today, what defines consumption and lifestyles as 'conspicuous', 'excessive', or 'unsustainable' are no longer only religious, ideological, or economic dogmas but planetary boundaries (Rockström et al. 2009; Steffen et al. 2011), principles of sustainability and embedded social justice (UN Agenda 21, Agenda 2030).

Decisions on how to transform the world to align development paths with a vision of a sustainable future require tough re-examination of our values and understandings of what is good and bad, right and wrong in the context of the global environmental crisis. Morality and ethics, therefore, are critical to sustainability transformations in different areas, including consumption patterns.

To inform academic and public debates and action aimed to transform consumption and production patterns from a moral perspective, it appears logical to seek guidance in the relevant literature on the ethics of consumption and perspectives on its moral dimensions. Surprisingly, though, consumption ethics never emerged as a field of applied ethics, as with bioethics or business ethics. There are some studies that look at 'consumption ethics' as a counterpart to business ethics from marketing and business administration standpoints (Belk et al. 2005; Brinkmann and Peattle 2008; Eckhardt et al. 2010). Another thread of research explores 'ethical consumption' as a recent phenomenon from the points of view of sociology, anthropology, and political science (e.g., Shaw and Newholm 2002; Barnett et al. 2005; Hall 2011). Neither research strand engages normative evaluations or critiques of consumption, but rather studies existing patterns as given.

Fragmented ethical perspectives on consumption can be traced in seminal works by Veblen [1899] (1925), Baudrillard [1998] (1970), Bourdieu (1984), and, more recently, Schor $(1991,1999)$ and De Graaf et al. $(2002,2014)$. In the past decade, scholars working on degrowth further criticized overconsumption as part of the dominant growth paradigm (e.g., Kallis 2011, 2019). While timely and powerful, these examples 
of the social and economic critique of consumption are distinct from the normative critiques that draw upon moral and ethical theories.

For decades, the Anglo-Saxon philosophical tradition avoided engaging directly with the topic of consumption. This reluctance may be attributed to the dominance of a neoliberal growth paradigm, which considers increasing consumption as an essential driver of prosperity and wellbeing. Moral dimensions of overconsumption by more affluent groups of people remained on the periphery of broader international distributive justice theories. With growing global interconnectedness, normative theories emerged to address how to share resources among countries in a fair manner (e.g., Singer 1972, 2011; Rawls 1999; Pogge 2002). With the rise of the climate change problem, research in climate ethics further developed perspectives on the sharing of limited resources (greenhouse gas emission reduction burdens) among countries (e.g., Shue 1993; Jamieson 1992; Caney 2005; Gardiner et al. 2010).

While these foundational ethical perspectives did not directly aim to reconfigure unsustainable consumption patterns, they proposed different principles and theories regarding the fair distribution of global resources. This body of literature, which mostly supports a sufficientarian perspective, i.e., that everyone should have resources and wellbeing above a certain threshold) could provide useful insights to inform reconfiguration of consumption patterns and flows among countries.

As the statistical data presented in the introduction clearly demonstrates, the main driving force behind unsustainable consumption patterns is overconsumption by the more affluent countries and groups of people who consume not only more than others but also more than they need and more than the planet can sustain. To date, there are very few ethical perspectives that explore the moral dimensions of excessive consumption by the rich, including moral permissibility of consuming above certain thresholds.

One account of justice that could inform further ethical inquiries regarding transforming unsustainable consumption patterns is a recent attempt to question moral permissibility of excessive wealth accumulation, a limitarian approach to upper levels of wealth distribution proposed by Robeyns (2017). Limitarianism, a non-ideal partial account of justice, states that being rich above a certain threshold is morally unacceptable. Robeyns argues that excessive accumulation of wealth by the rich undermines the value of democracy and prevents meeting the urgent needs of more vulnerable and poor populations by re-directing valuable resources (Robeyns 2017, p. 4). Extending limitarian logic to consumption, further research could justify why consumption above certain levels (by individuals or groups of people) is not 
morally acceptable and support further debates on how to overcome the 'wicked' problem of excessive consumption.

To conclude this section, ethical perspectives on consumption that build on existing moral theories are limited-especially moral examinations of the upper tail of consumption distribution. Ethics is lagging behind the global political processes described in the following section, which places transforming unsustainable consumption and production patterns among the top development priorities.

\section{Consumption and Sustainable Development Politics}

Three decades ago, the Brundtland Report (1987) and Agenda 21 (1992) acknowledged unsustainable lifestyles and overconsumption by more affluent countries as one of the key drivers increasing pressure on global natural resources. Under the lead of the United Nations Environment Program, which facilitated the so-called Marrakesh process, at the Rio+20 conference in 2012, countries adopted a 10 Year Framework of Programs (10YFP) on sustainable consumption and production. The goal of 10YFP is to "develop, replicate and scale up sustainable consumption and production policies and initiatives at all levels" (United Nations Environment Program 2012).

The framework includes six program areas that focus on sustainable public procurement, consumer information, sustainable tourism, sustainable lifestyles and education, sustainable buildings and construction, and sustainable food systems (United Nations Environment Program 2012). 10YFP is the first political attempt of this scale to disentangle various strands and dimensions of consumption patterns. It sets priorities for political action, although its implementation at a national level is admittedly limited in some countries (Hobson 2013).

The inclusion of consumption and production patterns into the list of SGDs in 2015 signaled a positive dynamic and acknowledgement of the problem. However, looking closer at SDG 12, its scope and reach leave much to be desired. The goal has 11 targets and 13 indicators that include actions by governments (public procurement), companies (voluntary disclosure of sustainability information), and individuals (access to information about sustainable lifestyles). The goal also covers thematic areas of waste management, management of chemicals, fossil fuel subsidies, and tourism.

Despite addressing a seemingly wide range of activities, SDG 12 is vague or silent on a number of issues critical to transforming consumption patterns. In the most comprehensive critical account of SDG 12 to date, Bengtsson et al. (2018) argue that, overall, the goal tends to adopt a perspective that favors 'efficiency' rather than 'systemic' change: targets under SDG 12 serve to improve existing processes and 
deliver technological fixes without addressing the root cause of the problem, which is overconsumption by more affluent countries and groups of people. Part of this bias is visible in the disproportionate emphasis on waste management. Three out of eleven targets focus on what is downstream of the economy and require no broad changes in production or consumption processes. Importantly, SDG 12 also contains no new political commitments in terms of consumption and upstream resource use or distribution (Bengtsson et al. 2018).

Other (limited) critiques of SDG 12 address the inadequacy of reporting mechanisms intended by the goal. Legal scholars argue that these mechanisms do not account for transboundary impacts of consumption in developed countries in the form of environmental harm in producing countries (Amos and Lydgate 2019). Moreover, civil society organizations criticized the goal for failing to acknowledge corporate dominance and capture that subverts meaningful transformation of consumption and production patterns (Ling 2016).

The most critical gap in SDG 12, however, is the lack of indication of upper limits to consumption, which the following section explores in more detail.

\section{The Challenge of Setting Upper Consumption Limits}

\subsection{Different Interpretations of Limits and Wellbeing}

Before moving on to discuss upper consumption limits, it is important to acknowledge that limits to consumption may be understood and interpreted differently. Spengler (2016) distinguishes between two types of sufficiency (or limits), delineating debates from practical environmental science on maxima consumption levels that are framed in terms of biophysical limits of the planet and discussions in abstract justice theory on minima standards of consumption that are required for a life of dignity. Spengler argues that for decades, these debates developed without interacting with each other-although they both address limits required by sustainability.

As Section 2 shows, existing ethical and normative perspectives on global resource distribution adopt exactly this minima-centered sufficentarian approach and do not engage actively with the maxima-related debates. Sustainable consumption levels, therefore, can be defined based on present perspectives as a range that would ensure that the poorest at least reach the minimum level of wellbeing according to agreed principles of justice, while the richest do not overconsume above the maximum levels determined by planetary boundaries.

Recently, several attempts have been made to bring together the upper and lower limits of resource consumption. Among them is the concept of 'doughnut economics', 
which combines planetary boundaries with minimal standards outlining a safe and fair space for humanity to operate (Raworth 2017). Research demonstrates that no country today can be placed within the 'doughnut': countries with good social systems have bypassed environmental thresholds and countries with the least environmental impact score low on their social threshold indicators ( $\mathrm{O}^{\prime}$ Neill et al. 2018). Moreover, none of the four world largest economies (EU, USA, China, and India) operate within the planetary boundaries (Lucas et al. 2020).

Another recent attempt to reconcile minima and maxima consumption limits is the concept of 'consumption corridors' ((Di Giulio and Defila 2019; Defila and Di Giulio 2020; Fuchs 2020). The aim of consumption corridors is to reconfigure consumption within established minima and maxima in a way that would give individuals opportunities to live a 'good life'. This reconfiguration is complicated by the existing power dynamics and institutional bias towards growth (Di Giulio and Fuchs 2014) and the notion of individual freedom of choice and associated negative perceptions of upper limits (Fuchs 2020, p. 299).

Redefining wellbeing and the idea of 'good life' are central to reconfiguring consumption patterns within existing biophysical or socially constructed limits. Various research strands explore possible ways for this re-definition (Gough 2017; Kjell 2011; Hämäläinen 2014; Princen 2003, 2005; Steinberger and Timmons Roberts 2010; Schäpke and Rauschmayer 2014; Bottery 2012; Bocken and Short 2016; Vita et al. 2019; and Sahakian et al. 2019). Moreover, a growing body of degrowth literature criticizes growth as the ultimate indicator of prosperity and suggests ways to improve wellbeing (and limit overconsumption) by introducing basic income, environmental and consumption taxes, capping working hours, and exercising control over advertising (Kallis 2011; Kallis et al. 2014; Martínez-Alier et al. 2010).

In the presence of the rich literature that recognizes the need to formulate consumption limits and reconfigure consumption patterns by redefining what wellbeing means, it is surprising that Agenda 2030, the world's vision of a sustainable future, avoids any meaningful discussion of upper limits and makes no mention of consumption limits in SDG 12. The following sections explore why this may be the case.

\subsection{From Planetary Boundaries to Upper Consumption Limits}

Agenda 2030, in its Preamble, states that parties "are determined to protect the planet from degradation, including through sustainable consumption and production, sustainably managing its natural resources and taking urgent action on climate change, so that it can support the needs of the present and future generations" (United Nation 
2015; Agenda 2030 Preamble, p. 5). Further, the document states that parties "envisage a world in which every country enjoys sustained, inclusive and sustainable economic growth and decent work for all ... [a] world in which consumption and production patterns and use of all natural resources-from air to land, from rivers, lakes and aquifers to oceans and seas-are sustainable" (United Nation 2015, p. 7).

While on the surface, Agenda 2030 incorporates intra- and intergenerational justice concerns and demonstrates transformative ambition, the impact of these statements becomes questionable without defining what 'sustainable' levels of consumption, production, natural resource use, or growth are. 'Sustainable' implies upper limits; and yet, neither Agenda 2030 nor SDG 12 discuss restrictions to consumption or growth, not to mention much needed reductions in material overconsumption in affluent countries. Rather, it appears the narrative aims to reconfigure consumption under the umbrella of 'inclusive growth', which implies that there is still ecological capacity for increase (Bengtsson et al. 2018).

Scientific evidence clearly signals that ecological capacity for increase does not exist. Since at least the 1970s it has become evident that growth contingent on the extraction of natural resources has limits (Meadows et al. 1972). Yet, forty years later, the UNEP flagship report on decoupling states that one of the major challenges to the decoupling strategy is "to convince policymakers (and the public) ... of the reality of physical limits to the quantity of natural resources available for human use and [limits to] the negative environmental impacts of economic activities" (UNEP 2011, p. xcv).

Over the past ten years, the concept of planetary boundaries has emerged and gained prominence in scientific and policy-making circles. The framework developed by an interdisciplinary group of Earth scientists in Stockholm presents indicators of biophysical limits of Earth in a number of critical areas, including climate change, biosphere integrity, land-system change, freshwater use, phosphorus and nitrogen cycles, ocean acidification, atmospheric aerosol loading, ozone depletion, and emission of novel entities (Rockström et al. 2009; Steffen et al. 2011). Planetary boundaries on biosphere integrity in terms of genetic diversity, biochemical flows in terms of disruption in nitrogen and phosphorus cycles have already been breached 'beyond [the] zone of uncertainty' posing high risk of systemic disruptions. Climate change and land-system change boundaries are 'in [the] zone of uncertainty' posing 'increasing risk' (Steffen et al. 2015). It is important to stress that planetary boundaries are breached as a result of anthropogenic activity, especially industrial and agricultural processes. 
Defining sustainable levels of consumption is a complex undertaking which requires rigorous accounting (Wackernagel et al. 2017; Clift et al. 2017). However, research on planetary boundaries in the past few years has substantially advanced our understanding of how to translate the biophysical limits of the planet into more actionable targets and guidance that can be used by governments. Häyhä et al. (2016) propose a three-step framework that includes (1) formulating planetary boundaries as indicators to measure biophysical dimensions (in the form of environmental data and models); (2) translating biophysical limits into indicators to measure socio-economic dimensions (in the form of footprints); and (3) translating socio-economic limits into limits per country according to agreed-upon principles of distributive justice.

According to Häyhä et al. (2016), socio-economic dynamics are nothing but consumption and production patterns-the anthropogenic activities that drive overuse of resources, emissions of GHG, and generation of waste in different forms. These processes are subordinate to the global biophysical limits: if we want to have a livable planet in a Holocene-like state that can support flourishing human and non-human life, we need to limit our socio-economic activity accordingly by transforming unsustainable consumption and production patterns. Biophysical limits indicate how much we can consume (develop, grow), while principles of equity allocate how we should share available safe operating space.

Lucas et al. (2020) build on the framework of Häyhä et al. (2016) and calculate shares of global safe operating space for the four largest global economies (EU, USA, China, and India) based on different principles of distributive justice: grandfathering (current shares of environmental pressure), equal per capita shares, and ability to pay. The study scales down global limits for selected planetary boundaries to national resource budgets and demonstrates that future budgets vary significantly according to selected allocation principles. Allocation of future resource use budgets based on the grandfathering approach yields the most favorable outcomes for the European Union and the United States as it accommodates their existing high material footprint and unsustainable lifestyles as part of the current share of environmental pressure. For China and India, 'equal per capita' and 'ability to pay' approaches resulted in the highest future budgets. The study further suggests that global reduction efforts to stay within the safe operating space imply reductions of $\mathrm{CO}_{2}$ emissions by $77 \%$ compared to the global ecological footprint of 2010 (a 77-101\% decrease for the EU and a $77-120 \%$ decrease for the US).

The scale of reductions echoes the findings from another cornerstone study that translated the global temperature stabilization goal at 1.5 degrees Celsius from the Paris Agreement into consumption reduction targets for some countries 
(Akenji et al. 2019). The 1.5 Degree Lifestyles Report focused on lifestyle footprints and household consumption and excluded government consumption and capital formation, such as infrastructure. The findings indicate that changes in lifestyles (household consumption) are critical to achieving climate goals and that lifestyle footprints in developed countries need to be reduced $80-93 \%$ by 2050 (Akenji et al. 2019). Both Lucas et al. (2020) and Akenji et al. (2019) demonstrate that it is possible to translate global biophysical limits into indicators that formulate upper limits to consumption in terms of socio-economic activities.

While both studies rely heavily on existing climate change literature, including modeling pathways towards emission reductions, planetary boundaries research demonstrates that there are more Earth system processes than climate change that can lead to global environmental degradation. And we need to take all of them into account—especially boundaries that have already been surpassed—when calculating global development budgets within a safe global operating space.

\subsection{The Challenge of Moral Corruption}

If the goal of Agenda 2030 is, as stated, to protect our planet from degradation, then international sustainable development agreements should integrate scientific findings that indicate the biophysical limits of our planet and translate these upper limits into operational indicators that measure socio-economic activity in relation to environmental impacts. This section provides an ethical perspective on why this has not been done so far.

Since the Kyoto Protocol (1995), biophysical limits in terms of temperature increase and the magnitude of emission reductions have been apparent. Despite the clear biophysical limits imposed by climate change, there has been a continuous increase and acceleration of the industrial and agricultural activities, including resource extraction, that directly feed global GHG levels. It is evident that translating biophysical limits into limits to consumption as socio-economic activity is possible (Akenji et al. 2019; Lucas et al. 2020). The methodologies are admittedly complex and accounting is further complicated by fragmented availability of data for some control variables in scientific models; but, there is clearly a scientific possibility to calculate these upper limits.

Limits to consumption in the form of indicators capping socio-economic activity are absent from Agenda 2030 and the Sustainable Development Goals. Why, despite the strong connection between climate change, sustainable development, and consumption, have international political processes for thirty years evaded meaningful action to address overconsumption and transform unsustainable 
consumption and production patterns? There is a problem of inaction, translation, and framing, which may be explained by what Gardiner (2004, 2011) calls 'moral corruption'.

Influenced by stagnating climate politics of the early 2000s, including the US decision not to ratify the Kyoto Protocol, Gardiner developed a comprehensive ethical framework to understand what obstructs action on climate change. He explained the ethical tragedy of climate change as a combination of three moral 'storms'. A global storm involves ethical issues linked to existing systemic global inequalities and institutional failure. An intergenerational storm concerns our treatment of future generations, including remote future generations in the context of the global crisis, with long-term consequences for humanity. A theoretical storm highlights the inadequacy of our existing moral and political theories to provide guidance on a problem of such temporal and spatial scales, and with such urgency as climate change. Gardiner argues that the three storms collide in a 'perfect moral storm' for humanity, which leads to moral corruption.

Unlike the more habitual use of the term 'corruption', moral corruption refers to the more subtle ways in which we think and speak about a problem that obscure the moral implications of our actions. According to Gardiner's interpretation, moral corruption is a way to avoid engaging with a morally difficult challenge via the following mechanisms: distraction, complacency, selective attention, unreasonable doubt, delusion, pandering, and hypocrisy. In climate change politics, examples of moral corruption can be seen in how some political actors emphasize considerations that make inaction excusable or even desirable, such as uncertainty or simplistic economic calculations with high discount rates at the expense of those considerations that impose an immediate and clear need for action, such as scientific consensus (Gardiner 2011, p. 45).

Gardiner's account of moral corruption may be useful in explaining the failure to translate biophysical limits of our planet into upper consumption limits. For decades, growth that relies on increasing consumption has been the beacon of development. Scientific consensus on the effects of climate change and on the necessary levels of GHG reduction has called for substantial and urgent changes to the unsustainable patterns of socio-economic activity: changes in how and how much we consume and produce. Policymakers were faced with a difficult challenge: temperature stabilization goals essentially implied not only slowing down but curtailing development and growth. Instead of translating biophysical limits into specific limits to socio-economic activity and addressing the problem of overconsumption, international negotiations continued to proceed, leaving references to biophysical limits (such as temperature 
stabilization goals and GHG emission reduction) conveniently abstract and complex enough to translate into activities relevant to people's daily lives.

Framing of the problem and the solutions is of critical importance. Consider two scenarios in which governments inform their citizens about a global problem that requires urgent and concerted action by all stakeholders (the global climate crisis). In one, the government communicates that, to address the crisis, the global temperature increase may not bypass 1.5 degrees Celsius. To achieve this, developed countries should limit or reduce their emissions of GHGs. This framing uses abstract scientific data and biophysical indicators to communicate the problem and the solution but does not translate them into limits to the individual and collective socio-economic activity. This approach distracts attention from meaningful action and veils the urgency and profoundness of the required changes. For the daily lives of most people, temperature stabilization goals from the Paris Agreement are of no more relevance than information about the time it takes to get from Mars to Venus or the exact number of pi.

Imagine another scenario in which biophysical boundaries are clearly translated into consumption limits by country (provided stakeholders agree on the allocation principles among countries). In this scenario, every government can present their citizens with a national 'consumption' quota (as opposed to a 'GHG mission reduction' quota) - how much of the global resources the country and its citizens can consume per year, for example. Citizens would also know their individual 'consumption budgets' (agreed based on the principles of distributive justice to account for different kinds of inequalities), with clear information on the environmental and social impacts of different socio-economic activities.

Such framing clarifies possible ways forward, making obscure temperature stabilization goals or limits to reactive nitrogen emissions more relevant to peoples' daily lives. When limits to socio-economic activity are formulated, growth as a pathway for development becomes inadequate, obsolete and, perhaps, even morally unacceptable. This simplistic scenario comparison does not account for power dynamics, systemic inequalities, and the challenge of entitlement re-distribution, but it gives an idea of how different framings hinder or clarify action that, indeed, should be collective and urgent.

A double track of climate change politics and sustainable development politics over the course of the 1990s and 2000s indicates, in a way, separating discussions of biophysical limits (translated in climate politics as far as GHG emission reduction by country) from conversations on how to reframe practices that enable and encourage economic growth in a more 'sustainable' way. When the two tracks finally merged 
in 2015 in the SDGs, the real, biophysical limits got lost behind the notion of 'inclusive' or 'green' growth that envisages both reductions in global emissions and continuous growth of the global economy. The idea of decoupling growth from the use of resources creates an illusion that there is a way to resolve the problem of overconsumption without limiting it.

It is precisely this illusion, the evasiveness, vagueness of language and definitions, that calls out moral corruption in Agenda 2030 and the SDGs. Leaving the term 'sustainable' conveniently undefined or putting the weight of transformation on decoupling strategies without acknowledging physical limits to resources-in Gardiner's terms, the parties to Agenda 2030 are 'passing the buck' of filling the blanks and dealing with the difficult moral choices onto future generations.

The harsh reality is that we need to drastically reduce consumption in more affluent countries and do so with upper limits but also lower limits of social standards in mind. The room for reconfiguring consumption and lifestyles is very limited. Reconfiguration is bound to cause major socio-economic transformation in developed countries. This is not desirable for the present generation and especially not for those who lead carbon-intensive lifestyles. Framing solutions to the global environmental crisis in terms of abstract biophysical limits confuses and deters action that would inevitably disrupt the existing socio-economic status quo. Failure to formulate consumption limits, therefore, is an ethical failure of our generation and its leaders that is caused by moral corruption.

\section{Conclusions and Future Research}

Moral corruption is only one of many ethical challenges associated with consumption, and moral and political philosophers could provide valuable contributions to the debate. Among the more obvious avenues for ethical inquiry, there is a need to develop allocation frameworks for safe operating space among and within countries. Such frameworks could build on climate ethics literature but design more appropriate allocation principles for different planetary boundaries (Lucas et al. 2020).

Ethicists could also contribute by further considering different agents of justice - not only states but corporations, groups of people, and individuals- to move the inquiry from the domain of international justice to the sphere of global justice. Distributive justice concerns emerge at every step of the way towards reconfiguring consumption: from decisions on how to divide the global resource 'pie' into country shares to allocating consumption budgets within states and among generations. 
More broadly, we are lacking an ethical framework tailored to guide the transformation of consumption and production patterns towards sustainability. Such a framework would extend beyond allocation approaches and principles of distribution to provide a comprehensive justice account of consumption. As a starting point, such an account could question the moral permissibility of overconsumption. Failure to establish, clearly and unequivocally, that overconsumption is morally wrong fuels moral corruption and defers much needed action.

Conflicts of Interest: The author declares no conflicts of interest.

\section{References}

Akenji, Lewis, Michael Lettenmeier, Ryu Koide, Viivi Toivio, and Aryanie Amellina. 2019. 1.5-Degree Lifestyles: Targets and Options for Reducing Lifestyle Carbon Footprints. Hayama: Institute for Global Environmental Strategies, Aalto: Aalto University, D-Mat Ltd.

Alexander, Samuel, Jonathan Rutherford, and Josh Floyd. 2017. A Critique of the Decoupling Strategy: A Limits to Growth Perspective. Simplicity Institute.

Amos, Rob, and Emily Lydgate. 2019. Trade, transboundary impacts and the implementation of SDG 12. Sustainability Science, 1-12. [CrossRef]

Amsler, Sarah S. 2009. Embracing the politics of ambiguity: Towards a normative theory of "sustainability". Capitalism Nature Socialism 20: 111-25. [CrossRef]

Barnett, Clive, Paul Cloke, Nick Clarke, and Alice Malpass. 2005. Consuming ethics: Articulating the subjects and spaces of ethical consumption. Antipode 37:23-45. [CrossRef]

Baudrillard, Jean. 1970. The Consumer Society. Paris: Gallimard. First published 1998.

Belk, Russell, Timothy Devinney, and Giana Eckhardt. 2005. Consumer ethics across cultures. Consumption Markets \& Culture 8: 275-89.

Bengtsson, Magnus, Eva Alfredsson, Maurie Cohen, Sylvia Lorek, and Patrick Schroeder. 2018. Transforming systems of consumption and production for achieving the sustainable development goals: Moving beyond efficiency. Sustainability Science 13: 1533-47. [CrossRef] [PubMed]

Bocken, Nancy M. P., and Samuel W. Short. 2016. Towards a sufficiency-driven business model: Experiences and opportunities. Environmental Innovation and Societal Transitions 18: 41-61. [CrossRef]

Bottery, Mike. 2012. Leadership, the Logic of Sufficiency and the Sustainability of Education. Educational Management Administration \& Leadership 40: 449-63.

Bourdieu, Pierre. 1984. Distinction: A Social Critique of the Judgement of Taste. Cambridge: Harvard University Press.

Brinkmann, Johannes, and Ken Peattle. 2008. Consumer ethics research: Reframing the debate about consumption for good. EJBO-Electronic Journal of Business Ethics and Organization Studies 13: 22-31. 
Caney, Simon. 2005. Cosmopolitan justice, responsibility, and global climate change. Leiden Journal of International Law 18: 747-75. [CrossRef]

Clift, Roland, Sarah Sim, Henry King, Jonathan L. Chenoweth, Ian Christie, Julie Clavreul, Carina Mueller, Leo Posthuma, Anne-Marie Boulay, Rebecca Chaplin-Kramer, and et al. 2017. The challenges of applying planetary boundaries as a basis for strategic decision-making in companies with global supply chains. Sustainability 9: 279. [CrossRef]

De Graaf, John, David Wann, and Thomas H. Naylor. 2002. Affluenza: The all-consuming epidemic. Environmental Management and Health 13: 224. [CrossRef]

De Graaf, John, David Wann, and Thomas H. Naylor. 2014. Affluenza: How Overconsumption Is Killing Us-And How to Fight Back. San Francisco: Berrett-Koehler Publishers.

Defila, Rico, and Antonietta Di Giulio. 2020. The Concept of "Consumption Corridors" Meets Society: How an Idea for Fundamental Changes in Consumption is Received. Journal of Consumer Policy, 1-30. [CrossRef]

Di Giulio, Antonietta, and Rico Defila. 2019. The Good life and Protected Needs. In The Routledge Handbook of Global Sustainability Governance. Edited by Agni Kalfagianni, Doris Fuchs and Hayden und Anders. London: Routledge.

Di Giulio, Antonietta, and Doris Fuchs. 2014. Sustainable consumption corridors: Concept, objections, and responses. GAIA-Ecological Perspectives for Science and Society 23: 184-92. [CrossRef]

Eckhardt, Giana M., Russell Belk, and Timothy M. Devinney. 2010. Why don't consumers consume ethically? Journal of Consumer Behaviour 9: 426-36. [CrossRef]

Fletcher, Robert, and Crelis Rammelt. 2017. Decoupling: A key fantasy of the post-2015 sustainable development agenda. Globalizations 14: 450-67. [CrossRef]

Fuchs, Doris. 2020. Living well within limits: The vision of consumption corridors. In Routledge Handbook of Global Sustainability Governance. London: Routledge, pp. 296-307.

Gardiner, Stephen M. 2004. Ethics and global climate change. Ethics 114: 555-600. [CrossRef]

Gardiner, Stephen M. 2011. A Perfect Moral Storm: The Ethical Tragedy of Climate Change. Oxford: Oxford University Press.

Gardiner, Stephen M., Simon Caney, Dale Jamieson, and Henry Shue, eds. 2010. Climate Ethics: Essential Readings. Oxford: Oxford University Press.

Gough, Ian. 2017. Heat, Greed and Human Need: Climate Change, Capitalism and Sustainable Wellbeing. Cheltenham: Edward Elgar Publishing.

Griessler, Erich, and Beate Littig. 2005. Social sustainability: A catchword between political pragmatism and social theory. International Journal for Sustainable Development 8: 65-79.

Hall, Sarah Marie. 2011. Exploring the 'ethical everyday': An ethnography of the ethics of family consumption. Geoforum 42: 627-37. [CrossRef]

Hämäläinen, Timo J. 2014. In search of coherence: Sketching a theory of sustainable well-being. In Well-Being and Beyond. Cheltenham: Edward Elgar Publishing. 
Häyhä, Tiina, Paul L. Lucas, Detlef P. van Vuuren, Sarah E. Cornell, and Holger Hoff. 2016. From Planetary Boundaries to national fair shares of the global safe operating space-How can the scales be bridged? Global Environmental Change 40: 60-72. [CrossRef]

Hobson, Kersty. 2013. 'Weak' or 'Strong' Sustainable Consumption? Efficiency, Degrowth, and the 10 Year Framework of Programmes. Environment and Planning C: Government and Policy 31: 1082-98. [CrossRef]

Jacob, Merle. 1994. Toward a methodological critique of sustainable development. The Journal of Developing Areas 28: 37-252.

Jamieson, Dale. 1992. Ethics, public policy, and global warming. Global Bioethics 5: 31-42. [CrossRef]

Kallis, Giorgos. 2011. In defence of degrowth. Ecological Economics 70: 873-80. [CrossRef]

Kallis, Giorgos. 2019. Limits: Why Malthus Was Wrong and Why Environmentalists should Care. Redwood City: Stanford University Press.

Kallis, Giorgos, Federico Demaria, and Giacomo D'Alisa. 2014. Introduction: Degrowth. In Degrowth. Abingdon-on-Thames: Routledge, pp. 29-46.

Kjell, Oscar N. E. 2011. Sustainable well-being: A potential synergy between sustainability and well-being research. Review of General Psychology 15: 255-66. [CrossRef]

Klimková, Andrea. 2017. Deconstruction and Evaluation of Agenda 2030 and Local Agenda 21 in the Context of Applied Ethics. Zeszyty Naukowe: Organizacja i Zarządzanie/ Politechnika Śląska.

Ling, Chee Y. 2016. Corporate capture subverts production and consumption transformation. In Spotlight on Sustainable Development 2016: Report of the Reflection Group on the 2030 Agenda for Sustainable Development. Quezon City: Social Watch.

Lucas, Paul L., Harry C. Wilting, Andries F. Hof, and Detlef P. van Vuuren. 2020. Allocating planetary boundaries to large economies: Distributional consequences of alternative perspectives on distributive fairness. Global Environmental Change 60: 102017. [CrossRef]

Martínez-Alier, Joan, Unai Pascual, Franck-Dominique Vivien, and Edwin Zaccai. 2010. Sustainable de-growth: Mapping the context, criticisms and future prospects of an emergent paradigm. Ecological Economics 69: 1741-47. [CrossRef]

Meadows, Donella H., Dennis L. Meadows, Jorgen Randers, and William W. Behrens. 1972. The limits to growth. New York 102: 27.

O'Neill, Daniel W., Andrew L. Fanning, William F. Lamb, and Julia K. Steinberger. 2018. A good life for all within planetary boundaries. Nature Sustainability 1: 88-95. [CrossRef]

Pogge, Thomas. 2002. World Poverty and Human Rights. Cambridge: Polity Press.

Princen, Thomas. 2003. Principles for sustainability: From cooperation and efficiency to sufficiency. Global Environmental Politics 3: 33-50. [CrossRef]

Princen, Thomas. 2005. The Logic of Sufficiency. Cambridge: MIT Press, vol. 30.

Rawls, John. 1999. The Law of Peoples: With, the Idea Of Public Reason Revisited. Cambridge: Harvard University Press. 
Raworth, Kate. 2017. Doughnut Economics: Seven Ways to Think Like a 21st-Century Economist. White River Junction: Chelsea Green Publishing.

Robeyns, Ingrid. 2017. Having too much. Nomos 58: 1-44.

Rockström, Johan, Will Steffen, Kevin Noone, Åsa Persson, F. Stuart Chapin III, Eric Lambin, Timothy M. Lenton, Marten Scheffer, Carl Folke, Hans Joachim Schellnhuber, and et al. 2009. Planetary boundaries: Exploring the safe operating space for humanity. Ecology and Society 14: 33. [CrossRef]

Sahakian, Marlyne, Patrick Naef, Charlotte Jensen, Gary Goggins, and Frances Fahy. 2019. Challenging conventions towards energy sufficiency: Ruptures in laundry and heating routines in Europe. Paper presented at the ECEEE 2019, Presqu'île de Giens, France, June 3-8. ECEEE 2019 Summer Study.

Schäpke, Niko, and Felix Rauschmayer. 2014. Going beyond efficiency: Including altruistic motives in behavioral models for sustainability transitions to address sufficiency. Sustainability: Science, Practice and Policy 10: 29-44. [CrossRef]

Schor, Juliet. 1991. The Overworked American: The unexpected Decline of Leisure. New York: Basic Books.

Schor, Juliet. 1999. The Overspent American. New York: Harper Perennial.

Shaw, Deirdre, and Terry Newholm. 2002. Voluntary simplicity and the ethics of consumption. Psychology \& Marketing 19: 167-85.

Shue, Henry. 1993. Subsistence emissions and luxury emissions. Law \& Policy 15: 39-60.

Singer, Peter. 1972. Famine, Affluence and Morality. Philosophy and Public Affairs 1: 229-43.

Singer, Peter. 2011. The Expanding Circle: Ethics, Evolution, and Moral Progress. Princeton: Princeton University Press.

Spengler, Laura. 2016. Two types of 'enough': Sufficiency as minimum and maximum. Environmental Politics 25: 921-40. [CrossRef]

Steffen, Will L., Johan Rockström, and Robert Costanza. 2011. How defining planetary boundaries can transform our approach to growth. Solutions: For A Sustainable E Desirable Future 2: 59-65.

Steffen, Will, Katherine Richardson, Johan Rockström, Sarah E. Cornell, Ingo Fetzer, Elena M. Bennett, Reinette Biggs, Stephen R. Carpenter, Wim de Vries, Cynthia A de Wit, and et al. 2015. Planetary boundaries: Guiding human development on a changing planet. Science 347: 1259855. [CrossRef]

Steinberger, Julia K., and J. Timmons Roberts. 2010. From constraint to sufficiency: The decoupling of energy and carbon from human needs, 1975-2005. Ecological Economics 70: 425-33. [CrossRef]

Trentmann, Frank. 2016. The Empire of Things: How We Became a World of Consumers, from the Fifteenth Century to the Twenty-First. Westminster: Allen Lane Publishing, p. 880. 
UNEP. 2011. Decoupling Natural Resource Use and Environmental Impacts from Economic Growth. A Report of the Working Group on Decoupling to the International Resource Panel. Athens: UNEP.

United Nation. 2015. Transforming Our World: The 2030 Agenda for Sustainable Development. New York: United Nations.

United Nation. 2019. Special Edition: Progress Towards the Sustainable Development Goals. Report of the Secretary-General. New York: United Nation, May 8.

United Nations Environment Program. 2012. 10 Year Framework of Programs on Sustainable Consumption and Production Patterns. Available online: https://www.unenvironment.org/explore-topics/resource-efficiency/what-we-do/ one-planet-network/10yfp-10-year-framework-programmes (accessed on 10 April 2020). United Nations Statistics Division. 2018. High-Level Political Forum Goals in Focus. Goal 12: Ensure Sustainable Consumption and Production Patterns. Available online: https: //unstats.un.org/sdgs/report/2018/goal-12/ (accessed on 10 April 2020).

Vasconcellos Oliveira, Rita. 2018. Back to the Future: The potential of intergenerational justice for the achievement of the sustainable development goals. Sustainability 10: 427. [CrossRef]

Veblen, Thornstein. 1925. Theory of the Leisure Class. London: Unwin. First Published 1899.

Vita, Gibran, Johan R. Lundström, Edgar G. Hertwich, Jaco Quist, Diana Ivanova, Konstantin Stadler, and Richard Wood. 2019. The Environmental Impact of Green Consumption and Sufficiency Lifestyles Scenarios in Europe: Connecting Local Sustainability Visions to Global Consequences. Ecological Economics 164: 106322. [CrossRef] Wackernagel, Mathis, Laurel Hanscom, and David Lin. 2017. Making the sustainable development goals consistent with sustainability. Frontiers in Energy Research 5: 18. [CrossRef]

World Bank. 2020. Population Data. Available online: https://data.worldbank.org/indicator/sp. pop.totl (accessed on 10 April 2020).

(C) 2020 by the author. Licensee MDPI, Basel, Switzerland. This article is an open access article distributed under the terms and conditions of the Creative Commons Attribution (CC BY) license (http://creativecommons.org/licenses/by/4.0/). 
MDPI

St. Alban-Anlage 66 4052 Basel

Switzerland

Tel. +41616837734

Fax +4161302 8918

www.mdpi.com

MDPI Books Editorial Office

E-mail: books@mdpi.com

www.mdpi.com/books

\section{MDPI}





\section{MDPI}

St. Alban-Anlage 66 4052 Basel

Switzerland

Tel: +41 616837734

Fax: +41 613028918 